\author{
UNIVERSIDADE DE SÃO PAULO \\ ESCOLA DE ENGENHARIA DE SÃO CARLOS \\ FACULDADE DE MEDICINA DE RIBEIRÃO PRETO \\ INSTITUTO DE QUÍMICA DE SÃO CARLOS
}

LUCIANA BOLZAN AGNELLI MARTINEZ

DESENVOLVIMENTO NO BRASIL DE TERMOPLÁSTICOS DE BAIXA TEMPERATURA PARA ÓRTESES

São Carlos

2018 


\section{DESENVOLVIMENTO NO BRASIL DE TERMOPLÁSTICOS DE BAIXA TEMPERATURA PARA ÓRTESES}

\section{Versão Corrigida}

Tese apresentada ao Programa de Pós-Graduação Interunidades em Bioengenharia / Escola de Engenharia de São Carlos - Faculdade de Medicina de Ribeirão Preto e Instituto de Química de São Carlos da Universidade de São Paulo, como requisito para a obtenção do Título de Doutor em Ciências.

Área de Concentração: Bioengenharia

Orientadora: Profa. Dra. Valéria Meirelles Carril Elui

São Carlos 
AUTORIZO A REPRODUÇÃO E DIVULGAÇÃO TOTAL OU PARCIAL DESTE TRABALHO, POR QUALQUER MEIO CONVENCIONAL OU ELETRÔNICO, PARA FINS DE ESTUDO E PESQUISA, DESDE QUE CITADA A FONTE.

A271d Agnelli Martinez, Luciana Bolzan temperatura para órteses / Luciana Bolzan Agnelli Martinez; orientadora Valéria Meirelles Carril Elui. -- São Carlos, 2018 .

Tese (Doutorado) - Programa de Pós-Graduação Interunidades em Bioengenharia e área de Concentração em Bioengenharia -- Escola de Engenharia de são Carlos; Faculdade de Medicina de Ribeirão Preto; Instituto de Qu'mica de são Carlos da Universidade de São Paulo, 2018.

1. Aparelhos ortopédicos. 2. Ensaios de materiais. 3. Reabilitação. 4. Polímeros. 5. Termoplásticos de baixa temperatura. 6. Terapia ocupacional. I. Titulo. 
FOLHA DE JULGAMENTO

\section{Candidato(a): Luciana Bolzan Agnelli Martinez}

Título: " Desenvolvimento no Brasil de termoplásticos de baixa temperatura para órteses"

Data da defesa: $26 / 10 / 2018$

\section{Comissão Julgadora}

Resultado

Assinatura

Jaluia me Elui aprovada

Prof(a). Dr(a). Valéria Meirelles Carril Elui FZEA/USP

Prof(a). Dr(a). Cristina Yoshi Toyoda UNESP

Prof(a). Dr(a). Marisa de Cassia Registro Fonseca FMRP/USP

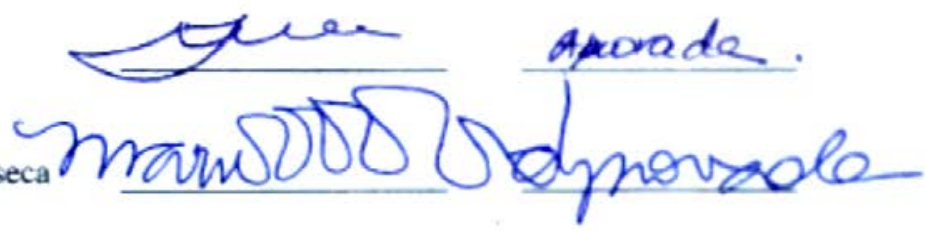

Prgf(a). Dr(a). Eliana Cristina da Silva Rigo FZEA/USP

Prof(a). Dr(a). Nilson Casimiro Pereira IPEN 


\section{AGRADECIMENTOS}

À Universidade de São Paulo, especialmente ao Programa de Pós-Graduação Interunidades em Bioengenharia EESC / FMRP / IQSC, pela oportunidade de realização deste doutoramento.

À Profa. Dra. Valéria Meirelles Carril Elui, minha orientadora neste trabalho, por me permitir partilhar de sua experiência e por me contagiar com suas ideias. Agradeço pela amizade, pela compreensão e por todos os ensinamentos e contribuições!

À Profa. Dra. Cristina Yoshie Toyoda, a quem devo pelo início de minha vida como pesquisadora, conduzindo minha Iniciação Científica na época da Graduação, responsável por meu primeiro contato com a investigação na área de materiais para órteses.

Ao Laboratório de Polímeros do Departamento de Engenharia de Materiais da Universidade Federal de São Carlos, por ceder o espaço e os equipamentos. Agradeço aos membros da equipe envolvidos, pela pareceria que possibilitou a realização deste trabalho, especialmente: José Augusto, Suzan, Osvaldo e Elias, pela colaboração e pelo tempo dedicado.

Às terapeutas ocupacionais e fisioterapeutas que participaram deste estudo, por partilharem sua experiência e contribuírem com a execução deste trabalho.

Ao meu filho Antônio Augusto, luz em minha vida, meu refúgio e meu bem mais precioso, que me faz tirar forças quando acho que não tenho.

Ao meu esposo, meu porto seguro e companheiro de todas as horas e contextos, pela entrega gratuita de sua vida e de seu trabalho. Agradeço por toda a colaboração nessa jornada pelo Doutorado. Esse título é nosso.

Aos meus pais, amigos fiéis e exemplo para tudo o que eu busco, a quem não tenho como retribuir tudo o que fizeram e fazem por mim. Agradeço por todo o apoio em mais uma etapa de minha vida, pois sem vocês eu não teria conseguido.

A todos os demais amigos e familiares que fizeram parte de minha trajetória, especialmente minha sogra, meus irmãos e cunhados, por todo o apoio e carinho.

Finalmente agradeço a Deus pelo dom da vida, pelas experiências que pude vivenciar, por minha família, pelas pessoas que me acompanham e por todas as bênçãos que recebo diariamente, me permitindo estudar e trabalhar em áreas que me realizam. 
“Se não puder voar, corra. Se não puder correr, ande. Se não puder andar, rasteje, mas continue em frente de qualquer jeito."

Martin Luther King 


\section{RESUMO}

AGNELLI MARTINEZ, L. B. Desenvolvimento no Brasil de termoplásticos de baixa temperatura para órteses. 2018. 205 f. Tese (Doutorado) - Programa de Pós-Graduação Interunidades em Bioengenharia da Escola de Engenharia de São Carlos - Faculdade de Medicina de Ribeirão Preto e Instituto de Química de São Carlos da Universidade de São Paulo, São Carlos, 2018.

As órteses para os membros superiores são utilizadas em conjunto com outras estratégias de tratamento para melhorar o desempenho ocupacional de pessoas com algum impedimento funcional, sendo que os materiais mais utilizados na sua confecção são os termoplásticos de baixa temperatura, cujas marcas comerciais disponíveis no mercado são importadas. O presente estudo teve por objetivo criar uma metodologia para o desenvolvimento e teste de termoplásticos de baixa temperatura, além de desenvolver novos materiais no Brasil, verificando sua aplicabilidade e viabilidade na prática clínica. Na primeira fase da pesquisa (exploratória) foi realizado um levantamento das características e dos componentes que os materiais desenvolvidos devem ter, criando-se uma matriz de requisitos e procedimentos metodológicos que conduziram a formulação dos materiais. Foi realizado um estudo acerca de dois produtos comerciais similares atualmente disponíveis no mercado, de diferentes fabricantes, através dos seguintes experimentos: Espectroscopia no Infravermelho com Transformada de Fourier (FTIR), Calorimetria Exploratória Diferencial (DSC), Análise Dinâmico-Mecânica (DMA), Termogravimetria (TG), Teor de Cinzas por Calcinação e Microscopia Eletrônica de Varredura (MEV) acoplada com a Espectroscopia por Dispersão de Energia de Raios X (EDS). Ainda na fase exploratória, foram processados novos materiais, obtendo-se 17 amostras de termoplásticos de baixa temperatura, dentre os quais foram selecionados dois, que obtiveram êxito durante o processo de avaliação utilizando o "Roteiro de Procedimentos de Testes Práticos Empíricos”. Além disso foi criado um instrumento denominado “Manuseio Padronizado para Materiais Termoplásticos para Órteses” (MPMTO). A segunda fase do estudo apresentou caráter experimental, em que os materiais desenvolvidos foram testados e comparados a materiais comerciais, através do MPMTO, e foram analisados com critérios da prática clínica, por 24 profissionais que atuam na área. O principal instrumento de coleta de dados para os participantes foi um questionário organizado no formato de escala do tipo Likert. Destacam-se como resultados: o desenvolvimento de dois materiais termoplásticos de baixa temperatura no Brasil, avaliados como viáveis pelos profissionais, especialmente o Material B; a elaboração de etapas metodológicas para o desenvolvimento de materiais; e a criação dois instrumentos destinados à avaliação de materiais para órteses, um 
prático empírico e outro padronizado. Além de apresentar relevância social, ampliando as opções de materiais para a confecção de órtese e, consequentemente, gerando melhorias à população, representa um avanço científico e tecnológico para o país.

Palavras-chave: Aparelhos ortopédicos. Ensaios de materiais. Reabilitação. Polímeros. Termoplásticos de baixa temperatura. Terapia Ocupacional. 


\begin{abstract}
AGNELLI MARTINEZ, L. B. Development in Brazil of low temperature thermoplastics for orthoses. 2018. 205 f. Tese (Doutorado) - Programa de Pós-Graduação Interunidades em Bioengenharia da Escola de Engenharia de São Carlos - Faculdade de Medicina de Ribeirão Preto e Instituto de Química de São Carlos da Universidade de São Paulo, São Carlos, 2018.
\end{abstract}

Upper limb orthoses are used in conjunction with other treatment strategies to improve occupational performance of person with functional impairments, and the most commonly used materials are thermoplastics of low temperature, whose commercially available trademarks are imported. The present study aimed to create a methodology for the development and testing of low temperature thermoplastics, in addition to developing new materials in Brazil, verifying their applicability and viability in clinical practice. In the first phase of the research (exploratory) a survey of the characteristics and the components that the developed materials were developed was created by producing a matrix of requirements and methodological procedures that led to the formulation of the materials. A study was carried out on two commercially available commercial products from different manufacturers, using the following experiments: Fourier Transform Infrared Spectroscopy (FTIR), Differential Scanning Calorimetry (DSC), Dynamic-Mechanical Analysis (DMA), Thermogravimetry (TG), Ash Content by Calcination and Scanning Electron Microscopy (SEM) coupled with X-ray Energy Dispersion Spectroscopy (EDS). Also in the exploratory phase, new materials were processed, obtaining 17 samples of thermoplastics of low temperature, among which were selected two, that were successful during the evaluation process using the "Roadmap of Procedures of Empirical Practical Tests". In addition, an instrument called "Standardized Handling for Thermoplastic Materials for Orthotics" (MPMTO) was created. The second phase of the study was experimental, in which the materials developed were tested and compared to commercial materials through MPMTO and were analyzed with clinical practice criteria by professionals working in the area. The main instrument of data collection for the participants was a questionnaire organized in the Likert-type scale format. The results are as follows: the development of two thermoplastic materials of low temperature in Brazil, evaluated as viable by 24 professionals, especially Material B; the elaboration of methodological steps for the development of materials; and the creation of two instruments for the evaluation of materials for orthotics, an empirical practical and another standardized. In addition to presenting social relevance, expanding the options of materials for the preparation of bracing and, consequently, generating improvements to the population, represents a scientific and technological advance for the country. 
Keywords: Orthotic Devices. Materials Testing. Rehabilitation. Polymers. Low Temperature Thermoplastics. Occupational Therapy. 


\section{LISTA DE ILUSTRAÇÕES}

Figura 1 - Informações sobre diferentes espessuras de materiais termoplásticos para órteses, segundo o fabricante Performance Health / Patterson Medical....

Figura 2 - Informações sobre diferentes tipos de placas perfuradas, em comparação à placa lisa, segundo o fabricante Performance Health / Patterson Medical ......................................... 43

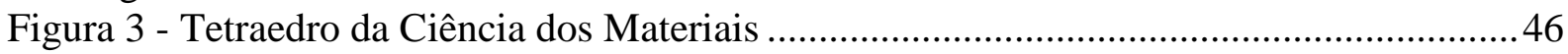

Figura 4 - Espectrômetro FTIR, modelo Nexus 4700, Thermo Nicolet.....................................55

Figura 5 - Calorímetro Modulado DSC, modelo Q100, TA Instruments.................................55

Figura 6 - Analisador Dinâmico-Mecânico, modelo DMA Q800, TA Instruments..................56

Figura 7 - a) e b) Analisador Termogravimétrico TG, modelo Q50, TA Instruments ..............57

Figura 8 - Forno de Micro-Ondas CEM, Airwave 7000, Microwave Furnace ........................58

Figura 9 - Matriz de Requisitos / Matriz da Qualidade ..........................................................60

Figura 10 - Processo de pesagem dos componentes: a) tara, b) e c) acréscimo de componente

Figura 11 - Homogeneizador de Alta Rotação, modelo MH-100, MH Equipamentos ( $a$ e $b$ ). 64 Figura 12 - a) Colocação dos componentes no misturador e b) Aspecto após

mistura/homogeneização

Figura 13 - Remoção do material do misturador $(a$ e $b)$ e material removido $(c)$.....................65

Figura 14 - Prensa hidráulica com aquecimento $(a)$ e prensagem do material no molde

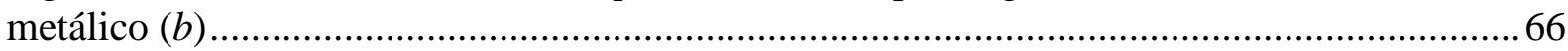

Figura 15 - Amostra após a prensagem, ainda no molde metálico .......................................66

Figura 16 - Rebarbamento (remoção de excesso e farpas) da amostra, após prensagem e

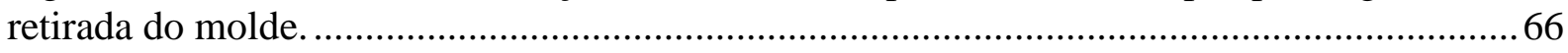

Figura 17 - Extrusora Dupla Rosca, modelo DRC 30:40 IF, IMACOM ( $a$ e $b)$......................69

Figura 18 - Injetora, modelo Prática 130, ROMI....................................................................... 70

Figura 19 - Sistema A, projetado para os Ensaios de Moldabilidade (quesito Conformação) e

de Memória: $a$ ) ainda sem a amostra inserida e $b$ ) com a amostra inserida..............................73

Figura 20 - Objeto esférico a ser usado no Sistema A, para o Ensaio de Moldabilidade

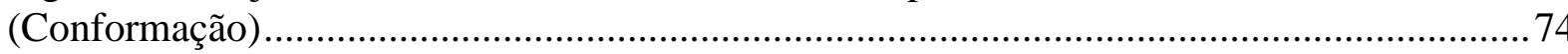

Figura 21 - Desenho esquemático do Sistema B, montado para o Ensaio de Moldabilidade (quesito caimento). A placa está fixada e centralizada por meio de dois pinos .......................74

Figura 22 - Sistema C - Projetado para compor o Ensaio de Autoaderência............................. 74

Figura 23 - Padronização da medida de referência para o ensaio de Conformação .................. 79 Figura 24 - Procedimentos iniciais do ensaio de Conformação: $a$ ) amostra inserida no sistema $\mathrm{A}, b$ ) peso, $c$ ) pré-aquecimento e $d$ ) peso inserido ...............................................................79 Figura 25 - Sequência final de procedimentos para o ensaio de Conformação (sistema A): peso inserido $(a)$, remoção para resfriamento $(b)$ e medição $(c)$.............................................. 80 Figura 26 - Esquema para a sequência de etapas do sistema A (Conformação), com medidas as serem realizadas: medida inicial $(a)$, inserção do peso $(b)$, amostra conformada pelo peso (c) e medida deformada $(d)$ .80 Figura 27 - Referência para as medidas do ensaio de Caimento (sistema B): 0\% de caimento (a), uma porcentagem intermediária $(b)$ e $100 \%$ de caimento $(c)$...........................................81 Figura 28 - Uso do sistema de ensaio de Caimento: amostra fixada (a), inserção no banho aquecido $(b)$, caimento dentro do banho aquecido $(c)$, retirada para resfriamento com continuação do caimento $(d)$ e medição $(e)$...

Figura 29 - Medidas a serem consideradas no ensaio de Memória: medição inicial (a), medida deformada $(b)$ e medida de recuperação $(c)$...

Figura 30 - Desenho esquemático da preparação de amostras para a aderência (a); amostras aderidas após a retirada da massa $(b)$ e disposição final da amostra, preparando para o teste de tração $(c)$ 
Figura 31 - Desenho esquemático do ensaio de flexão em três pontos ...................................88

Figura 32 - Foto do ensaio de flexão em três pontos ............................................................. 88

Figura 33 - Medidor de Temperatura HDT/VICAT, modelo HDT 6 Vicat P/N 6921, CEAST

Figura 34 - Máquina Universal de Ensaios Mecânicos, modelo 5569, INSTRON..................90

Figura 35 - Espectros de absorção no infravermelho dos Produtos 1 (a) e 2 (b) .....................96

Figura 36 - Comparação entre Espectros de Infravermelho do Produto 1 e do Padrão

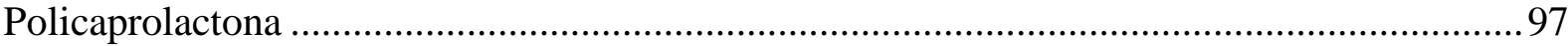

Figura 37 - Comparação entre Espectros de Infravermelho do Produto 2 e do Padrão

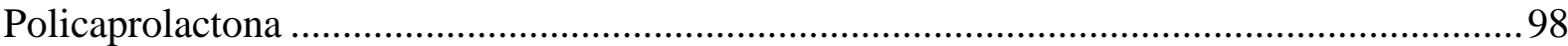

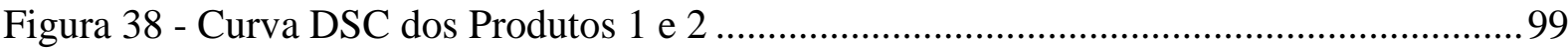

Figura 39 - Sobreposição das Curvas DSC para o Produto 1 e para o Produto 2.................... 100

Figura 40 - Curva DSC do polímero Policaprolactona (PCL) CAPA 6500, da Perstorp....... 101

Figura 41 - Sobreposição das Curvas DSC: Produto 1, Produto 2 e do Polímero PCL CAPA

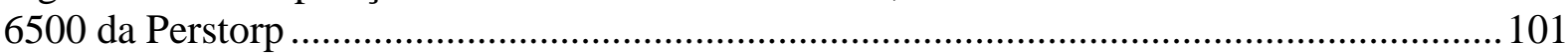

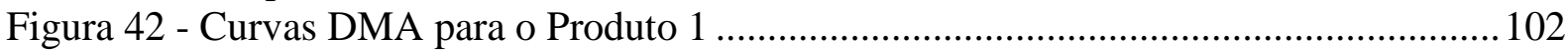

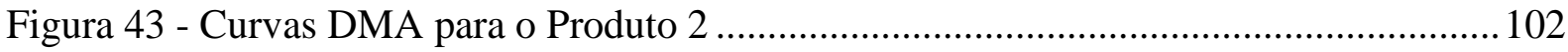

Figura 44 - Curvas DMA para o Polímero PCL Puro .............................................................. 103

Figura 45 - Sobreposição das Curvas DMA para o Produto 1, para o Produto 2 e para o PCL

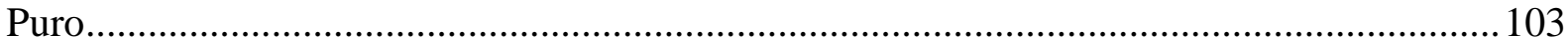

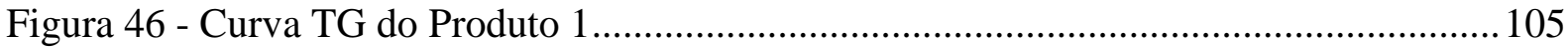

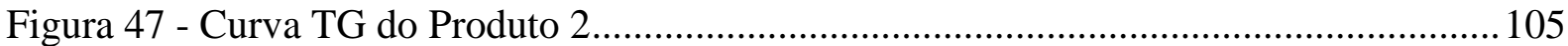

Figura 48 - Sobreposição das Curvas TG: Produto 1 e Produto 2......................................... 105

Figura 49 - Micrografia dos constituintes inorgânicos do Produto 1 (a marcação 1 é um ponto

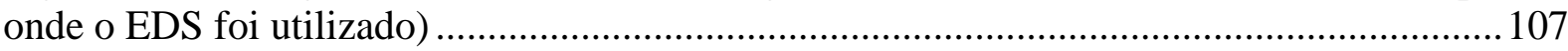

Figura 50 - Micrografia dos constituintes inorgânicos do Produto 2. (marcações 1 e 2 são

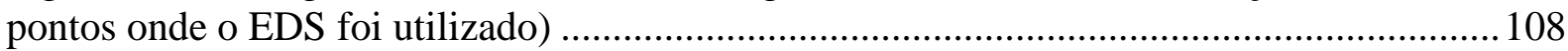

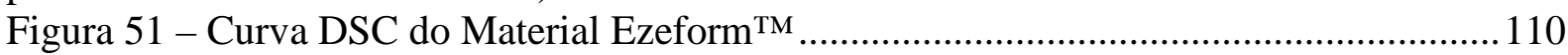

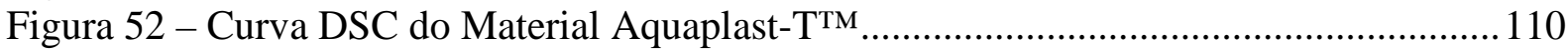

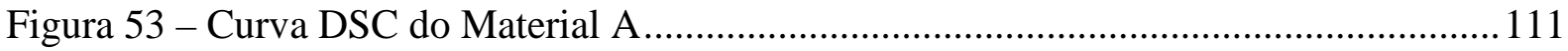

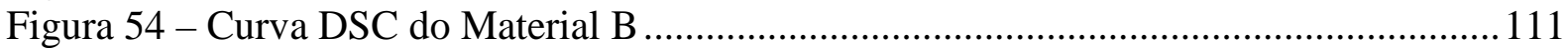

Figura 55 - Sobreposição das Curvas DSC para os 4 materiais............................................112

Figura 56 - Realização do ensaio de Moldabilidade com aplicação de força, no parâmetro

Conformação $(a)$ e e realização da medida de deformação utilizando paquímetro $(b)$..........116

Figura 57 - Realização do ensaio de Moldabilidade, no parâmetro Caimento: no banho

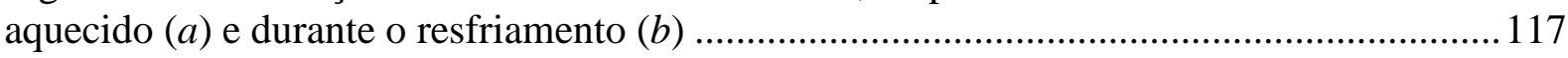

Figura 58 - Realização do ensaio de Moldabilidade, simultaneamente nos dois quesitos

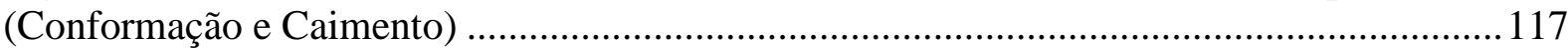

Figura 59 - Resultado do ensaio de Moldabilidade no quesito Caimento, para o material

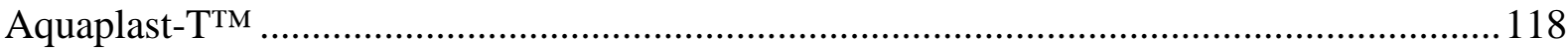

Figura 60 - Escala de Conformabilidade e de Resistência dos termoplásticos de baixa

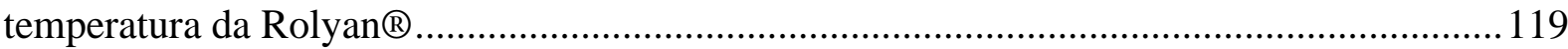

Figura 61 - Gráfico Radar dos Ensaios de Moldabilidade e Memória ..................................122

Figura 62 - Sistema construído para realização da aderência de forma padronizada ( $a$ ) e

durante o uso $(b)$.......................................................................................................... 124

Figura 63 - Amostra preparada para o Ensaio de Aderência com solicitação de tração........124

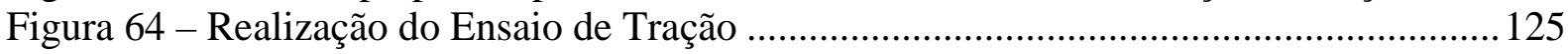

Figura 65 - Curvas da Resistência da Adesão (ao destacamento) ..........................................126

Figura 66 - Ensaio de Aderência com solicitação de tração, com o Material Ezeform ${ }^{\mathrm{TM}}$......127 
Figura 67 - Ensaio de Aderência com solicitação de tração, com o Material Aquaplast-TTM, início do teste $(a)$, destacamento repentino $(b)$

Figura 68 - Ensaio de Aderência com solicitação de tração, com o Material A em dois

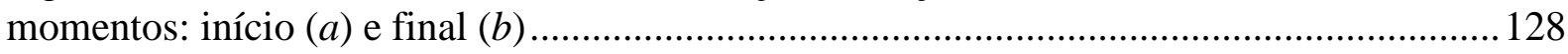

Figura 69 - Ensaio de Aderência com solicitação de tração, com o Material B .....................129

Figura 70 - Curvas médias para os ensaios de flexão dos quatro materiais...........................131

Figura 71 - Gráfico contendo as áreas de atuação dos profissionais participantes .................136

Figura 72 - Materiais utilizados na confecção de órteses pelos profissionais participantes..137

Figura 73 - Marcas comerciais de termoplásticos de baixa temperatura para órteses utilizadas

pelos participantes

Figura 74 - Espessuras (a) e tipos de placas $(b)$ utilizadas pelos participantes deste estudo.139

Figura 75 - Materiais escolhidos pelos participantes como o mais utilizado

Figura 76 - Pontuações médias e desvio padrão (x) em relação a cada característica dos materiais

Figura 77 - Gráfico referente à satisfação dos profissionais participantes com os materiais desenvolvidos (A e B)

Figura 78 - Satisfação geral em relação aos materiais desenvolvidos, de acordo com o material que cada participante mais utiliza 


\section{LISTA DE TABELAS}

Tabela 1 - Resultados dos testes empíricos realizados com as 17 amostras, onde verde mosta a faixa de resultados aceitaveis, vermelho mostra a faxa de resultados não aceitaveis e $\mathrm{X}$ os resultados encontrados

Tabela 2 - Descrição dos Picos e das Bandas de Absorção apresentadas nos Espectros de

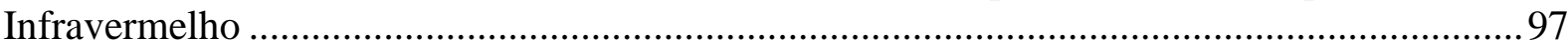

Tabela 3 - Resultados quanto à Temperatura de Fusão Cristalina para os Produtos 1 e 2 .....100

Tabela 4 - Resultados do Teor de Inorgânicos obtidos por Termogravimetria (TG) .............106

Tabela 5 - Resultados do Teor de Inorgânicos obtido por Calcinação ...................................106

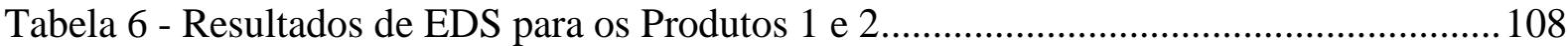

Tabela 7 - Temperatura de Amolecmento Vicat para os quatro materiais .............................113

Tabela 8 - Características térmicas e Faixa de Temperatura de Trabalho MPMTO .............113

Tabela 9 - Resultados dos dois Ensaios de Moldabilidade do MPMTO ...............................118

Tabela 10 - Relação entre a descrição do fabricante e os resultados do MPMTO quanto a

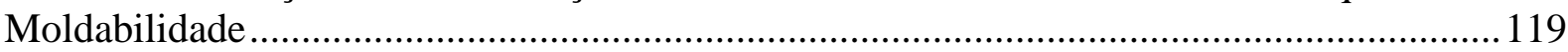

Tabela 11 - Resultados do Ensaio de Memória ....................................................................121

Tabela 12 - Relação entre a descrição do fabricante e os resultados do MPMTO no quesito

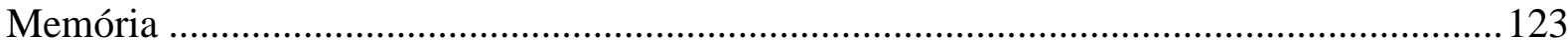

Tabela 13 - Valores obtidos no Ensaio de Aderência com solicitação de tração, relacionados à

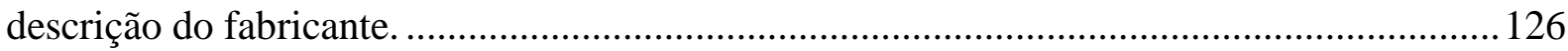

Tabela 14 - Valores obtidos no Ensaio de Flexão em três pontos ..........................................131

Tabela 15 - Relação entre a descrição do fabricante e os resultados do MPMTO no quesito

Rigidez 


\section{SUMÁRIO}

1 INTRODUÇÃO

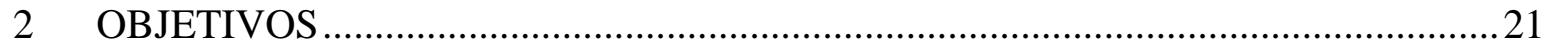

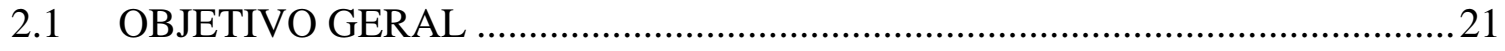

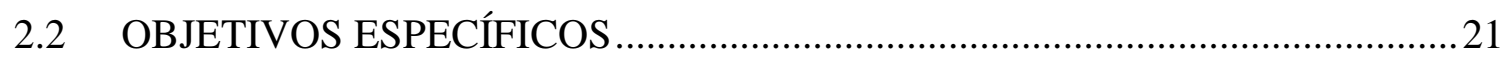

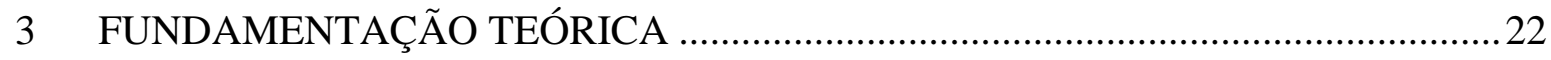

3.1 ÓRTESES: DEFINIÇÕES, OBJETIVOS E CLASSIFICAÇÕES ..........................22

3.2 INDICAÇÃO E PRESCRIÇÃO DE ÓRTESES PARA OS MEMBROS

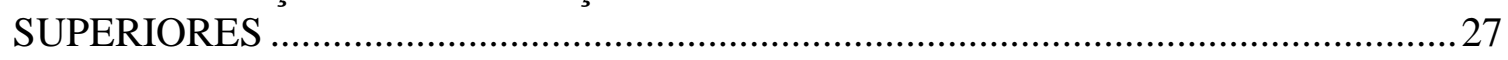

3.3 MATERIAIS UTILIZADOS NA CONFECÇÃO DE ÓRTESES.......................... 30

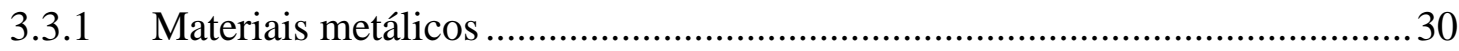

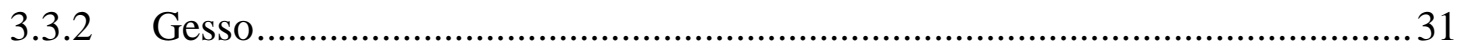

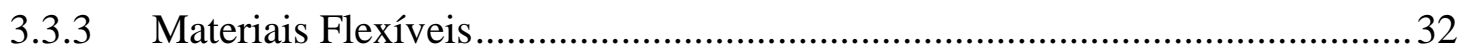

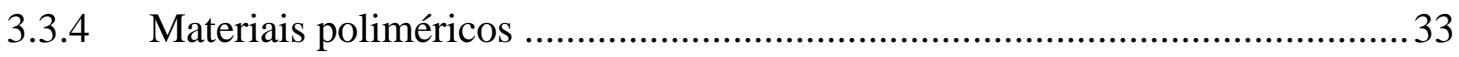

3.4 TERMOPLÁSTICOS DE BAIXA TEMPERATURA: CENÁRIO ATUAL ........38

3.5 PROPRIEDADES DOS MATERIAIS TERMOPLÁSTICOS E SUAS

CARACTERÍSTICAS PARA A CONFECÇÃO DE ÓRTESES ......................................4 45

3.6 ENSAIOS DE MATERIAIS PARA ÓRTESES ................................................ 48

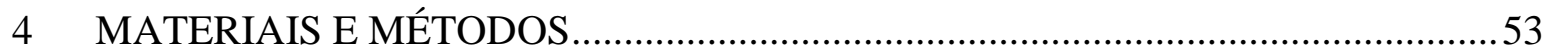

4.1 FASE EXPLORATÓRIA: DESENVOLVIMENTO DOS MATERIAIS E DOS MÉTODOS.

4.1.1 $\quad 1^{\text {a }}$ etapa - Estudo dos materiais existentes no mercado..................................53

4.1.2 2 2a etapa - Elaboração da matriz de requisitos ................................................59

4.1.3 $\quad 3^{\text {a }}$ etapa - Elaboração de instrumento para a realização de testes práticos empíricos

4.1.4 4 a etapa - Formulação e processamento de amostras de diferentes materiais.63

4.1.5 5 a etapa - Ajustes das formulações na busca por materiais viáveis .................67

4.1.6 $6^{a}$ etapa - Seleção e produção de dois materiais para a Fase Experimental ....69

4.1.7 $\quad 7^{\text {a }}$ etapa - Criação do instrumento de avaliação "Manuseio Padronizado de Materiais Termoplásticos para Órteses (MPMTO)” .....................................................71

4.2 FASE EXPERIMENTAL: APLICAÇÃO DO INSTRUMENTO MPMTO E AVALIAÇÃO DOS MATERIAIS DESENVOLVIDOS

4.2.1 $\quad 1^{\text {a }}$ etapa - Aplicação do instrumento MPMTO: caracterização físico-mecânica 89

4.2.2 2 2a etapa - Avaliação de dois materiais desenvolvidos, de acordo com critérios da prática clínica, por profissionais com experiência na área .......................................91

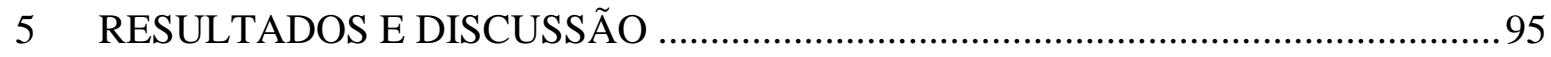

5.1 ESTUDO DOS MATERIAIS EXISTENTES NO MERCADO (FASE EXPLORATÓRIA). 


\subsection{FASE EXPERIMENTAL: APLICAÇÃO DO INSTRUMENTO MPMTO E}

TESTE DOS MATERIAIS DESENVOLVIDOS

5.2.1 Aplicação do instrumento MPMTO: caracterização físico-mecânica 109

5.2.2 Avaliação de dois materiais desenvolvidos, de acordo com critérios da prática clínica, por profissionais com experiência na área

5.3 Considerações sobre a potencial aplicabilidade clínica 148

6 CONCLUSÕES 152

7 LIMITAÇÕES DO ESTUDO E SUGESTÕES PARA TRABALHOS FUTUROS .154 REFERÊNCIAS

APÊNDICE I Roteiro de Procedimentos de Testes Práticos Empíricos 167

APÊNDICE II Termo de Consentimento Livre e Esclarecido. 172

APÊNDICE III Guia de Instruções para o Teste Prático de Materiais 176

APÊNDICE IV Formulário para Pesquisa Inicial sobre Confecção de Órteses 181

APÊNDICE V Formulário para Avaliação dos Materiais Termoplásticos 187

APÊNDICE VI Análise Complementar Termogravimetria 193

ANEXO I Parecer do Comitê de Ética em Pesquisas envolvendo seres humanos. 198 


\section{INTRODUÇÃO}

A diversidade de temas e abordagens da linha de pesquisa “Tecnologias em Saúde”, mais especificamente à área de "Inovação, Tecnologia Assistiva e Recursos Terapêuticos", concentram pesquisas socialmente relevantes, na medida em que respondem a muitas necessidades da sociedade brasileira, além de representar um avanço científico e tecnológico. Muitas propostas dentro dessas temáticas constituem objetos de investigação em terapia ocupacional, uma vez que se relacionam à qualidade de vida da população, em diferentes contextos de vida.

Os avanços tecnológicos têm causado impacto na vida das pessoas, em todas as faixas etárias, e estão influenciando toda a sociedade, de forma intensa e decisiva. Na área da saúde são cada vez mais crescentes os avanços e novas descobertas tecnocientíficas, como: facilidade e modernização de exames, diagnósticos e intervenções médicas; informação e comunicação instantânea; novos medicamentos e vacinas; implantes e transplantes; produção artificial de células humanas; próteses, órteses e exoesqueletos; além de muitos outros exemplos que poderiam ser citados (FUNDAÇÃO DE AMPARO A PESQUISA DO ESTADO DE SÃO PAULO - FAPESP, 2016; GRADIM; PAIVA, 2018; LORENZETTI et al., 2012).

Além disso o desenvolvimento tecnológico tem influenciado especificamente o campo da reabilitação e observa-se um crescente investimento na utilização de recursos com finalidades terapêuticas diversas, como por exemplo os equipamentos destinados a eletroestimulação; a modernização de dispositivos ortopédicos, com novos materiais a cada ano; os recursos tecnológicos para o monitoramento de condições de saúde; dispositivos eletrônicos para a prevenção de quedas em idosos; uso de realidade virtual como ferramenta de intervenção para reabilitação motora e cognitiva e outras tecnologias em reabilitação.

Outros recursos passam a compor opções de acessibilidade e funcionalidade para as pessoas com deficiência ou com mobilidade reduzida, como é o caso dos sistemas de automação residencial; das novas soluções para a mobilidade em cadeiras de roda e veículos adaptados; vocalizadores eletrônicos; softwares para uso de internet e para a comunicação de pessoas com diferentes tipos de deficiência; dentre muitos outros exemplos que poderiam ser descritos em função da grande variedade de subáreas que compõem a Tecnologia Assistiva.

Considerando-se a atualidade acerca dos avanços tecnológicos e sua importância para o setor saúde e para a sociedade, a Terapia Ocupacional está diante de um desafio promissor: envolver-se cada vez mais com essa temática e desenvolver pesquisas que utilizem as tecnologias disponíveis de maneira eficiente, abordando diferentes necessidades da população, 
além de pesquisas envolvendo inovações tecnológicas ligadas a reabilitação, acessibilidade, inclusão social e qualidade de vida.

Nesse contexto, a proposta do presente trabalho está voltada para o desenvolvimento de novos materiais para a área da saúde, destinados especificamente à confecção de órteses e de recursos de tecnologia assistiva, aliado à criação de métodos e instrumentos para o teste de materiais para essa finalidade.

Dentre uma gama de recursos e equipamentos utilizados em reabilitação física, as órteses são empregadas para modificar aspectos estruturais do sistema musculoesquelético ou ainda para modificar características funcionais e melhorar a independência das pessoas (RODRIGUES; CAVALCANTI; GALVÃO, 2007). A aplicação clínica da órtese envolve uma série de fatores essenciais para atingir o objetivo desejado, desde uma avaliação criteriosa do indivíduo até o conhecimento dos princípios biomecânicos e dos materiais a serem aplicados na fabricação do dispositivo.

Não existe um material adequado para todos os tipos de órtese e, dessa forma, para se atingir o sucesso na confecção é necessária a compreensão de suas características e propriedades, bem como das vantagens e desvantagens dos materiais para cada aplicação.

A busca por novos e melhores materiais tem sido contínua na reabilitação ortótica. Antes do advento dos termoplásticos, os materiais utilizados na construção de órteses eram, em sua maioria, materiais metálicos, dos quais destacavam-se o aço, o alumínio, as ligas de titânio e as ligas de magnésio. Outro material bastante antigo na confecção de órteses é o gesso, que não precisa de aquecimento para ser moldado. Materiais mais flexíveis, como neoprene e outros tecidos, também podem ser usados, a depender do objetivo e das condições do cliente, tanto para a confecção de órteses flexíveis como para alguns componentes de fixação e/ou forração (FERRIGNO, 2007; RODRIGUES; CAVALCANTI; GALVÃO, 2007).

Em um levantamento realizado por Danckwardt (2016), identificou-se que atualmente os polímeros são os principais materiais utilizados no processo de fabricação de órteses no Brasil, seja para forrações (Copolímero etileno-acetato de vinila - EVA), para velcros e fechamentos (Poliamidas) ou para a estrutura dos dispositivos, com a utilização majoritária dos termoplásticos, seja de alta ou de baixa temperatura.

As técnicas de confecção de órteses evoluíram e os materiais utilizados também têm acompanhado o avanço da tecnologia (FESS, 2002), sendo necessária a continuidade de estudos envolvendo ambos os aspectos, uma vez que não existe consenso quanto à satisfação em relação aos materiais, considerando a diversidade de aplicações existentes. 
No que diz respeito à confecção de órteses para os membros superiores, devido às características térmicas e mecânicas, os termoplásticos de baixa temperatura são os mais utilizados e recomendados. Um dos maiores benefícios é o fato de serem termomoldáveis, como podem ser denominados, e possibilitarem acomodação anatômica da parte do corpo que se pretende imobilizar, uma vez que podem ser moldados diretamente na pele do usuário. Esta característica é importante não apenas para a confecção de aparelhos ortóticos, mas também para a utilização em dispositivos de tecnologia assistiva que precisam ser anatômicos, como por exemplo os substituidores de preensão e as adaptações para utensílios, visando a obtenção de recursos individualizados, com a possibilidade de remodelagens e ajustes ao longo do tempo (AGNELLI; TOYODA, 2003; FESS, 2011; MACKEE; RIVARD, 2011; SAURON, 2003).

Existe uma variedade de materiais desse grupo, com diversas marcas e modelos, sendo que os três principais fabricantes apresentam representação e distribuição no Brasil. Contudo todos os materiais são importados e não existem termoplásticos de baixa temperatura nacionais, disponíveis comercialmente, destinados à confecção de órteses. O custo, portanto, ainda é considerado alto, visto que é acrescido de impostos e condicionado à cotação do dólar. O custo final é absorvido pelo governo, no caso de serviços e hospitais públicos que utilizam o material, ou ainda repassado para a população, quando adquire as órteses em serviços privados (LEITE, 2007; SOUZA, 2014).

Apesar do custo ainda ser considerado um fator negativo, isto não impede a utilização deste grupo de materiais por profissionais no Brasil, devido a sua qualidade quando comparados a outros materiais. Uma estratégia adotada por profissionais e serviços de saúde é optar pela compra do material termomoldável mais barato, desconsiderando suas características específicas em função da aplicação. Alguns profissionais afirmam que utilizam materiais mais baratos na confecção de órteses para membros superiores por falta de opção e não porque são considerados os mais adequados (AGNELLI; TOYODA, 2003; RODRIGUES; CAVALCANTI; GALVÃO, 2007).

Se, por um lado, há uma gama de materiais que podem ser utilizados na confecção de órteses, após uma seleção em busca de qualidade, praticidade e viabilidade, não se tem tantas opções. Essa situação tende a melhorar com o investimento em pesquisas na área da saúde e na área de desenvolvimento de novos materiais no país. Com base em estudos realizados anteriormente (AGNELLI; TOYODA, 2003; AGNELLI; TOYODA; FERRIGNO, 2010; LINDEMAYER, 2004; MENG; HU; ZHU, 2008; SOUZA, 2014), sabe-se que os termoplásticos de baixa temperatura disponíveis no mercado foram desenvolvidos com fundamentos avançados da ciência dos materiais, o que não impede que outros materiais sejam 
pesquisados e formulados, especialmente no Brasil, seja para melhorar determinadas características, para reduzir o custo ou ainda para ampliar a diversidade de materiais em vista da multiplicidade de possíveis aplicações.

A pesquisa propôs um estudo exploratório e experimental voltado para os termoplásticos de baixa temperatura para órteses, visando o desenvolvimento de materiais nacionais que apresentem características viáveis para a aplicação em órteses. O estudo também envolveu inovação no que diz respeito à criação de procedimentos e instrumentos de avaliação voltados para esse grupo de materiais, com critérios estabelecidos de acordo com a prática clínica, podendo gerar melhorias à população. 


\section{OBJETIVOS}

\subsection{OBJETIVO GERAL}

Criar uma metodologia para o desenvolvimento e teste de termoplásticos de baixa temperatura, a partir das características verificadas na prática clínica. Objetivou-se desenvolver novos materiais e analisar suas principais características para a confecção de órteses para membros superiores, além de analisar, através de profissionais que atuam na área, sua viabilidade para esse tipo de aplicação.

\subsection{OBJETIVOS ESPECÍFICOS}

- Realizar um levantamento bibliográfico acerca dos materiais atualmente utilizados na confecção de órteses para membros superiores, no âmbito nacional e internacional;

- Desenvolver uma metodologia para o desenvolvimento de novos materiais para a confecção de órteses;

- Elaborar um protocolo para testar, e de forma padronizada, os termoplásticos de baixa temperatura de acordo com as exigências da prática clínica;

- Desenvolver termoplásticos de baixa temperatura no Brasil;

- Realizar análise dos aspectos estruturais e físico-mecânicos de alguns materiais termoplásticos de baixa temperatura existentes no mercado e dos materiais desenvolvidos, realizando um estudo comparativo entre eles;

- Avaliar os materiais desenvolvidos segundo critérios da prática clínica, por terapeutas ocupacionais e fisioterapeutas que atuam nessa área no país. 


\section{FUNDAMENTAÇÃO TEÓRICA}

\section{1 ÓRTESES: DEFINIÇÕES, OBJETIVOS E CLASSIFICAÇÕES}

A ortótica refere-se à área da reabilitação que envolve a prescrição, seleção, modelo, fabricação, testes e treinamento do uso de dispositivos que podem ser aplicados a um segmento do corpo, para recuperar ou substituir uma função perdida (DESHAIS, 2005). As órteses fazem parte de um arsenal de recursos terapêuticos e seu objetivo principal é promover equilíbrio biomecânico por meio da aplicação de forças de contenção externa ao segmento comprometido (FERRIGNO, 2007). De uma forma geral, podem ser definidas como dispositivos ou aparelhos, aplicados externamente a algum segmento do corpo, para modificar características funcionais ou estruturais do sistema musculoesquelético (INTERNATIONAL ORGANIZATION FOR STANDARTIZATION - ISO, 2016; RODRIGUES; CAVALCANTI; GALVÃO, 2007).

Podem ser aplicadas em qualquer parte do corpo e utilizadas em conjunto com outras estratégias de tratamento para melhorar o desempenho ocupacional, direta ou indiretamente (CALLINAN, 2005; MCKEE; MORGAN, 1998). O profissional que, envolvendo-se com a confecção de órteses e adaptações, visa e planeja maior independência do indivíduo no desempenho de tarefas ocupacionais, certamente atua no projeto, na construção, na verificação final e no treinamento/acompanhamento do uso destes dispositivos (AGNELLI; TOYODA, 2003).

O termo órtese (orthosis) origina-se do grego orthós, que significa reto ou normal, no sentido de endireitar, corrigir e alinhar, de forma que o aparelho ortopédico seja projetado para oferecer apoio a alguma parte do corpo que necessita de intervenção. Os termos splint, brace e orthosis tem sido utilizados de forma intercambiável, muitas vezes como sinônimos, para designar os dispositivos ortopédicos. Atualmente recomenda-se o uso do termo orthosis para o singular (órtese) e o termo ortheses para o plural (órteses), preferencialmente aos demais termos com que formalmente eram referidas (FESS, 2002; ISO, 2016; MCKEE; MORGAN, 1998; O’BRIEN, 2013). Outros termos podem ser usados, como splinting, para se referir ao plano de tratamento e intervenção ortopédica, e orthotic, que é utilizado mais como um adjetivo, relacionado à prática e à ciência de uma reabilitação com abordagem no manejo de dispositivos (O’BRIEN, 2013).

Através de uma revisão da literatura, Fess (2002) identificou mais de 20 finalidades para as órteses referidas por autores consagrados na área, as quais listou de acordo com a frequência de citação, sendo que as mais citadas foram: 1) aumentar a função; 2) prevenir deformidades; 3) corrigir deformidades; 4) proteger estruturas em cicatrização; 5) restringir o movimento; 6) 
permitir remodelação. As três primeiras definições foram citadas em mais de vinte referências diferentes, abrangendo mais de 50 anos. A revisão histórica realizada confirma que, ao longo do tempo, as órteses foram um elemento importante para o tratamento envolvendo o sistema musculoesquelético (FESS, 2002, 2011).

As órteses podem ser categorizadas de acordo com diferentes critérios, sendo que uma classificação usual e comumente relatada na literatura se baseia nos componentes estruturais e nas características mecânicas inerentes, dividindo-as em estáticas e dinâmicas. As órteses estáticas, sem partes móveis, fornecem apoio/suporte, estabilização, proteção ou imobilização. Elas mantêm o correto alinhamento articular e podem manter determinadas estruturas no máximo alongamento possível, evitando deformidades (CARVALHO, 2013; DESHAIS, 2005; FERRIGNO, 2007; MALICK, 1978). Quando o objetivo terapêutico é a restauração de uma lesão, o controle de processos inflamatórios e/ou a redução da dor, pode ser indicada para uso contínuo, como repouso (RODRIGUES; CAVALCANTI; GALVÃO, 2007). As órteses dinâmicas permitem mobilidade controlada das articulações e restauração de algum movimento, já que possuem partes que se movimentam. Este modelo de órtese aplica força em uma direção enquanto permite o movimento resistido na direção oposta (ASSUMPÇÃO, 2005). Segundo Fess (2011), órteses destinadas à mobilização podem ser usadas para corrigir deformidades, através da aplicação de forças, ou para substituir o movimento ativo perdido, melhorando assim o uso da mão.

Diante das dificuldades em classificar alguns tipos de órteses simplesmente em dois grupos, alguns autores mencionam, além destes, outras categorias atribuídas principalmente à funcionalidade e indicação terapêutica, tais como: estáticas seriadas, estáticas progressivas, drop-out e articuladas (CARVALHO, 2013; FESS, 2011; STANLEY; TRIBUZI, 1992).

As órteses estáticas seriadas são destinadas a alongar tecidos e readquirir a amplitude de movimento, ao manter o segmento em uma posição alongada por períodos prolongados. Através da aplicação de órteses em série, de gesso ou termoplásticas, é possível manter a articulação ou o tecido encurtado em seu comprimento ou amplitude máxima disponível, sendo remodeladas com o tempo, conforme se aumenta a amplitude de movimento. Recomenda-se estabilizar apenas as articulações envolvidas e que nunca sejam usadas mais do que o fisiologicamente necessário, a fim de não causar efeitos indesejáveis, como atrofia e rigidez (DESHAIS, 2005; MCKEE; RIVARD, 2011). As estáticas progressivas criam uma força mobilizadora para manter o tecido próximo do fim do seu limite elástico, mas diferem das dinâmicas porque a aplicação de força não é elástica, ou seja, não permite que seja realizado o movimento na direção contrária. Diferem também das estáticas seriadas porque estas 
distribuem a força igualmente sobre toda a superfície de aplicação, enquanto as progressivas concentram a força sobre a área que aplica a pressão (ASSUMPÇÃO, 2005). Considerando o avanço da experiência e do conhecimento em órteses, Fess (2011) refere que o termo “estática progressiva” foi introduzido após o reconhecimento de que as órteses estáticas são eficazes para melhorar a amplitude de movimento através de alterações consecutivas em sua configuração.

As órteses articuladas são compostas por dois componentes estáticos que se conectam, permitindo regulagem por parte do terapeuta ao definir o grau de limite do arco de movimento (FERRIGNO, 2007). As órteses drop-out permitem o movimento de determinada articulação em uma direção, mas bloqueiam em outra, permitindo a realização de alguns movimentos ativos (RODRIGUES; CAVALCANTI; GALVÃO, 2007).

Como existe uma grande variedade de órteses, destinadas a diversas partes do corpo, faz-se necessário identificar a localização anatômica do dispositivo, seja de uma forma genérica, dividindo-se entre órteses para os membros inferiores, para os membros superiores e órteses espinhais, ou, preferencialmente, através das articulações envolvidas (REDFORD; BASMAJIAN; TRAUTMAN, 1995). Existem ainda tipos específicos de órteses para o rosto, como é o caso de alguns dispositivos orais para o tratamento de sequelas de queimaduras (IMAMURA et al., 2012; NAIR et al., 2008).

Uma outra classificação é feita quanto à manufatura e sistema de confecção, podendo der divididas em órteses customizadas ou fabricadas sob medida e pré-fabricadas, que se referem aos equipamentos produzidos em larga escala e que são comercializados prontos para o uso (MCKEE; MORGAN, 1998; MCKEE; RIVARD, 2011). Embora sejam encontradas órteses pré-fabricadas de vários modelos no mercado, muitas vezes elas não se adaptam bem e não são toleradas pelo usuário, especialmente as destinadas aos membros superiores, de maneira que, neste caso, as órteses feitas sob medida substituíram, em grande parte, as primeiras (ALMEIDA et al., 2016; ASSUMPÇÃO, 2005). Ferrigno et al. (2009) alertam para o consenso que parece existir entre os terapeutas brasileiros de que as órteses pré-fabricadas são impróprias. Apesar de serem comercializadas em tamanhos padronizados e nem sempre se adequarem aos parâmetros definidos pela individualidade do paciente, há controvérsias sobre os efeitos de algumas órteses pré-fabricadas. Devido à variedade de opções que existem atualmente, alguns modelos podem ajustar-se adequadamente, como por exemplo, diante de algumas alterações ortopédicas.

Nesse contexto, alguns autores definem ainda as órteses pré-fabricadas ajustáveis, que permitem a realização de ajustes e adequações visando melhores resultados, conforto e/ou 
níveis de funcionalidade (CARVALHO, 2013; MCKEE; MORGAN, 1998). Elas podem substituir algumas órteses que até então eram confeccionadas somente sob medida.

Devido às limitações nas classificações, especialmente diante de novos modelos que foram sendo criados e das dificuldades ainda existentes para se definir e nomear os dispositivos, a Sociedade Americana de Terapeutas da Mão (ASHT) criou, em 1989, uma comissão para buscar e propor soluções conclusivas para as divergências na nomenclatura das órteses (FESS, 2002, 2011; RODRIGUES; CAVALCANTI; GALVÃO, 2007). O resultado foi a criação de um Sistema de Classificação das Órteses (SCS), que posteriormente foi expandido com uma categoria adicional, de forma que são apresentados seis critérios descritivos: 1) Articular ou Não articular; 2) Localização anatômica; 3) Direção cinemática; 4) Finalidade ou objetivo primário da órtese (mobilizar, imobilizar ou restringir o movimento); 5) Tipo (inclusão e número de articulações secundárias envolvidas; 6) Número total de articulações envolvidas em uma órtese. Esses seis critérios se combinam para formar uma "sentença”, a fim de descrever claramente uma órtese (FESS, 2011).

Rodrigues, Cavalcanti e Galvão (2007) mencionam que esta classificação uniformizou categorias de órteses para os membros superiores e para os membros inferiores, nomeando-as de acordo com o propósito funcional. Segundo Ferrigno (2007), o sistema de classificação recomendado pela ASHT prioriza a função das órteses e não se restringe ao diagnóstico pelo qual foram indicadas, sendo necessário iniciar a aplicação na prática clínica no Brasil, para se obter dados concretos sobre sua viabilidade.

Independentemente do sistema de classificação utilizado, existem órteses cujo objetivo primário destina-se a auxiliar determinados movimentos durante atividades funcionais, especialmente nos casos de lesões agudas, traumas cumulativos, intervenções cirúrgicas e deficiências permanentes, como malformações congênitas e doenças degenerativas. Elas podem ser denominadas como órteses assistivas ou funcionais (MCKEE; MORGAN, 1998).

A órtese abdutora do polegar, frequentemente aplicada em crianças com alterações neurológicas, como na paralisia cerebral, pode ser considerada uma órtese estática e funcional, na medida em que posiciona o polegar, facilita a preensão e beneficia a função da mão durante as atividades (SILVA, 2001). Outro modelo de órtese frequentemente indicada diante de alterações neurológicas é a suropodálica, que visa minimizar ou corrigir o padrão equino no ortostatismo e deambulação. Embora muitos estudos que investigam o efeito dessas órteses apontem para benefícios estruturais no corpo, há comprovações que mostram seu benefício na mobilidade funcional e no desempenho de atividades motoras da rotina diária de crianças com paralisia cerebral, como andar, correr e subir/descer escadas (CURY et al., 2006). 
Independentemente do modelo e dos componentes estruturais que uma órtese apresenta, o que realmente irá classificá-la como funcional, será a sua aplicação para cada indivíduo.

Dentre uma gama de recursos e equipamentos utilizados para maximizar alguma função e propiciar uma vida mais independente, as órteses funcionais fazem parte de uma das categorias da Tecnologia Assistiva (TA). No Brasil, para elaborar um conceito que pudesse subsidiar as políticas públicas brasileiras, após a instituição do Comitê de Ajudas Técnicas (CAT) em 2006, seus membros fizeram uma profunda revisão no referencial teórico internacional, pesquisando os termos “Ajudas Técnicas”, “Tecnologia Assistiva” e “Tecnologia de Apoio” (BERSCH, 2017). Apesar dos demais termos ainda serem utilizados na prática clínica, a terminologia foi oficializada pelo Comitê de Ajudas Técnicas, dirigido pela Coordenadoria Nacional para Integração da Pessoa com Deficiência (CORDE) e vinculado à Secretaria Especial dos Direitos Humanos. O comitê se refere à Tecnologia Assistiva como uma área de conhecimento, de característica multidisciplinar, composta por produtos, recursos, estratégias, práticas, processos, métodos e serviços, tendo por objetivos promover a funcionalidade (atividade e participação de pessoas com deficiência, mobilidade reduzida ou idosas, visando sua autonomia, independência, qualidade de vida e inclusão social (CORDE, 2008).

Os recursos são organizados de acordo com objetivos funcionais e várias classificações foram desenvolvidas para finalidades distintas, dentre as quais pode ser destacada a ISO 9999 (ISO, 2016), aplicada em vários países, na qual uma categoria engloba “Órteses e Próteses”. Esta é a mesma classificação utilizada no Portal Nacional de Tecnologia Assistiva, um instrumento de troca de informações e conhecimentos na área de TA e inovação no Brasil.

Os materiais termoplásticos de baixa temperatura são os mais indicados na confecção de órteses funcionais, uma vez que permitem a individualização do dispositivo a uma necessidade específica. Além das órteses, esse tipo de material é recomendado, desde sua ascensão, para a utilização em outros recursos de tecnologia assistiva, tais como substituidores de preensão em utensílios para as atividades da vida diária, adaptações para materiais escolares, ponteiras para uso do computador, dentre outros dispositivos que podem ser confeccionados para otimizar a função, podendo ser associados a algum tipo de órtese, na medida em que for necessário (AGNELLI; TOYODA, 2003; FESS, 2002; ORFIT INDUSTRIES, 2018). 


\subsection{INDICAÇÃO E PRESCRIÇÃO DE ÓRTESES PARA OS MEMBROS SUPERIORES}

A confecção de órteses é um dos pilares da reabilitação da mão e a literatura apresenta diversos tipos de estudo contendo a indicação de órteses para os membros superiores, nas mais variadas aplicações: lesões de nervos periféricos da mão (COLDITZ, 2011); fraturas fechadas na mão, que apresentam mínimo deslocamento (HARDY; FREELAND, 2011); para melhora da dor e da força de preensão em pacientes com osteoartrite do polegar (ALMEIDA et al., 2016; BANI et al., 2013); lesões agudas ou crônicas para os casos de “dedo em martelo” (O’BRIEN; BAILEY, 2011); síndrome do túnel do carpo (VAN PETTEN, ÁVILA; LIMA, 2014); para o tratamento de lesões por queimaduras (MOORE; DEWEY; RICHARD, 2009); diferentes modelos de dispositivos indicados na artrite reumatoide (ALMEIDA et al., 2015; BEASLEY, 2011; GOIA, 2012); para a prevenção de deformidades em crianças com paralisia cerebral (RODRIGUES; CAVALCANTI; GALVÃO, 2007); órteses para pessoas com alterações neurológicas, seja por acidente vascular encefálico ou por traumatismo crânio encefálico (SAURON, 2003); anomalias congênitas da mão (MORAN; TOMHAVE, 2011); dentre muitas outras que poderiam ser citadas.

Independentemente da aplicação e das especificidades de cada caso, seja para aliviar a dor, proporcionar estabilização ou proteger os tecidos vulneráveis, órteses bem projetadas podem fazer a diferença na vida da pessoa, permitindo executar ocupações valorizadas e sua participação em atividades relevantes e com significado. Ao contrário de outras ações na área de reabilitação, a intervenção ortótica deve resultar em um dispositivo individualizado que atenda necessidades biológicas e ocupacionais, para a utilização fora da clínica, sendo que Mckee e Rivard (2011) ressaltam que esse processo deve ser centrado no cliente. Esta abordagem envolve identificar os fatores biológicos que interferem na participação do indivíduo, implicando em barreiras ocupacionais, e projetar órteses usando uma perspectiva ocupacional, que inclua atributos físicos, cognitivos e afetivos, de acordo com os contextos ambientais.

O projeto e a confecção de órteses para membros superiores envolvem criatividade combinada com o conhecimento em diversas áreas (ASSUMPÇÃO, 2005; CALLINAN, 2005). Mckee e Morgan (1998) consideram que envolve arte e ciência: arte pois está ligada à criatividade e habilidades do terapeuta para o design e ciência uma vez que envolve necessariamente conhecimentos específicos. A aplicação clínica das órteses, portanto, requer um caminho de aprendizado e não implica simplesmente em saber confeccionar alguns 
modelos, mas ter conhecimentos específicos, incluindo necessariamente as condições individuais do cliente, pois a órtese deve ser única e criada de acordo com as necessidades de cada pessoa, em uma relação de colaboração entre cliente e terapeuta (ALMEIDA et al., 2015; ASSUMPÇÃO, 2005; MCKEE; RIVARD, 2011). Schaf (2004) ressalta a importância da participação ativa do paciente no processo de desenvolvimento da órtese, além de melhorar a adesão ao dispositivo.

Segundo Deshais (2005) o resultado de uma órtese bem-sucedida é servir a sua finalidade e ser aceita, dependendo, muitas vezes, da maneira de pensar do terapeuta, que deve ser crítico e criativo. O papel multifacetado deste profissional inclui avaliar a necessidade da órtese em termos clínicos e funcionais; selecionar a órtese mais apropriada; providenciar e ou fabricar o aparelho; avaliar a adaptação da órtese; capacitar o usuário e seus responsáveis, informando a finalidade do uso, os cuidados e procedimentos que envolvem a órtese. A prescrição e confecção, portanto, compõem um processo que envolve muitas variáveis determinantes para a saúde e qualidade de vida de um paciente (GRADIM; PAIVA, 2018).

Além de uma avaliação criteriosa e de um projeto adequado da órtese, bem como sua confecção, faz-se necessário o monitoramento contínuo, a fim de determinar se a órtese está sendo utilizada corretamente, se está cumprindo a finalidade inicialmente desejada e se necessita de algum tipo de ajuste, na medida em que forem detectados problemas na usabilidade, desconfortos, pontos de pressão, imobilizações desnecessárias, entre outros (FESS, 2011). Lindemayer (2004) afirma que, após a confecção da órtese, é necessário o acompanhamento do paciente, que deverá ser devidamente orientado sobre: os objetivos do aparelho, sua colocação e retirada, rotina de utilização, limpeza e higienização do material e dúvidas ou dificuldades que podem aparecer.

Assumpção (2005) aponta que as órteses feitas sob medida, por mais simples que seja seu design, requerem os mesmos conhecimentos, a fim de que sejam aplicadas as forças adequadas a depender do objetivo que se espera e do modelo indicado. Este processo exige do terapeuta conhecimento em anatomia e fisiologia, biomecânica, ocupação humana, materiais ortopédicos e princípios mecânicos e técnicas de fabricação, avaliação física com aplicação de forças corretivas e provas musculares, além de habilidades em análise de atividade e orientação do cliente (MAC DONALD, 1998; MCKEE; RIVARD, 2011)

A partir da década de 70, foram aplicados conceitos mecânicos a projetos comuns de órteses manuais, através de trigonometria e desenhos simples em escala, a fim de calcular as forças básicas geradas e melhorar a qualidade e eficácia dos produtos (FESS, 2002; FESS; PHILIPS, 1987). Se os princípios da mecânica, design, ajuste e construção não forem 
considerados e se os materiais não forem aplicados corretamente, com a força necessária, especialmente nas órteses dinâmicas, resultados efetivos não serão alcançados (FESS, 2011).

A maior parte das órteses pode ser compreendida como um sistema de forças paralelas e opostas, também conhecido como sistema de três pontos, que tem como base o sistema de alavanca de $1^{\text {a }}$ classe (FESS, 1995). Este incorpora força, resistência, eixo de rotação e braços de movimento, em que o eixo está entre a força e a resistência. A área de maior tensão na órtese está localizada no eixo, onde normalmente o dispositivo pode se romper com o uso, e o controle da aplicação de forças ao se confeccionar o aparelho possibilitará maior durabilidade. Esse mesmo princípio pode ser usado para se considerar o efeito do torque sobre uma articulação, sendo que, para otimizar a vantagem mecânica do dispositivo, recomenda-se, de uma forma geral, um braço de alavanca tão longo quanto possível (FERRIGNO, 2007; FESS, 1995; MCKEE; RIVARD, 2011; RODRIGUES; CAVALCANTI; GALVÃO, 2007)

Nesse contexto, Mckee e Rivard (2011) destacam algumas estratégias que devem ser adotadas durante a confecção de órteses, tais como aumentar a superfície de contato com o material a fim de melhorar a distribuição da pressão, arredondar todas as bordas para evitar lesões na pele e acomodar adequadamente o segmento do corpo, por exemplo, através de uma órtese que se estenda até um pouco mais da metade das laterais do antebraço.

Outro princípio que pode ser utilizado para melhorar a qualidade e a durabilidade das órteses confeccionadas sob medida diz respeito à força através de contorno, sendo que um corpo plano é mais flexível do que um corpo côncavo ou abaulado. Isso pode ser aplicado durante a confecção, modelando-se o material com curvaturas e acrescentando-se tubos circunferenciais à base das órteses (FERRIGNO, 2007; FESS; PHILIPS, 1987; RODRIGUES; CAVALCANTI; GALVÃO, 2007)

Com o advento dos termomoldáveis a confecção de dispositivos passou efetivamente a fazer parte do cotidiano do terapeuta, possibilitando projetar e construir um tipo adequado de órtese, que atendesse as reais necessidades das pessoas. Embora outros materiais ainda sejam utilizados, Fess (2011) relata que os termoplásticos trouxeram um avanço significativo para a área, favorecendo as etapas de montagem e confecção das órteses, porém afirma que isto não leva automaticamente a uma melhor compreensão do desenho e uso da órtese. Faz-se necessária uma compreensão das condições patológicas da mão e dos objetivos realistas esperados, a fim de otimizar as características e possibilidades que os diferentes materiais oferecem.

Dessa forma, o conhecimento e a escolha dos materiais adequados constitui fator fundamental na rotina do profissional (VAN PETEEN et al., 2014). 
Dentre os aspectos a serem considerados, encontram-se: o peso, que deve ser compatível ao esforço humano; as possibilidades financeiras do cliente, que deve participar de forma ativa de todo o processo; a resistência do material, para suportar os movimentos aos quais é submetido; a tolerância ao desgaste e à deformação; nível de toxicidade; estética; dentre outras características a serem consideradas (AGNELLI; TOYODA, 2003).

\subsection{MATERIAIS UTILIZADOS NA CONFECÇÃO DE ÓRTESES}

Os fatores históricos que influenciaram a prática da confecção de órteses, desde a época de Hipócrates até os dias atuais, incluem doenças, conflitos políticos, avanços em medicina e tecnologia, tomadas de decisões organizacionais, centros de prática e disponibilidade de informações. Durante o século XX, grandes avanços na tecnologia de materiais para a confecção de órteses foram alcançados, com uma transição de materiais à base de fibras naturais, como madeira e tecido, passando por metal e gesso, até uma longa linha de materiais plásticos progressivamente mais sofisticados (FESS, 2002). Esses avanços não resultaram de pesquisas específicas nessa área, mas foram subprodutos do rápido desenvolvimento da tecnologia aeroespacial e de demandas geradas por lesões em guerras.

A dinâmica evolução dos materiais também gerou mudanças nos processos de fabricação, porém a atualização nos conceitos de design das órteses foi mais lenta. Fess (2002) refere que os sistemas mecânicos das órteses foram revisados brevemente por alguns autores no início do século XX. Porém as informações ainda eram inconsistentes, em comparação com as novidades sobre os materiais e instruções de confecção. Apesar de ser um elemento importante para o sucesso de uma órtese, os princípios da mecânica foram melhor abordados a partir da década de 80.

\subsubsection{Materiais metálicos}

Desde as eras do bronze e do ferro, os metais são materiais muito utilizados pela humanidade. A subdivisão em duas classes, metais ferrosos e metais não ferrosos, evidencia a importância do ferro para os materiais metálicos. Apesar de muitos destes serem utilizados na sua forma pura ou elementar, em aplicações de engenharia, a maioria das aplicações ocorre quando estão associados a outros elementos (metálicos ou não), originando as ligas metálicas (NAVARRO, 2001). Dessa forma, antes do desenvolvimento e uso frequente dos materiais termoplásticos, as órteses eram construídas com aço, alumínio, ligas de titânio e ligas de magnésio. O aço, liga à base de ferro, que é trabalhável em algumas faixas de temperatura, pode 
ser dividido em vários tipos, porém a maior parte deles preserva uma alta ductilidade e rigidez, principalmente quando são acrescentados elementos que favoreçam esta característica, como por exemplo o níquel. Preferencialmente por esta razão o aço era comumente usado em aparelhos ortopédicos, principalmente o aço inoxidável, mas com desvantagens relativas ao peso elevado e baixa flexibilidade. As ligas de alumínio eram muito usadas em órteses devido sua resistência à tração e baixo peso específico, quando comparadas ao aço. Dessa forma, nas órteses para os membros superiores, por exemplo, em que era necessário baixo peso, utilizavase ligas de alumínio, enquanto que nas órteses de membro inferior o aço era o material mais utilizado. Em contrapartida, ligas de titânio e de magnésio eram usadas quando se precisava de pouco volume e muita resistência, pois possuem maior resistência à corrosão e pequeno peso específico, apresentando menor densidade. São consideradas mecanicamente superiores ao aço e ao alumínio, porém devido a sua baixa disponibilidade e alto custo, não eram utilizadas com muita frequência. De modo geral, usava-se materiais metálicos para elementos estruturais e tecidos como feltro, courvin e couro para revestimento da armadura metálica, sendo usados como elementos de contato (VANALLE, 1987).

Ainda hoje são utilizados na construção de próteses e de órteses, mais comumente para os membros inferiores, os tubos, barbatanas e armaduras em aço inox, duralumínio e titânio. É importante salientar que esses dispositivos, incluindo aqui os colares cervicais e os coletes de coluna, estão modernizados e são, na maioria, acolchoados com espuma e revestidos com courvin ou lona (ASSOCIAÇÃO DE ASSISTÊNCIA À CRIANÇA DEFICIENTE - AACD, 2018). Lindemayer (2004) relata o uso de hastes de metal junto a órteses para os membros superiores em crianças com paralisia cerebral, confeccionadas com termoplástico de baixa temperatura. As órteses estáticas progressivas utilizam componentes não dinâmicos, como articulações e parafusos metálicos que, associados ao uso de velcro e tensores elásticos possibilitam criar força mobilizadora para a recuperação do movimento (ASSUMPÇÃO, 2005). Além disso podem ser usados, neste modelo de órtese, molas e fios (FESS; PHILIPS, 1987).

\subsubsection{Gesso}

Outro material bastante antigo na confecção de órteses é o gesso, que não precisa de aquecimento para ser moldado. Quando a água é adicionada ao pó de gesso, este se torna maleável e pode se conformar à articulação ou tecido alvo na posição desejada. No entanto, esse tipo de material exige cuidado, pois facilita a produção de escaras (ferimentos decorrentes do contato da pele com um material rígido), além de não ser lavável, de difícil higienização e pouco resistente a quedas ou mesmo a umidade. Várias tentativas foram feitas para a 
substituição e aperfeiçoamento do gesso na confecção de aparelhos de imobilização, porém as ataduras gessadas comuns ainda são utilizadas nas órteses de membro superior, por apresentarem baixo peso e terem baixo custo (CAPELLO; TOYODA, 2000; COOMBES; GREENWOOD; SHORTER, 1996).

O gesso de Paris (anidrido sulfato de cálcio amorfo) ainda é um material disponível e rentável, tornando-se adaptável a uma variedade de circunstâncias, incluindo enfermarias hospitalares e unidades de cuidados intensivos. Vieira et al. (2006) realizaram testes mecânicos em ataduras gessadas (POP- Plaster of Paris) de três diferentes fabricantes existentes no mercado (A - Cremer ${ }^{\circledR}$, B - Medi House ${ }^{\circledR}$ e C-Polar Fix ${ }^{\circledR}$ ) e constataram que a marca pode interferir significativamente na qualidade do material, uma vez que os resultados apontaram que o fabricante “A” apresentou-se superior aos demais em relação a todas as propriedades avaliadas. Os autores acreditam que o gesso ainda pode ser considerado eficiente, principalmente na fabricação de órteses seriadas estáticas, embora mostrem preocupação com a incidência de quebra nas órteses gessadas.

Uma outra opção de material comercial dentro deste grupo é a atadura gessada impregnada de resina de poliuretano, ou seja, o "gesso sintético". Este é mais caro que o anterior, mas sua resistência aumenta exponencialmente ao acréscimo de cada camada, enquanto que para o gesso convencional esta variação é linear (ROSSI et al., 1987). Uma das dificuldades do gesso sintético é sua moldagem, que solicita rapidez e destreza na confecção. Como é áspero quando pronto, exige do terapeuta acabamento aprimorado e uso de materiais acolchoadas como espuma, feltro e outras forrações, algumas denominadas como “cushion”.

\subsubsection{Materiais Flexíveis}

Materiais mais flexíveis, como os tecidos acolchoados e os diversos tipos de espuma, podem ser usados primeiramente como componentes mais macios para fixação e conforto, associados a materiais rígidos, visto que as pessoas com lesões de pele, edema, dor e outros sinais podem se beneficiar de forrações e materiais de contato que não provoquem atrito ou pressão excessiva (FERRIGNO, 2007). Além disso materiais como neoprene ${ }^{\circledR}$ e outros tecidos passaram a ser aplicados na confecção de órteses propriamente ditas, a depender do objetivo e das condições do cliente, podendo ser adquiridas comercialmente ou, como afirmam Casey e Kratz (1988), confeccionadas sob medida.

O neoprene ${ }^{\circledR}$ é o nome comercial de um elastômero sintético, sendo leve, durável, atóxico e lavável. O elastômero é comercializado com revestimento de poliamida e suas principais características são: flexibilidade, elasticidade, resistência e proteção térmica, 
podendo ser indicado como material alternativo para a confecção de órteses diante da necessidade de mobilidade dinâmica. Estes materiais também se enquadram no item 3.3.4. (BARROSO, 2015; DANCKWARDT, 2016)

Ao avaliar crianças com paralisia cerebral do tipo hemiparesia espástica, Barroso (2010) constatou que o uso de órtese abdutora de polegar e extensora de punho inovada (denominada como EPAPI pela autora), feita com neoprene ${ }^{\circledR}$, influenciou positivamente na amplitude de movimento, força muscular e habilidade manual. Este material também possibilita feedback sensorial durante a movimentação, o que pode ser benéfico, por exemplo, para estimular a abdução do polegar e supinação do antebraço (CASEY; KRATZ, 1988)

Um outro exemplo de órtese nacional confeccionada com materiais flexíveis está descrito em um trabalho com pacientes com hanseníase que apresentam garra ulnar e/ou garra ulno-mediana móvel. Elui (2001) descreve uma órtese dinâmica composta por uma pulseira de couro com elásticos e a compara com um mesmo modelo confeccionado em material termoplástico. Apesar da órtese termoplástica contribuir mais para a correção da garra, a órtese confeccionada em couro também se mostrou eficiente, principalmente porque não interferiu tanto na força de preensão, quando comparada ao termoplástico, e, segundo os participantes da pesquisa, facilitou a função da mão (ELUI, 2001).

\subsubsection{Materiais poliméricos}

A evolução da indústria polimérica, a partir dos anos 70 e 80, somada à expansão da cirurgia de mão e da reumatologia, fez com que o mercado de materiais ortóticos se expandisse, trazendo novas opções para um tratamento eficaz (MELVIN, 1995). De acordo com Padilha (1997), o grupo dos materiais poliméricos tem propriedades que o torna útil na construção de dispositivos em geral, pois são geralmente leves, flexíveis e apresentam boa resistência à corrosão.

Os polímeros naturais foram usados por milênios e a borracha natural, um dos exemplos característicos deste grupo, passou a ser usada no revestimento de estruturas ortóticas metálicas. Além de confortar e absorver choques, é um elemento isolante e protetor, podendo auxiliar na movimentação e no posicionamento de algumas articulações. A borracha natural tem excelentes propriedades elásticas. As borrachas sintéticas, como, por exemplo, a borracha butílica, apesar de não terem muita resistência ao desgaste, têm grande resistência ao calor, à água, ao envelhecimento e a alguns produtos químicos (VANALLE, 1987).

Pesquisas apontam o uso dos elastômeros, por exemplo, como biomateriais, encontrando-se em crescente utilização na área médica por oferecem biocompatibilidade, 
durabilidade, flexibilidade de design e desempenho favorável (YODA, 1998). Estes e outros polímeros, em grande número, são amplamente utilizados como biomateriais, porque estão disponíveis em uma ampla variedade de composições, propriedades e formas (sólidos, fibras, tecidos, filmes e géis), e podem ser fabricados em estruturas complexas (RAMAKRISHNA et al., 2001).

Pode-se dizer que, quanto à aplicação na confecção de órteses, os plásticos, grande grupo característico dos materiais poliméricos, revolucionaram a reabilitação, apresentando facilidade na manipulação e grau de modelagem relativamente alto, além de não serem tóxicos e não serem atacados por líquidos como água, urina e óleos.

Segundo Mano (1991) e Nunes e Lopes (2014), os plásticos podem ser divididos em dois grupos:

- termorrígidos ou termofixos- apresentam formas acabadas quando aquecidos, mantendo irreversivelmente esta forma final. Assim, não deformam quando reaquecidos e não podem ser remodelados.

- termoplásticos- se deformam quando aquecidos e endurecem quando resfriados. Podem ser moldados e remodelados com o calor. Estes são bem mais utilizados na prática clínica, pois podem ser remodelados diversas vezes.

Os termoplásticos, utilizados com frequência na prática clínica, podem ser moldados e remodelados com o calor, sendo que a temperatura com que se tornam moldáveis os subdividem em duas categorias distintas, conforme serão descritas a seguir, o que influencia diretamente no processo de confecção e indicação das órteses.

Um dos primeiros materiais plásticos disponíveis para os terapeutas utilizarem em imobilizações foi o Celastic, que era associado a outros materiais, incluindo bandagens elásticas e termoplásticos. Na mesma época foram introduzidos o Polietileno e o Poliuretano para as órteses de mãos, pés, pescoço e tronco, que foram aquecidos juntos a uma temperatura de aproximadamente $120^{\circ} \mathrm{C}$, sendo que o polietileno amoleceu e se fundiu ao poliuretano. Os materiais aquecidos e fundidos foram rapidamente adaptados diretamente ao paciente, com o lado de poliuretano resistente ao calor ao lado da pele, atuando como uma barreira protetora (FESS, 2002). Essas talas eram leves, duráveis e impermeáveis à umidade e às secreções, mas não possuíam a capacidade de contornar anatomicamente o segmento do corpo, sendo que o Gesso de Paris continuava sendo o material concorrente.

Maitz (2015) realizou uma revisão sobre as aplicações de polímeros na clínica médica e apontou múltiplos polímeros biológicos, sintéticos e híbridos utilizados atualmente em um vasto campo de aplicações, tais como materiais para implantes, materiais de suturas, cateteres 
vasculares, dispositivos em oftalmologia, odontologia, microcirurgia, entre outras. Como há diversas aplicações na área da saúde, algumas características preliminares para selecionar o polímero adequado para cada situação envolvem os níveis de toxicidade e biocompatibilidade. Produtos poliméricos são particularmente atraentes para implantes, pois apresentam propriedades comparáveis às dos tecidos hospedeiros (RAMAKRISHNA et al., 2001). Trajano (2012) afirma que a aplicação de materiais poliméricos para propósitos médicos cresce muito rapidamente e tem sido evidenciada em diversos campos.

Além disso uma variedade de materiais poliméricos é utilizada especificamente para a aplicação em órteses, sendo que uma ampla gama de combinações de polímeros está disponível para aumentar a rigidez, melhorar a resistência à temperatura ou alguma outra característica do aparelho. Além dos termoplásticos, muito utilizados para acomodar a parte do corpo a ser imobilizada, verifica-se o uso de materiais poliméricos nos acessórios, velcros e forrações das órteses, como é o caso do copolímero etileno-acetato de vinila (EVA), a poliamida (Nylon), o poliéster, o policloropreno (Neoprene), dentre outros que poderiam ser mencionados (DANCKWARDT, 2016). Bani et al. (2013) relata a utilização de espumas de polietileno reticulado de células fechadas, tais como Plastazote ${ }^{\circledR}$, em órteses para o membro superior.

\subsubsection{Termoplásticos de alta temperatura}

Os termoplásticos de alta temperatura tornam-se moldáveis quando aquecidos em temperaturas superiores a $150^{\circ} \mathrm{C}$, sendo fortes, rígidos e muito resistentes quando resfriados. $\mathrm{O}$ polipropileno, que faz parte deste grupo, é frequentemente usado na confecção de órteses para membros inferiores, pois ele é um dos materiais que mais associa leveza, resistência e plasticidade em nível ótimo. Devido à alta temperatura, a técnica de confecção do polipropileno e de outros termoplásticos deste grupo, consiste basicamente em fazer o engessamento do segmento do corpo que receberá o aparelho, aquecer a placa do material e revestir o molde positivo já obtido, não podendo ser aplicados diretamente ao paciente. (SILVEIRA, 1981).

A partir do final da década de 50 alguns termoplásticos de alta temperatura estavam a caminho de se tornarem importantes acréscimos na fabricação ortótica, como Plexiglas, Lucite e Royalite. Os terapeutas tiveram que adequar o processo de confecção às características desse tipo de material, em que a moldagem era feita sobre um molde e não diretamente no usuário (BREGGER-LEE; BUFORD JUNIOR, 1992). Apesar disto, Fess (2002) afirma que estes plásticos foram entusiasticamente bem-vindos devido à sua relativa facilidade de maleabilidade, rigidez e eficiência em comparação ao metal. O alumínio foi consequentemente 
relegado a componentes de reforço das órteses, e materiais que exigiam solvente, como o Celastic, foram abandonados em favor dos materiais termoplásticos de alta temperatura mais facilmente trabalháveis. Assim que novos materiais termoplásticos de alta temperatura se tornaram comercialmente disponíveis, foram avaliados quanto ao potencial de imobilização, incluindo Kydex, Lexan, Merlon e Boltaron.

Em meados da década de 60 os termoplásticos de baixa temperatura foram introduzidos e começaram a substituir os de alta temperatura para algumas aplicações. Embora não tivessem resistência, começaram a ganhar espaço na confecção de órteses manuais, mas não substituíram o uso de materiais mais resistentes para a fabricação de aparelhos destinados à deambulação, como por exemplo o polipropileno, que é mais durável (COOMBES; GREENWOOD; SHORTER, 1996).

Ainda hoje os termoplásticos de alta temperatura são os mais utilizados nas órteses para os membros inferiores. Meng, Hu e Zhu (2008) mencionam que os polímeros mais utilizados são, além do polipropileno, o polietileno de ultra alto peso molecular e o poli (tereftalato de etileno), porém todos eles com temperatura de amolecimento superior a $150^{\circ} \mathrm{C}$, não podendo ser aplicados diretamente ao paciente. As órteses de polietileno ou polipropileno podem ser acolchoadas, sendo que a temperatura, neste caso, é uma vantagem para a adesão entre o termoplástico quente e uma espuma flexível posicionada no molde, facilitando o revestimento das órteses e melhorando o conforto.

Para a aplicação em membros inferiores, na qual este grupo de material é utilizado em larga escala, existem pesquisas apontando combinações de fibras junto aos materiais poliméricos, a fim de melhorar a resistência e a qualidade das órteses, como por exemplo as fibras de carbono (WACH, 2015). Do mesmo modo, as fibras de vidro, reconhecidas por sua resistência à tração e flexibilidade, podem ser utilizadas como reforço adicional para enrijecimento e fortalecimento de materiais. Segundo Danckwardt (2016), a indústria ortopédica costuma empregar fibra de carbono e fibra de vidro pois possibilitam a fabricação de aparelhos extremamente resistentes e de baixíssimo peso, favorecendo a aplicação em órteses.

Embora termoplásticos de alta temperatura sejam atualmente mais indicados para os membros inferiores, no Brasil alguns profissionais desenvolveram uma técnica para a utilização do Poli (cloreto de vinila) - PVC na confecção de órteses para os membros superiores, a fim de diminuir o custo da matéria prima bruta. Nesse caso utiliza-se tubos de PVC rígido para a produção de placas para posteriormente ser confeccionada a órtese (SILVA, 2014). Como a moldagem não pode ser realizada diretamente no corpo da pessoa, são realizadas medidas 
antropométricas do segmento a ser imobilizado e marcações anatômicas, identificando-se proeminências ósseas, articulações, condições de pele, entre outras características. O dispositivo é modelado na fonte de calor, a cerca de $100^{\circ} \mathrm{C}$, respeitando-se as marcações realizadas e seus ajustes finais são feitos com soprador térmico (RODRIGUES JUNIOR, 2012). Silva (2014) ressalta que deve haver cautela nessa aplicação, pois se trata de um material mais rígido do que os comumente usados para os membros superiores, além do risco de menor acomodação anatômica, devido ao processo de confecção.

Outras aplicações são descritas para os termoplásticos de alta temperatura, como por exemplo o produto comercial Rolyan ${ }^{\circledR} \mathrm{W}$-Clear ${ }^{\mathrm{TM}}$, projetado para ser usado em máscaras faciais. $\mathrm{O}$ material se aquece de $163^{\circ} \mathrm{C}$ a $177^{\circ} \mathrm{C}$ e pode ser moldado sobre um molde de gesso com as mãos protegidas. Pequenas modificações são possíveis usando um soprador térmico (FESS, 2002).

\subsubsection{Termoplásticos de baixa temperatura}

Na década de 60, segundo Lindemayer (2004), novos desenvolvimentos em termoplásticos possibilitaram diminuir a temperatura de amolecimento. Portanto, com temperatura de trabalho na faixa de $45-70^{\circ} \mathrm{C}$, alguns polímeros termoplásticos, tais como policaprolactona e trans-poliisopreno, podem ser aplicados diretamente ao corpo e favorecem a fabricação de aparelhos ortopédicos anatômicos (MENG; HU; ZHU, 2008).

O primeiro termoplástico de baixa temperatura introduzido no mercado foi o Prenyl ${ }^{\circledR}$, da Ortho Industries, em 1964, mas ainda era difícil de se adaptar a pequenas áreas da mão e precisava de 10 minutos para resfriar. Posteriormente o produto Orthoplast ${ }^{\circledR}$, da Johnson e Johnson, chamado inicialmente de Isoprene, começou a ser utilizado na prática clínica dos profissionais e se tornou o favorito para as órteses de mão na época, especialmente nos Estados Unidos. Um material semelhante a ele, San Splint ${ }^{\mathrm{TM}}$, foi comercializado no Canadá (FESS, 2002).

No final dos anos 70 apareceram produtos à base de policaprolactona, sendo que os primeiros foram Polyform ${ }^{\mathrm{TM}}$ e Aquaplast- $\mathrm{T}^{\mathrm{TM}}$. Outros materiais chegaram ao mercado em meados dos anos 80, tais como Kay Splint ${ }^{\mathrm{TM}}$, Polyflex ${ }^{\mathrm{TM}}$ e Orfit ${ }^{\circledR}$. As alterações de composição química e de formulação provocaram uma otimização nas propriedades destes produtos (LINDEMAYER, 2004

), proporcionando maior conformabilidade e facilidade de fabricação das órteses. Altamente maleáveis quando aquecidos a uma temperatura na faixa de $45-70^{\circ} \mathrm{C}$ (temperatura 
de trabalho), permitem a confecção de órteses sob medida, moldadas diretamente no segmento do corpo que se pretende imobilizar.

\subsection{TERMOPLÁSTICOS DE BAIXA TEMPERATURA: CENÁRIO ATUAL}

O grupo dos materiais poliméricos tem sido utilizado com frequência no mercado ortopédico a partir dos anos 70 e 80, pois são geralmente leves, flexíveis, apresentam boa resistência à corrosão e são constituídos por macromoléculas orgânicas, sintéticas ou naturais (MAITZ, 2015; MANO, 1991; MELVIN, 1995; RAMAKRISHNA et al., 2001). Dentro deste grupo, os materiais termoplásticos têm sido os mais utilizados na confecção de órteses, uma vez que, segundo a definição, se deformam quando aquecidos e endurecem quando resfriados, podendo ser moldados e remodelados quando aquecidos (CANEVROLO, 2010; LINDEMAYER, 2004; MANO, 1991; MELVIN, 1995; MENG; HU; ZHU, 2008).

Após o advento dos termoplásticos de baixa temperatura, sua prevalência na confecção de órteses para membros superiores é identificada por vários autores, em pesquisas nacionais e internacionais (AGNELLI; TOYODA, 2003; ALMEIDA et al.,2016; FESS, 2011; LINDEMAYER, 2004; MALICK, 1978; MCKEE; MORGAN, 1998; MCKEE; RIVARD, 2011; MENG; HU; ZHU, 2008; SILVA, 2001, 2014). Em pesquisas realizadas no Brasil, cujas amostragens eram compostas por terapeutas ocupacionais atuantes na confecção de órteses para membros superiores, 90,9\% dos profissionais mencionou o uso de termoplásticos de baixa temperatura, no estudo de Agnelli e Toyoda (2003), 83\% dos participantes da pesquisa conduzida por Silva (2014) e 83\% no estudo de Almeida et al. (2016).

Esse grupo de materiais apresenta vantagens para a aplicação em órteses, seja na neurologia ou na ortopedia, uma vez que apresenta características que favorecem a moldagem e o processo de confecção de órteses, as quais lhes conferem melhor aplicabilidade para uma ou outra patologia (LINDEMAYER, 2004). Souza (2014) afirma que são os mais utilizados devido ao potencial para a fabricação de órteses sob medida, moldada sobre o corpo, o que simplifica também o processo de confecção. Após uma avaliação criteriosa e definição do projeto e modelo da órtese, a confecção consiste basicamente em recortar a placa na medida e no molde desejado, aquecer o material, moldar diretamente sobre o(s) segmento(s) do corpo envolvido(s) e realizar o acabamento. Como o material resfria-se rapidamente, tornando-se rígido, muitas vezes é possível o usuário levar o dispositivo no mesmo dia, para que possa testar e verificar a eficiência. 
Algumas características precisam ser consideradas diante da utilização de termoplásticos de baixa temperatura, tais como a temperatura específica de trabalho, o tempo de aquecimento e o tempo de resfriamento. Meng, Hu e Zhu (2008) relatam que esses materiais favorecem a fabricação de aparelhos ortopédicos anatômicos, tornando-se moldáveis a partir de $45^{\circ} \mathrm{C}$.

Os produtos baseados em materiais termoplásticos de baixa temperatura utilizados na confecção de órteses são desenvolvidos à partir de uma matriz polimérica, com variações na quantidade do polímero, associada a cargas, reforços, resinas e elastômeros, as quais influenciam na memória, na rigidez e em outras características do material. Os dois principais polímeros utilizados como base para esta aplicação são a policaprolactona e o transpoliisopreno, sendo o primeiro mais frequente (BREGER-LEE; BUFORD JUNIOR, 1992; MENG; HU; ZHU, 2008).

A policaprolactona (PCL), da família dos poliésteres alifáticos, é um polímero biodegradável e biocompatível, não tóxico, amplamente utilizado na área médica e aprovado para uso em seres humanos (COOMBES et al., 2004; RAMOS, 2011; SINHA et al., 2004; TRAJANO, 2012; WESSLER, 2007). Segundo Sasmazel, Gümüşderelioğlu e Gürpinar (2008) as aplicações desse polímero na área da saúde são diversas, tais como: sistemas para liberação controlada de fármacos, cânulas uretrais e engenharia tecidual (tecido epidérmico, muscular, ósseo e cartilaginoso). Para a aplicação em produtos destinados à confecção de órteses, destacam-se as características térmicas e mecânicas, pois trata-se de um polímero facilmente moldável, sem a necessidade de equipamentos específicos, podendo ser manipulado apenas com água em temperaturas próximas a 60 C (DANCKWARDT, 2016; RAMOS, 2011).

Anteriormente foi descrita pela Polymed Industries e pela North Coast Medical, uma classificação dos termoplásticos de baixa temperatura em que foram divididos em quatro grupos, de acordo com a matriz polimérica: 1) Elástico; 2) Plástico; 3) Borracha; 4) Misto Plástico-Borracha (BREGER-LEE; BUFORD JUNIOR, 1992; RODRIGUES; CAVALCANTI; GALVÃO, 2007). Os grupos “plástico” e “borracha” são os mais utilizados na prática clínica, cujos constituintes são respectivamente a Policaprolactona (PCL) e o Transpoliisoprene (TPI). Segundo essa classificação, os materiais do grupo plástico apresentam boa moldabilidade, com a obtenção de órteses anatômicas sem a necessidade de força excessiva, como por exemplo o Rolyan ${ }^{\circledR}$ Aquaplast-T ${ }^{\mathrm{TM}}$. Essas e outras características dependem da quantidade de PCL e da presença de outros possíveis componentes. Os materiais do grupo borracha, como por exemplo o Rolyan ${ }^{\circledR}$ SanSplint ${ }^{\mathrm{TM}}$, tendem a ser mais resistentes ao alongamento e a impressões digitais. Os materiais combinados, do tipo borracha/plástico, tem 
um grau moderado de moldagem, podendo ser utilizados tanto para pequenas como para grandes órteses (MN, 2018). Atualmente a classificação consta no website de uma das empresas distribuidoras de termoplásticos de baixa temperatura no Brasil, porém não foi encontrada em referências atuais na literatura, nem mesmo no site ou catálogos das referidas indústrias.

Existe hoje uma grande variedade de produtos, com lançamento de novos tipos a cada ano, estando disponíveis materiais com diferentes composições químicas e propriedades de trabalho, além de variadas cores, espessuras, texturas e perfurações (ASSUMPÇÃO, 2005; FESS, 2002; RODRIGUES, 2007), o que dificulta caracterizá-los somente quanto ao polímero base. Os principais fabricantes atuais estão apresentados a seguir, juntamente com os produtos comerciais de maior destaque nesse ramo.

\section{PERFORMANCE HEALTH (ANTERIORMENTE PATTERSON MEDICAL)}

Sediada em Chicago, Illinois, é fabricante e distribuidora de produtos para os mercados de reabilitação e medicina esportiva, dentre os quais se encontram os termoplásticos para órteses. Com operações nos EUA e internacionalmente, de acordo com o website da empresa, suas marcas são: Biofreeze ${ }^{\circledR}$, TheraBand ${ }^{\circledR}$, TheraPearl ${ }^{\circledR}$, Cramer ${ }^{\circledR}$, Sammons Preston ${ }^{\circledR}$ e Rolyan ${ }^{\circledR}$ (PERFORMANCE HEALTH, 2018a). A maioria dos materiais termoplásticos produzidos e comercializados em placas é da marca registrada Rolyan, dentre os quais encontram-se: Polyform ${ }^{\mathrm{TM}}$, Kay-Splint $\mathrm{II}^{\mathrm{TM}}$, Polyflex $\mathrm{II}^{\mathrm{TM}}$, Orthoplast $\mathrm{II}^{\mathrm{TM}}$, Cura Drape ${ }^{\mathrm{TM}}$, Aquaplast-T ${ }^{\mathrm{TM}}$ ProDrape ${ }^{\mathrm{TM}}-\mathrm{T}$, TailorSplint ${ }^{\mathrm{TM}}$, KaySplint IIITM, Aquaplast-T $^{\mathrm{TM}}$ Original, Aquaplast-T $^{\mathrm{TM}}$, Ezeform ${ }^{\mathrm{TM}}$, Aquaplast-T ${ }^{\mathrm{TM}}$ Orignal Resilient ${ }^{\mathrm{TM}}$, Synergy ${ }^{\mathrm{TM}}$ e San-Splint ${ }^{\mathrm{TM}}$. A empresa também é distribuidora de alguns produtos da linha Orfit ${ }^{\circledR}$. A empresa distribuidora desse fabricante no Brasil é a Politec Saúde, que atua no setor médico-hospitalar e representa a marca Rolyan ${ }^{\circledR}$. A matriz está localizada em Barueri-SP, mas a empresa tem lojas e distribuidores em vários pontos do país.

\section{INDÚSTRIAS ORFIT}

A empresa, sediada na Bélgica, desenvolve e produz materiais termoplásticos para dispositivos médicos, os quais são comercializados em diversos países, em três grandes áreas: Sistemas de imobilização para oncologia por radiação; Materiais de fabricação de ortopedia para pacientes em reabilitação física; e Materiais de encaixe protético para pacientes amputados. Todos os materiais termoplásticos são desenvolvidos e produzidos internamente e são agrupados da seguinte forma: 
- Produtos elásticos: Orficast ${ }^{\circledR}$ Thermoplastic Tape; Orfit ${ }^{\circledR}$ Classic; Orfit ${ }^{\circledR}$ NS; Orfit ${ }^{\circledR}$ Colors NS; Orfit ${ }^{\circledR}$ Strips; Orfilight ${ }^{\circledR}\left(\right.$ Orfilight ${ }^{\circledR}$; Orfilight ${ }^{\circledR}$ Black NS e Orfilight ${ }^{\circledR}$ Atomic Blue NS); Aquafit $^{\mathrm{TM}}$ NS; Tecnofit ${ }^{\mathrm{TM}}$ e Produtos da linha Orfizip ${ }^{\circledR}$.

- Produtos com alta resistência ao estiramento: Orfit ${ }^{\circledR}$ Eco (Orfit ${ }^{\circledR}$ Eco e Orfit ${ }^{\circledR}$ Eco Black NS) e Orfibrace ${ }^{\mathrm{TM}}$ NS.

- Produtos de alta acomodação a contornos (drape): Orfit ${ }^{\circledR}$ Flex NS.

A empresa Efectiv Medical Devices, localizada em Santana-SP, é representante exclusiva da Orfit ${ }^{\circledR}$ no Brasil.

\section{NORTH COAST MEDICAL}

A empresa foi fundada em 1974, na Califórnia, e mantém excelente reputação no mercado global de reabilitação. A empresa produz equipamentos, com algumas marcas proprietárias, mas também distribui produtos, equipamentos e suprimentos de empresas parceiras. Dentre os produtos oferecidos encontram-se vários termoplásticos de baixa temperatura para órteses de marcas proprietárias, além da marca registrada Orfit, da qual a North Coast Medical consta como empresa distribuidora. A empresa classifica todos os materiais que oferece, de acordo com diferentes graus de resistência ao estiramento e sugere aplicações, conforme se segue:

- Materiais de resistência mínima ao estiramento, que necessitam de toques leves ou ação da gravidade para se esticarem, sendo mais indicados para órteses menores, de mão e punho, ou para casos pós-cirúrgicos. Encontram-se neste grupo: Clinic ${ }^{\circledR}$ Orfit ${ }^{\circledR}$ Soft-Fit NS, Orfit ${ }^{\circledR}$ Classic, Orfit ${ }^{\circledR}$ Natural NS, Orfit ${ }^{\circledR}$ NS (resistência mínima), Orfit ${ }^{\circledR}$ Colors NS, Orfilight $^{\mathrm{TM}}$, Encore ${ }^{\mathrm{TM}}$ e Preferred ${ }^{\circledR}$ (mínima a moderada resistência).

- Materiais com resistência moderada ao estiramento, que requerem pressão moderada e são recomendados pelo fabricante para todos os tipos de órteses (dedos, cotovelo, pulso, tornozelo, tronco, imobilizadores de joelhos e órteses para os pés). Fazem parte deste grupo Vanilla $^{\mathrm{TM}}$, Spectrum ${ }^{\mathrm{TM}}$ e Prism ${ }^{\mathrm{TM}}$.

- Materiais com resistência máxima ao estiramento, cujo manuseio precisa ser firme para se acomodar, sendo que o material precisa ser mantido na posição até resfriar. Estes materiais resistem a impressões digitais e marcas e são indicados para órteses maiores, ou seja, cotovelo, ombro, extremidade inferior e tronco. Também são interessantes para caos em que há espasticidade. São eles: Omega ${ }^{\mathrm{TM}}$ Max, Solaris ${ }^{\mathrm{TM}}$ e Orfibrace $^{\mathrm{TM}}$ (de moderada a máxima resistência) e Omega ${ }^{\mathrm{TM}}$ Plus e Orthoplast ${ }^{\circledR}$ (máxima resistência). 
Além da resistência ao estiramento, a North Coast Medical apresenta informações sobre caimento, memória, rigidez, aderência e acabamento superficial de cada material, classificando essas características nos mesmos níveis citados: mínimo, médio e máximo.

A empresa que representa a North Coast Medical no país é a "MN Importação, Exportação e Comércio de Suprimentos Terapêuticos e de Reabilitação Ltda”, localizada em São Paulo-SP, que importa e comercializa materiais e suprimentos terapêuticos nas áreas de Terapia da Mão e Terapia Assistiva.

Segundo informações de todos os fabricantes de materiais termoplásticos para órteses, existem espessuras diferentes de placas, com vantagens e exemplos de aplicações para cada uma. Apesar de haver variação das medidas entre os diferentes fabricantes, todos apresentam pelo menos quatro possibilidades. A Figura 1 ilustra as opções de um dos fabricantes quanto à espessura das placas comercializadas.

Figura 1 - Informações sobre diferentes espessuras de materiais termoplásticos para órteses, segundo o fabricante Performance Health / Patterson Medical

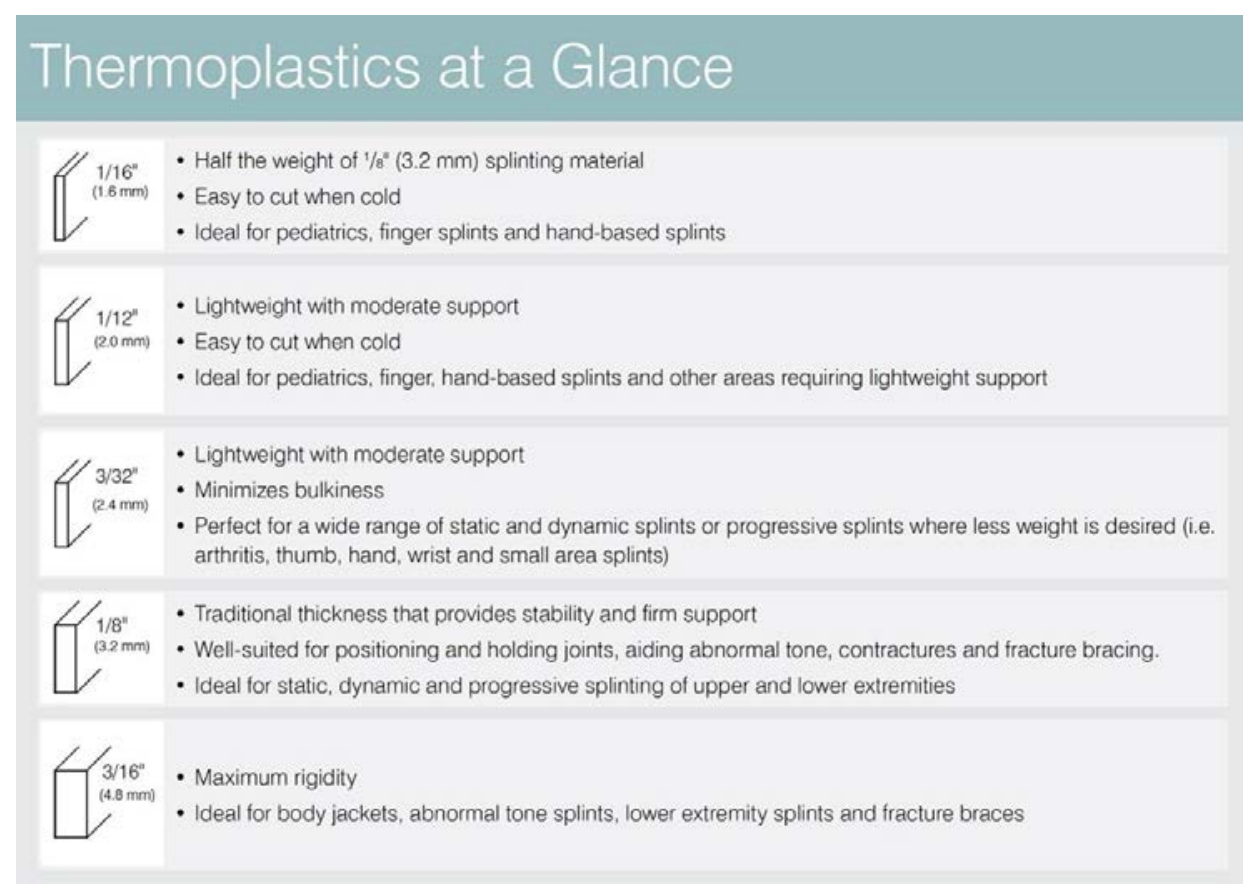

Fonte: Performance Health (2018b)

Também existe uma variedade de tipos de placa disponíveis, podendo ser lisas ou perfuradas. Um dos fabricantes disponibiliza em seu website uma relação (Figura 2) que apresenta a variedade de placas perfuradas existentes, em comparação à placa lisa. 
Figura 2 - Informações sobre diferentes tipos de placas perfuradas, em comparação à placa lisa, segundo o fabricante Performance Health / Patterson Medical

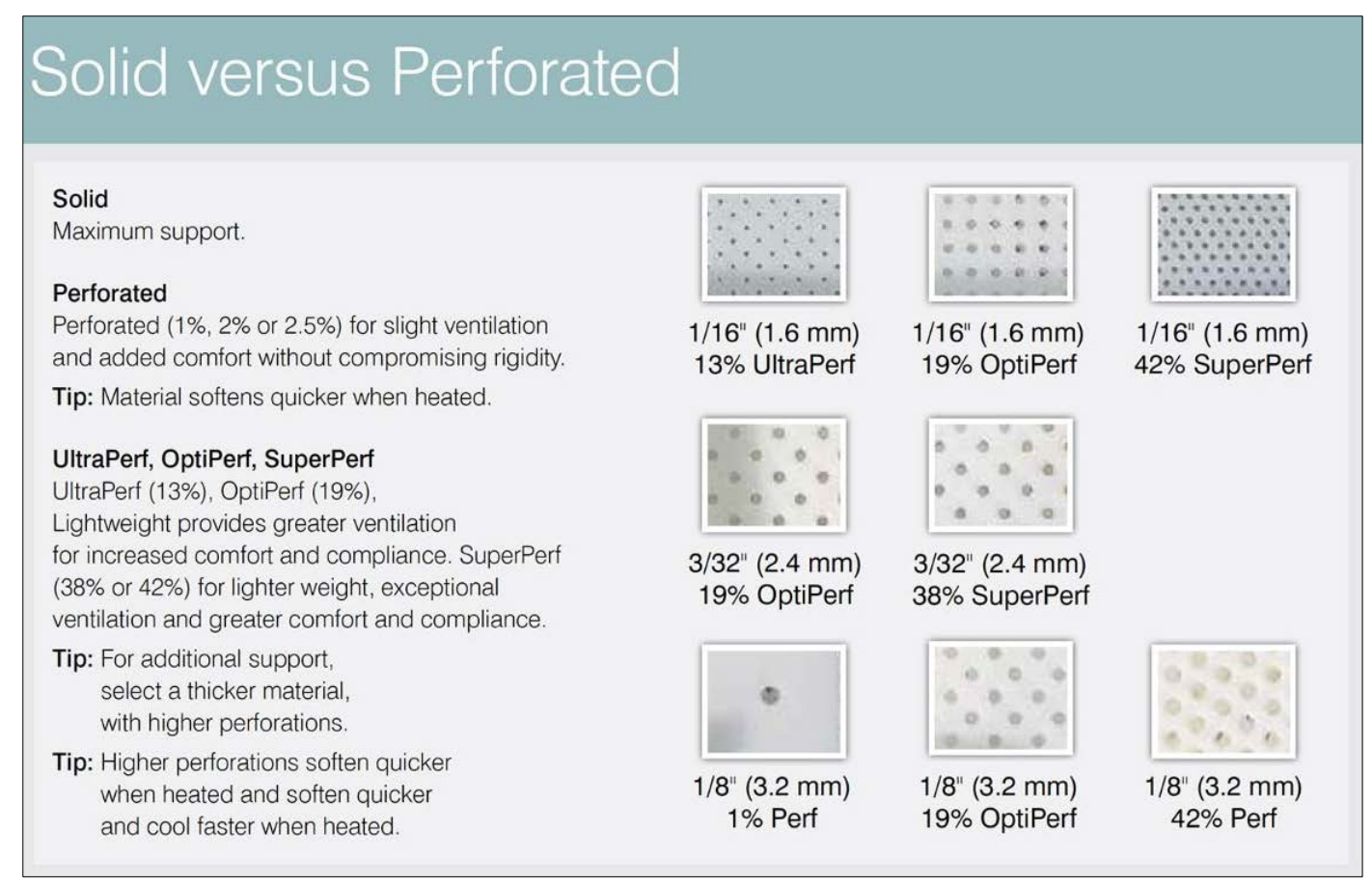

Fonte: Performance Health (2018b)

Além de placas, estão disponíveis comercialmente termoplásticos em tiras pré-cortadas, com bordas lisas e cortadas em máquina, com bom acabamento, disponível em larguras e espessuras diferentes. Essa pode ser uma estratégia para evitar o desperdício de material e também para produzir órteses e dispositivos assistivos melhores quanto à estética.

Alguns tipos de malha ou fita cuja base é de polímero termoplástico de baixa temperatura, são comercializados em rolos. Muitas vezes ventiladas e respiráveis, podem ser indicadas para órteses pequenas, para o acabamento das bordas, para prender acessórios e para o reforço de órteses que exigem rigidez, aplicando-se de duas a três camadas para um suporte semi-flexível ou mais camadas para dispositivos firmes. Dentre estes produtos encontram-se: Orficast $^{\mathrm{TM}}$ Thermoplastic Tape, Orficast ${ }^{\circledR}$ More, Plast-O-Fit ${ }^{\mathrm{TM}}$ (ORFIT INDUSTRIES, 2018), X-Lite Thermoplastic e Rolyan ${ }^{\circledR}$ Quickcast (PERFORMANCE HEALTH, 2018a). Alguns modelos são mais elásticos e requerem calor seco para aderência.

Uma outra opção atualmente disponível é o termoplástico em grânulos, com tempo de fusão rápida e que pode ser considerado prático para algumas aplicações. Podem ser indicados para moldar órteses menores, como dedeiras e espaçadores para a comissura dos dedos, além de dispositivos de tecnologia assistiva como adaptadores de talheres, extensores de freios de cadeira de rodas, entre outros. Alguns exemplos disponíveis no mercado são Thermo-Pellets ${ }^{\mathrm{TM}}$ (NORTH COAST MEDICAL, 2018; POLITEC SAÚDE, 2018) e Allfit (ORFIT 
INDUSTRIES, 2018). Este se torna transparente quando aquecido, indicando que o material está pronto para ser moldado e opaco quando resfriado.

Todas as empresas fabricantes oferecem, além das placas termoplásticas: órteses préfabricadas; moldes pré-cortados planificados, para serem moldados pelo terapeuta; materiais de forração, compostos por diversificados tipos e espessuras de espuma, alguns deles autoadesivos; velcros e outros tipos de materiais para fixação, em cores variadas e inclusive transparentes; elásticos, dobradiças e outros acessórios complementares, especialmente para a fabricação de órteses dinâmicas.

As características dos materiais disponíveis no mercado sofrem variações de acordo com o tipo e com a marca, o que pode influenciar na indicação e seleção do material mais adequado para cada situação. Para os casos em que há espasticidade, por exemplo, pode ser necessário que a órtese seja remodelada a medida que o tônus muscular se adequa e/ou se consegue ganhos na amplitude dos movimentos. Segundo participantes do estudo conduzido por Agnelli e Toyoda (2003), tanto nos adultos como nas crianças com espasticidade, em casos de paralisia cerebral ou acidente vascular cerebral, são muito utilizados o Ômega e o Ezeform ${ }^{\mathrm{TM}}$, que, segundo os terapeutas, retornam ao seu estado original e se mostram resistentes. Na área de queimaduras o mesmo estudo apontou que a maioria das órteses precisa ser reajustada com bastante frequência, por vezes semanalmente, também foram sugeridos o Ômega e o Ezeform ${ }^{\mathrm{TM}}$.

Conhecer os produtos existentes no mercado e as principais características deste grupo de materiais é importante para a prática clínica, seja para a escolha do material ou para seu melhor aproveitamento e manuseio durante a confecção da órtese (LINDEMAYER, 2004). Diante das opções de materiais termoplásticos de baixa temperatura, Breger-Lee e Buford Junior (1992) afirmam que o terapeuta é desafiado a otimizar suas características e fabricar órteses personalizadas de qualidade, escolhendo a espessura e tipo de placa mais adequado para as necessidades do usuário. De acordo com os autores, é preciso determinar os materiais certos para cada situação.

Para isso, é importante conhecer bem suas características, tais como: conformabilidade, aderência, memória, rigidez, resistência ao estiramento, acabamento superficial, durabilidade, condições de higiene, conforto ao usuário, custo, entre outras (LINDEMAYER, 2004; MCKEE; RIVARD, 2011; SAURON, 2003). A compreensão das propriedades físicas e mecânicas melhora o processo de seleção do material a ser utilizado, fator fundamental na rotina do profissional, que segue uma lógica para combinar as características do material à função desejável para cada órtese (CANELÓN, 1995; FESS, 2011; VAN PETTEN et al., 2014). 


\subsection{PROPRIEDADES DOS MATERIAIS TERMOPLÁSTICOS E SUAS CARACTERÍSTICAS PARA A CONFECÇÃO DE ÓRTESES}

Vários autores concordam que o bom êxito na escolha do material depende do conhecimento das características e propriedades do mesmo, sendo que as mais relatadas são: moldabilidade ou conformabilidade, memória, tempo de moldagem, resistência, aderência e rigidez (AGNELLI; TOYODA, 2003; ASSUMPÇÃO, 2005; BREGER-LEE; BUFORD JUNIOR, 1992; CANELÓN, 1995; FERRIGNO, 2007; LINDEMAYER, 2004; MCKEE; MORGAN, 1998; MCKEE; RIVARD, 2011; SAURON, 2003). Antes de escolher o material adequado para cada situação e modelo de órtese, o terapeuta deve buscar informações sobre suas principais características, além de revisar as informações técnicas do fabricante (CANELÓN, 1995).

O conhecimento relativo à estrutura dos materiais e suas características térmicas e mecânicas é de alta relevância para o entendimento do comportamento dos materiais termoplásticos de baixa temperatura e merece atenção por parte dos profissionais da área da saúde que trabalham com a indicação e/ou confecção de órteses (AGNELLI; TOYODA; FERRIGNO, 2010).

A estrutura de um material, seja ele polimérico ou não, pode ser considerada em vários níveis ou escalas e diz respeito à composição dos materiais, afetando seu comportamento (PEREIRA, 2006). As propriedades dos materiais podem ser divididas em grupos: propriedades mecânicas, que descrevem como o material se comporta quando submetido a uma solicitação mecânica; propriedades físicas, que incluem propriedades elétricas, magnéticas, ópticas e térmicas; e propriedades químicas (MANO; MENDES, 1999; NUNES; LOPES, 2014). Finalmente o processamento dos materiais refere-se aos métodos e condições utilizados para sua fabricação e estabelecimento da forma final. A relação entre esses três elementos, estruturapropriedades-processamento, é de extrema importância para a ciência dos materiais, sendo necessário considerar também sua aplicação. O desenho esquemático do tetraedro (Figura 3), que contém a caracterização no centro, permite a visualização dos principais influenciadores a serem avaliados no desenvolvimento e seleção de materiais e deve também ser considerado para melhoria de produtos. 
Figura 3 - Tetraedro da Ciência dos Materiais

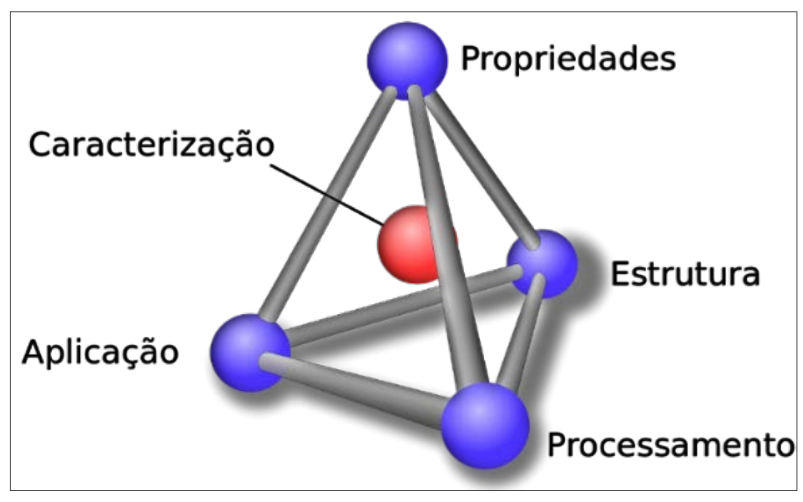

Fonte: Wikipedia.(2018)

As propriedades dos polímeros são influenciadas pela mobilidade das cadeias poliméricas, o que determina as características físicas do produto. A mobilidade das macromoléculas é diretamente proporcional à temperatura. Nunes e Lopes (2014) relatam que um dos fatores que mais afeta as propriedades dos polímeros está relacionado às temperaturas nas quais ocorrem as transições de fase: temperatura de fusão cristalina, temperatura de transição vítrea e temperatura de cristalização, o que também está relacionado à estrutura molecular.

Nesse contexto, para a aplicação em órteses, destacam-se algumas características importantes, a começar pela temperatura de fusão cristalina $\left(T_{m}\right)$, que se refere à temperatura na qual o polímero cristalino perde toda a cristalinidade, ou seja, a temperatura em que o material atingirá o estado viscoso (fundido), podendo ser manuseado e modelado antes de seu resfriamento.

Além das características térmicas, estão descritas na literatura algumas propriedades dos materiais termoplásticos de baixa temperatura consideradas as mais importantes para a confecção de órteses (AGNELLI; TOYODA, 2003; ASSUMPÇÃO, 2005; BREGER-LEE; BUFORD JUNIOR, 1992; CANELÓN, 1995; FERRIGNO, 2007; FESS, 2011; FOSSCAMPBELL, 1998; FRANCISCO, 2004; LINDEMAYER, 2004; MAC DONALD, 1998; MCKEE; MORGAN, 1998; MCKEE; RIVARD, 2011; SAURON, 2003), tais como:

- Moldabilidade: diz respeito ao ajuste do material à região na qual se aplica, ou seja, à facilidade com que o material está em conformidade com a anatomia da região a ser imobilizada. O termoplástico deve acomodar os contornos do corpo, sem nenhuma abertura, com boa distribuição de pressão. A porção do material que não estiver em contato com o corpo, de forma ajustada, dificilmente cumprirá sua função. Outros termos são usados para descrever esta característica, como conformabilidade, maleabilidade ou capacidade de moldagem, ou 
ainda na literatura internacional: drape ou drapability. Essa característica está ligada à plasticidade dos materiais, portanto se considera que materiais plásticos sejam mais facilmente moldáveis.

- Adesão ou autoaderência: resistência à separação quando suas partes são unidas. Esta característica é importante porque pode determinar a integridade de uma órtese;

- Resistência ao estiramento: quanto o material aquecido pode ou não alterar seu tamanho inicial. A quantidade de força necessária para esticar um material quando está quente e viscoso está ligada ao manuseio que ele pode suportar;

- Rigidez: intensidade da deformação em flexão, tração ou compressão, que ocorre em resposta à quantidade de tensão aplicada, na região do comportamento elástico, na temperatura ambiente. A presença de alguns tipos de fibra de reforço nos materiais, como as fibras de carbono e as fibras de vidro, podem aumentar a rigidez;

- Durabilidade: capacidade de um material em resistir a estresse repetitivo. Está ligada à resistência do material diante de um longo período de uso.

- Memória: tendência do material em retornar ao seu estado original, sendo mais fácil de ser modelado e remodelado. Isto se relaciona à elasticidade de um polímero. A presença de elastômeros em um determinado produto pode aumentar a capacidade de memória;

- Acabamento: suscetibilidade a absorção de marcas na superfície enquanto quentes, como impressão digital e trama da malha tubular.

Além das propriedades citadas, outras características são mencionadas para verificação dos materiais para órteses, tais como: densidade (CANELÓN, 1995); facilidade na fabricação (CANELÓN, 1995); capacidade de ventilação do material (FOSS-CAMPBELL, 1998); peso (AGNELLI; TOYODA, 2003; CAPELLO; TOYODA, 2000; FOSS-CAMPBELL, 1998; FRANCISCO, 2004); conforto do material (FOSS-CAMPBELL, 1998; MCKEE; RIVARD, 2011); limpeza/higiene (FRANCISCO, 2004; MAC DONALD, 1998); Tempo para confecção (BREGER-LEE; BUFORD JUNIOR, 1992; FRANCISCO, 2004, LINDEMAYER, 2004); custo (AGNELLI; TOYODA, 2003; CAPELLO; TOYODA, 2000; FRANCISCO, 2004; LEITE, 2007; SILVA, 2001, 2014; SOUZA, 2014); estética (AGNELLI; TOYODA, 2003; ASSUMPÇÃO, 2005; DESHAIS, 2005; MAC DONALD, 1998)

A maioria dos produtos atualmente disponíveis são misturas especificas de policaprolactonas ou, com menor frequência, de trans-poliisoprenos, em quantidades variáveis e associadas a outros componentes, proporcionando um conjunto quase infinito de propriedades potenciais de materiais para órteses. A modificação da estrutura e do comportamento, interfere, consequentemente, na escolha do material mais adequado para cada situação. 
Um trabalho realizado no Brasil avaliou 6 materiais termoplásticos disponíveis no mercado e constatou que eles apresentam similaridades na composição dos polímeros orgânicos (similaridade na temperatura de fusão cristalina do termoplástico de baixa temperatura), mas distinção acentuada na formulação de constituintes inorgânicos. De acordo com os resultados, sugeriu-se ainda que dois produtos comerciais, o Preferred ${ }^{\circledR}$ e o Omega ${ }^{\mathrm{TM}}$ Plus, contêm modificadores do tipo termoplásticos de alta temperatura, formando misturas poliméricas (AGNELLI; TOYODA; FERRIGNO, 2010).

Meng e Hu (2009), que têm realizado pesquisas fora do Brasil com novos materiais termoplásticos para a aplicação em órteses, afirmam que os compósitos dos polímeros com memória de forma e as misturas realizadas podem apresentar novas propriedades, significativamente diferentes das suas contrapartes puras, de modo que eles podem ser adequados para várias aplicações.

$\mathrm{Na}$ literatura internacional se observa relativa insatisfação quanto às propriedades mecânicas dos termoplásticos de baixa temperatura, sendo que Meng, Hu e Zhu (2008) apontam que estes materiais podem apresentar falhas quando usados em circunstâncias de elevada resistência à tração. Muitos esforços têm sido feitos para melhorar estas propriedades, tais como o reforço com fibras de vidro, fibra de carbono, fibra de aramida, introdução de ligações cruzadas e mistura física de polímeros. Diante disso, os autores testaram diferentes poliuretanos, modificados com policaprolactona - PCL, e compararam suas propriedades mecânicas com um material disponível no mercado, Orfit ${ }^{\circledR}$. Os resultados do material testado foram satisfatórios em termos de temperatura de trabalho e desempenho mecânico, podendo ser viável para futura aplicação na confecção de órteses.

Embora as propriedades dos materiais estejam inter-relacionadas e influenciando umas nas outras, é importante que os profissionais que atuam com a fabricação de órteses saibam a que se refere cada propriedade e como determinados materiais se comportam para cada uma delas. Para que seja possível conhecer melhor as características e comparar os materiais existentes, faz-se necessário uma avaliação criteriosa, envolvendo não apenas a percepção do profissional, como acontece frequentemente na prática clínica, mas também uma análise consistente ao se testar e experimentar os materiais, bem como interpretar os resultados.

\subsection{ENSAIOS DE MATERIAIS PARA ÓRTESES}

Os materiais para órteses de membros superiores e a maioria de suas propriedades nem sempre são avaliadas de forma objetiva e com valores numéricos pelos profissionais, mas a 
partir das facilidades e dificuldades durante o manuseio (FRANCISCO, 2004; LINDEMAYER, 2004; SOUZA, 2014).

A prática e a experiência do terapeuta em lidar com determinados materiais são importantes para a confecção de órteses e auxiliam no processo de seleção do melhor material para cada situação (FESS, 2011). Mas para que seja possível conhecer as características e comparar os materiais existentes, faz-se necessária uma avaliação dessas propriedades de maneira criteriosa, envolvendo não apenas a percepção do profissional, como acontece frequentemente na prática clínica.

É importante que exista consistência na maneira de avaliar, testar e experimentar os materiais, bem como interpretar os resultados. Segundo Lindemayer (2004), algumas estratégias podem ser adotadas para tornar essa avaliação objetiva e outros métodos podem ser associados, como por exemplo a realização de ensaios para verificar as propriedades dos materiais. De acordo com Garcia, Spim e Santos (2000), os ensaios de materiais são importantes pois permitem desenvolver novas informações sobre os mesmos, criar e/ou modificar processos de fabricação e tratamentos.

Ensaios padronizados podem proporcionar uma análise precisa dos materiais a serem utilizados em alguns contextos de reabilitação ou ainda para a produção de conhecimento científico. Essa normalização é fundamental para que se estabeleça uma linguagem comum entre diferentes profissionais e áreas envolvidas (CALLISTER; RETHWISCH, 2016).

A organização mais ativa nos Estados Unidos, e com boa aceitação no Brasil, para o estabelecimento e publicação de normas para testes com materiais é a ASTM - American Society for Testing and Materials (CALLISTER; RETHWISCH, 2016). No Brasil, a padronização de normas é realizada pela Associação Brasileira de Normas Técnicas (ABNT, 2018).

Alguns estudos envolvendo os materiais termoplásticos para órteses apontam a utilização de ensaios de laboratório já normatizados, como o trabalho conduzido por Danckwardt (2016). A partir de um levantamento realizado junto ao Catálogo Nacional de Produtos de Tecnologia Assistiva (PORTAL NACIONAL DE TECNOLOGIA ASSISTIVA, 2018) e instituições de reabilitação no Rio Grande do Sul, foram categorizados e caracterizados alguns dos materiais mais utilizados na fabricação de órteses no país. Após agrupar os materiais em poliméricos, metálicos, naturais e fibras, seguiu-se a caracterização por meio de sete métodos: Microscopia Eletrônica de Varredura (MEV), Espectroscopia por Energia Dispersiva (EDS), Espectroscopia no Infravermelho por Transformada de Fourier (FTIR), Análise Dinâmico-Mecânica (DMA), Espectrometria de Fluorescência de Raios X, Ensaios de Tração 
e de Compressão. Segundo o pesquisador, os ensaios e análises selecionados se mostraram satisfatórios para avaliar materiais para órteses, tanto para membros superiores como para membros inferiores.

Lindemayer (2004) utilizou duas análises da composição estrutural de cinco marcas comerciais de termoplásticos de baixa temperatura: Espectroscopia no Infravermelho por Transformada de Fourier (FTIR) e Espectroscopia Raman, para verificar a estrutura química, além de um ensaio normatizado, o Ensaio de Tração, para verificar as propriedades mecânicas dos materiais avaliados. Souza (2014) utilizou o ensaio de tração para verificar a resistência do material após alterações em sua composição (como por exemplo após o acréscimo de carga). Outros autores também mencionam a realização do ensaio de tração em materiais termoplásticos para órteses (DANCKWARDT, 2016; LEITE, 2007; RAMOS, 2017) e a literatura o aponta como um ensaio adequado para se verificar o que na prática clínica corresponde à resistência ao estiramento.

Para a verificação da rigidez, há relatos do uso do Ensaio de Flexão em três pontos, utilizado para comparar os materiais termoplásticos de baixa temperatura a um polímero derivado do óleo de mamona (LEITE, 2007); a um material do tipo compósito sanduíche (RODRIGUES, 2007), ao Poli (cloreto de vinila) - PVC (SILVA, 2014) e também para analisar 6 marcas comerciais de termoplásticos (AGNELLI; TOYODA; FERRIGNO, 2010).

Para a caracterização térmica dos materiais para órteses, foram identificadas na literatura as técnicas de Calorimetria Exploratória Diferencial - DSC, Temperatura de Amolecimento Vicat e Termogravimetria - TG (AGNELLI, TOYODA e FERRIGNO, 2010; LEITE, 2007; SILVA, 2014), além da Análise Dinâmico-Mecânica (LEITE, 2007; SOUZA, 2014).

Outros ensaios e análises também foram utilizados em materiais termoplásticos para órteses, tais como o Ensaio de Compressão (LEITE, 2007; DANCKWARDT, 2016) e o Ensaio de Dureza (SOUZA, 2014).

Como se verifica, as pesquisas envolvendo o estudo e a avaliação de materiais termomoldáveis para órteses, apresentam análises de laboratório diversificadas e normatizadas, que foram satisfatórias para avaliar algumas propriedades dos materiais. No entanto não foram encontrados ensaios normatizados que correspondem a algumas propriedades específicas, importantes para a aplicação em órteses, como a moldabilidade e a memória. Embora estas duas características sejam bastante valorizadas e ressaltadas para a aplicação em órteses (AGNELLI; TOYODA, 2003; BREGER-LEE; BUFORD JUNIOR, 1992; FERRIGNO, 2007; FESS, 2002; LINDEMAYER, 2004; MENG; HU; ZHU, 2008), não foram encontrados ensaios 
de laboratório que pudessem avaliar exatamente o que se espera de um material para essa finalidade.

Depois que os materiais termoplásticos de baixa temperatura foram incorporados na prática clínica envolvendo a confecção de órteses para os membros superiores, Breger-Lee e Buford Junior (1992) conduziram um dos principais estudos envolvendo a análise de propriedades aplicadas desse grupo de materiais. Os pesquisadores desenvolveram um teste padronizado para avaliar 16 diferentes produtos disponíveis comercialmente na época, quanto à Moldabilidade. $\mathrm{O}$ ensaio consistiu em perfurar amostras retangulares de diferentes materiais (a $1 \mathrm{~cm}$ da extremidade) e, após o aquecimento com o controle de tempo e de temperatura, pendurá-las em ganchos. Simultaneamente a isso, uma massa de $50 \mathrm{~g}$ foi pendurado na extremidade oposta de cada amostra até o resfriamento do material.

Os autores também avaliaram 21 produtos quanto à Durabilidade e Rigidez, utilizando uma Máquina Universal de Ensaios, assim como em outros estudos, porém elaboraram um protocolo específico para isso, em que as amostras passaram por 10.000 ciclos de carga compressiva. Essa quantidade foi calculada para garantir mudanças significativas nas propriedades do material, proporcionando assim resultados comparativos, de forma que um indivíduo ativo teria que usar a órtese por 3 meses ou mais para efetuar uma quantidade equivalente de solicitação mecânica. As amostras eram côncavas (meio cilindro), moldadas sobre o mesmo diâmetro, buscando uma aproximação com o formato final de uma órtese. Com os dois testes desenvolvidos os autores conseguiram classificar os materiais e relatam ter sido o primeiro passo para quantificar algumas alterações no comportamento dos materiais que são aplicáveis a essa finalidade.

Alguns estudos desenvolveram testes práticos empíricos para verificação das facilidades e dificuldades durante a moldagem das órteses e alguns deles envolvem a percepção de quem os manipula. Lindemayer (2004) apresentou dois testes qualitativos envolvendo o manuseio dos materiais, um teste de alongamento e um teste de memória. Em linhas gerais o teste de alongamento foi proposto com o objetivo de observar o alongamento máximo de cada material e seu comportamento após o manuseio. O teste de memória foi elaborado para observar o retorno do material quando recolocado na água quente, após ser esticado, e verificar a assimilação de digitais e marcas durante o manuseio do material. A pesquisadora encontrou resultados interessantes, relacionando, por exemplo, a capacidade de o material retornar ao seu estado original à quantidade de borracha presente na composição dos materiais.

O estudo de Souza (2014) caracterizou o material polimérico à base de óleo vegetal desenvolvido por Leite (2007), em comparação a alguns materiais termoplásticos do mercado. 
Para isso adotou alguns procedimentos para verificar a moldabilidade e os denominou como ensaio empírico e comparativo, no qual padronizou temperatura, tempo de imersão na água e modelo da órtese a ser confeccionada, a fim de verificar e anotar as características observadas durante a moldagem, comparando vantagens e desvantagens de diferentes materiais. A autora também desenvolveu um ensaio que denominou como memória, mas que foi aplicado para verificar se um material é capaz de se manter no formato moldado, após resfriado, verificando sua estabilidade dimensional. Para isso, após a confecção, a pesquisadora estabeleceu pontos e mediu a distância entre as bordas da órtese, no punho e na palma, utilizando um paquímetro, para identificar se houve perda da moldagem ao longo do tempo. As mensurações foram feitas a cada minuto até o $5^{\circ}$ minuto e posteriormente no $10^{\circ}$, no $20^{\circ}$ e no $30^{\circ}$ minuto (na primeira e na segunda hora).

Souza (2014) elaborou ainda mais dois ensaios: um "ensaio de temperatura de contato com a pele humana”, para verificar qual é a faixa de temperatura segura e confortável para o indivíduo durante a moldagem de órteses, e um “ensaio de resfriamento”, em que monitorou a velocidade de sua perda de calor, a fim de determinar quanto tempo é necessário para que ele retorne à temperatura ambiente.

No estudo prospectivo conduzido por Francisco (2004), foram avaliadas três órteses para o punho, confeccionadas em três materiais alternativos: atadura gessada, atadura gessada com revestimento de resina de poliéster e órteses de PET (Polietileno Tereftalato) pós-consumo. Embora não tenha utilizado materiais termoplásticos de baixa temperatura, a autora propõe testes práticos empíricos em relação a 10 características dos materiais avaliados, considerados essenciais para o bom desempenho e confecção de uma órtese: 1) Resistência aos procedimentos de higienização; 2) Resistência ao calor; 3) Peso; 4) Conformabilidade; 5)Formação de pontos de pressão; 6) Facilidade na confecção; 7) Tempo para confecção; 8) Remodelagem; 9) Durabilidade; 10) Custo.

Lindemayer (2004) afirma que a realização de ensaios padronizados para verificar as propriedades dos materiais para órteses pode ajudar a esclarecer o que empiricamente se percebe no cotidiano da prática clínica. Outros autores também discursam nessa linha e afirmam que as propriedades dos polímeros podem ser quantificadas através de empirismo e de normas técnicas, de maneira complementar (RODOLFO; NUNES; ORMANJI, 2006; SOUZA; ALMEIDA, 2015). 


\section{MATERIAIS E MÉTODOS}

A primeira fase da pesquisa foi exploratória e consistiu no desenvolvimento de materiais brasileiros baseados em termoplásticos de baixa temperatura, com a criação de uma metodologia que conduziu a formulação dos materiais, de acordo com a finalidade que se desejava para estes.

A segunda fase do trabalho apresentou caráter experimental, transversal e predominantemente quantitativo, em que dois materiais desenvolvidos, juntamente com dois termoplásticos comerciais, passaram por uma análise físico-mecânica e por manuseios padronizados, através da aplicação do instrumento elaborado. Além disso os materiais desenvolvidos foram avaliados de acordo com critérios da prática clínica, por profissionais que atuam na área de confecção de órteses.

\subsection{FASE EXPLORATÓRIA: DESENVOLVIMENTO DOS MATERIAIS E DOS MÉTODOS}

Para que os materiais pudessem ser desenvolvidos com embasamento científico e através de observação e experimentação empíricas, em uma relação de complementaridade, foram estabelecidas etapas para a fase exploratória, incluindo a elaboração de procedimentos e a criação de instrumentos de avaliação.

$1^{\mathrm{a}}$ etapa - Estudo dos materiais existentes no mercado;

$2^{\mathrm{a}}$ etapa - Elaboração da matriz de requisitos;

$3^{\text {a }}$ etapa - Elaboração de instrumento para a realização de testes práticos empíricos;

$4^{\mathrm{a}}$ etapa - Formulação e processamento de amostras de diferentes materiais;

$5^{\text {a }}$ etapa - Ajustes das formulações na busca por materiais viáveis

$6^{\text {a }}$ etapa - Seleção e produção de dois materiais desenvolvidos para a Fase Experimental;

$7^{\mathrm{a}}$ etapa - Criação do instrumento de avaliação "Manuseio Padronizado de Materiais Termoplásticos para Órteses (MPMTO)”.

\subsection{1 $\quad 1^{\text {a }}$ etapa - Estudo dos materiais existentes no mercado}

Foram escolhidos dois termoplásticos de baixa temperatura disponíveis no mercado, utilizados em larga escala para a confecção de órteses para membros superiores, identificados pelas marcas registradas e respectivos fabricantes:

- Rolyan ${ }^{\circledR}$ Ezeform ${ }^{\mathrm{TM}} /$ Performance Health (anteriormente Patterson Medical);

- Solaris ${ }^{\mathrm{TM}} /$ North Coast Medical. 
Optou-se por selecionar e realizar experimentos com dois produtos comerciais similares quanto às propriedades observadas na prática clínica, visando a identificação das suas estruturas. As amostras para todas as análises e ensaios foram obtidas a partir de placas com espessura de 3,2 $\mathrm{mm}$.

A escolha dos seis procedimentos analíticos realizados foi baseada em pesquisa bibliográfica sobre o tema e em estudos anteriores que indicaram a seguinte constituição geral para os materiais pesquisados: matriz contínua de termoplástico de baixa temperatura, podendo ou não ser modificada com um outro material polimérico, e um ou mais modificadores inorgânicos, diferindo em teor, composição química e formato físico; outros aditivos complementares, tais como pigmentos e modificadores de superfície (AGNELLI; TOYODA; FERRIGNO, 2010). A matriz termoplástica é decisiva nas características térmicas de amolecimento e moldagem, enquanto os modificadores inorgânicos são responsáveis pela rigidez do material, tendo também grande influência no seu custo final.

Quatro análises (DSC, DMA, TG e Teor de Cinzas por Calcinação) foram realizadas no Laboratório de Polímeros, do Departamento de Engenharia de Materiais - UFSCar, em equipamentos aferidos e calibrados, com a execução sendo realizada por profissionais qualificados. Os outros dois experimentos (FTIR e MEV/EDS) foram realizados junto ao Centro de Caracterização e Desenvolvimento de Materiais (CCDM) - UFSCar.

A seguir estão apresentados os procedimentos analíticos aplicados e os respectivos materiais e métodos utilizados.

\section{Espectroscopia no Infravermelho com Transformada de Fourier (FTIR)}

A técnica instrumental denominada Espectroscopia no Infravermelho com Transformada de Fourier - FTIR (ASTM, 2013) foi utilizada para a obtenção de dados referentes à estrutura química de dois produtos poliméricos comerciais aplicados na confecção de órteses. Nos experimentos empregou-se radiação eletromagnética correspondente à faixa do infravermelho médio (números de onda entre $4.000 \mathrm{~cm}^{-1}$ e $400 \mathrm{~cm}^{-1}$ ) incidindo sobre os dois produtos analisados. A energia associada a estes números de onda uma vez absorvida pelas macromoléculas poliméricas converte-se em energia de rotação-vibração molecular. Este fenômeno de absorção é extremamente quantizado e altamente dependente dos grupamentos químicos que estão presentes na amostra. Portanto a análise e a interpretação de Espectros no Infravermelho de um polímero mostram os grupamentos químicos presentes em sua estrutura.

Para os dois produtos poliméricos comerciais foram inicialmente preparadas soluções das respectivas amostras poliméricas no solvente clorofórmio. A posterior evaporação do 
solvente permitiu a produção de filmes finos, empregados na análise por FTIR. Foi utilizado o Espectrômetro FTIR, modelo Nexus 4700, Thermo Nicolet (Figura 4) e os espectros de infravermelho foram obtidos com 32 repetições, leitura de $4.000 \mathrm{~cm}^{-1}$ a $400 \mathrm{~cm}^{-1}$, e resolução igual a $4 \mathrm{~cm}^{-1}$.

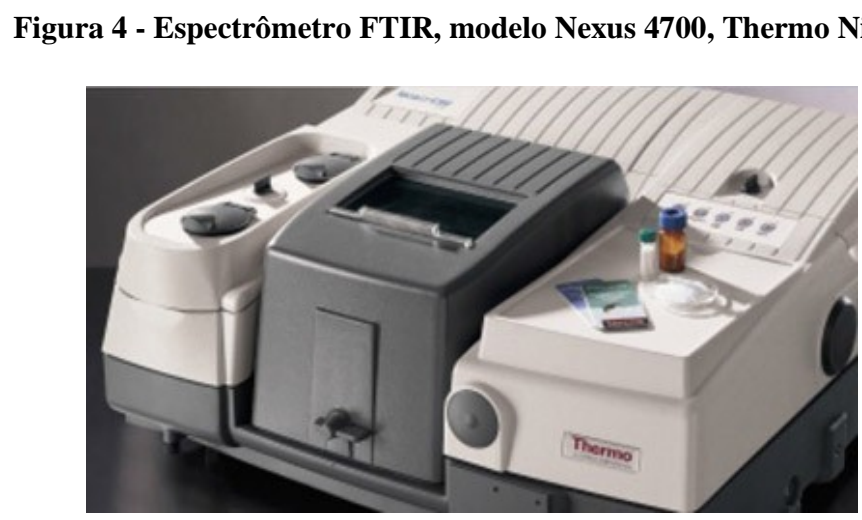

Fonte: GMI Trusted Laboratory Solutions (2018)

\section{Calorimetria Exploratória Diferencial (DSC)}

A Calorimetria Exploratória Diferencial - DSC (ASTM, 2015) foi empregada para complementar a técnica de FTIR e para verificar a temperatura de fusão cristalina do termoplástico de baixa temperatura, além de gerar dados sobre outras informações relevantes do comportamento térmico dos dois Produtos avaliados.

No experimento de DSC foi empregado o Calorímetro Modulado DSC, modelo Q100, TA Instruments (Figura 5), sendo obtidas Curvas DSC no primeiro aquecimento, com taxa de $20^{\circ} \mathrm{C} / \mathrm{min}$, para a faixa de temperatura entre $-85^{\circ} \mathrm{C}$ e $300^{\circ} \mathrm{C}$. Esta análise foi efetuada com pequenos pedaços cortados da placa dos materiais, até 10mg.

\section{Figura 5 - Calorímetro Modulado DSC, modelo Q100, TA Instruments}

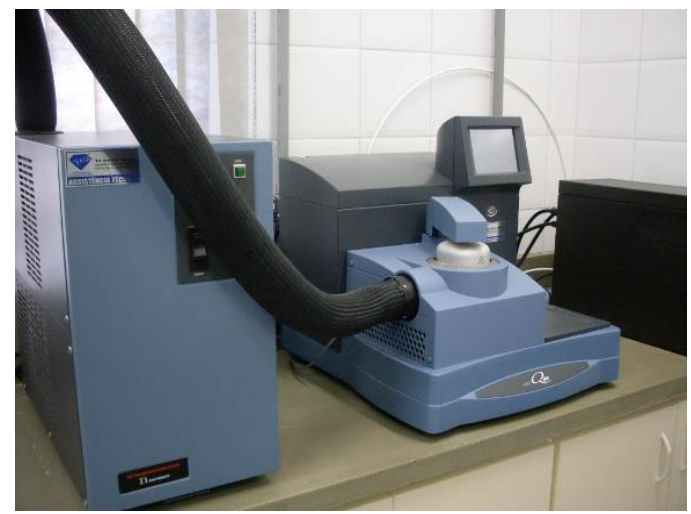

Fonte: elaborada pela autora 


\section{Análise Dinâmico-Mecânica (DMA)}

A Análise Dinâmico-Mecânica - DMA (ASTM, 2012), também denominada Análise Térmica Dinâmico-Mecânica (DMTA), foi utilizada para complementar as análises da verificação do polímero principal e da presença de possíveis modificadores nos materiais avaliados. A detecção de modificadores presentes em pequenas quantidades é muito difícil de ser observada pelas outras técnicas utilizadas, como por exemplo DSC. Além disto, estes modificadores podem ser materiais poliméricos elastoméricos, cuja Temperatura de Transição Vítrea (Tg) é muito baixa.

Na análise por DMA foi utilizado o Analisador Dinâmico-Mecânico, modelo DMA Q800, TA Instruments (Figura 6), sendo determinados o Módulo de Armazenamento (E'), o Módulo de Perda (E") e a Tangente Delta (Tangente do Ângulo de Perda $\delta$, que é igual a E"/E'). A temperatura nos experimentos variou entre $-100^{\circ} \mathrm{C}$ e $50^{\circ} \mathrm{C}$ e a taxa de aquecimento foi de $20^{\circ} \mathrm{C} / \mathrm{min}$. As amostras foram solicitadas mecanicamente por flexão em 3 pontos, com carregamento central (garra “dual cantilever”), amplitude de 25 micrômetros e frequência de $1 \mathrm{~Hz}$.

O critério utilizado para a determinação das Temperaturas de Transição Vítrea (Tg) foi o ponto de máximo na Curva da Tangente $\delta$ em função da Temperatura.

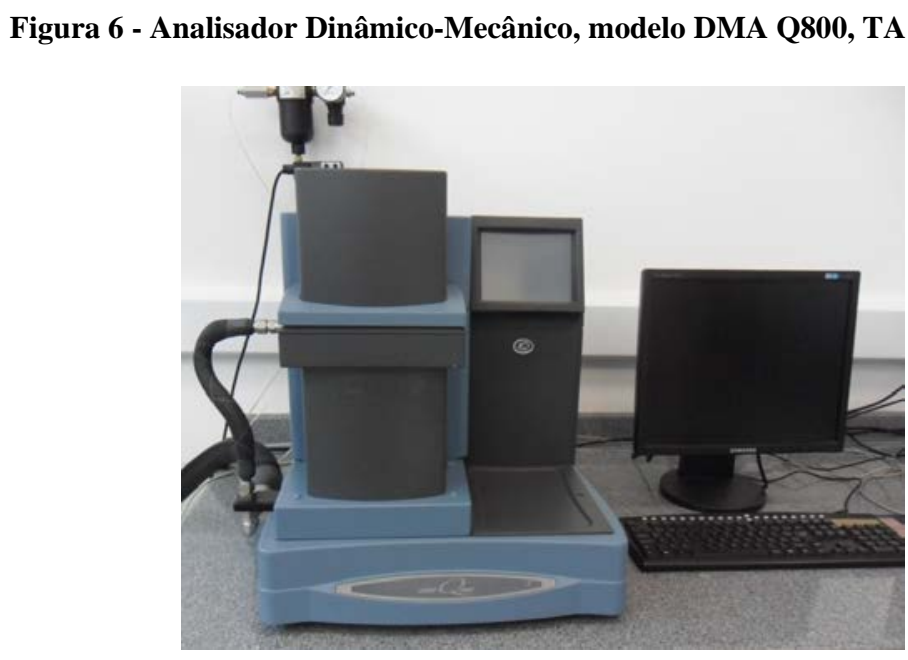

Fonte: elaborada pela autora

\section{Termogravimetria (TG)}

A técnica quantitativa de análise térmica denominada Termogravimetria - TG (ASTM, 2014b) é baseada na obtenção de curvas que registram a variação de massa da amostra analisada em função da temperatura. 
Esta técnica permite avaliar tanto o padrão de decomposição térmica das composições poliméricas (orgânicas) e, principalmente, determinar o teor de inorgânicos (ou teor de cinzas) destas composições, obtido como a porcentagem de massa residual após a eliminação dos componentes orgânicos.

Nesse experimento foi empregado o Analisador Termogravimétrico TG, modelo Q50, TA Instruments (Figura 7), sendo obtidas Curvas TG (perda de massa em função da temperatura) e DTG (derivada da perda de massa em função da temperatura), com taxa de aquecimento de $20^{\circ} \mathrm{C} / \mathrm{min}$, para a faixa de temperatura entre $23^{\circ} \mathrm{C}$ e $800^{\circ} \mathrm{C}$.

Figura 7 - a) e b) Analisador Termogravimétrico TG, modelo Q50, TA Instruments

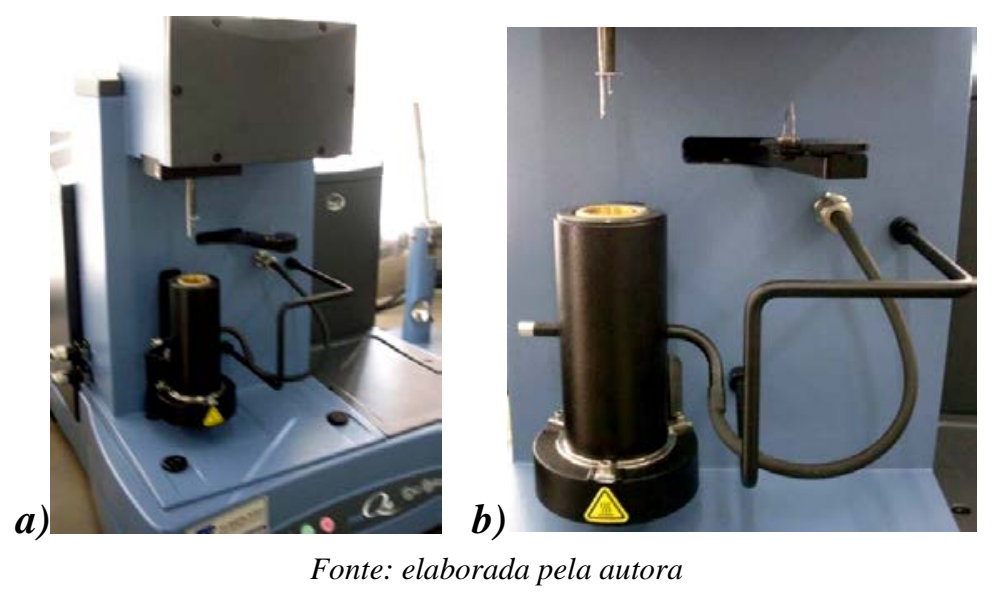

\section{Teor de Cinzas por Calcinação}

O Teor de Cinzas (ou Resíduo de Calcinação ou Teor de Inorgânicos) foi determinado com base na Norma ISO 3451/1 (calcinação direta), com a queima de compostos orgânicos ocorrendo a $550^{\circ} \mathrm{C}$, durante 1 hora. Foi utilizado o Forno de Micro-Ondas CEM, Airwave 7000, Microwave Furnace (Figura 8).

Trata-se de uma outra metodologia de determinação do teor de cinzas, possibilitando a obtenção de uma quantidade adequada de material inorgânico e viabilizando a sua análise pela técnica de Microscopia Eletrônica de Varredura (MEV). 
Figura 8 - Forno de Micro-Ondas CEM, Airwave 7000, Microwave Furnace

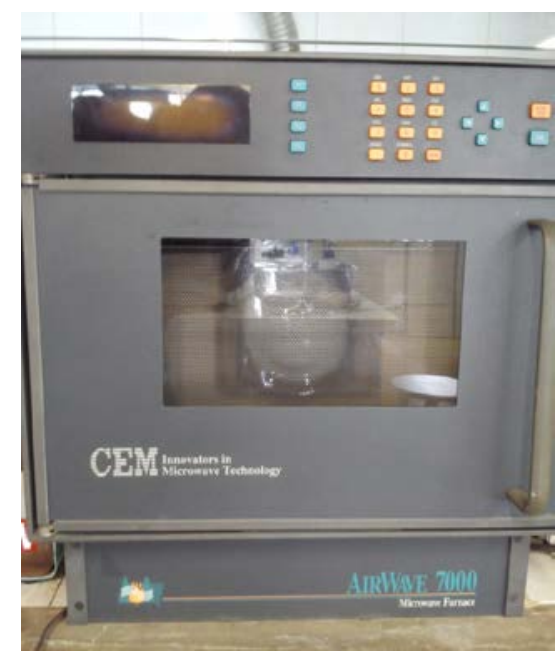

Fonte: elaborada pela autora

\section{Microscopia Eletrônica de Varredura (MEV) acoplada com a Espectroscopia por Dispersão} de Energia de Raios $X$ (EDS)

Os resíduos da calcinação, isto é, os constituintes inorgânicos dos dois produtos foram caracterizados por Microscopia Eletrônica de Varredura (MEV) acoplada com a identificação química qualitativa dos elementos químicos via Espectroscopia por Dispersão de Energia de Raios X (EDS). A análise possibilitou a obtenção de micrografias do material inorgânico com a verificação de formato físico (fibroso e/ou particulado) e indicativo dos principais elementos químicos presentes na sua composição.

A identificação dos elementos químicos presentes nos constituintes inorgânicos das amostras foi realizada utilizando-se o Equipamento EDS, modelo INCAx-Sigth, Oxford Instruments, acoplado ao Microscópio Eletrônico de Varredura (MEV), modelo Quanta LX 400, FEI. É importante destacar que a análise por EDS é uma técnica que caracteriza os elementos químicos presentes no material inorgânico e não os compostos, sendo que o limite de detecção desta técnica pode chegar a 0,1\% de concentração em massa.

A análise utilizou detector de elétrons retroespalhados (DualBSD). As micrografias obtidas apresentam as imagens de elétrons retroespalhados, que geram contrastes de cor dependentes da composição da amostra. Desta forma, os elementos químicos de maior número atômico aparecem nas micrografias como pontos claros e elementos químicos de menor número atômico aparecem como pontos mais escuros. 


\subsection{2 $2^{\mathrm{a}}$ etapa - Elaboração da matriz de requisitos}

Para que o processo de desenvolvimento dos materiais brasileiros pudesse garantir qualidade, optou-se por sistematizar o seu planejamento a partir das reais necessidades identificadas na área de confecção de órteses.

Foi elaborada uma matriz de requisitos, em que estes foram relacionados às características que o material precisa ter para ser eficiente na confecção de órteses para membros superiores. Para esta etapa, optou-se por adotar os princípios do Quality Function Deployment (QFD), um método importante e reconhecido na Gestão de Desenvolvimento de Produto, com enfoque em alcançar a Garantia da Qualidade (AKAO, 1996; CHENG, 1995; CHENG; MELO FILHO, 2007). O trabalho utilizou apenas uma das quatro etapas constituintes desta metodologia, o Planejamento do produto (estágio I), com adequação de algumas terminologias, de acordo com o contexto e objetivos desta pesquisa.

A primeira matriz proposta pelo QFD, elaborada para o planejamento do produto/material, é conhecida como house of quality (“casa da qualidade”) e assegura boas relações e comunicação entre os vários grupos e áreas funcionais envolvidos. Permite a conversão das necessidades e desejos do cliente ou "voz do cliente” (o quê?) em parâmetros e requisitos técnicos ou "voz da engenharia” (como?) (CHENG; MELO FILHO, 2007). Ela apresenta, portanto, os requisitos que o material nacional deve ter para que seja eficaz na confecção de órteses para membros superiores.

Dessa forma, o desenvolvimento do material seguiu etapas bem definidas e o seu planejamento foi feito a partir das reais necessidades identificadas na área de confecção de órteses, seguindo-se o raciocínio da metodologia Quality Function Deployment (QFD), que levou à construção de uma matriz: a Matriz da Qualidade. O principal objetivo dessa matriz é traduzir as necessidades do cliente em especificações de desempenho, utilizando-se a linguagem necessária para o desenvolvimento e implementação do produto. Criou-se, portanto, uma matriz (Figura 9) contendo algumas das principais necessidades e requisitos esperados para os novos materiais, associados a parâmetros técnicos, definidos e denominados em conjunto com a equipe de engenharia.

Para o preenchimento das necessidades que os materiais desenvolvidos deveriam ter, foram consideradas a experiência clínica de profissionais que atuam na área, os relatos de usuários de órteses em relação aos materiais e as necessidades identificadas na literatura. Os requisitos do material (“voz do cliente”), estão dispostos nas linhas da matriz, e descrevem as 
características que o material precisa apresentar para ser eficiente na confecção de órteses para membros superiores.

Figura 9 - Matriz de Requisitos / Matriz da Qualidade

\begin{tabular}{|c|c|c|c|c|c|}
\hline $\begin{array}{c}\text { Requisitos } \\
\text { do Material }\end{array}$ & 苞 & 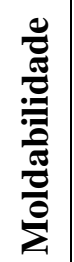 & 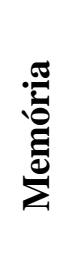 & 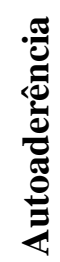 & 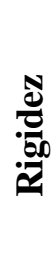 \\
\hline $\begin{array}{c}\text { Possibilitar moldagem diretamente no } \\
\text { corpo do usuário (água entre } 55^{\circ} \mathrm{C} \text { e } \\
70^{\circ} \mathrm{C} \text { ) }\end{array}$ & • & $\bullet$ & 0 & & \\
\hline $\begin{array}{c}\text { Ajustar-se à região do corpo que se } \\
\text { pretende imobilizar, possibilitando } \\
\text { acomodação de curvas e relevos } \\
\text { anatômicos }\end{array}$ & $\nabla$ & $\bullet$ & 0 & & \\
\hline $\begin{array}{l}\text { Retornar ao seu tamanho e curvatura } \\
\text { original, possibilitando ajustes e } \\
\text { remodelamento de órteses ao longo } \\
\text { do tempo. }\end{array}$ & & 0 & $\bullet$ & & \\
\hline $\begin{array}{c}\text { Boa capacidade de duas superfícies } \\
\text { aquecidas se aderirem quando } \\
\text { pressionadas }\end{array}$ & $\nabla$ & & & $\bullet$ & \\
\hline $\begin{array}{l}\text { Resistente a deformações quando } \\
\text { alguma força é aplicada } \\
\text { constantemente (considerando o } \\
\text { material resfriado, já moldado) }\end{array}$ & & & & & $\bullet$ \\
\hline
\end{tabular}

Fonte: elaborada pela autora

Legenda das

Relações:

Forte

Média

Fraca

Os requisitos foram convertidos em parâmetros técnicos ("voz da engenharia”) que traduzem as necessidades do material estipuladas por este estudo e que são: Temperatura, Moldabilidade, Memória, Autoaderência e Rigidez. As relações entre os requisitos do material e os parâmetros técnicos podem ser classificadas como forte, média ou fraca e se encontram no quadrado central da matriz, representadas por símbolos conforme a legenda. Ao determinar as relações entre os requisitos, nota-se que existe forte associação entre as propriedades do material, o que certamente reflete no manuseio durante a confecção de órteses.

O método QFD tem ferramentas para considerar as necessidades do cliente no processo de desenvolvimento do produto, desde o projeto conceitual até fabricação, sendo que não foi dada continuidade, neste trabalho, às demais etapas propostas pelo método. A primeira matriz elaborada e o raciocínio estabelecido foram fundamentais na determinação dos requisitos e 
foram a base para a criação dos instrumentos utilizados na criação e teste dos materiais. Apesar de não construir a segunda matriz, a equipe trabalhou para realizar o desdobramento das especificações da engenharia e utilizar os princípios do Desenvolvimento do produto (estágio II do QFD), buscando soluções para atingir as necessidades desejadas para o novo material, através das formulações elaboradas.

O QFD apresenta o potencial para ouvir, traduzir e transmitir de forma priorizada, a voz do cliente e tem sido adotado no desenvolvimento de novos produtos e para a melhoria de produtos existentes, em vários setores da indústria, assim como em pesquisas envolvendo inovações tecnológicas orientadas para o cliente (CHENG; MELO FILHO, 2007; CRISTIANO; LIKER; WHITE, 2000; FARIA et al., 2011).

\subsection{3 $3^{\mathrm{a}}$ etapa - Elaboração de instrumento para a realização de testes práticos empíricos}

Antes de dar início ao processo de formulação e processamento de diferentes amostras de materiais, foi elaborado um instrumento para determinar e organizar os testes práticos a serem realizados com cada material, à medida em que fosse processado.

As características dos materiais utilizados na confecção de órteses são geralmente analisadas pelo profissional que os manipula, a partir das facilidades e dificuldades durante o manuseio. O Roteiro de Procedimentos para Testes Práticos Empíricos (Apêndice I), desenvolvido e apresentado neste estudo, valoriza a experiência prática do profissional e foi elaborado a partir do que se considera importante na literatura específica da área, conforme relatado na fundamentação teórica. Ele é focado na análise do material (não envolvendo clientes) e apresenta recomendações de procedimentos para testes práticos a serem realizados com os materiais, em relação a 14 itens de avaliação:

1) Facilidade para cortar o material resfriado

2) Facilidade para cortar o material aquecido

3) Percepção Térmica

4) Tempo de Trabalho

5) Moldabilidade

6) Memória

7) Facilidade de acabamento

8) Autoaderência

9) Suscetibilidade a impressões digitais 
10) Conforto ao toque após moldado

11) Rigidez

12) Estética do material

13) Peso do material

14) Fixação de velcros

Foram adotadas de três a cinco alternativas para a avaliação de cada item, com uma graduação nas respostas, a fim de facilitar o preenchimento e a descrição dos resultados do manuseio realizado com cada material. O roteiro foi utilizado ao longo do desenvolvimento dos materiais, a fim de verificar as características de cada material formulado, identificar as necessidades de melhoria e fornecer dados que pudessem conduzir as decisões voltadas para os ajustes nas formulações.

O instrumento foi decisivo no processo de formulação e desenvolvimento dos materiais nacionais e pode ser utilizado como um guia de avaliação prática para outras situações envolvendo termoplásticos de baixa temperatura. Dessa forma, sua elaboração traz uma importante contribuição pois, mesmo tratando-se de testes práticos e empíricos, fez-se necessário adotar critérios padronizados para descrever as características observadas, com pelo menos três alternativas de resposta para cada item, e para comparar as amostras, à medida em que as mesmas eram processadas. Apesar de não gerar dados numéricos, o roteiro trouxe objetividade às percepções empíricas e as características verificadas nos testes influenciaram diretamente na decisão sobre os componentes a serem ajustados (no que diz respeito à quantidade), suprimidos ou acrescentados.

Ressalta-se que o instrumento elaborado e a aproximação junto à equipe de engenharia foram fundamentais para a comunicação e o alinhamento sobre as necessidades do material, a partir de parâmetros da prática clínica. Como neste trabalho, outras pesquisas envolvendo materiais termomoldáveis para órteses também fizeram a opção por testes práticos empíricos para avaliar ou complementar a análise dos materiais (BREGER-LEE; BUFORD JUNIOR, 1992; FRANCISCO, 2004; LINDEMAYER, 2004; SOUZA, 2014). Mesmo reconhecendo a importância de tornar a avaliação mais objetiva e com critérios definidos, os autores concordam que a experiência do terapeuta e/ou pesquisador na confecção de órteses e sua opinião em relação aos materiais são importantes e devem ser consideradas. 


\subsection{4 $4^{\mathrm{a}}$ etapa - Formulação e processamento de amostras de diferentes materiais}

O processamento dos materiais seguiu uma programação com procedimentos e equipamentos específicos, conforme se segue.

\section{$\left.1^{\circ}\right)$ Cálculo da quantidade de cada componente para as formulações}

Foram feitas formulações contendo uma matriz termoplástica associada a diferentes componentes e aditivos. A porcentagem das cargas inorgânicas para cada material processado foi de 18 a 23\%, mesmo teor encontrado nos experimentos da $1^{\text {a }}$ etapa da Fase Exploratória. As formulações foram elaboradas e planejadas de acordo com requisitos pré-estabelecidos e seu detalhamento está apresentado nas etapas seguintes da metodologia, assim como nos resultados deste trabalho. A quantidade de formulação era limitada em $128 \mathrm{~cm}^{3}$, ou seja, a capacidade máxima do homogeneizador aliado à capacidade da placa molde para prensagem.

\section{$\left.2^{\circ}\right)$ Pesagem dos componentes a serem utilizados}

Para a pesagem precisa dos componentes utilizados em cada formulação, foi utilizada uma balança analítica, modelo PB8001-S, Mettler Toledo (Figura 10).

Figura 10 - Processo de pesagem dos componentes: a) tara, b) e c) acréscimo de componente
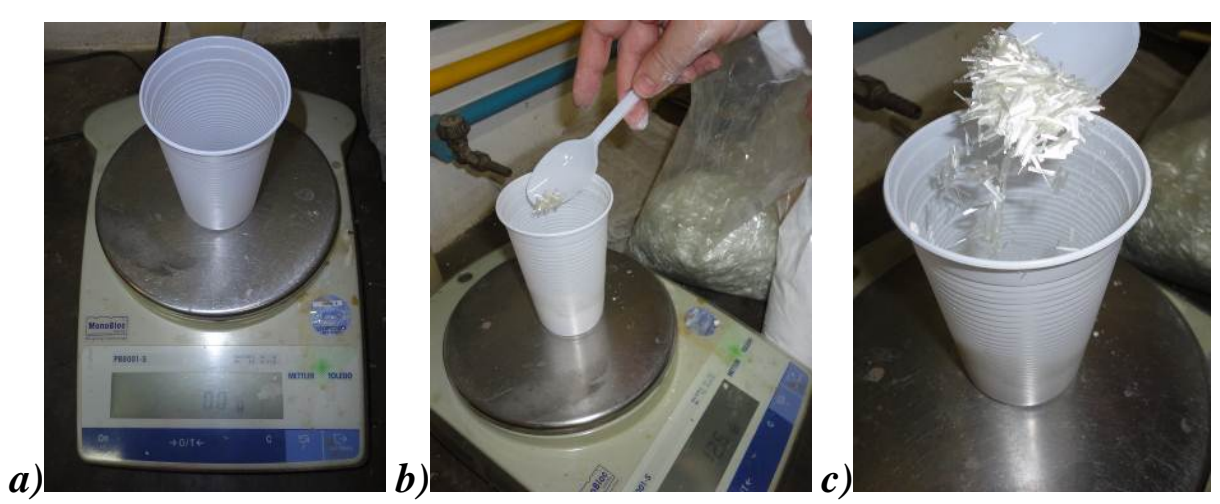

Fonte: elaborada pela autora

\section{$\left.3^{\circ}\right)$ Mistura de componentes}

Os componentes selecionados e pesados para cada formulação foram misturados em um equipamento Homogeneizador de Alta Rotação, modelo MH-100, MH Equipamentos (Figura 11). Todos os componentes foram inseridos na câmara do homogeneizador que era então ligado por aproximadamente 30 segundos, até que a corrente do equipamento sofresse uma diminuição (menor que 10 Amperes), indicando a fusão dos componentes, e então havia uma contagem de 15 segundos para mistura e homogeneização dos componentes (Figura 12). 
Figura 11 - Homogeneizador de Alta Rotação, modelo MH-100, MH Equipamentos ( $a$ e $b$ )
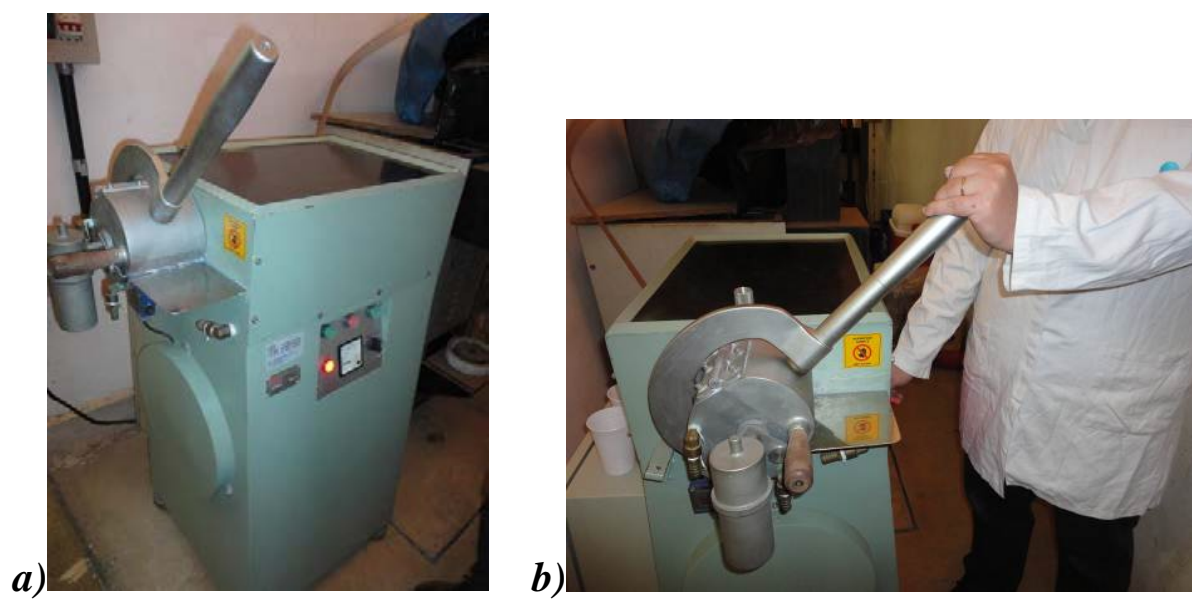

Fonte: elaborada pela autora

Figura 12 - a) Colocação dos componentes no misturador e b) Aspecto após mistura/homogeneização
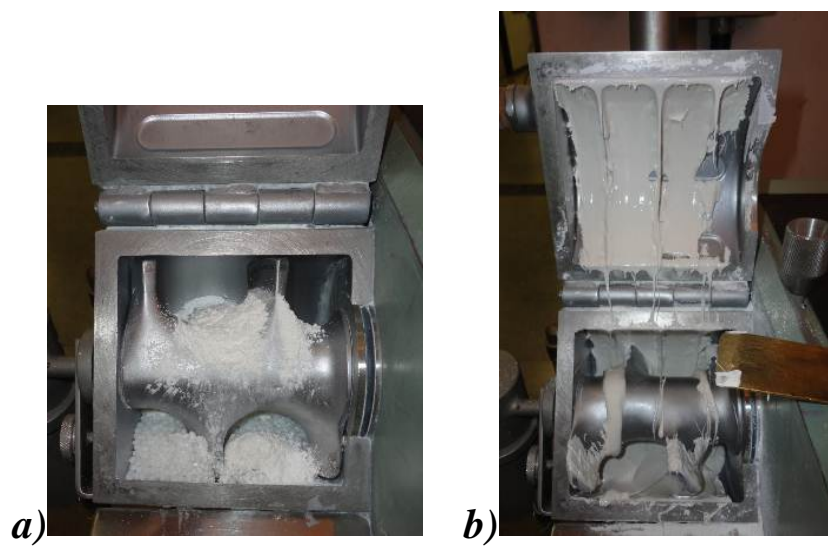

Fonte: elaborada pela autora

Devido a limitação na quantidade de matérias primas para a realização do trabalho, a mistura dos componentes foi feita no Homogeneizador de Alta Rotação. Apesar deste equipamento não fornecer misturas tão homogêneas, permite a utilização de uma pequena quantidade de matéria prima e possibilitou, consequentemente, a obtenção de várias formulações diferentes, o que foi prioritário para que o estudo fosse concluído.

Os aspectos negativos da mesma foram: dificuldade de controle dos parâmetros do processo, como temperatura e rotação, gerando uma consequente variação de homogeneidade, além de possível degradação do material. Quando era observada uma mistura não homogênea dos componentes ou então a degradação do material, era necessária a repetição da formulação. A cada nova formulação foi dispendido um tempo considerável para limpeza e preparação do 
sistema para a próxima amostra, sendo que este não foi o método ideal para a obtenção de amostras.

\section{$\left.4^{\circ}\right)$ Acabamento}

Após a mistura homogênea dos componentes, o material obtido apresenta-se desforme e inviável para o teste prático (Figura 13).

Figura 13 - Remoção do material do misturador ( $a$ e $b$ ) e material removido (c)
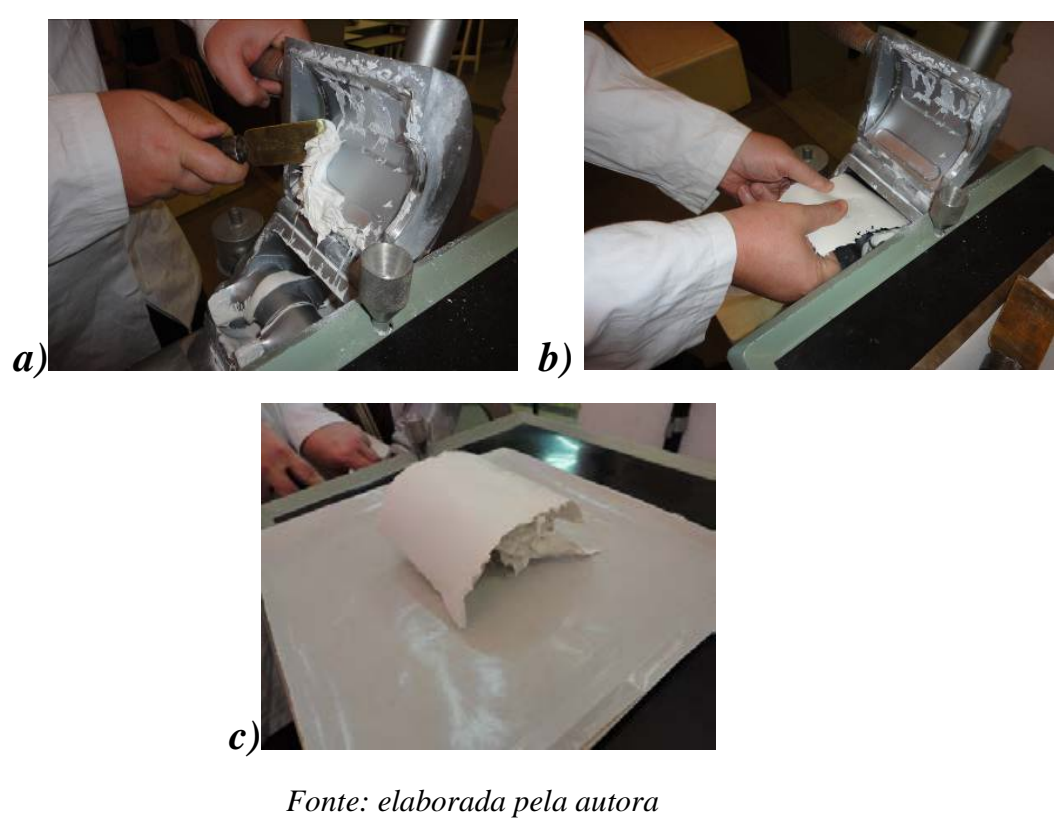

Dessa forma, para produzir amostras em formato de placa, semelhantes às placas de material utilizadas na confecção de órteses para membros superiores, foi utilizada uma Prensa Hidráulica, modelo LPB-35-15, Luxor, com controle de temperatura, ajustado a $100^{\circ} \mathrm{C}$, na qual o material foi depositado e prensado dentro de um molde metálico (Figura 14). Este era composto por duas chapas de ferro e um espaçador de 3 milímetros de espessura, com abertura quadrada de $20 \mathrm{~cm} \mathrm{X} \mathrm{20cm} \mathrm{(Figura} \mathrm{15).}$ 
Figura 14 - Prensa hidráulica com aquecimento (a) e prensagem do material no molde metálico (b)
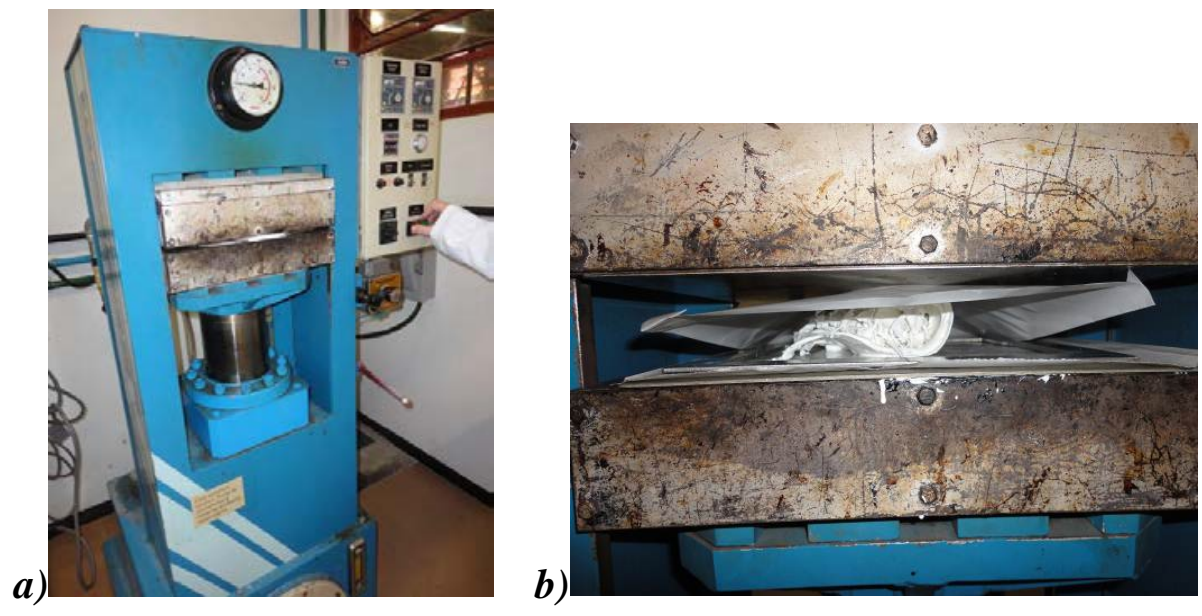

Fonte: elaborada pela autora

Figura 15 - Amostra após a prensagem, ainda no molde metálico

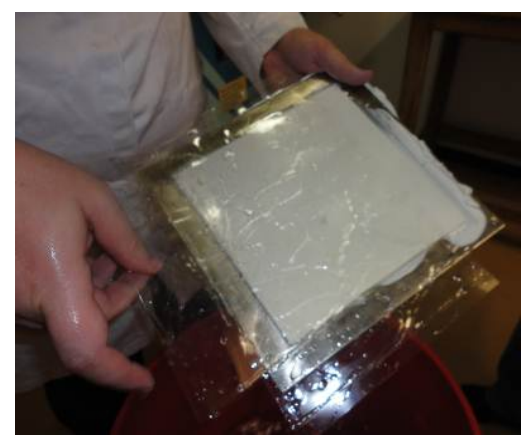

Fonte: elaborada pela autora

Foram utilizadas duas folhas de filme de poli (tereftalato de etileno) - PET sem tratamento superficial (para não contaminar a amostra), uma em cima e outra embaixo da amostra, entre o molde e o material, a fim de evitar a aderência deste às chapas metálicas e proporcionar um aspecto liso e uniforme da placa. Dessa forma, ao serem prensadas com o filme PET, as amostras apresentaram melhor acabamento, com a superfície lisa e uniforme.

As amostras produzidas mediam 20x20 cm e 3mm de espessura, de acordo com o espaçador utilizado para molde (Figura 16).

Figura 16 - Rebarbamento (remoção de excesso e farpas) da amostra, após prensagem e retirada do molde.

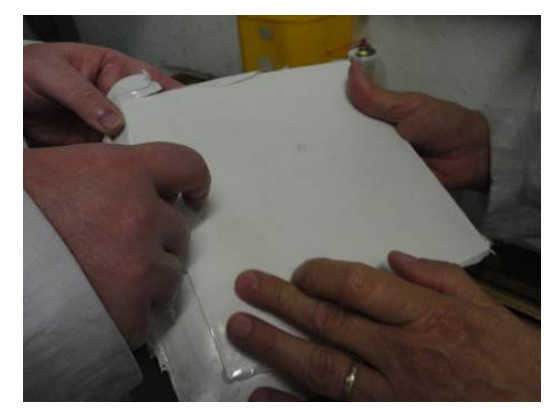

Fonte: elaborada pela autora 
Após o processamento, cada material permaneceu em repouso durante 24 horas, em temperatura ambiente, para descanso e estabilização, antes de ser manuseado e avaliado através dos testes empíricos.

\subsection{5 $5^{\mathrm{a}}$ etapa - Ajustes das formulações na busca por materiais viáveis}

Após o levantamento das características que os materiais devem apresentar, através do estudo realizado com os materiais disponíveis no mercado e da criação das matrizes de requisitos, foi possível selecionar alguns componentes a serem usados na formulação das amostras. Para que o material pudesse ser aplicado sobre a pele humana, foram utilizados em sua formulação componentes amplamente utilizados na área médica e na ortopedia, e cujos aspectos de biocompatibilidade já foram investigados (COOMBES et al., 2004; RAMOS, 2011; SINHA et al., 2004; TRAJANO, 2012; WESSLER, 2007).

A matriz termoplástica selecionada para o material nacional foi o polímero PCL (Policaprolactona). Foram associados a ele, em diferentes proporções e combinações, os seguintes componentes: polímero modificador elastomérico, carga mineral, fibra de reforço e pigmento. Nesta etapa as variações nos teores e tipos de componentes foram realizadas de acordo com o resultado dos testes práticos empíricos realizados, que geraram modificações e novos materiais, ficando cada vez mais próximos do esperado.

Ao longo desse processo de busca por materiais viáveis, foram realizados testes empíricos com cada material à medida em que era processado, gerando informações para modificações nos materiais, criando-se ajustes ou novas formulações. Nesse processo interativo, foram processados 17 materiais, sendo que a observação e a experimentação empírica das amostras elegeu as últimas três (amostras 15, 16 e 17) como viáveis para a aplicação em órteses.

A Tabela 1 apresenta os resultados dos testes realizados com cada uma das 17 amostras, através do Roteiro de Procedimentos de Testes Práticos Empíricos, sendo que a partir das alternativas de resposta determinou-se, para cada item, uma faixa considerada aceitável para a aplicação em órteses (linhas marcadas em verde). Os campos marcados em vermelho representam respostas de alerta, apontando características não desejadas. Essas análises, somadas às impressões pessoais dos pesquisadores, conduziram o processo das formulações. 
Tabela 1 - Resultados dos testes empíricos realizados com as 17 amostras, onde verde mosta a faixa de resultados aceitaveis, vermelho mostra a faxa de resultados não aceitaveis e $X$ os resultados encontrados

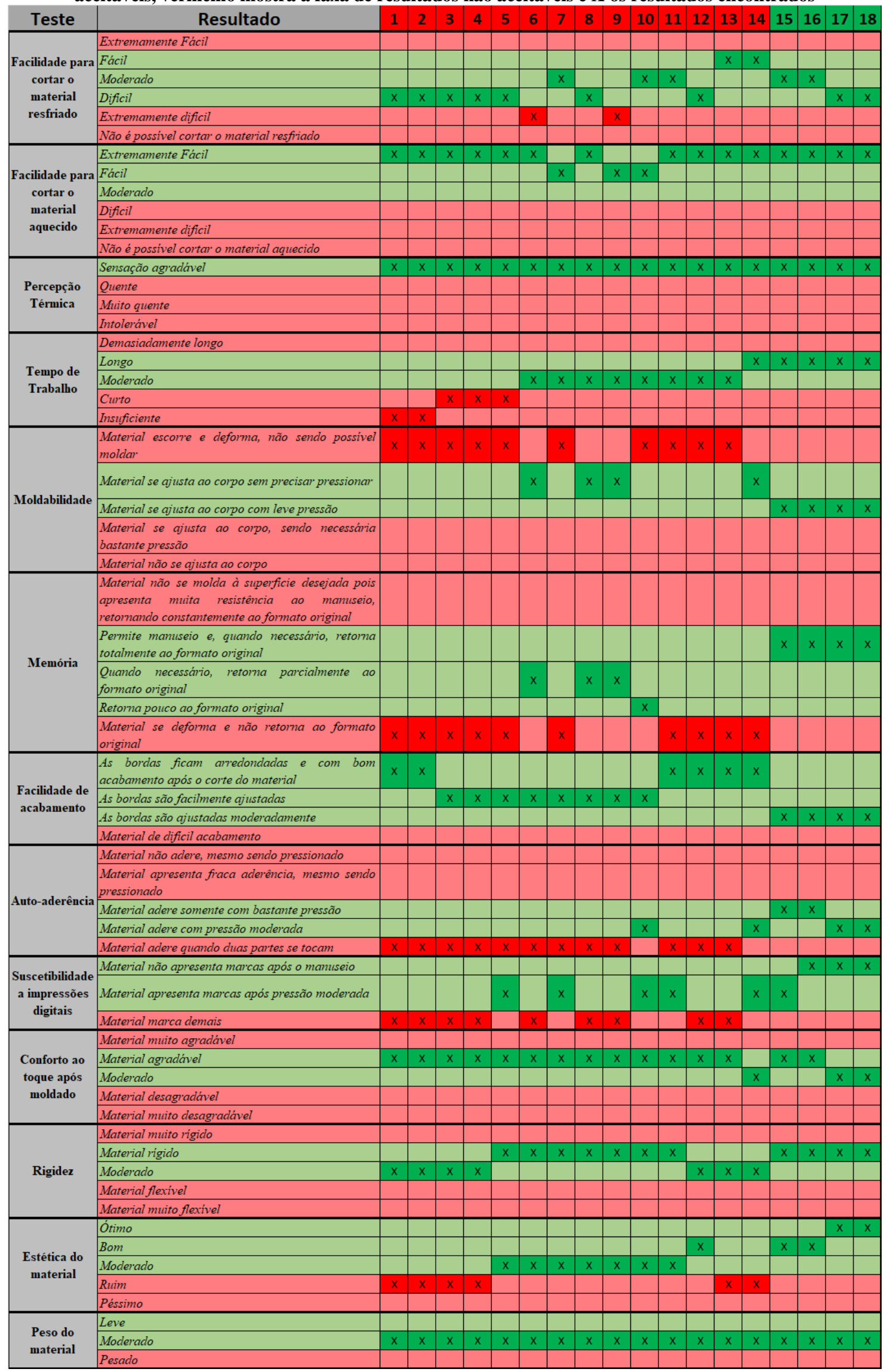

Fonte: elaborada pela autora 
Verifica-se que os itens selecionados para o roteiro de testes empíricos foram satisfatórios para direcionar o processo de desenvolvimento de novos materiais termoplásticos para órteses.

\subsection{6 $6^{\mathrm{a}}$ etapa - Seleção e produção de dois materiais para a Fase Experimental}

Visando a obtenção de amostras com melhor qualidade, os três materiais considerados viáveis (amostras 15, 16 e 17) foram processados novamente, por meio de Extrusão e Injeção, dois tipos de processamento diferentes dos adotados anteriormente.

A Extrusão é uma técnica de processamento contínuo empregada para a fabricação de produtos, na forma de perfis, e para a obtenção de grânulos de composições poliméricas, que posteriormente são transformadas em produtos por outros processos, como por exemplo a Moldagem por Injeção.

A Extrusão foi adotada para a produção de grânulos das composições. Foi utilizada a Extrusora Dupla Rosca corrotacional, modular, modelo DRC 30:40 IF (diâmetro de rosca de 30mm e razão L/D correspondente a 40), IMACOM, mostrada na Figura 17. O perfil das roscas foi montado para a produção de polímeros modificados com fibras de reforço, cargas minerais e pigmentos inorgânicos.

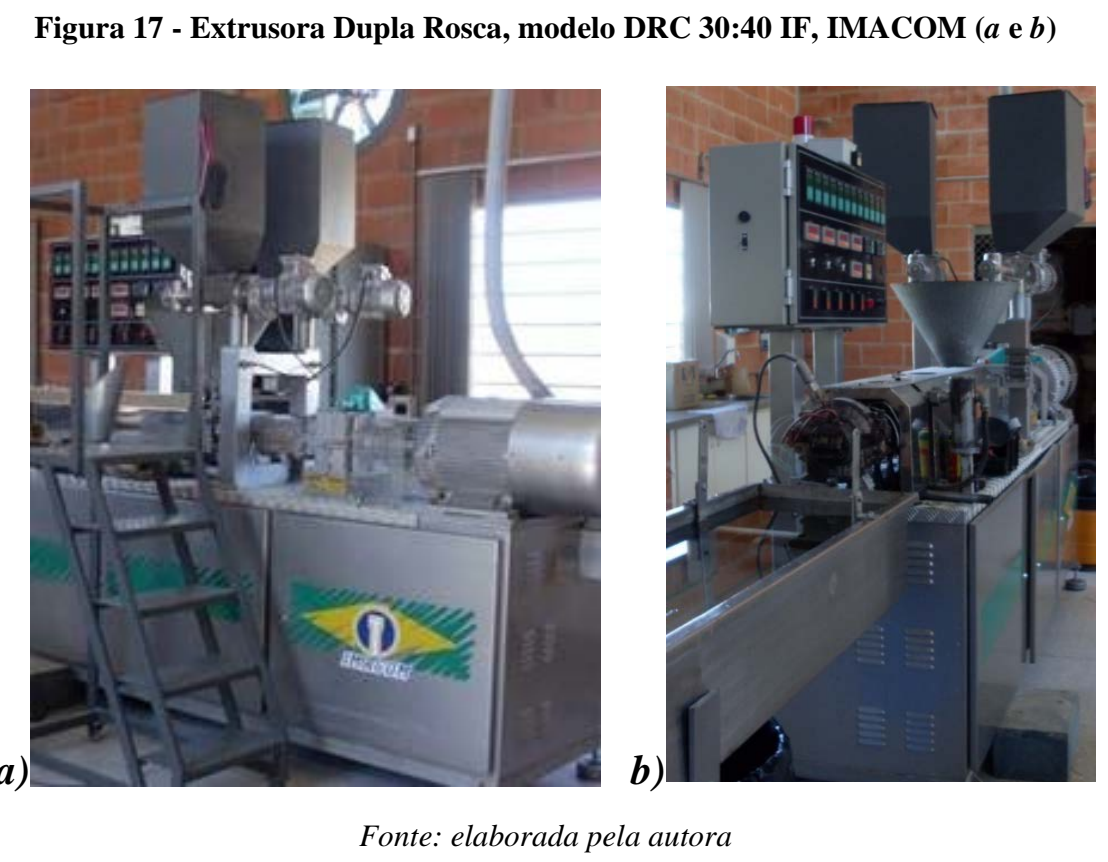


As placas dos três materiais foram injetadas na Injetora, modelo Pratica 130, ROMI, mostrada na Figura 18. Para cada produto foram injetadas placas, com as seguintes dimensões: $16,3 \mathrm{~cm}$ de comprimento, $12,2 \mathrm{~cm}$ de largura e espessura de $3,2 \mathrm{~mm}$.

Figura 18 - Injetora, modelo Prática 130, ROMI

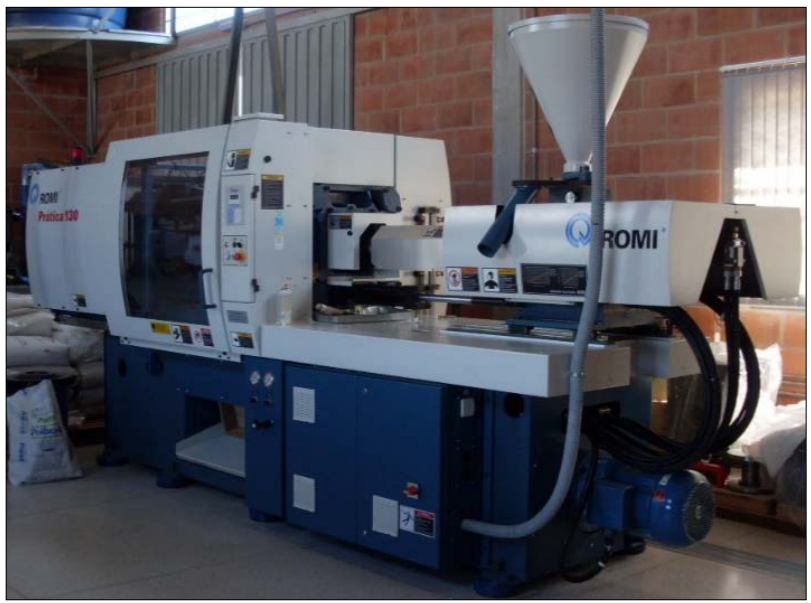

Fonte: elaborada pela autora

As condições de Extrusão e de Injeção foram definidas pelos técnicos do Laboratório de Polímeros do DEMa - UFSCar. A injetora e os moldes de placas (considerando as configurações dos canais de injeção) não eram os mais adequados para o trabalho em questão, mas foram utilizados pois eram os que estavam disponíveis. Devido a limitações na quantidade de matérias-primas, não foi possível uma investigação detalhada dos parâmetros de injeção, o que fez com que as placas obtidas apresentassem, após o primeiro aquecimento, deformações e contrações anisotrópicas e levou as amostras a apresentarem uma característica rugosa após o aquecimento.

Independentemente dessas dificuldades, esse novo processo propiciou a obtenção de amostras homogêneas e com mistura uniforme. Os três materiais, a partir das placas produzidas por injeção, foram analisados através dos testes empíricos já descritos e foram selecionados dois deles: os materiais 15 e 17, respectivamente denominados, para a Fase Experimental, como Material A e Material B, dos quais foram produzidas aproximadamente 50 placas de cada.

Os testes preliminares realizados e o empirismo que conduziu os ajustes na formulação reforçaram a necessidade de ensaios normatizados e de uma padronização dos manuseios realizados na prática clínica, especialmente diante da necessidade de quantificar as propriedades, visando uma comparação objetiva entre materiais diferentes, e/ou para fins de pesquisa. 


\subsection{7 $7^{\text {a }}$ etapa - Criação do instrumento de avaliação "Manuseio Padronizado de Materiais Termoplásticos para Órteses (MPMTO)”}

Para que os materiais, sejam eles comerciais ou desenvolvidos pela pesquisa, pudessem ser avaliados não apenas de forma empírica, mas com critérios definidos e de forma padronizada, foi elaborado um instrumento específico para termoplásticos de baixa temperatura, denominado como "Manuseio Padronizado de Materiais Termoplásticos para Órteses” (MPMTO). Ele contém a padronização de testes práticos a serem realizados com os dois materiais desenvolvidos selecionados e com dois materiais comerciais, a fim de testar e mensurar os requisitos apresentados nas matrizes, comparando-os.

A elaboração do instrumento e dos procedimentos realizados seguiu três passos: 1) Planejamento e determinação de parâmetros técnicos; 2) Seleção dos ensaios normatizados que compõem o protocolo; 3) Desenvolvimento e criação dos sistemas de ensaio.

\subsubsection{Planejamento e determinação de parâmetros técnicos}

Inicialmente foram realizadas reuniões da equipe de Terapia Ocupacional em conjunto com a Engenharia de Materiais para a troca de experiências em relação às propriedades dos materiais termoplásticos e respectivos ensaios já existentes, a fim de planejar a elaboração de um instrumento que fosse voltado para a análise de algumas características dos materiais (consideradas mais importantes pelos pesquisadores), mas levando em conta as especificidades necessárias para a aplicação destes materiais na confecção de órteses principalmente para os membros superiores.

O protocolo apresenta cinco seções, sendo que cada uma delas corresponde a uma propriedade a ser testada nos materiais termoplásticos de baixa temperatura, de acordo com os requisitos determinados na matriz. Foram então estabelecidas as definições técnicas adotadas como referência para o instrumento, embasadas na literatura, e foram determinadas as principais considerações de cada uma para a aplicação em órteses.

\subsubsection{Seleção dos ensaios normatizados}

Após a verificação das definições técnicas e das principais considerações para a aplicação em órteses, adotadas para a elaboração do instrumento de avaliação, foi feito um levantamento de ensaios existentes para testar essas propriedades nos materiais e que atendessem minimamente as exigências da prática clínica. 
Foram selecionados quatro ensaios normatizados:

- Calorimetria Exploratória Diferencial - DSC (ASTM D3418, 2015);

- Temperatura de Amolecimento Vicat (ASTM D1525, 2017b);

- Ensaio de Tração (ASTM D638, 2014a);

- Ensaio de Flexão (ASTM D790, 2017a).

Os ensaios selecionados atendem algumas exigências para a confecção de órteses e foram incorporados na avaliação de três itens do protocolo: Temperatura de Trabalho (DSC e Temperatura de Amolecimento Vicat) e os demais respectivamente para Autoaderência e Rigidez. Mesmo com a seleção dos ensaios, houve a necessidade de criar procedimentos e/ou parâmetros específicos para a avaliação final de cada item, a fim de direcionar a avaliação dos materiais para a finalidade que se deseja.

Apesar da existência de outros ensaios normatizados, identificou-se que eles não correspondem exatamente aos manuseios realizados durante o processo de confecção de órteses e optou-se por criar ensaios específicos para as propriedades de moldabilidade, memória e autoaderência.

\subsubsection{Desenvolvimento e criação dos sistemas de ensaio}

Utilizando a expertise do grupo de pesquisa, foram criados ensaios e procedimentos padronizados, de forma a simular os manuseios realizados na prática clínica com os materiais termoplásticos e possibilitar medidas reprodutíveis e objetivas em relação a moldabilidade, memória e autoaderência, visando assim a comparação entre materiais e sua replicação. Para compor a avaliação destas três propriedades, portanto, foi necessária a criação de sistemas de ensaio, com peças projetadas especificamente para os ensaios elaborados.

Foram criados três sistemas de ensaio (A, B e C), sendo que todos os componentes foram projetados através do sistema CAD (Computer Aided Design), com o propósito dos ensaios serem reprodutíveis.

Os sistemas A e B correspondem a dois parâmetros diferentes para se avaliar os materiais quanto à Moldabilidade: o sistema A tem a finalidade de avaliar a moldagem do material com aplicação de força e verificar a conformação do material ao objeto, enquanto o sistema B avalia o caimento do material à superfície em que for depositado, com a ação do próprio peso. Embora o propósito inicial de criação destes dois sistemas tenha sido avaliar a Moldabilidade, houve um planejamento para que o sistema A também pudesse ser utilizado para a padronização do teste de Memória. 
As peças dos sistemas A e B foram manufaturadas utilizando a impressão 3D, pelo processo de Fused Deposition Modeling (FDM), no equipamento Dimension ELITE 3D Stratasys ${ }^{\circledR}$, com o material ABS (P430-RP) e com o Software CatalystEX.

O sistema C compõe o ensaio de Autoaderência e foi construído basicamente de madeira, com alguns componentes metálicos.

Após a produção destes sistemas, foi feito um estudo de pré-teste dos três itens que contêm ensaios inéditos (Moldabilidade, Memória e Autoaderência), através do qual foram determinados: todos os materiais e equipamentos a serem utilizados; o tamanho da amostra dos materiais a ser testada em cada item; o tempo de permanência na água; o cálculo do peso do objeto esférico a ser aplicado no teste de moldabilidade; o cálculo da pressão a ser aplicada no teste de aderência; e a referência correta para as medidas a serem realizadas durante os testes. O pré-teste também possibilitou identificar a necessidade de algumas modificações nos sistemas de ensaios e os projetos de cada item foram ajustados e testados novamente, sendo que a versão final dos sistemas está apresentada a seguir.

Sistema de ensaio A: composto por peças que se encaixam e formam um suporte para receber e fixar o material a ser testado, sendo que o componente que recebe diretamente o material consiste em uma base plana, com um orifício central de $8 \mathrm{~cm}$ de diâmetro (Figura 19). Além disso compõem este sistema uma peça superior para o fechamento, com guia para manter o objeto centralizado no orifício, e um objeto que tenha formato esférico em pelo menos uma das extremidades, com 2 polegadas de diâmetro (aproximadamente $5 \mathrm{~cm}$ ), pesando $300 \mathrm{~g}$ (Figura 20).

Figura 19 - Sistema A, projetado para os Ensaios de Moldabilidade (quesito Conformação) e de Memória: a) ainda sem a amostra inserida e $b$ ) com a amostra inserida.

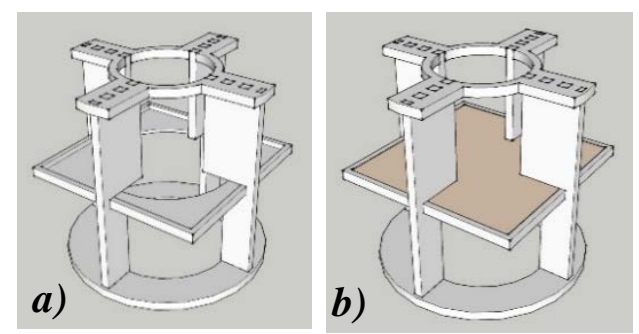

Fonte: elaborada pela autora 
Figura 20 - Objeto esférico a ser usado no Sistema A, para o Ensaio de Moldabilidade (Conformação)

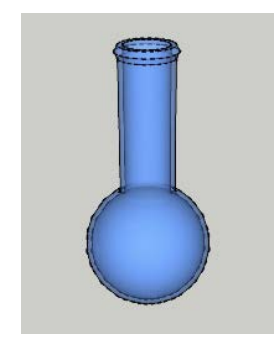

Fonte: elaborada pela autora

A massa de 300 gramas foi dimensionada baseando-se no material mais utilizado no mercado nacional, o qual provocava uma deformação de aproximadamente metade da área útil de medida (60mm), possibilitando, portanto, medidas comparativas inferiores e superiores ao mesmo.

Sistema de ensaio B: composto por um suporte com formato cilíndrico superiormente, medindo $5 \mathrm{~cm}$ de diâmetro e $10 \mathrm{~cm}$ de comprimento, com pinos ou pregos nas extremidades (Figura 21).

Figura 21 - Desenho esquemático do Sistema B, montado para o Ensaio de Moldabilidade (quesito caimento). A placa está fixada e centralizada por meio de dois pinos

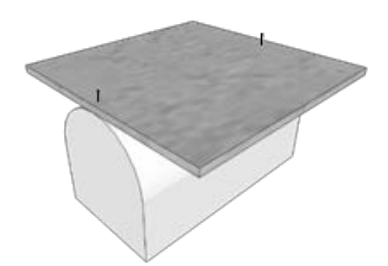

Fonte: elaborada pela autora

Sistema de ensaio C: consiste em um peso ajustável, com suportes para mantê-lo na vertical e paralelo ao plano de aplicação, além de uma plataforma e alavancas para possibilitar suspender e abaixar controladamente o mesmo (Figura 22).

Figura 22 - Sistema C - Projetado para compor o Ensaio de Autoaderência

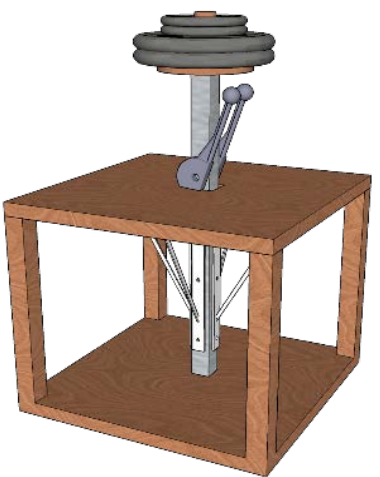

Fonte: elaborada pela autora 


\subsubsection{Versão final do instrumento MPMTO}

A versão final do MPMTO possibilita a avaliação padronizada e com métricas precisas quanto a propriedades importantes para a aplicação clínica (Temperatura de Trabalho, Moldabilidade, Memória, Autoaderência e Rigidez) e, ao mesmo tempo, possibilita sua replicação.

Ao simular as exigências da prática clínica, o protocolo padronizou testes práticos que normalmente são realizados por profissionais da área da saúde, estabelecendo critérios para: manuseio, medidas e resultados. Os testes desenvolvidos e os sistemas de ensaio construídos para avaliar a Moldabilidade, a Memória e a Autoaderência representam uma significativa evolução no que diz respeito à comparação entre materiais, possibilitando quantificar essas propriedades.

Além disso, os testes normatizados selecionados para compor o instrumento nos itens de Temperatura de Trabalho, Autoaderência e Rigidez, são métodos padronizados e reconhecidos para verificar, respectivamente, as características de amolecimento térmico de termoplásticos, a força de adesão de duas superfícies do material e a resistência do material a deformações.

Se por um lado o Roteiro de Procedimentos de Testes Práticos Empíricos auxiliou na avaliação qualitativa dos materiais desenvolvidos nesta pesquisa, conduzindo o processo exploratório para a obtenção de novos termoplásticos, o instrumento MPMTO possibilitou quantificar as principais propriedades dos materiais e compará-los entre si.

Apresenta-se a seguir a versão final do instrumento, contendo os testes padronizados para cinco propriedades dos materiais, correspondentes aos requisitos listados nas matrizes: Temperatura de Trabalho, Moldabilidade, Memória, Autoaderência e Rigidez. Cada uma delas compõe um item de avaliação do protocolo, contendo as seguintes seções: definição técnica e parâmetros adotados para a aplicação em órteses, materiais e equipamentos utilizados e, por fim, a descrição do teste, com ilustrações.

Foi estabelecido um critério geral para a aplicação dos cinco itens do protocolo, que preconiza que todos os ensaios devem ser realizados em local climatizado, com controle de temperatura, de forma que todos os manuseios devem ocorrer a uma temperatura ambiente de $23^{\circ} \mathrm{C}$

Para melhor precisão dos dados, recomenda-se que cada teste seja realizado de três a cinco vezes, com amostras diferentes, para a obtenção de valores individuais e de um valor final que será o cálculo da média e considerando o desvio-padrão. 


\section{TEMPERATURA DE TRABALHO}

\section{Definição técnica adotada para o instrumento}

Nos processos de moldagem há uma faixa de temperatura de trabalho em que é possível a obtenção de um produto moldado. Esta faixa de temperatura depende do material, do seu formato inicial e do método de moldagem. Com base no aspecto estrutural, para um polímero termoplástico de baixa temperatura, pré-moldado na forma de placas, pode-se considerar que a faixa de temperatura para a moldagem manual tem como limite inferior à Temperatura de Fusão Cristalina $\left(\mathrm{T}_{\mathrm{m}}\right)$ do polímero base do produto e como limite superior em torno de $10^{\circ} \mathrm{C}$ acima desta $\mathrm{T}_{\mathrm{m}}$ (ANDRADE et al., 2001; CANEVAROLO, 2010).

\section{Parâmetros para o ensaio de TEMPERATURA DE TRABALHO}

Dentro do intervalo considerado na definição técnica, a Temperatura de Trabalho pode ser escolhida dependendo da espessura e do nível de detalhes (curvas e relevos anatômicos) necessários no produto moldado. O Produto Rolyan ${ }^{\circledR}$ Ezeform ${ }^{\mathrm{TM}}$, por exemplo, quando mantido por 1 minuto entre $70^{\circ} \mathrm{C}-75^{\circ} \mathrm{C}$ permite que o Tempo de Trabalho seja de aproximadamente 4 minutos, considerando placas de 3,2mm (PERFORMANCE HEALTH, 2018a).

Foram escolhidos para compor este protocolo os ensaios normatizados Calorimetria Exploratória Diferencial - DSC (ASTM, 2015), para identificação da Temperatura de Fusão Cristalina $\left(\mathrm{T}_{\mathrm{m}}\right)$ do polímero base de cada material que vai ser testado, e a Temperatura de Amolecimento Vicat (ASTM, 2017b). Deve-se eleger um dos ensaios para a obtenção da temperatura mínima para o manuseio, o que poderá ser definido de acordo com a disponibilidade de equipamentos e com as características estruturais do polímero base.

Conforme a definição e as considerações mencionadas, o protocolo MPMTO estabeleceu que a temperatura inicial de trabalho será de $5^{\circ} \mathrm{C}$ acima da Temperatura de Amolecimento Vicat e/ou a Temperatura de Fusão Cristalina ( $\left.\mathrm{T}_{\mathrm{m}}\right)$ e que a faixa de trabalho será de $10^{\circ} \mathrm{C}$. Portanto a faixa de temperatura de trabalho do material testado será o intervalo entre $5^{\circ} \mathrm{C}$ e $15^{\circ} \mathrm{C}$ acima da Temperatura de Amolecimento Vicat e/ou da Temperatura de Fusão Cristalina $\left(\mathrm{T}_{\mathrm{m}}\right)$.

Se houver possibilidade e ambos os ensaios sugeridos forem realizados, de maneira complementar, sugere-se considerar $5^{\circ} \mathrm{C}$ acima da Temperatura de Amolecimento Vicat como temperatura inicial de trabalho. 


\section{Materiais e equipamentos utilizados - DSC}

- 10mg do material a ser testado (cortados em pedaços de aproximadamente $1 \mathrm{~mm}^{3}$ );

- Cadinho descartável de alumínio para DSC;

- Analisador Térmico do tipo Calorímetro DSC.

\section{Materiais e equipamentos utilizados - Temperatura de Amolecimento Vicat}

- Três amostras de material na medida sugerida de 13mm x 13mm (na espessura desejada);

- Medidor de Temperatura de Amolecimento Vicat.

\section{Descrição dos Ensaios}

DSC: Depositar, no cadinho de alumínio, 10mg do material cortado em pedaços de aproximadamente $1 \mathrm{~mm}^{3}$, e realizar o aquecimento com taxa de $20^{\circ} \mathrm{C} / \mathrm{min}$ (abrangendo uma faixa entre $23^{\circ} \mathrm{C}$ e $200^{\circ} \mathrm{C}$ ). São obtidas Curvas DSC nas quais é possível verificar a Temperatura de Fusão Cristalina $\left(\mathrm{T}_{\mathrm{m}}\right)$ do termoplástico de baixa temperatura.

Temperatura de Amolecimento Vicat: O procedimento consiste em um banho de óleo inerte, tendo controle sensível da temperatura e contendo um penetrador na forma de uma agulha fina, montado de forma a permitir o registro do grau de penetração através de um relógio apalpador de precisão. No procedimento deste ensaio, a agulha, cuja área mede $1 \mathrm{~mm}^{2}$, atua com uma carga de $10 \mathrm{~N}$ sobre a amostra, sendo que a temperatura do banho de óleo aumenta a uma taxa de $50^{\circ} \mathrm{C} / \mathrm{h}$. A temperatura na qual a agulha penetra $1 \mathrm{~mm}$ é definida como Temperatura de Amolecimento Vicat.

\section{MOLDABILIDADE}

\section{Definição técnica adotada para o instrumento}

Característica estrutural de um material que permite a sua moldagem em produtos com diferentes dimensões e geometrias, ajustando-se à região na qual se aplica, com boa distribuição de pressão. A moldagem, que normalmente ocorre com o emprego de temperatura e/ou pressão, pode ser realizada por processos manuais ou com a utilização de equipamentos de moldagem (MANO, 1991; MANO; MENDES, 1999; SOUZA; ALMEIDA, 2015).

\section{Parâmetros para o ensaio de MOLDABILIDADE}

Considerando a aplicação para a confecção de órteses, um material com moldabilidade excelente é aquele que apresenta fácil manuseio e fornece um acabamento satisfatório do produto moldado (órtese), ajustando-se à região do corpo que se pretende imobilizar e possibilitando acomodação de curvas e relevos anatômicos. 
Foram elaborados dois ensaios para compor a Moldabilidade, a partir de dois parâmetros diferentes: um denominado de Conformação (utilizando o sistema de ensaio A) e outro denominado Caimento (utilizando o sistema de ensaio B). No quesito Conformação será verificada a moldabilidade do material com a aplicação de força, por meio de um objeto esférico, a fim de simular a pressão depositada pelo terapeuta sobre o material durante a confecção da órtese e verificar a conformação do material ao objeto. No quesito Caimento não será aplicada nenhuma força externa e será verificado o comportamento do material apenas com a ação da gravidade, em uma superfície cilíndrica.

Os dois ensaios criados para a avaliação da Moldabilidade (A e B) precisam ser realizados na Temperatura de Trabalho do material e, portanto, a moldagem ocorrerá em imersão na água, sendo que o material deverá permanecer durante 5 minutos em banho termostático. As medidas estabelecidas devem ser realizadas antes de cada sistema ser depositado na água, para a obtenção dos valores de referência para os ensaios de Moldabilidade e de Memória, e após a moldagem do material, quando já estiver resfriado. A diferença entre a medida inicial e a medida final determina a moldagem do material em cada sistema de ensaio.

\section{Materiais e equipamentos utilizados}

- Sistemas de ensaio A e B;

- Dez corpos de prova do material a ser testado, medindo $10 \mathrm{~cm}$ x $10 \mathrm{~cm}$ (cinco para cada sistema de ensaio);

- Um objeto com formato esférico em pelo menos uma das extremidades, com 2 polegadas de diâmetro (aproximadamente $5 \mathrm{~cm}$ ), com superfície antiaderente e pesando 300g;

- Reservatório de água “Banho Termostático”, com regulagem de temperatura;

- Instrumento de medição adequado (paquímetro);

- Termômetro infravermelho.

\section{Descrição do ensaio A - Moldabilidade com aplicação de força (Conformação)}

O material (amostra medindo $10 \mathrm{~cm}$ x 10cm) deve ser colocado no sistema e as medidas iniciais devem ser realizadas no centro do material, pois será o ponto de maior deformação. Conforme o esquema da Figura 23, para este ensaio padronizou-se utilizar sobre o sistema um aparato (por exemplo uma barra de alumínio), possibilitando a medida deste até o centro do material acoplado. 
Figura 23 - Padronização da medida de referência para o ensaio de Conformação

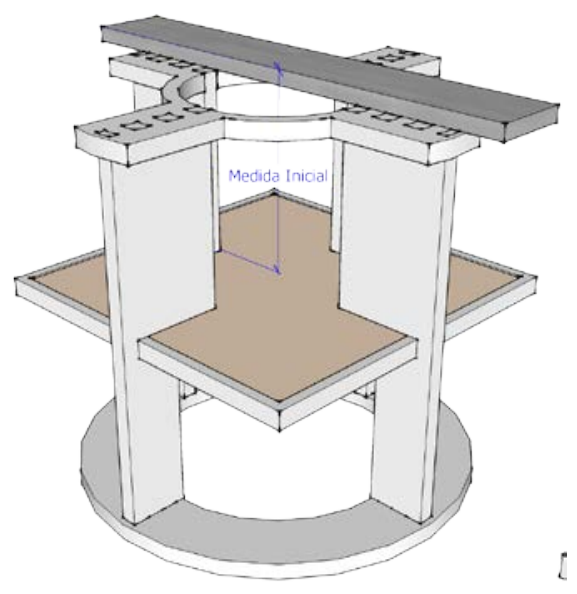

Fonte: elaborada pela autora

O material termoplástico deve ser acoplado no sistema correspondente (Figura 24-a) e este deve ser depositado na água, ao mesmo tempo em que o objeto esférico com massa de $300 \mathrm{~g}$ (Figura 24-b). Ambos devem permanecer separadamente na água, por 5 minutos (Figura 24-c), para que então o objeto seja depositado sobre a amostra, através da guia de centralização, de forma a ficar posicionado ao centro do orifício e com a extremidade esférica e antiaderente do objeto em contato com o material termoplástico (Figura 24-d).

Figura 24 - Procedimentos iniciais do ensaio de Conformação: a) amostra inserida no sistema A, b) peso, $c$ ) préaquecimento e $d$ ) peso inserido
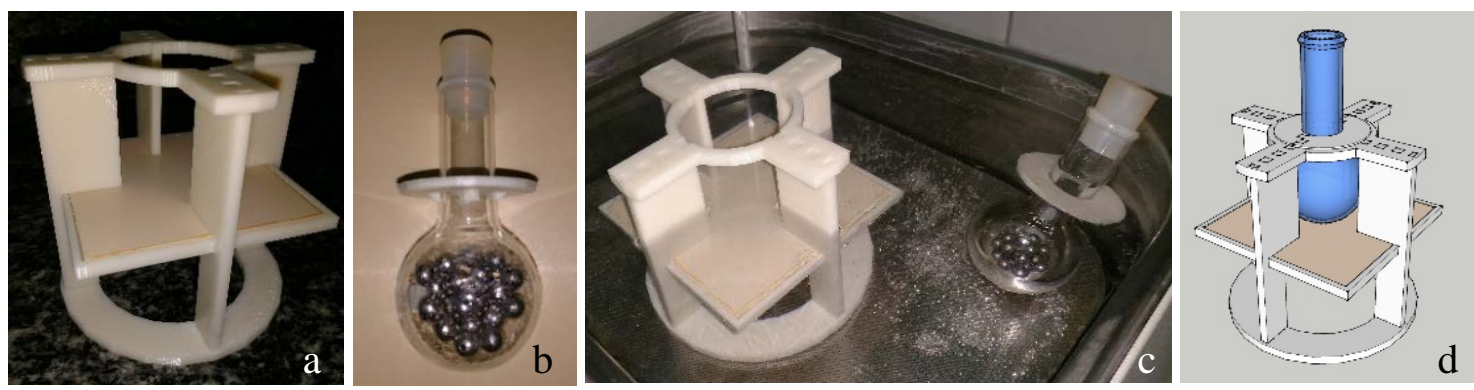

Fonte: elaborada pela autora

Todo esse sistema, agora completo, deve ficar dentro do reservatório de água aquecida (na Temperatura de Trabalho do material, definida no primeiro item deste protocolo) por 5 minutos cronometrados (Figura 25-a). Após a retirada da água, deve-se aguardar o resfriamento do material moldado, ainda com o objeto depositado, até a temperatura ambiente $\left(23^{\circ} \mathrm{C}\right)$, que pode ser verificada com auxílio de um termômetro infravermelho (Figura 25-b). Após o 
resfriamento, deve-se retirar o objeto esférico e realizar a medida final, posicionando-se o paquímetro ao centro, com auxílio de barra de alumínio apoiada sobre o suporte (Figura 25-c).

Figura 25 - Sequência final de procedimentos para o ensaio de Conformação (sistema A): peso inserido (a), remoção para resfriamento (b) e medição (c)
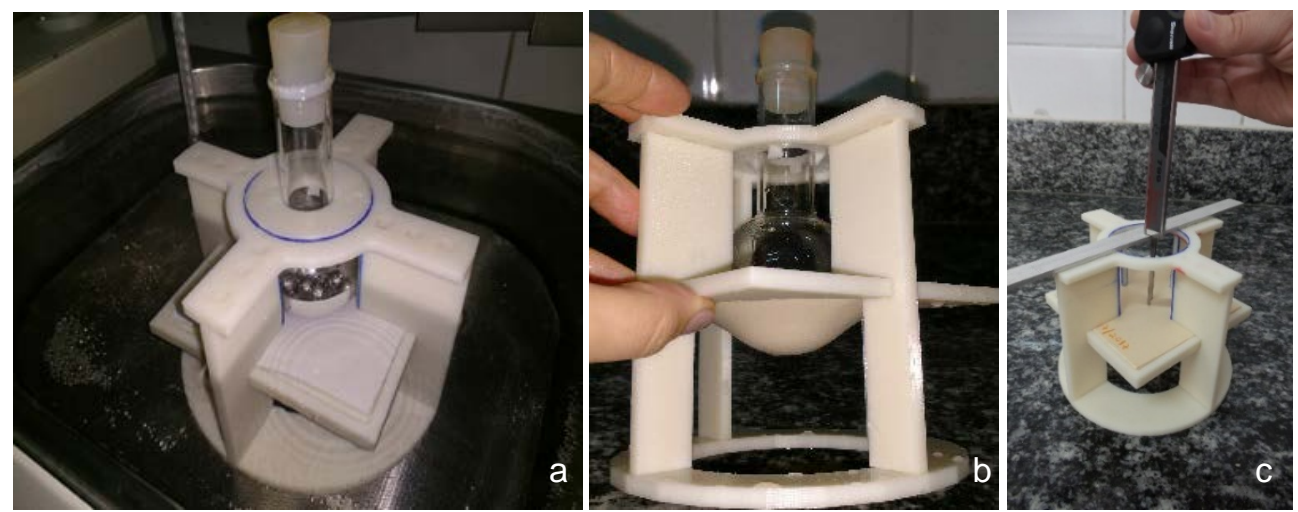

Fonte: elaborada pela autora

Ressalta-se que a medida de deformação deve ser realizada no material resfriado e moldado, ainda fixado no suporte, utilizando-se o mesmo procedimento da medida inicial. A Moldabilidade de um material poderá ser expressa, portanto, pela diferença entre a medida inicial e a medida final ou medida de deformação, sendo que o esquema da Figura 26 ilustra a sequência entre elas. Materiais com boa moldabilidade apresentam diferenças maiores entre as medidas inicial e final.

Figura 26 - Esquema para a sequência de etapas do sistema A (Conformação), com medidas as serem realizadas: medida inicial ( $a$ ), inserção do peso (b), amostra conformada pelo peso (c) e medida deformada (d)

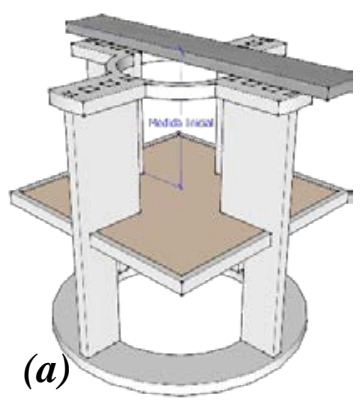

(b)

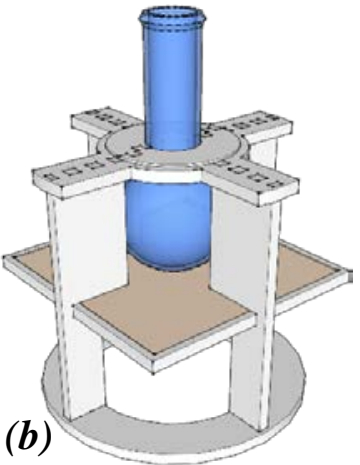

(c)

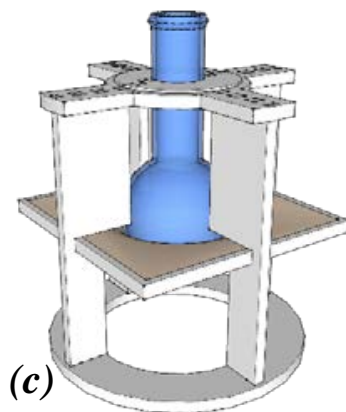

(d)

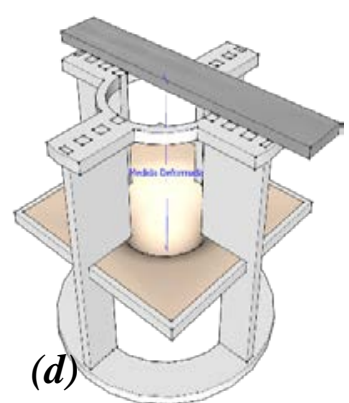

Fonte: elaborada pela autora

Nos testes de Moldabilidade no quesito Conformação ficou estabelecido 0\% para os casos em que não existir diferença entre a medida inicial e a medida deformada, e $100 \%$ de moldabilidade para os casos em que o material apresentar a diferença de 60mm (limite do instrumento). Conforme mencionado anteriormente, a massa de 300 gramas foi dimensionada 
baseando-se no material mais utilizado no mercado nacional, o qual provocava uma deformação de aproximadamente 30mm, que corresponde à metade da medida útil do equipamento.

\section{Descrição do ensaio B - Moldabilidade com ação do próprio peso (Caimento)}

O material deve ser fixado sobre a face cilíndrica do suporte, utilizando-se pinos ou pregos nas extremidades, a fim de que o material permaneça em contato com a base e centralizado. As medidas devem ser realizadas com o paquímetro, antes e após o ensaio, e, neste caso, correspondem à largura da placa, de uma extremidade a outra no sentido do caimento, tendo-se o esquema da Figura 27 como referência para a realização e quantificação do teste.

Figura 27 - Referência para as medidas do ensaio de Caimento (sistema B): $0 \%$ de caimento (a), uma porcentagem intermediária (b) e $100 \%$ de caimento (c).

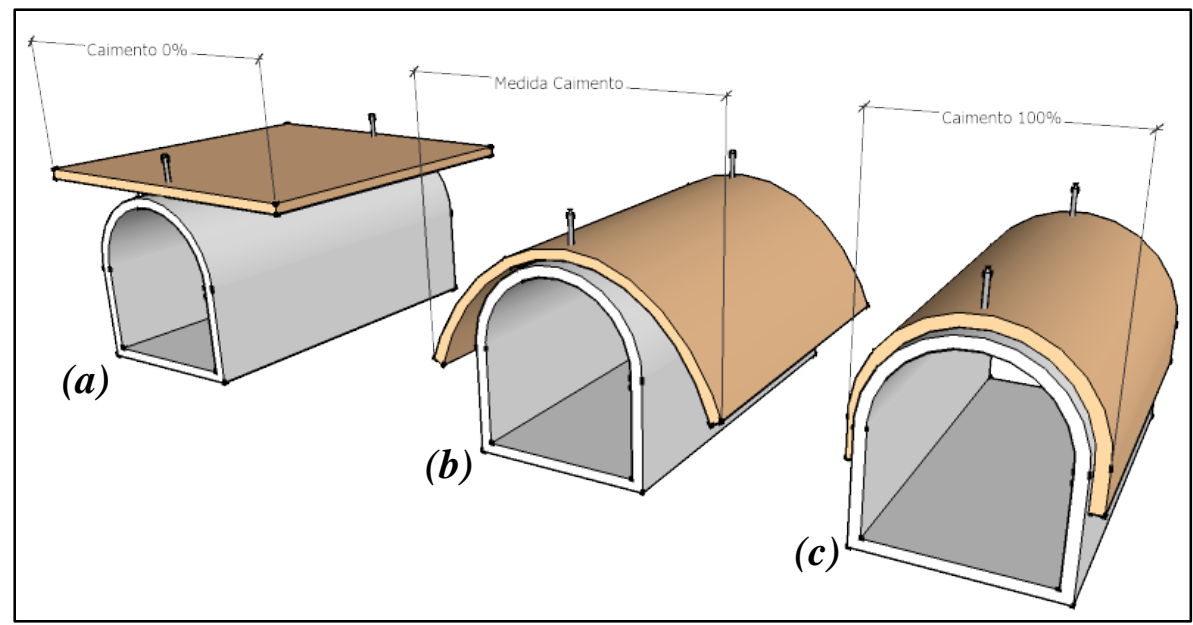

Fonte: elaborada pela autora

O sistema montado, com o material centralizado e fixado à base (Figura 28-a) deve ser imerso no reservatório de água aquecida (na temperatura de trabalho do material), no qual permanece por 5 minutos (Figura 28-b/c). Após a retirada da água, deve-se aguardar o caimento final do material e seu resfriamento até a temperatura ambiente $\left(23^{\circ} \mathrm{C}\right)$, conforme a Figura 28d, para que o material seja retirado do suporte e a medida de deformação seja realizada. A medida a ser realizada com o paquímetro é a largura da placa deformada sobre a superfície plana da mesa ou bancada (Figura 28-e), seguindo-se a referência 
Figura 28 - Uso do sistema de ensaio de Caimento: amostra fixada (a), inserção no banho aquecido (b), caimento dentro do banho aquecido $(c)$, retirada para resfriamento com continuação do caimento $(d)$ e medição $(e)$

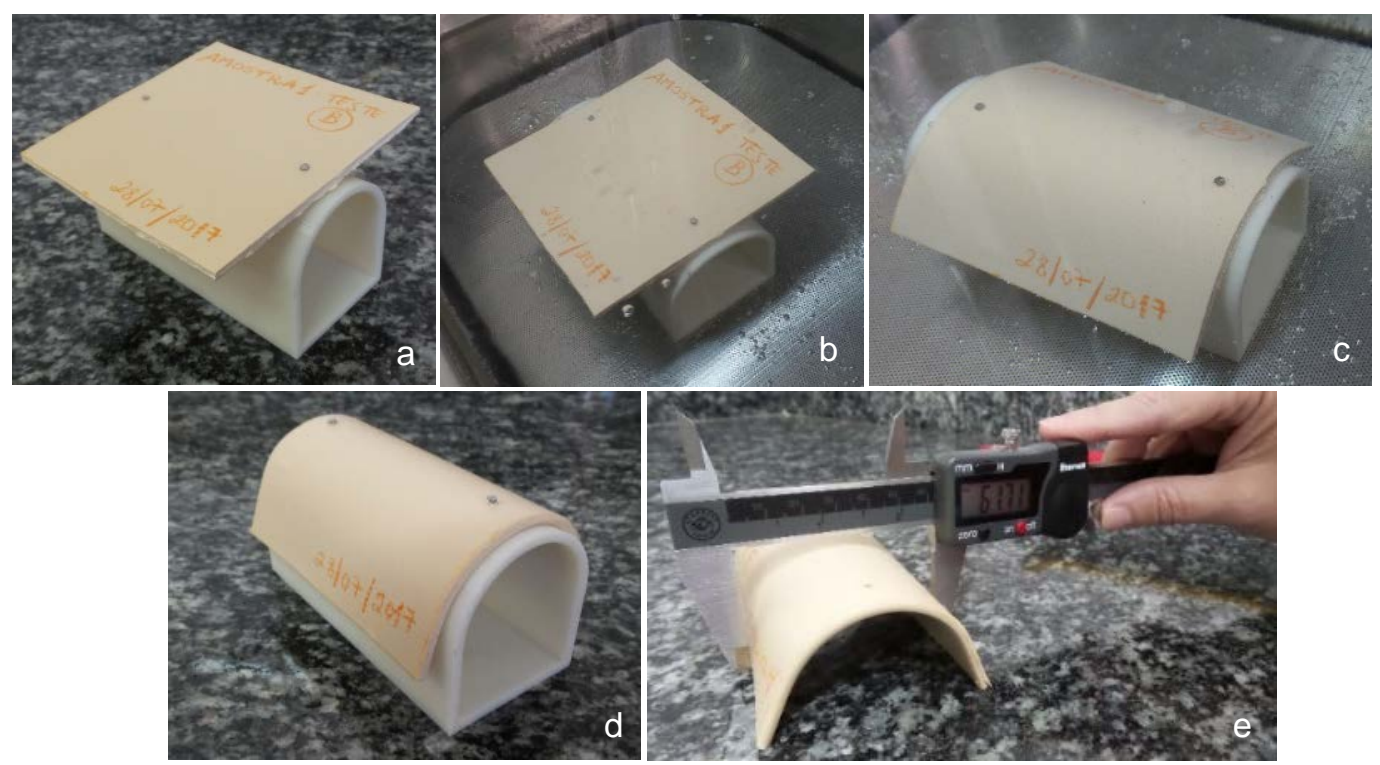

Fonte: elaborada pela autora

\section{MEMÓRIA}

\section{Definição técnica adotada para o instrumento}

A Memória de um produto polimérico é a tendência de permanência no formato inicial do material moldado, até uma certa temperatura. Para produtos moldados que apresentam efeito térmico de memória, a sua conformação pode ser modificada ao aquecer o material até a temperatura em que a história térmica da moldagem anterior seja destruída (BRETAS; D’ÁVILA, 2005; CANEVAROLO, 2010)

\section{Parâmetros para o ensaio de MEMÓRIA}

Um material que apresenta elevada memória, retornando ao seu tamanho e curvatura original, permite ajustes em uma órtese no ato da confecção, a fim de se atingir o posicionamento desejado, e possibilita o remodelamento ao longo do tempo, através de órteses seriadas.

Cabe ressaltar que uma melhor propriedade de memória está relacionada a uma menor deformação quando o material é reaquecido sem aplicação de força. Portanto, medidas mínimas ou próximas aos valores iniciais registrados no sistema significam pontuações mais altas para a propriedade de memória. 


\section{Materiais e equipamentos utilizados}

Para a avaliação da Memória, foi estabelecido pelo protocolo utilizar o material moldado através do ensaio A para Moldabilidade. Dessa forma, são necessários:

- Sistema de ensaio A;

- Reservatório de água "Banho Termostático", com regulagem e monitoramento de temperatura;

- Instrumento de medição adequado (paquímetro);

- Termômetro infravermelho.

\section{Descrição do ensaio}

O teste consiste em reaquecer o material moldado, ainda fixado no sistema A (mas sem o objeto esférico), e mensurar o seu retorno. O sistema A, com o material moldado acoplado, deve ser depositado no reservatório de água aquecida e permanecer imerso por 5 minutos. Após a retirada da água, aguarda-se o resfriamento do material até a temperatura ambiente $\left(23^{\circ} \mathrm{C}\right)$, o que pode ser verificado com o termômetro infravermelho, para que o mesmo procedimento de medida do ensaio seja realizado, registrando-se a altura entre o material e a parte superior do suporte, com auxílio de uma barra de alumínio, conforme o parâmetro estabelecido.

Como referência para o cálculo da porcentagem de recuperação (Memória) foi utilizada a medida da placa não deformada. Portanto, considera-se $100 \%$ de memória se o material retornar à medida inicial e 0\% se o material permanecer com a mesma medida de deformação. A Figura 29 mostra a medida inicial (a), a medida de deformação (b) e a medida final do ensaio de Memória, que corresponde à medida de recuperação (c). 
Figura 29 - Medidas a serem consideradas no ensaio de Memória: medição inicial (a), medida deformada (b) e medida de recuperação $(c)$
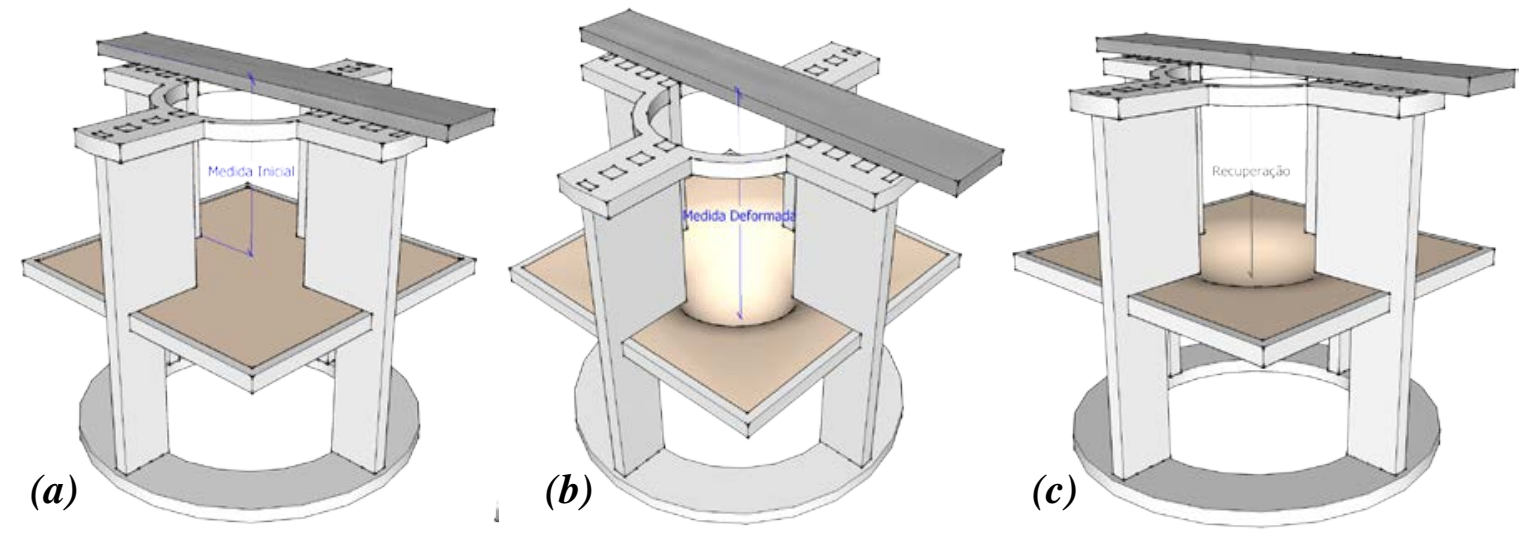

Fonte: elaborada pela autora

Comparando-se as medidas da Moldabilidade com as medidas realizadas após o reaquecimento do material, é possível quantificar a capacidade do material em retornar ao seu estado original.

\section{AUTOADERÊNCIA}

\section{Definição técnica adotada para o instrumento}

Definida como a propriedade de adesão de duas superfícies do material, que pode ser medida pela força de destacamento ou de descolamento destas superfícies (ANDRADE et al., 2001; MANO; MENDES, 1999).

\section{Parâmetros para o ensaio de AUTOADERÊNCIA}

Um material com boa capacidade de adesão facilita o processo de confecção, especialmente nos modelos em que é necessária a sobreposição de uma superfície sobre a outra. Além disso, o fato de duas superfícies aquecidas apresentarem autoaderência, quando pressionadas, favorece um bom acabamento, permitindo arredondamentos e dobras em algumas extremidades das órteses confeccionadas sob medida.

Com a finalidade de se determinar a força de autoaderência dos materiais, foi primeiramente estudada a pressão aproximada que um terapeuta aplica para unir duas partes de um termoplástico, resultando em uma pressão de $1,3 \mathrm{~kg} / \mathrm{cm}^{2}$. A partir do controle da massa a ser aplicada, foi criado um sistema de padronização para aderir duas partes do material e posteriormente mensurar a força de destacamento entre elas. Considerou-se que a Resistência da Adesão (ao destacamento) é a força média na região de escoamento dividida pela largura do corpo de prova $(3 \mathrm{~cm})$. 


\section{Materiais e equipamentos utilizados}

- Sistema C;

- Dez corpos de prova, medindo 3cm x 16cm (cada teste utiliza duas amostras);

- Uma folha de teflon;

- Reservatório de água “Banho Termostático”;

- Máquina Universal de Ensaios Mecânicos.

\section{Descrição do teste}

A primeira parte consiste em realizar a aderência de forma padronizada, iniciando pela imersão de duas amostras de material, medindo 3,0 cm x 10,0 cm x 0,32cm ( $\mathrm{L} \times \mathrm{C} \times \mathrm{A}$ ), no reservatório de água (na temperatura de trabalho do material). Após a retirada da água, deve-se realizar a secagem das amostras e colocá-las uma sobre a outra, de forma que apenas uma das extremidades do material fique em contato direto $(3,0 \mathrm{~cm} \times 3,0 \mathrm{~cm})$, sendo que o restante deve estar separado por uma lâmina antiaderente.

Conforme a Figura 30, os dois corpos de prova aquecidos devem ser unidos nas extremidades adjacentes, ao longo do comprimento, utilizando uma pressão de $1,3 \mathrm{~kg} / \mathrm{cm}^{2}$ (de acordo com o cálculo realizado e apresentado anteriormente), por um tempo de 10 segundos. O sistema de ensaio $C$ deve ser utilizado para depositar o peso na extremidade em que os materiais estiverem em contato. Após 10 segundos, deve-se retirar a pressão, remover a lâmina antiaderente e dispor as partes não aderidas em direções opostas, deixando-se resfriar e estabilizar, obtendo-se corpos de prova para o ensaio de aderência por destacamento ou arrancamento (peeling), com solicitação de tração. 
Figura 30 - Desenho esquemático da preparação de amostras para a aderência (a); amostras aderidas após a retirada da massa (b) e disposição final da amostra, preparando para o teste de tração (c)

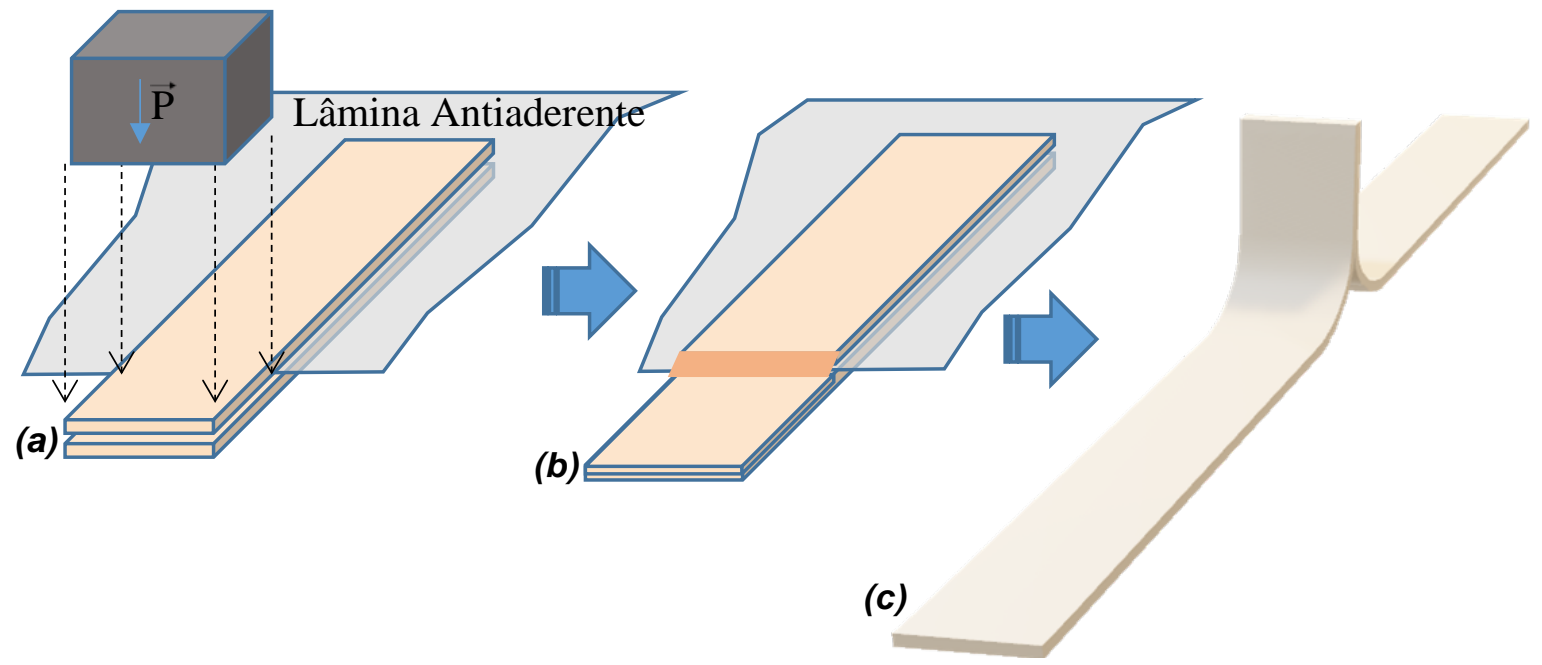

Fonte: elaborada pela autora

Após o resfriamento do material, as pontas livres devem ser fixadas em uma Máquina Universal de Ensaios para a aplicação de uma solicitação de tração (ASTM, 2014a).

Inicialmente foi executado um pré-teste com o produto Ezeform ${ }^{\mathrm{TM}}$, adotando velocidade de ensaio de $1 \mathrm{~mm} / \mathrm{min}$ e distância entre garras igual a $145 \mathrm{~mm}$. Nesta condição o ensaio foi muito longo. Foi necessário aumentar a velocidade do ensaio para $5 \mathrm{~mm} / \mathrm{min}$ (velocidade de ensaio especificada para plásticos rígidos, na ASTM D638), mantendo-se a distância entre garras de 145mm. Esta foi a condição padronizada para este ensaio, possibilitando o cálculo da Resistência da Adesão.

\section{RIGIDEZ}

\section{Definição técnica adotada para o instrumento}

De uma forma geral a rigidez de um material é uma propriedade medida pelo Módulo Elástico, expresso pela proporcionalidade entre a tensão mecânica aplicada e a deformação resultante, na região de deformação elástica, isto é, deformação reversível ou totalmente recuperada. A natureza da solicitação mecânica define o tipo de Módulo Elástico. Assim, quando houver o modo de deformação por flexão, calcula-se o Módulo de Elasticidade em Flexão, que é o critério internacional para a avaliação da Rigidez de um material (CANEVAROLO, 2010; MANO, 1991). 


\section{Parâmetros para o ensaio de RIGIDEZ}

Considerando o material resfriado em uma órtese que já foi moldada, sua rigidez é importante para conservar o posicionamento necessário. Algumas aplicações em órteses necessitam que o material seja resistente a deformações diante de uma força aplicada constantemente, principalmente quando o objetivo do dispositivo é alinhar, proteger e/ou imobilizar uma articulação, evitando deformidades, ou ainda nos casos de órteses seriadas com a finalidade de alongamento de tecidos e melhora da amplitude de movimento. Nos casos em que há espasticidade no segmento imobilizado, órteses confeccionadas com materiais mais rígidos possivelmente apresentam maior durabilidade.

Para a avaliação da rigidez este protocolo adota o Ensaio de Flexão (ASTM, 2017a), através do procedimento de flexão em três pontos, por ser esta uma das solicitações mais representativas das condições práticas do uso de órteses. Este ensaio mecânico possibilita a comparação quantitativa da Rigidez entre as amostras, avaliada pelo Módulo de Elasticidade em Flexão, cujo valor é empregado como critério mais importante para a avaliação da rigidez dos materiais poliméricos. Este protocolo estabelece como parâmetro para a aplicação em órteses, o valor da Tensão de Flexão a 5\% de deformação (MPa).

\section{Materiais e equipamentos utilizados}

- Máquina Universal de Ensaios;

- 5 amostras do material a ser testado, com as seguintes dimensões: $127 \mathrm{~mm}$ de comprimento, $12,7 \mathrm{~mm}$ de largura e $3,2 \mathrm{~mm}$ de espessura.

\section{Descrição do ensaio}

Realizar ensaio de flexão (ASTM, 2017a), adotando-se o procedimento de flexão em três pontos, com a aplicação de uma carga central sobre um corpo de prova suportado por dois apoios mantidos a uma distância $L(L=16$ x espessura, sendo igual a 51,2mm para um corpo de prova com espessura de 3,2mm) como mostra o desenho esquemático e foto do ensaio, respectivamente na Figura 31 e na Figura 32. 
Figura 31 - Desenho esquemático do ensaio de flexão em três pontos

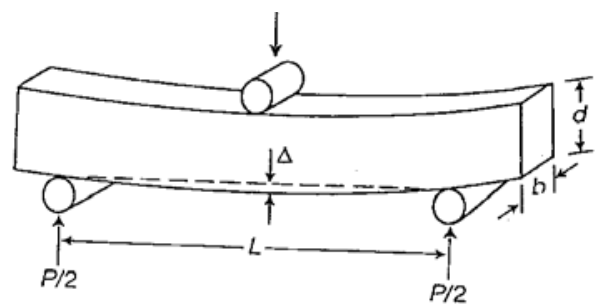

Fonte: Canevarolo (2004) baseado em ASTM (2017a)

Figura 32 - Foto do ensaio de flexão em três pontos

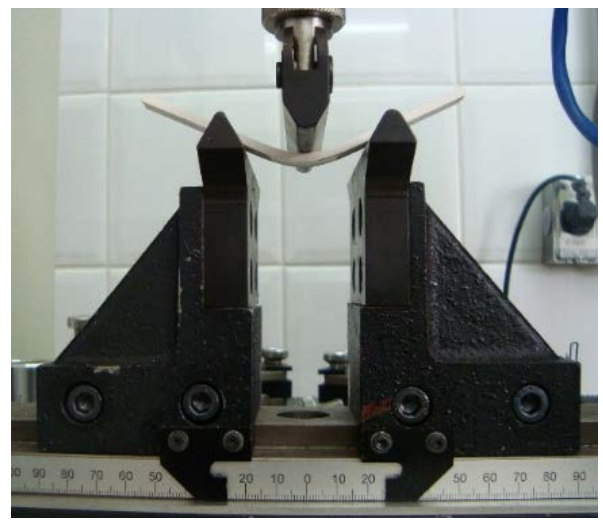

Fonte: elaborada pela autora

\subsection{FASE EXPERIMENTAL: APLICAÇÃO DO INSTRUMENTO MPMTO E AVALIAÇÃO DOS MATERIAIS DESENVOLVIDOS}

Para a fase experimental foram produzidas 50 placas de cada um dos dois materiais nacionais selecionados, medindo 16,3cm x 12,2cm x 3,2mm de espessura, sendo que uma parte delas foi utilizada para uma caracterização físico-mecânica dos materiais e outra parte foi avaliada por terapeutas que atuam na área de confecção de órteses.

A metodologia da Fase Experimental foi dividida em duas etapas principais:

$1^{\text {a }}$ etapa - Aplicação do Instrumento MPMTO para uma análise físico-mecânica aplicada e comparativa de quatro produtos com termoplásticos de baixa temperatura: dois disponíveis no mercado e dois produzidos por esta pesquisa;

$2^{\text {a }}$ etapa - Avaliação de dois materiais desenvolvidos, de acordo com critérios da prática clínica, por profissionais com experiência na área.

Após a execução dessas duas etapas, foi possível otimizar os materiais desenvolvidos e foi formulado e processado mais um material, identificado como material C. Este não foi testado pelos profissionais, uma vez que foi produzido após esta etapa do estudo e, quanto ao MPMTO, 
foi testado somente para a Moldabilidade e a Memória, sendo que os resultados serão apresentados junto com a análise dos materiais A e B.

\subsubsection{1a etapa - Aplicação do instrumento MPMTO: caracterização físico-mecânica}

O instrumento MPMTO foi aplicado, na íntegra, visando uma análise físico-mecânica de quatro materiais com termoplásticos de baixa temperatura:

- Dois materiais produzidos por esta pesquisa (A e B);

- Dois materiais disponíveis no mercado, utilizados em larga escala para a confecção de órteses para membros superiores, identificados pelas marcas registradas: Rolyan ${ }^{\circledR}$ Ezeform ${ }^{\mathrm{TM}}$, também utilizado na Fase Exploratória, e Rolyan® Aquaplast-T ${ }^{\mathrm{TM}}$, ambos fabricados pela Performance Health. Não foi possível manter a escolha pelo Solaris ${ }^{\mathrm{TM}}$ para a análise nesta fase do trabalho, devido a sua indisponibilidade no mercado nacional. Diante disso, optou-se pelo Rolyan ${ }^{\circledR}$ Aquaplast-T ${ }^{\mathrm{TM}}$, por ser do mesmo fabricante que o Rolyan ${ }^{\circledR}$ Ezeform ${ }^{\mathrm{TM}}$, facilitando a comparação das informações técnicas e análise dos resultados.

Conforme apresentado nos materiais e métodos, o MPMTO propõe cinco itens de avaliação, correspondentes a cinco propriedades dos materiais: 1) Temperatura de Trabalho; 2) Moldabilidade; 3) Memória; 4) Autoaderência; 5) Rigidez. Ele traz, em sua composição, quatro ensaios normatizados (DSC, Temperatura de Amolecimento Vicat, Ensaio de Autoaderência e Ensaio de Flexão) e outros três ensaios que foram originalmente elaborados para simular algumas exigências da prática clínica, fornecendo uma análise físico-mecânica mais aplicada ao contexto da confecção de órteses e possibilitando a comparação entre os materiais.

Seguiram-se os critérios e procedimentos descritos nos cinco itens do instrumento e os corpos de prova dos quatro materiais foram preparados previamente, de acordo com o tamanho previsto para cada teste, sendo utilizadas placas lisas com espessura de 3,2 mm.

Para os ensaios normatizados, seguem os equipamentos utilizados neste trabalho, localizados no Laboratório de Polímeros do Departamento de Engenharia de Materiais da UFSCar:

- Calorimetria Exploratória Diferencial - DSC (ASTM D3418, 2015): Calorímetro Modulado DSC, modelo Q100, TA Instruments (Figura 5)

- Temperatura de Amolecimento Vicat (ASTM D1525, 2017b): Medidor de Temperatura HDT/VICAT, modelo HDT 6 Vicat P/N 6921, CEAST (Figura 33). 
Figura 33 - Medidor de Temperatura HDT/VICAT, modelo HDT 6 Vicat P/N 6921, CEAST

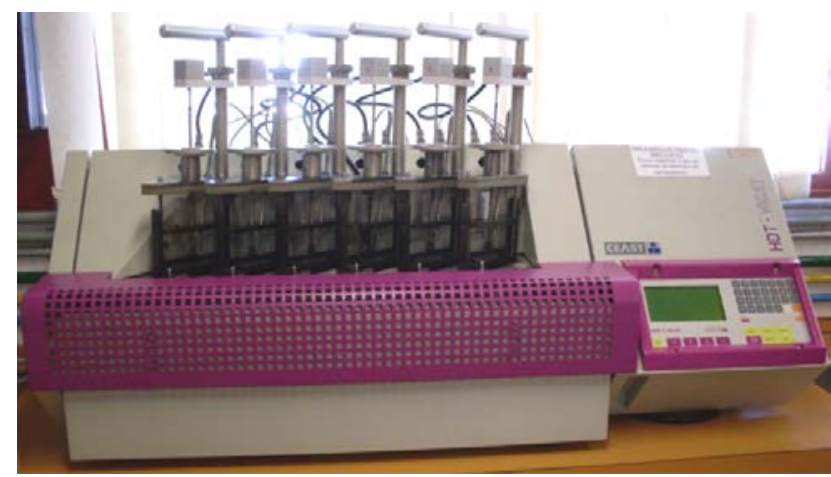

Fonte: elaborada pela autora

- Ensaio de Tração (ASTM D638, 2014a) e Ensaio de Flexão (ASTM D790, 2017a): Máquina Universal de Ensaios Mecânicos, modelo 5569, INSTRON (Figura 34).

Figura 34 - Máquina Universal de Ensaios Mecânicos, modelo 5569, INSTRON

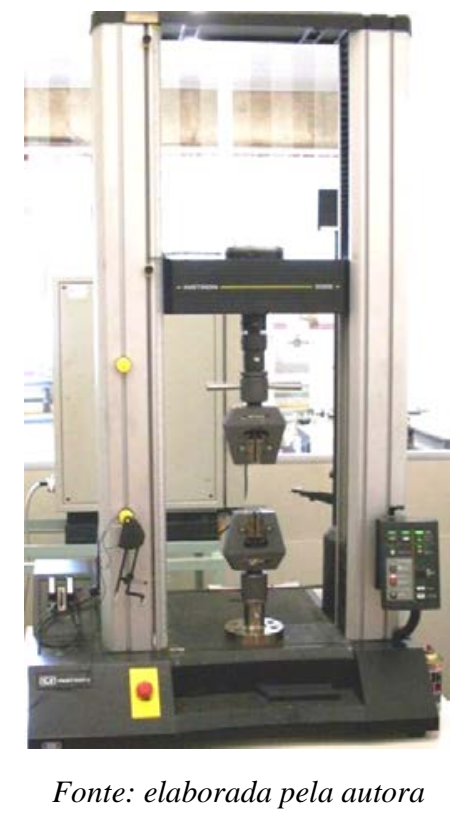

Além da aplicação dos experimentos descritos no MPMTO, foi realizada a análise complementar por Termogravimetria - TG (ASTM E1131, 2014b), para a caracterização dos quatro materiais avaliados nessa fase, com metodologia semelhante à Fase Exploratória desta pesquisa. 


\subsection{2 $2^{\mathrm{a}}$ etapa - Avaliação de dois materiais desenvolvidos, de acordo com critérios da prática clínica, por profissionais com experiência na área}

Essa etapa envolveu a participação de profissionais com experiência em reabilitação da mão e do membro superior (terapeutas ocupacionais e fisioterapeutas) e que atuam com a prescrição e confecção de órteses para membros superiores no Brasil. Dessa forma, a pesquisa foi submetida ao Comitê de Ética do Hospital das Clínicas da Faculdade de Medicina de Ribeirão Preto, sendo aprovada sob o Parecer n¹.827.471 e o Certificado de Apresentação para Apreciação Ética (CAAE) nº61275016.7.0000.5440, com data final de relatoria em 18 de novembro de 2016 (Anexo I). Os participantes assinaram um Termo de Consentimento Livre e Esclarecido (Apêndice II), contendo os objetivos do estudo, os riscos e benefícios.

Para que os Materiais A e B pudessem ser avaliados de acordo com critérios adotados na prática clínica, mais da metade das placas produzidas por injeção foi enviada e testada por terapeutas que apresentam experiência com o grupo de termoplásticos de baixa temperatura, sendo que a seleção dos participantes, os procedimentos adotados e os instrumentos elaborados para isso estão descritos a seguir.

\section{Participantes}

Foram convidados a participar da pesquisa profissionais com experiência em reabilitação da mão e do membro superior (terapeutas ocupacionais e fisioterapeutas) e que atuam com a prescrição e confecção de órteses para membros superiores no Brasil.

A técnica de amostragem não foi probabilística e não foi realizada por sorteio, sendo que a seleção dos participantes ficou a critério do pesquisador. Essa amostragem por conveniência, frequentemente utilizada para geração de ideias em pesquisas exploratórias, consiste em selecionar uma amostra da população que seja acessível e prontamente disponível para participar, proporcionando maior facilidade operacional.

Uma das principais fontes para a composição da amostra foi a Sociedade Brasileira de Terapeutas da Mão e do Membro Superior (SBTM), que congrega terapeutas ocupacionais e fisioterapeutas que atuam com reabilitação funcional da mão no país. Após consultar a lista da SBTM, foram contatados 20 associados. Outros 14 profissionais que não são associados também foram convidados, por estarem vinculados a universidades ou centros de reabilitação e por possuírem experiência com órteses na área de neurologia.

Para esta pesquisa foram escolhidos e convidados, portanto, 34 terapeutas no total, de acordo com o número de placas produzidas e considerando o interesse e disponibilidade dos terapeutas para realizarem os testes. 


\section{Critérios de Inclusão e Exclusão}

Como critérios de inclusão foi estabelecido: participantes com experiência na área de confecção de órteses de no mínimo 3 anos e que necessariamente utilizam os materiais termoplásticos de baixa temperatura para essa finalidade, o que foi informado no primeiro contato realizado por e-mail.

Como critérios de exclusão ficou determinado: profissionais que nunca trabalharam com materiais termoplásticos de baixa temperatura e que trabalham somente com outros tipos de materiais para órteses.

\section{Procedimentos}

Os profissionais foram contatados através de um e-mail contendo as principais informações sobre a pesquisa, os critérios de inclusão adotados e o convite para participarem. Na medida em que aceitaram, foram instruídos a confirmar seus dados, incluindo informações referentes aos critérios de inclusão, e a responderem uma pesquisa inicial através de um formulário eletrônico com informações sobre a confecção de órteses e sobre os materiais mais utilizados por eles atualmente na confecção de órteses para os membros superiores.

Durante esse levantamento inicial de informações, os participantes forneceram também o endereço atual para o envio das amostras de materiais desenvolvidos a serem testados. Os materiais eram enviados à medida em que os profissionais assinavam o TCLE e respondiam a Pesquisa Inicial sobre confecção de órteses.

Cada participante recebeu um kit de teste, contendo:

- Um guia de instruções impresso, contendo algumas recomendações e as condições para o teste prático a ser realizado com os materiais desenvolvidos;

- Duas amostras medindo 16,3cm x 12,2cm, com 3,2mm de espessura, uma de cada material, identificadas adequadamente como A e B. Estas foram separadas por uma folha de sulfite e envoltas com papelão, a fim de minimizar os riscos de danificar o material durante o transporte.

A maioria dos kits foi enviada pelo correio, para o endereço fornecido por cada terapeuta, após o aceite dos profissionais, e alguns kits foram entregues pessoalmente, a depender da localização ou do local de trabalho do participante.

Após o teste prático realizado com os materiais, focado na análise de suas propriedades, conforme as orientações fornecidas, e não envolvendo outros voluntários, os participantes responderam a outro formulário, também online, sobre a avaliação dos materiais propriamente dita. 


\section{Instrumentos utilizados}

Para a realização desta etapa da pesquisa foram elaborados três instrumentos, um deles para a orientação dos profissionais participantes quanto ao teste dos materiais e dois formulários voltados para a coleta de dados.

\section{Guia de Instruções para o Teste Prático de Materiais (Apêndice III)}

Este instrumento foi elaborado com o objetivo de fornecer recomendações e esclarecer sobre as condições do teste prático a ser realizado com os materiais desenvolvidos nesta pesquisa. Uma versão impressa do “Guia de Instruções para o Teste Prático de Materiais” foi enviada juntamente com os kits para teste, após o preenchimento do formulário para a Pesquisa Inicial sobre a confecção de órteses. Uma versão digital também foi enviada por e-mail.

Através deste guia os participantes foram orientados a aquecer os materiais utilizando água a uma temperatura na faixa de $70^{\circ} \mathrm{C}$ a $90^{\circ} \mathrm{C}$ e, para facilitar a comparação dos materiais desenvolvidos com os materiais comerciais, sugeriu-se que o profissional também realizasse os testes com o material que ele mais utiliza na prática clínica.

O teste teve ênfase na análise do material e, neste momento, não envolveu necessariamente usuários de órteses. O guia não estipula, portanto, um modelo de órtese a ser confeccionado, mas essa possibilidade foi sugerida, deixando o participante livre para confeccionar ou não uma órtese pequena, de um modelo a escolher, que fosse possível de acordo com o tamanho de cada amostra (16,3cm x 12,2cm, com 3,2mm de espessura). Exemplos de órteses que poderiam ser confeccionadas: canaleta para os dedos, órtese em “8”, órtese para abdução de polegar, órtese para dedo em gatilho, entre outras.

Embora estejam organizados de maneira diferente, o Guia de Instruções contém os mesmos itens apresentados no "Roteiro de Procedimentos de Testes Práticos Empíricos”, utilizado na Fase Exploratória da Pesquisa. Este guia enviado aos profissionais apresenta somente as definições e orientações relacionadas a estas características e não contém opções de resposta, sendo elaborado outro formulário específico para isso.

\section{Formulário para Pesquisa Inicial sobre Confecção de Órteses (Apêndice IV)}

Este foi o primeiro instrumento enviado aos participantes. Trata-se de um formulário eletrônico, elaborado através da plataforma Google Docs ${ }^{\circledR}$, sendo que o link foi enviado por email no primeiro contato realizado com os profissionais. O formulário continha inicialmente a apresentação do estudo, acompanhada pelo TCLE e, na medida em que os termos da pesquisa eram aceitos, o participante tinha acesso a questões sobre a confecção de órteses e os materiais mais utilizados na prática clínica. Além disso o instrumento também gerou informações sobre 
o perfil da amostra e sobre o endereço atual do terapeuta, visando o envio dos kits para o teste com os materiais.

\section{Formulário para Avaliação dos Materiais Termoplásticos (Apêndice V)}

Esse foi o instrumento elaborado, também através da plataforma Google Docs ${ }^{\circledR}$, para os participantes avaliarem os materiais termoplásticos desenvolvidos. Trata-se de um formulário eletrônico, disponível para ser respondido durante ou logo após o teste prático com as duas amostras (para que as percepções em relação aos materiais desenvolvidos sejam registradas, sem que as informações principais sejam perdidas).

O link para acessar o questionário foi enviado no endereço de e-mail registrado no preenchimento do formulário anterior, logo após o preenchimento deste, e o objetivo foi identificar a opinião e a satisfação do participante em relação aos materiais desenvolvidos, em comparação à marca e modelo que ele utiliza com mais frequência na prática clínica.

Várias questões do "Formulário para Avaliação dos Materiais Termoplásticos” foram organizadas a partir de uma abordagem de escala de classificação ou escala do tipo Likert. Nesta técnica de escalonamento não-comparativo e unidimensional, os participantes são convidados a indicar o seu nível de concordância com um determinado tema ou declaração dada por meio de uma escala ordinal (LIKERT, 1932). Dessa forma, utilizando opções de resposta de um extremo a outro, foi possível investigar níveis de opinião a respeito do material comercial que o participante normalmente mais utiliza e dos materiais desenvolvidos/testados, obtendo-se informações sobre algumas propriedades referidas na matriz de requisitos, das facilidades e dificuldades no manuseio e de outras características do processo de confecção das órteses. O questionário contém também campos destinados a comentários e opiniões dos profissionais, mais abrangentes e opcionais.

Ressalta-se que o instrumento investiga a opinião dos terapeutas sobre as propriedades e características dos materiais identificadas nos 14 itens selecionados para compor o "Roteiro de Procedimentos de Testes Práticos Empíricos” e definidos no guia de instruções, com opções de resposta padronizadas, de um extremo a outro, facilitando a análise dos dados. 


\section{RESULTADOS E DISCUSSÃO}

O caráter inovador desta pesquisa refere-se à criação de novos materiais termomoldáveis para órteses, desenvolvidos no Brasil, e também ao desenvolvimento de instrumentos padronizados de avaliação dos materiais para essa finalidade.

A Fase Exploratória resultou no desenvolvimento de novos materiais para moldagem direta no segmento do corpo do usuário, tendo como referência diversos termoplásticos de baixa temperatura, sendo este material o mais recomendado e utilizado atualmente para as órteses de membros superiores. Existem vários tipos de materiais deste grupo no mercado, porém todos importados, de forma que não existem termoplásticos de baixa temperatura nacionais, disponíveis comercialmente, destinados à confecção de órteses. Os dois instrumentos criados, denominados como "Roteiro de Procedimentos de Testes Práticos Empíricos” e “Manuseio Padronizado de Materiais Termoplásticos para Órteses”, foram necessários para a avaliação específica dos materiais e são resultados relevantes do estudo.

Na Fase Experimental foi possível colocar em prática os resultados gerados pela fase anterior, através do teste dos materiais desenvolvidos e da aplicação do principal instrumento de avaliação criado (MPMTO). O caminho metodológico, com critérios e procedimentos elaborados especificamente para isso, garantiu a qualidade desejada para a criação dos termoplásticos de baixa temperatura e sua comparação com materiais do mercado. Os instrumentos, assim como os sistemas de ensaio que foram desenvolvidos, poderão ser adotados por profissionais que trabalham na área e por outros pesquisadores que planejarem estudar os materiais para órteses.

Serão apresentados a seguir os resultados obtidos de maneira detalhada e na sequência da metodologia elaborada/adotada.

\subsection{ESTUDO DOS MATERIAIS EXISTENTES NO MERCADO (FASE EXPLORATÓRIA)}

O estudo de mercado envolveu dois termoplásticos de baixa temperatura comerciais, utilizados em larga escala para a confecção de órteses para membros superiores: Rolyan ${ }^{\circledR}$ Ezeform $^{\mathrm{TM}}$, identificado, neste trabalho, como Produto Polimérico Comercial 1, e Solaris ${ }^{\mathrm{TM}}$, identificado como Produto Polimérico Comercial 2.

Os seis procedimentos analíticos que estavam previstos foram realizados, conforme se segue, e os dados obtidos foram importantes para a continuidade da Fase Exploratória. 


\section{Espectroscopia no Infravermelho com Transformada de Fourier (FTIR)}

A Figura 35 apresenta, os Espectros de Absorção no Infravermelho, na região de $4.000 \mathrm{~cm}^{-1}$ a $400 \mathrm{~cm}^{-1}$ para o Produto Polimérico Comercial 1 (designado a seguir como Produto 1) e para o Produto Polimérico Comercial 2 (designado a seguir como Produto 2).

Figura 35 - Espectros de absorção no infravermelho dos Produtos 1 (a) e 2 (b)

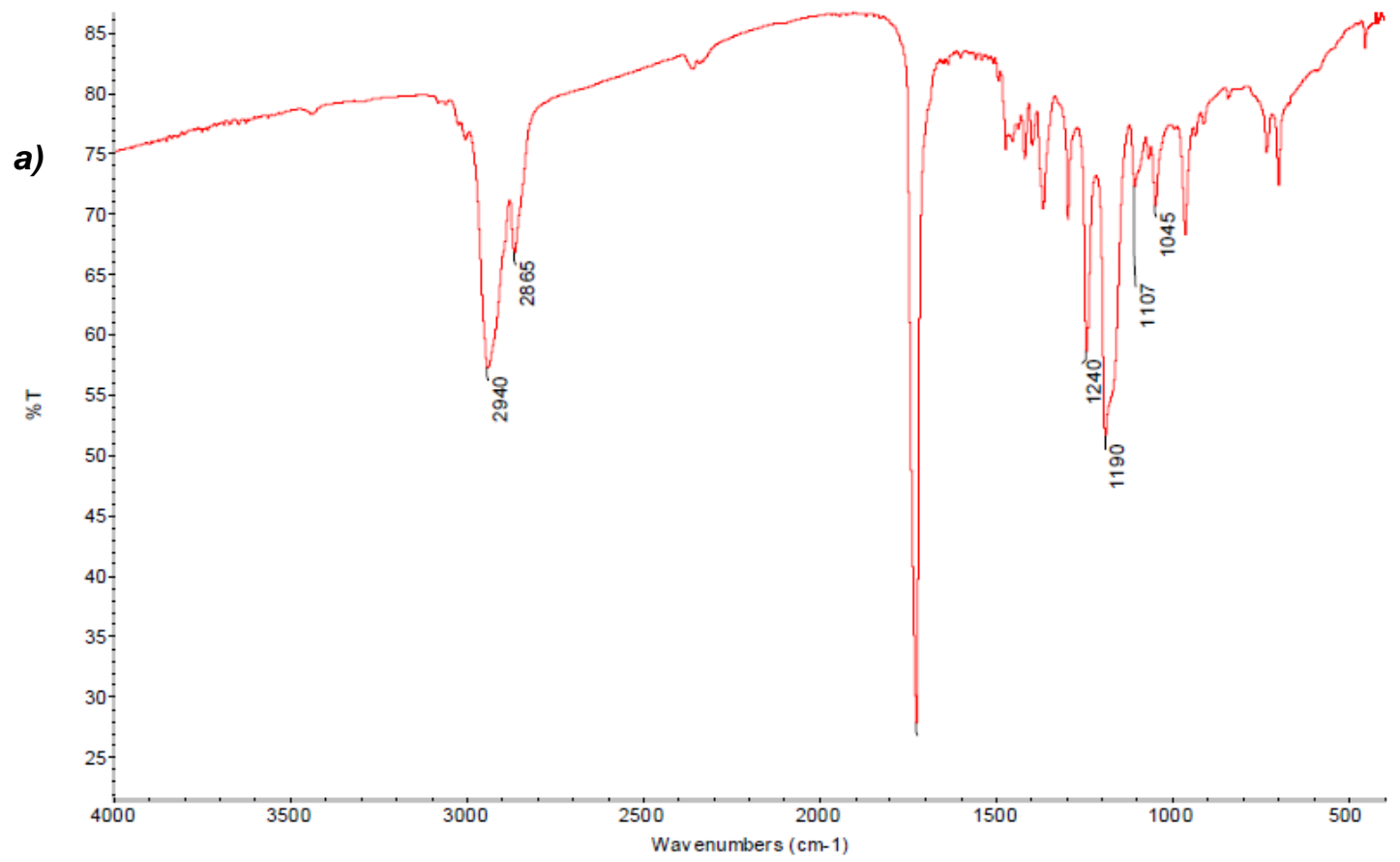

b)

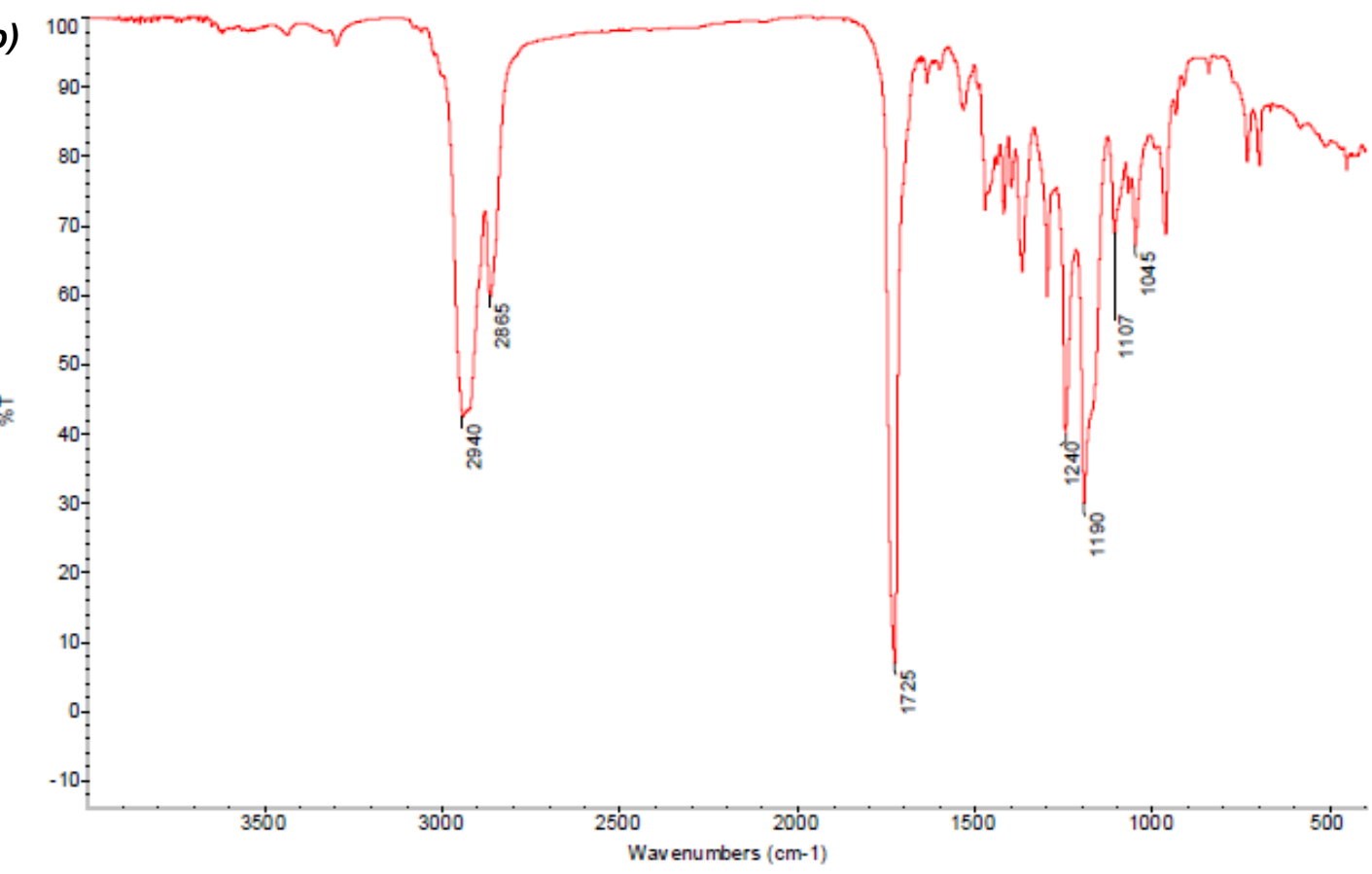

Fonte: elaborada pela autora 
A interpretação dos picos e das bandas de absorção utilizados na identificação dos dois Produtos está descrita na Tabela 2. Através dos Picos e Bandas de Absorção, pode-se observar que os dois Produtos são compostos basicamente por hidrocarbonetos alifáticos $\left(\mathrm{CH}_{2}\right.$ e $\left.\mathrm{CH}_{3}\right)$ e grupamentos éster.

Tabela 2 - Descrição dos Picos e das Bandas de Absorção apresentadas nos Espectros de Infravermelho

\section{Número de Onda $\left(\mathrm{cm}^{-1}\right) \quad$ Grupamento Característico}

\begin{tabular}{cc}
\hline $2940-2865$ & $\begin{array}{c}\text { Deformação axial de } \mathrm{CH} \text { alifático } \\
2940 \mathrm{~cm}^{-1}-\text { assimétrica de } \mathrm{CH}_{3} \\
2865 \mathrm{~cm}^{-1}-\text { simétrica de } \mathrm{CH}_{2}\end{array}$ \\
\hline 1725 & $\mathrm{C}=\mathrm{O}$ \\
\hline $1240-1190$ & Deformação do C-O-C de ligaçães tipo \\
\hline $1107-1045$ & Deformação simétrica C-O \\
\hline $1107-1045$ & Deformação simétrica C-O \\
\hline \hline
\end{tabular}

Fonte: elaborada pela autora com base no Certificado de Ensaio LCP15-000091 do CCDM, DEMa/UFSCar

Comparando o Espectro de Infravermelho do Produto 1 com Espectros de Infravermelho do Banco de Dados constatou-se que o grau de sobreposição entre as absorções do Produto 1 com as absorções de uma policaprolactona considerada padrão foi superior a 94\%. Para o Produto 2 esta mesma comparação indicou um grau de sobreposição superior a 93\%. O polímero PCL apresenta os mesmos grupamentos químicos mostrados na Tabela 2.

A comparação entre os Espectros de Infravermelho pode ser observada na Figura 36 (Produto 1 e PCL) e na Figura 37 (Produto 2 e PCL).

Figura 36 - Comparação entre Espectros de Infravermelho do Produto 1 e do Padrão Policaprolactona

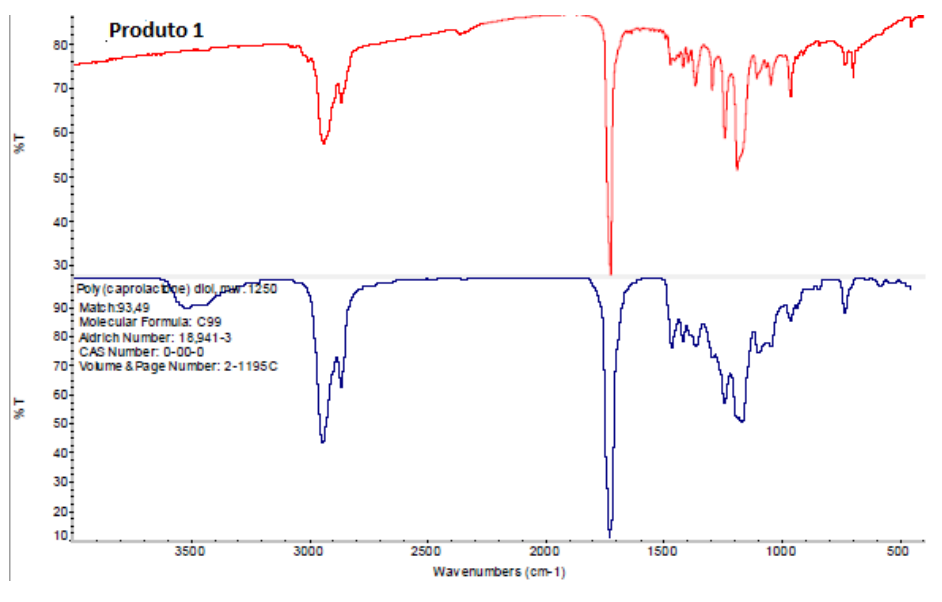

Fonte: elaborada pela autora 
Figura 37 - Comparação entre Espectros de Infravermelho do Produto 2 e do Padrão Policaprolactona

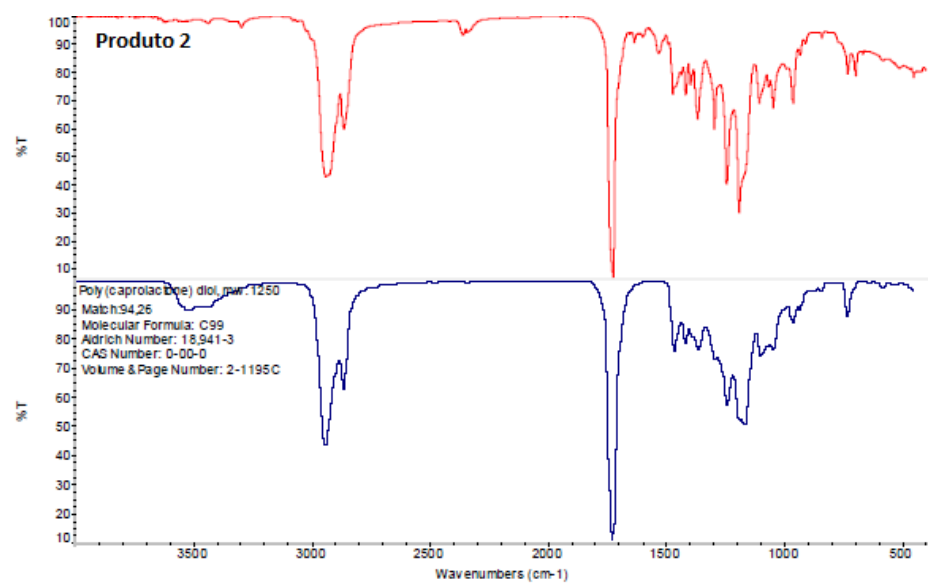

Fonte: elaborada pela autora

\section{Calorimetria Exploratória Diferencial (DSC)}

As Curvas DSC referentes ao primeiro aquecimento das amostras dos dois Produtos estão apresentadas na Figura 38. O primeiro aquecimento revela a estrutura do material polimérico nos respectivos produtos.

Para uma melhor visualização, a Figura 39 apresenta a Sobreposição das Curvas DSC referentes às amostras dos dois Produtos. De acordo com a Figura 39 e a Tabela 3 é possível observar uma grande similaridade entre os materiais poliméricos de baixa temperatura, quando avaliados no critério da temperatura de fusão cristalina. Em relação à entalpia de fusão (calculada pela área de fusão e que é diretamente proporcional à \% de cristalinidade do polímero e ao seu teor em cada produto, de acordo com os resultados da Termogravimetria e da Calcinação apresentados posteriormente) constatou-se que o polímero do Produto 1 apresentou uma maior \% de cristalinidade. 
Figura 38 - Curva DSC dos Produtos 1 e 2
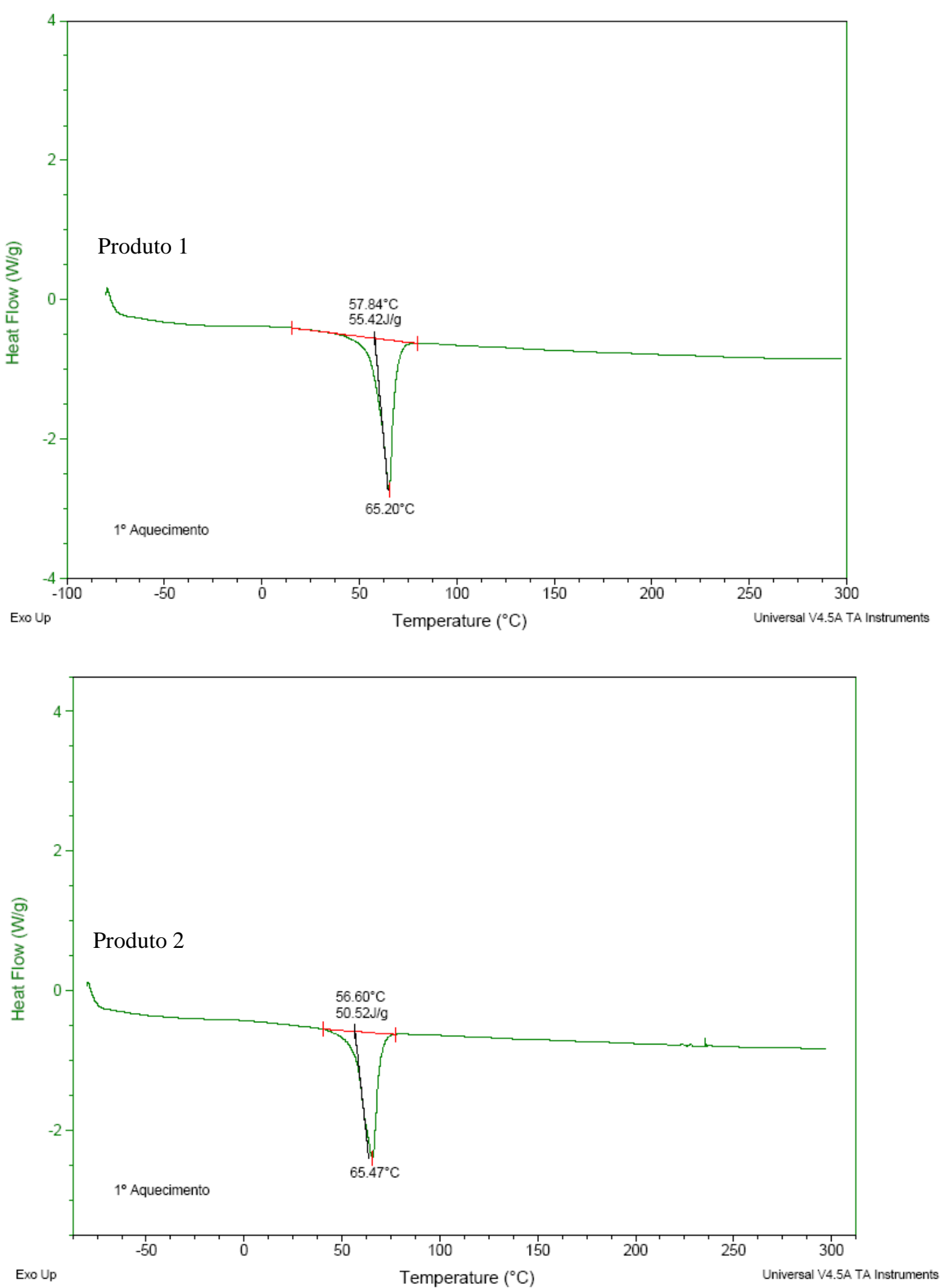

Fonte: elaborada pela autora 
Figura 39 - Sobreposição das Curvas DSC para o Produto 1 e para o Produto 2

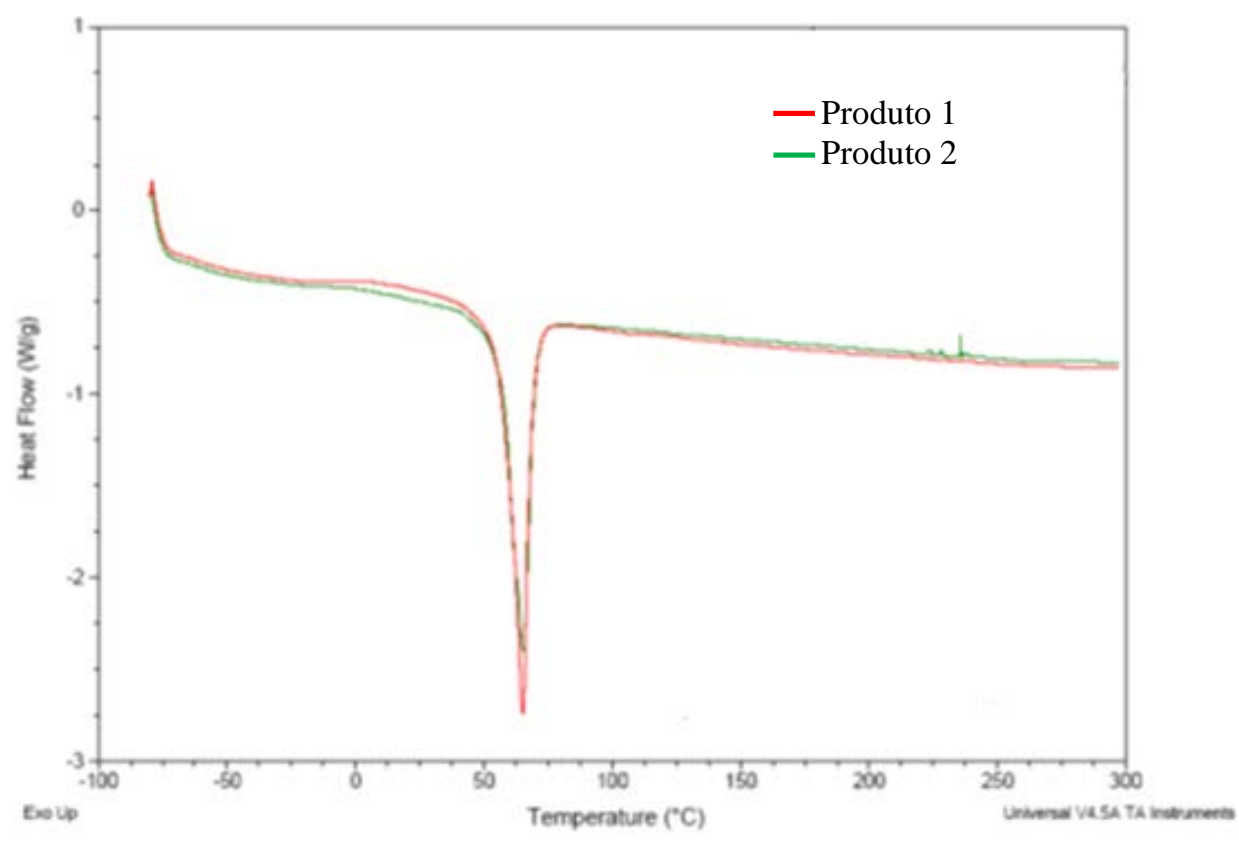

Fonte: elaborada pela autora

Tabela 3 - Resultados quanto à Temperatura de Fusão Cristalina para os Produtos 1 e 2

\begin{tabular}{|c|c|}
\hline \hline Material & $\begin{array}{l}\text { Temperatura de Fusão Cristalina }\left(\mathbf{T}_{\mathbf{m}}\right) \mathbf{d o} \\
\text { Termoplástico de Baixa Temperatura }\left({ }^{\circ} \mathbf{C}\right)\end{array}$ \\
\hline \hline Produto 1 & 65,2 \\
\hline \hline Produto 2 & 65,5 \\
\hline
\end{tabular}

Fonte: elaborada pela autora

A literatura e a caracterização por FTIR indicaram o PCL como polímero de referência dos produtos (polímero matriz). Dessa forma, também foi realizada uma análise por DSC do Polímero Policaprolactona (PCL) CAPA 6500, da Perstorp, sem constituintes inorgânicos. A Curva DSC deste polímero está apresentada na Figura 40.

Para facilitar a visualização de uma análise comparativa, a Figura 41 apresenta a Sobreposição das Curvas DSC referentes às amostras dos dois Produtos e ao polímero puro PCL CAPA 6500 da Perstorp. De acordo com a Figura 41 é possível observar uma boa similaridade entre os materiais poliméricos avaliados, no que diz respeito à Temperatura de Fusão Cristalina do termoplástico de baixa temperatura. As áreas de fusão não podem ser comparadas, pois o polímero PCL CAPA 6500 da Perstorp é um polímero puro, sem constituintes inorgânicos. 
Figura 40 - Curva DSC do polímero Policaprolactona (PCL) CAPA 6500, da Perstorp.

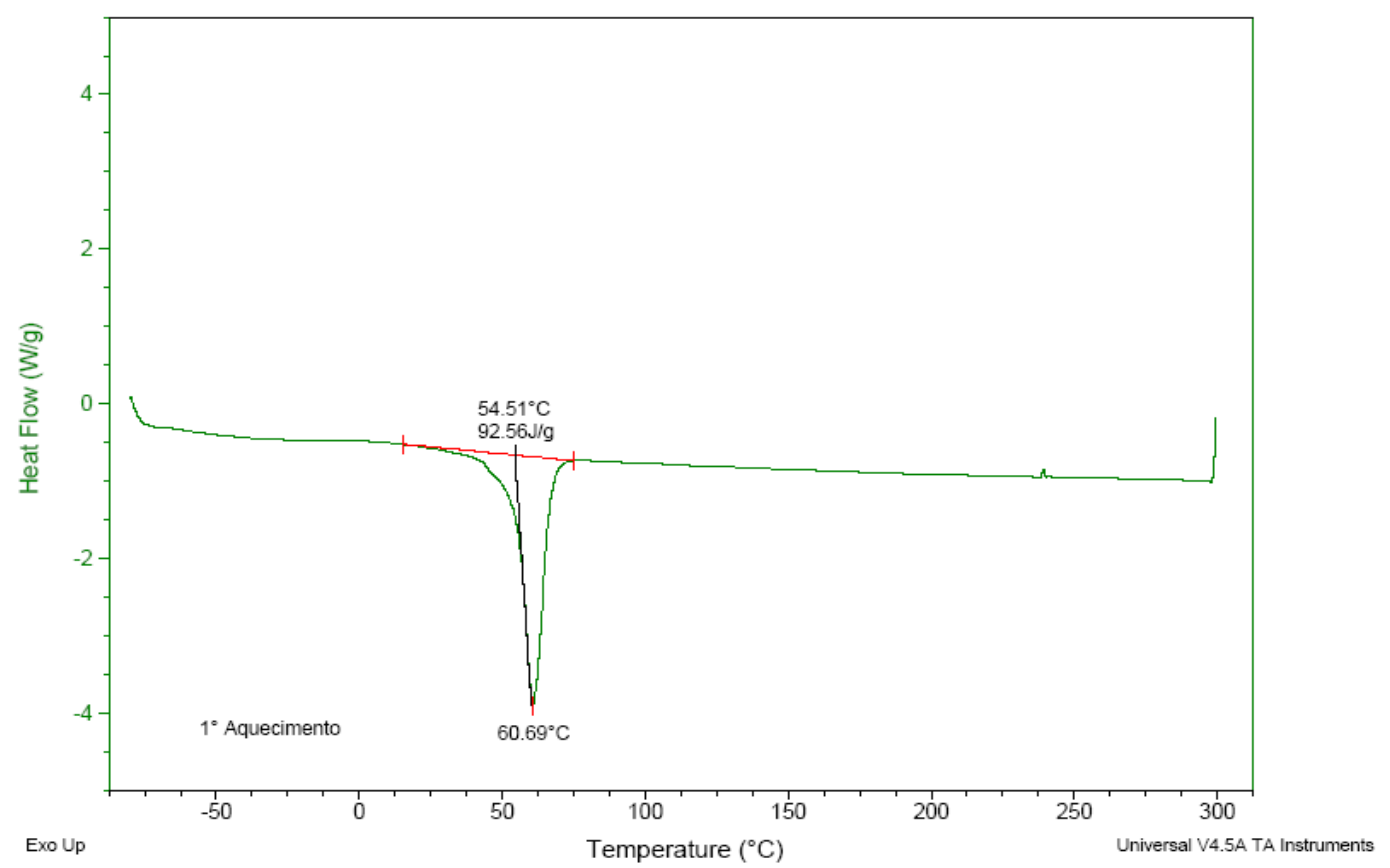

Fonte: elaborada pela autora

Figura 41 - Sobreposição das Curvas DSC: Produto 1, Produto 2 e do Polímero PCL CAPA 6500 da Perstorp

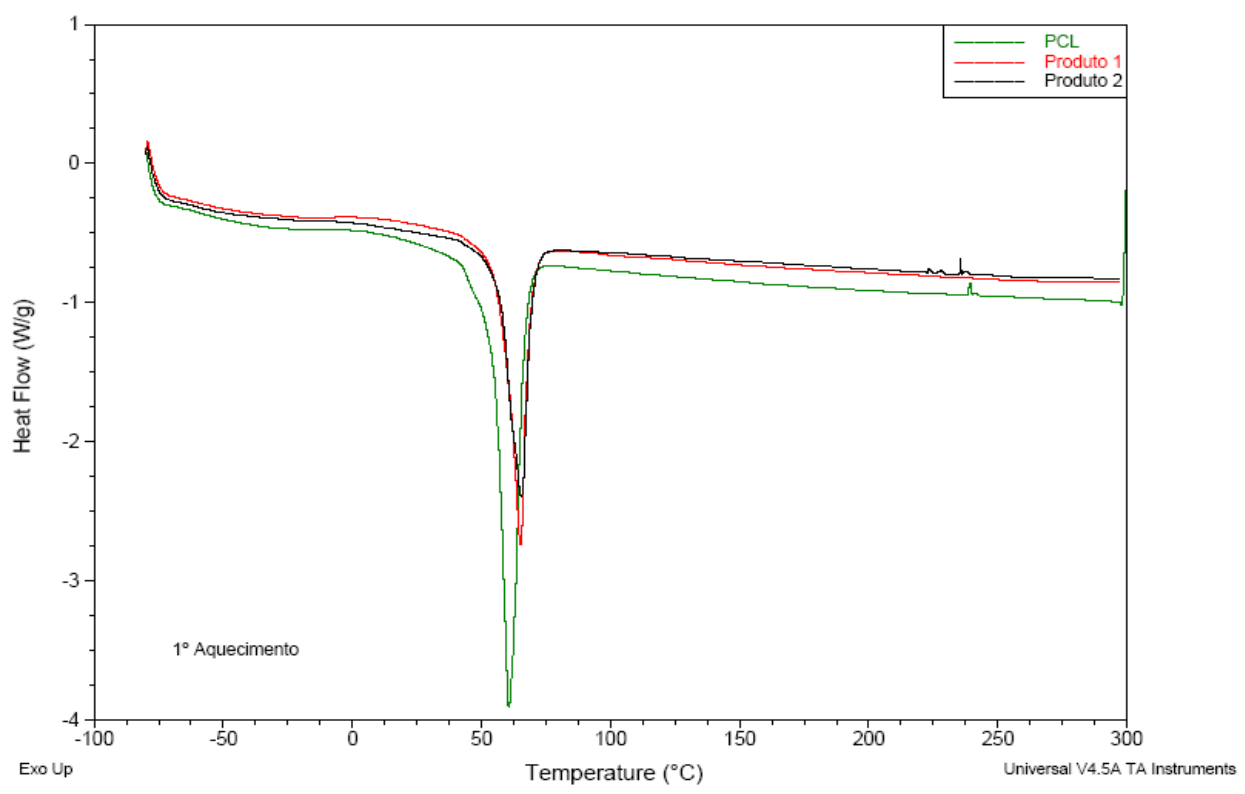

Fonte: elaborada pela autora 


\section{Análise Dinâmico-Mecânica (DMA)}

As Curvas DMA referentes às amostras dos dois Produtos estão apresentadas nas Figura 42 e Figura 43.

Figura 42 - Curvas DMA para o Produto 1

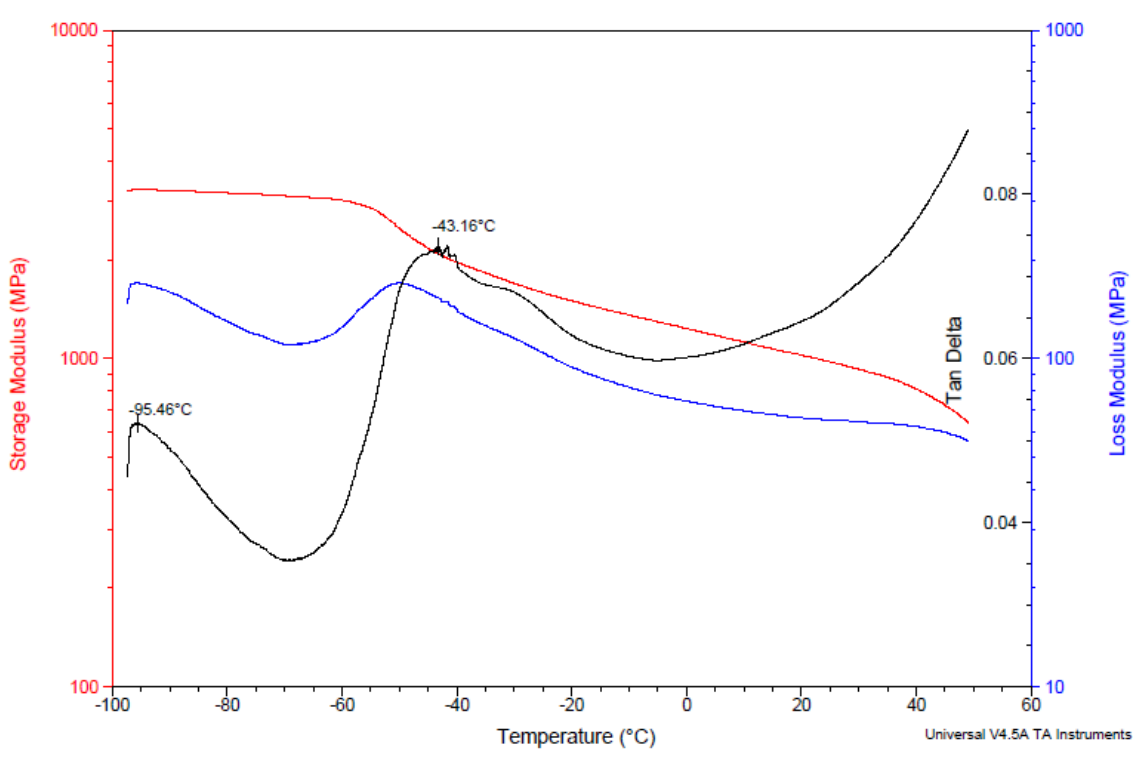

Fonte: elaborada pela autora

Figura 43 - Curvas DMA para o Produto 2

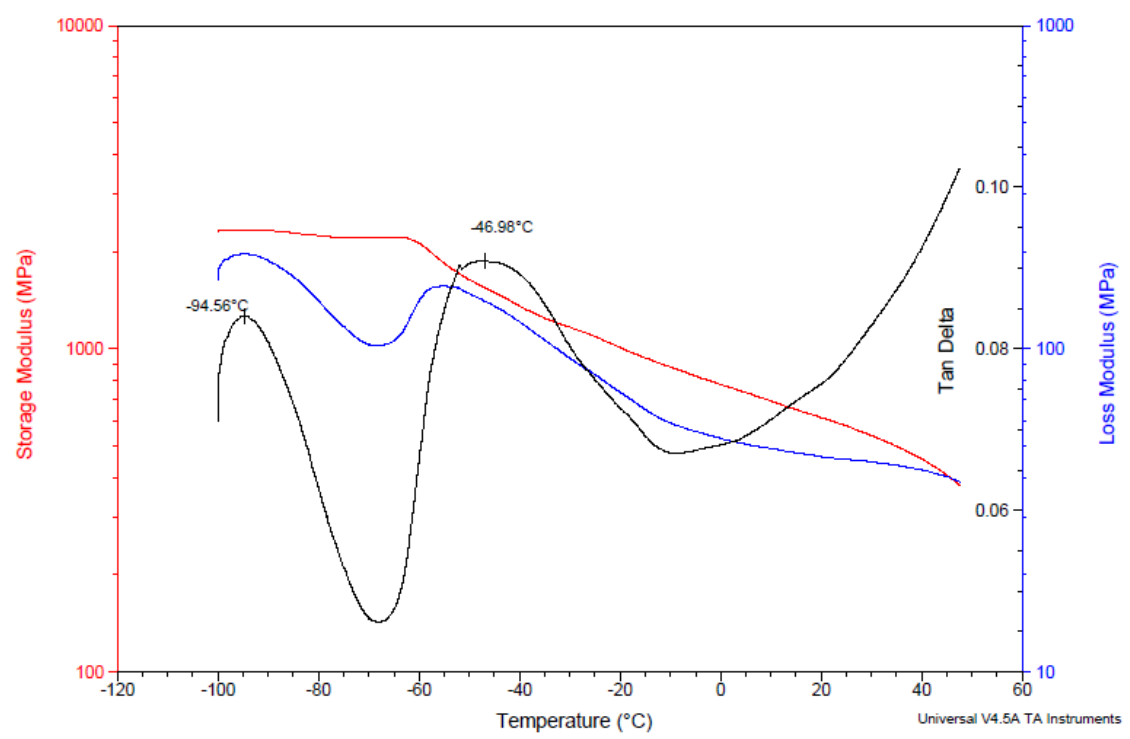

Fonte: elaborada pela autora 
Também foi realizada uma análise por DMA do Polímero Policaprolactona (PCL) CAPA 6500, da Perstorp, sem constituintes inorgânicos. A Curva DSC do PCL Puro está apresentada na Figura 44.

Figura 44 - Curvas DMA para o Polímero PCL Puro

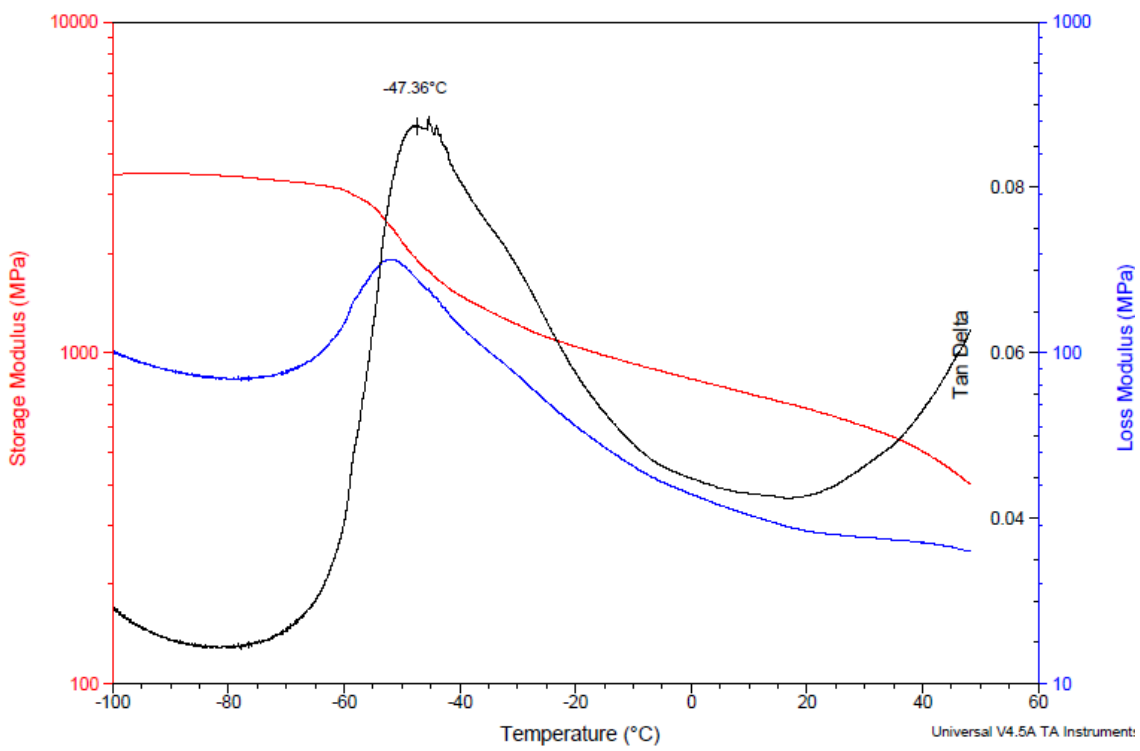

Fonte: elaborada pela autora

Para facilitar a visualização de uma análise comparativa, a Figura 45 apresenta a Sobreposição das Curvas DMA referentes às amostras dos dois Produtos e ao Polímero Puro PCL CAPA 6500 da Perstorp.

Figura 45 - Sobreposição das Curvas DMA para o Produto 1, para o Produto 2 e para o PCL Puro

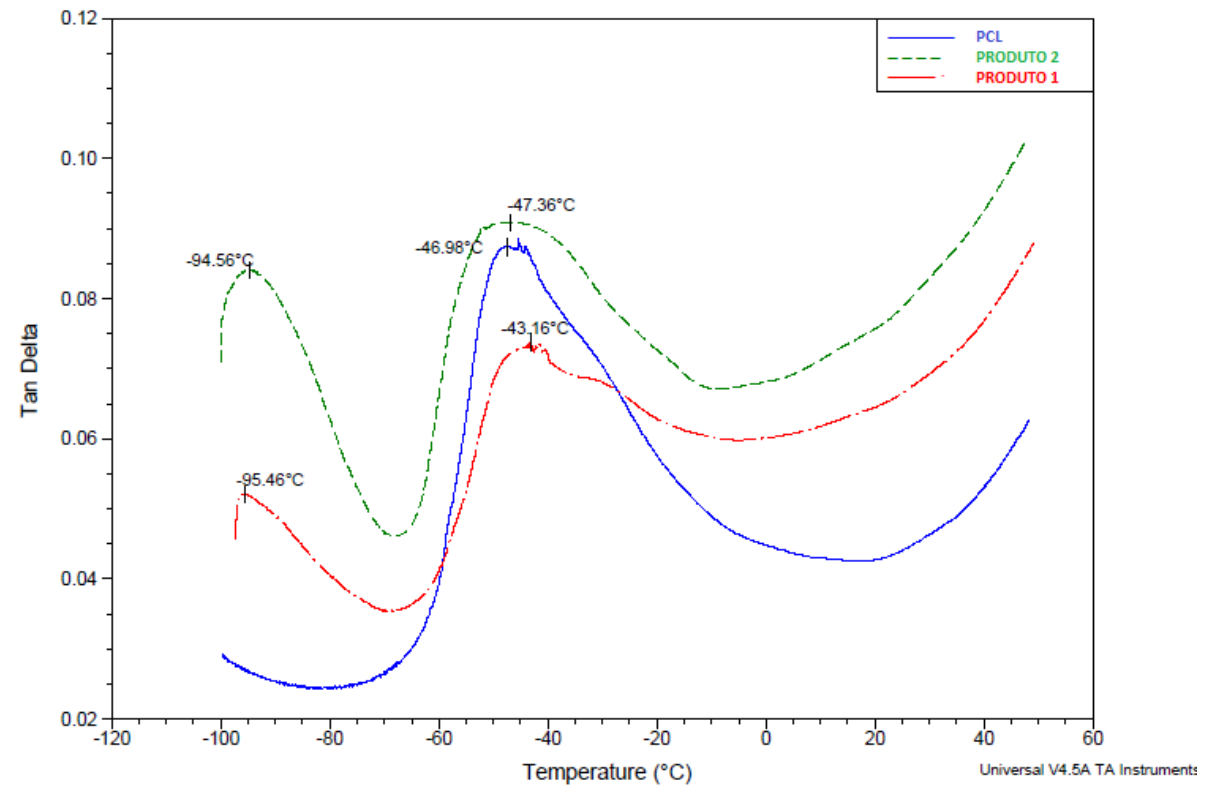

Fonte: elaborada pela autora 
De acordo com as informações da Figura 42 à Figura 45 é possível observar que nos principais pontos de valor máximo para a Tan $\delta$, atribuídos como as Temperaturas de Transição Vítrea (Tg) do PCL Puro $\left(-47,0^{\circ} \mathrm{C}\right)$, do Produto $1\left(-43,2^{\circ} \mathrm{C}\right)$ e do Produto $2\left(-47,4^{\circ} \mathrm{C}\right)$, houve uma grande similaridade. A pequena variação entre os valores de Tg foi considerada como erro experimental da Técnica de DMA, influenciada também pelos tipos de PCL. Este resultado reforça a comprovação dos experimentos realizados por outras Técnicas Analíticas onde já houve a indicação de que os Produtos 1 e 2 são majoritariamente constituídos pelo PCL.

Um resultado complementar, exclusivo da Técnica de DMA, foi a presença de outro ponto de máximo para a Tan $\delta$. Esta outra Transição Vítrea, presente nos Produtos 1 e 2, mas ausente no PCL Puro, indica a existência de uma outra Fase Polimérica, considerada como um Modificador Elastomérico dos dois Produtos. Os valores máximos para a Tan $\delta$, atribuídos como valores das Temperaturas de Transição Vítrea (Tg) do Modificador Elastomérico foram - 94,6 ${ }^{\circ} \mathrm{C}$ para o Produto 1 e - 95, $5^{\circ} \mathrm{C}$ para o Produto 2. Admitiu-se que os dois Produtos contêm o mesmo Modificador Elastomérico.

Os resultados obtidos com DMA permitiram concluir que os dois Produtos Comerciais são composições poliméricas baseadas no polímero Policaprolactona (PCL), em teor muito majoritário, contendo também um outro modificador polimérico elastomérico em menor quantidade. Provavelmente o teor do modificador elastomérico seja maior no Produto 2, na comparação com o Produto 1.

\section{Termogravimetria (TG)}

As Curvas TG e DTG referentes às amostras dos dois Produtos estão apresentadas na Figura 46 e Figura 47. Para uma melhor visualização, a Figura 48 apresenta a sobreposição das Curvas TG. É possível observar uma boa similaridade entre as composições poliméricas. Após a eliminação dos componentes orgânicos (polímero(s) e aditivos orgânicos), a massa residual corresponde ao teor de material inorgânico contido nos Produtos, como mostrado na Tabela 4. Com base nos resultados de Termogravimetria verificou-se que os dois Produtos avaliados apresentaram teores de inorgânicos muito próximos. 


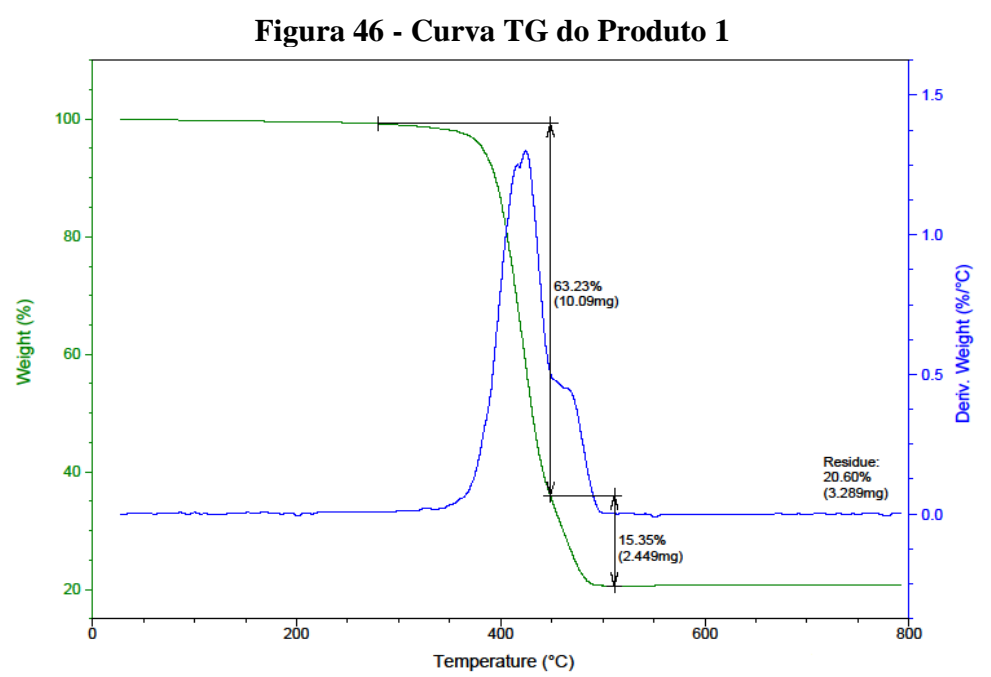

Fonte: elaborada pela autora

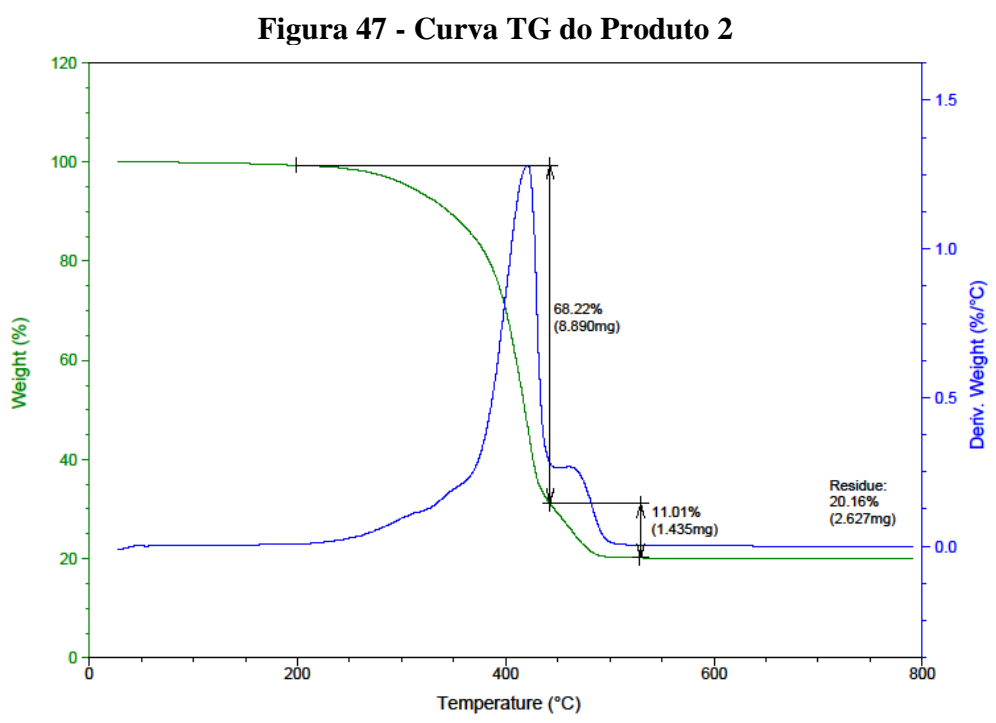

Fonte: elaborada pela autora

Figura 48 - Sobreposição das Curvas TG: Produto 1 e Produto 2

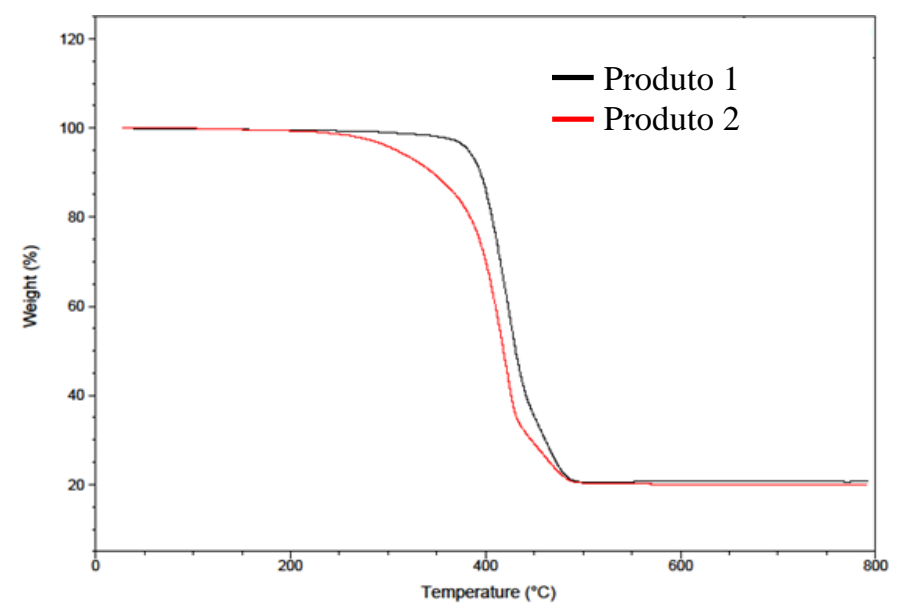

Fonte: elaborada pela autora 
Tabela 4 - Resultados do Teor de Inorgânicos obtidos por Termogravimetria (TG)

\begin{tabular}{|c|c|}
\hline Produto & Teor de Inorgânicos (\%) \\
\hline Produto 1 & 20,6 \\
\hline Produto 2 & 20,2 \\
\hline \multicolumn{2}{|c|}{ Fonte: elaborada pela autora } \\
\hline
\end{tabular}

De uma forma geral, maiores teores de inorgânicos devem gerar menor custo, além de materiais mais rígidos e com maior estabilidade dimensional, o que poderia significar, na aplicação em órteses, a manutenção do posicionamento planejado no momento da moldagem/confecção.

\section{Teor de Cinzas por Calcinação}

Para validar os resultados da TG, foi realizado um outro ensaio para a determinação do Teor de Cinzas por Calcinação do Produto 1 e do Produto 2, apresentados na Tabela 5.

Tabela 5 - Resultados do Teor de Inorgânicos obtido por Calcinação

\begin{tabular}{|c|c|c|}
\hline & $\begin{array}{c}\text { Teor de Inorgânicos (\%) } \\
\text { Produto 1 }\end{array}$ & $\begin{array}{c}\text { Teor de Inorgânicos (\%) } \\
\text { Produto 2 }\end{array}$ \\
\hline Medida 1 & 21,2 & 24,7 \\
\hline Medida 2 & 21,1 & 21,8 \\
\hline Medida 3 & 21,2 & 23,1 \\
\hline Média e desvio-padrão & $\mathbf{2 1 , 2} \pm \mathbf{0 , 1}$ & $\mathbf{2 3 , 2} \pm \mathbf{1 , 5}$ \\
\hline
\end{tabular}

Fonte: elaborada pela autora

Os resultados da calcinação dos 2 Produtos foram considerados mais representativos, na comparação com a Termogravimetria, e indicaram que o Produto 2 contém um teor de inorgânicos ligeiramente superior. O desvio-padrão das medidas indica que o Produto 1 tem uma melhor distribuição dos modificadores inorgânicos na matriz polimérica.

\section{Microscopia Eletrônica de Varredura (MEV) acoplada com a Espectroscopia por Dispersão} de Energia de Raios $X$ (EDS)

No comportamento da composição polimérica, além dos teores de inorgânicos, também há a influência do seu tipo (por exemplo, fibra de vidro, talco, carbonato de cálcio, etc.) e do formato físico do modificador inorgânico (fibroso e/ou particulado). A constatação destes 
parâmetros foi obtida com base na análise por Microscopia Eletrônica de Varredura (MEV) com EDS, a fim de verificar a constituição química e o formato físico das cargas inorgânicas.

Os resíduos da calcinação, isto é, os constituintes inorgânicos dos dois Produtos foram caracterizados por MEV/EDS. A análise utilizou detector de elétrons retroespalhados. As micrografias obtidas apresentam as imagens de elétrons retroespalhados, que geram contrastes de cor dependentes da composição da amostra. Desta forma, os elementos químicos de maior número atômico aparecem nas micrografias como pontos claros e elementos químicos de menor número atômico aparecem como pontos mais escuros.

A micrografia dos constituintes inorgânicos do Produto 1 pode ser vista na Figura 49 e a do Produto 2 na Figura 50. A Tabela 6 apresenta os resultados de EDS para estas composições, em pontos relacionados nas figuras.

O Produto 1 apresentou constituinte inorgânico acentuadamente fibroso e o Produto 2 apresentou uma mistura de constituintes inorgânicos fibrosos e particulados. Estes provavelmente são formados por talco e dióxido de titânio, enquanto os componentes fibrosos de ambos os Produtos correspondem a fibras de vidro (com base nos resultados de EDS e demais técnicas).

Figura 49 - Micrografia dos constituintes inorgânicos do Produto 1 (a marcação 1 é um ponto onde o EDS foi utilizado)

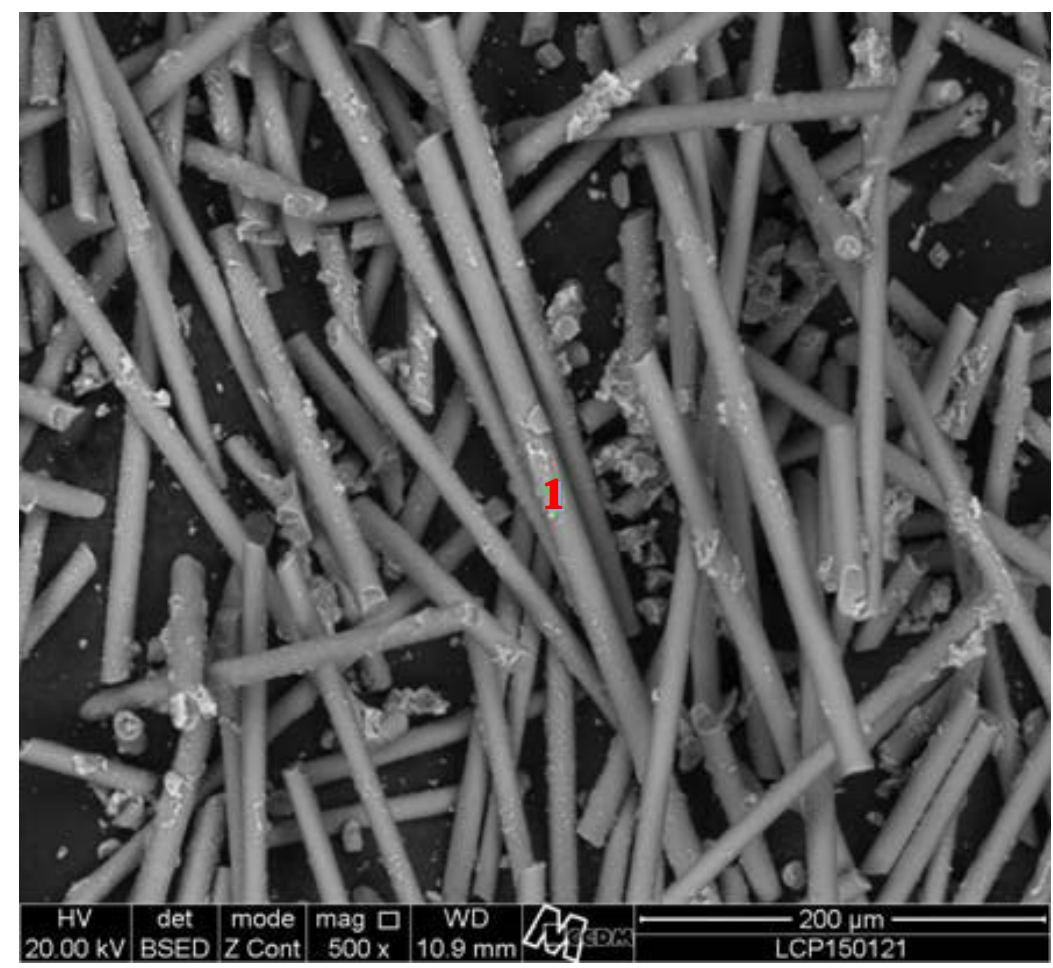

Fonte: elaborada pela autora 
Figura 50 - Micrografia dos constituintes inorgânicos do Produto 2. (marcações 1 e 2 são pontos onde o EDS foi utilizado)

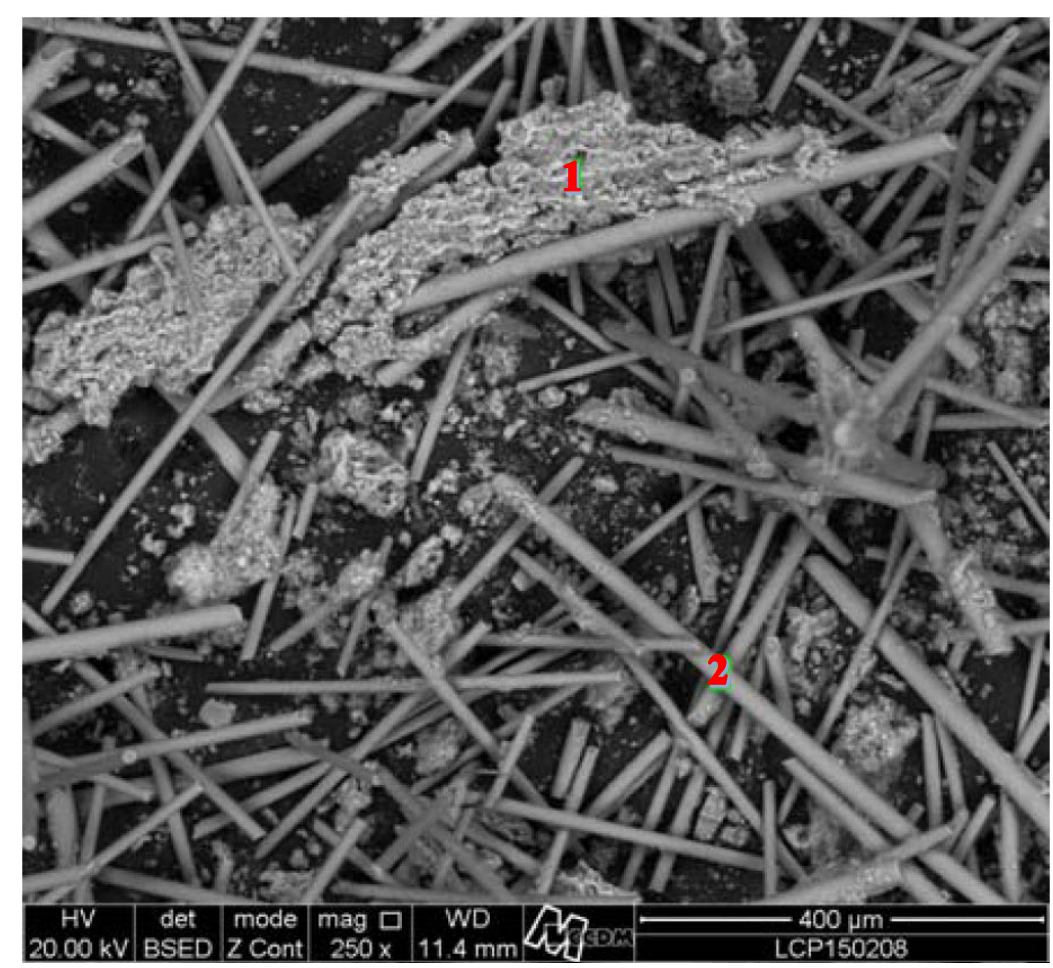

Fonte: elaborada pela autora

Tabela 6 - Resultados de EDS para os Produtos 1 e 2

\begin{tabular}{|c|c|c|c|}
\hline \multirow{2}{*}{ ELEMENTO } & \multicolumn{1}{|c||}{ Produto 1 } & \multicolumn{2}{c|}{ Produto 2 } \\
\cline { 2 - 4 } & PONTO 1 (\%) & Ponto 1 (\%) & Ponto 2 (\%) \\
\hline \hline Carbono & 23,92 & 3,56 & ---- \\
\hline Oxigênio & 43,23 & 50,36 & 54,06 \\
\hline Sódio & 0,27 & 0,10 & 0,27 \\
\hline Magnésio & 0,87 & 3,27 & 1,38 \\
\hline Alumínio & 3,47 & 3,37 & 6,57 \\
\hline Silício & 13,36 & 13,71 & 23,05 \\
\hline Fósforo & 0,11 & 0,22 & 0,07 \\
\hline Enxofre & 0,03 & 0,04 & ---- \\
\hline Potássio & 0,07 & 0,37 & 0,30 \\
\hline Cálcio & 9,46 & 4,29 & 12,57 \\
\hline Titânio & 4,70 & 17,93 & 1,15 \\
\hline Ferro & 0,20 & 2,00 & 0,26 \\
\hline Níquel & 0,02 & ---- & ---- \\
\hline Cobre & 0,30 & 0,43 & 0,27 \\
\hline Zinco & ---- & 0,35 & 0,04 \\
\hline
\end{tabular}

Fonte: elaborada pela autora 


\section{Análise geral do estudo dos materiais de mercado}

Os dois produtos comerciais são considerados similares quanto a várias características pelos profissionais que atuam na área de confecção de órteses e os ensaios realizados confirmaram e quantificaram essas percepções.

Os resultados obtidos com os procedimentos analíticos descritos permitiram concluir que os dois Produtos Comerciais são composições poliméricas baseadas no polímero Policaprolactona (PCL), em teor muito majoritário, contendo também um outro modificador polimérico elastomérico em menor quantidade. Provavelmente o teor do modificador elastomérico seja maior no Produto 2, na comparação com o Produto 1.

O Produto 1 apresentou constituinte inorgânico acentuadamente fibroso, muito provavelmente fibras de vidro, com teor em torno de 21\%. Já o Produto 2 apresentou uma mistura de constituintes inorgânicos fibrosos (muito provavelmente fibras de vidro) e particulados (provavelmente talco e dióxido de titânio), com um teor em torno de 23\%.

\subsection{FASE EXPERIMENTAL: APLICAÇÃO DO INSTRUMENTO MPMTO E TESTE DOS MATERIAIS DESENVOLVIDOS}

\subsubsection{Aplicação do instrumento MPMTO: caracterização físico-mecânica}

O MPMTO foi aplicado com 4 termoplásticos de baixa temperatura: os materiais A e B, desenvolvidos nesta pesquisa, e dois materiais disponíveis no mercado, identificados pelas marcas registradas Rolyan ${ }^{\circledR}$ Ezeform ${ }^{\mathrm{TM}}$ e Aquaplast-T ${ }^{\mathrm{TM}}$.

\section{1) TEMPERATURA DE TRABALHO}

Para a determinação da Temperatura de Trabalho dos materiais foram realizados os dois ensaios normatizados previstos no Instrumento: a Calorimetria Exploratória Diferencial - DSC (ASTM, 2015) e a Temperatura de Amolecimento Vicat (ASTM, 2017b).

As Curvas DSC referentes ao primeiro aquecimento das amostras dos 4 materiais estão apresentadas da Figura 51 à Figura 54. Para uma melhor visualização, a Figura 55 apresenta a Sobreposição das Curvas DSC referentes às amostras dos 4 materiais. 
Figura 51 - Curva DSC do Material Ezeform ${ }^{\mathrm{TM}}$

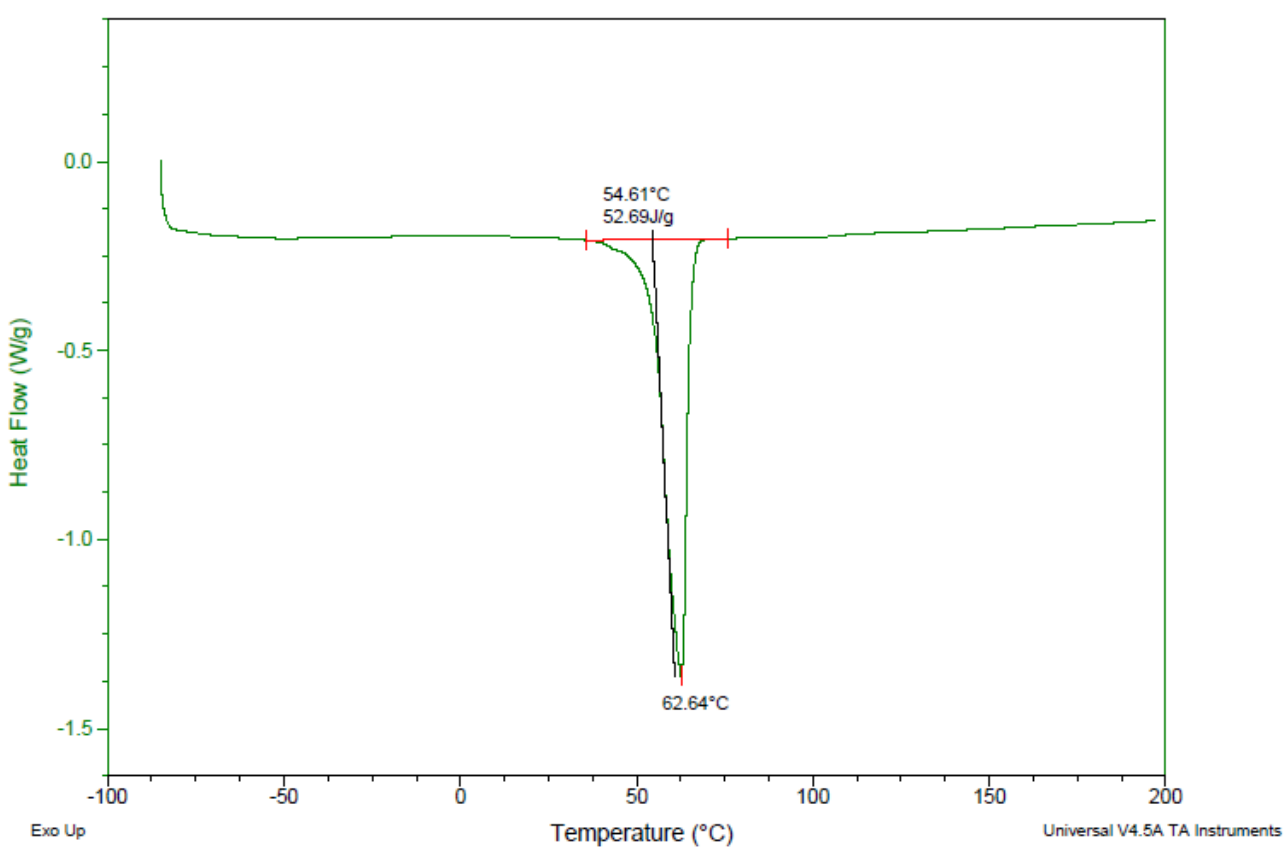

Fonte: elaborada pela autora

Figura 52 - Curva DSC do Material Aquaplast-T ${ }^{\mathrm{TM}}$

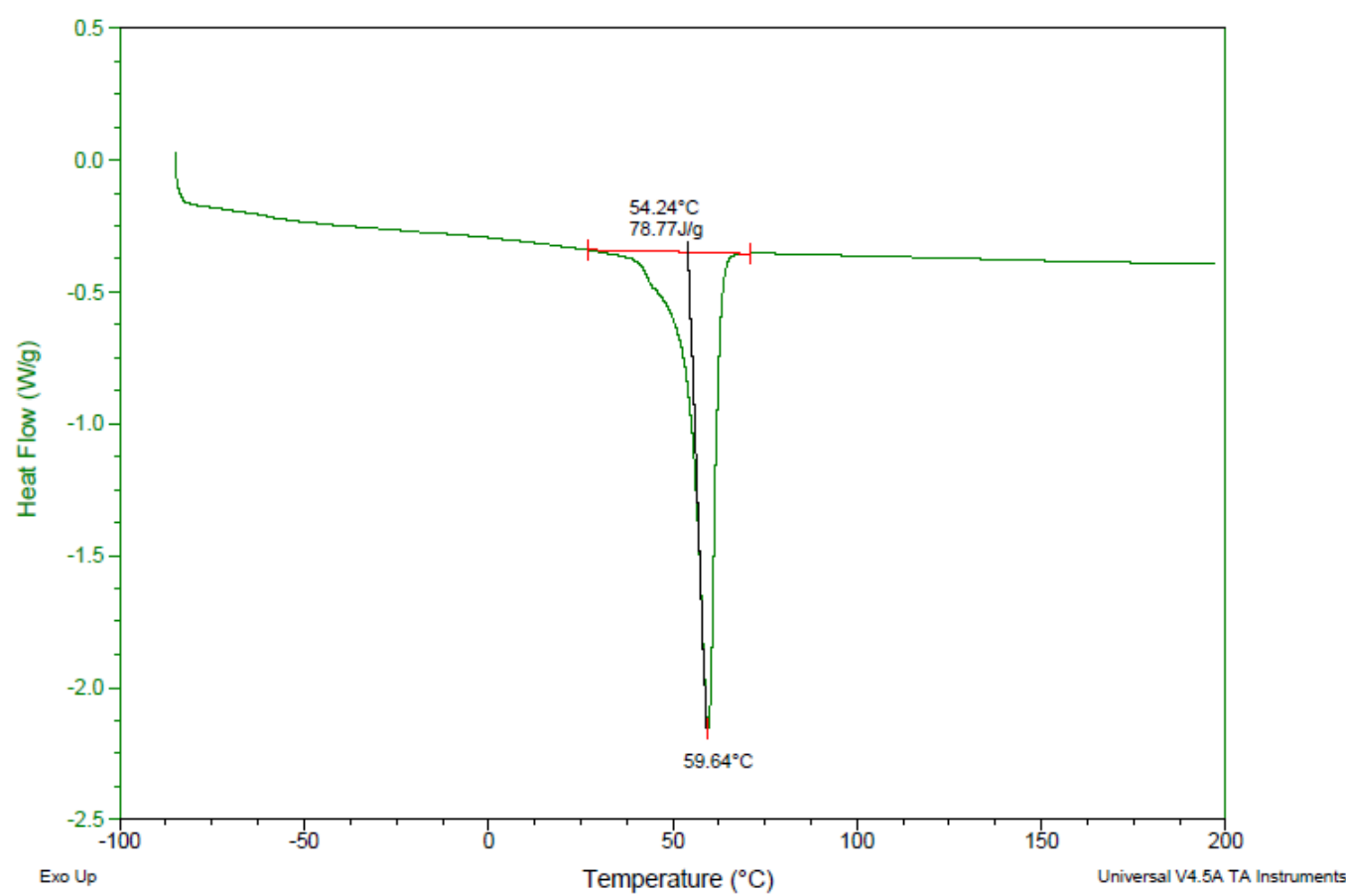

Fonte: elaborada pela autora 
Figura 53 - Curva DSC do Material A

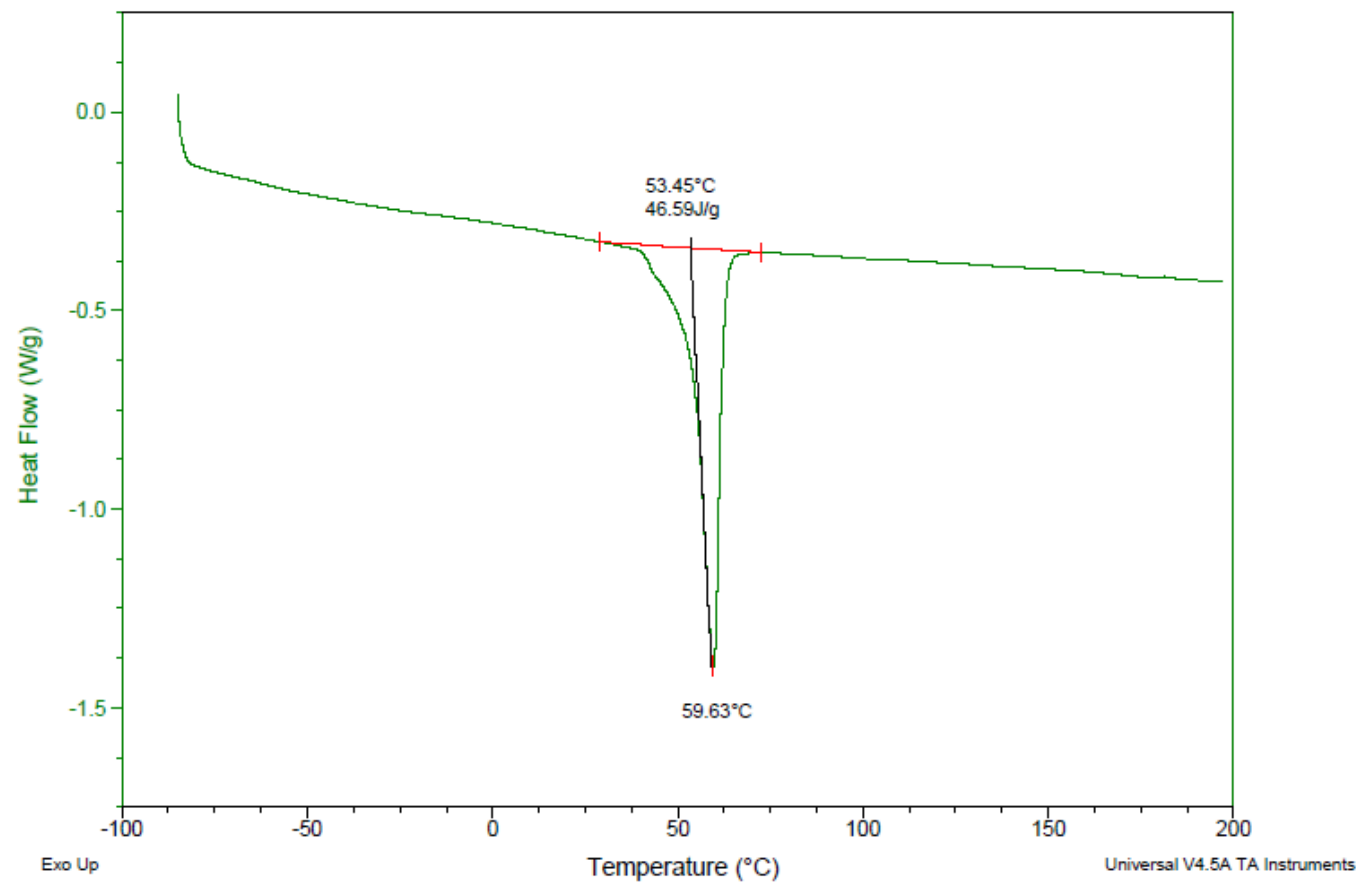

Fonte: elaborada pela autora

Figura 54 - Curva DSC do Material B

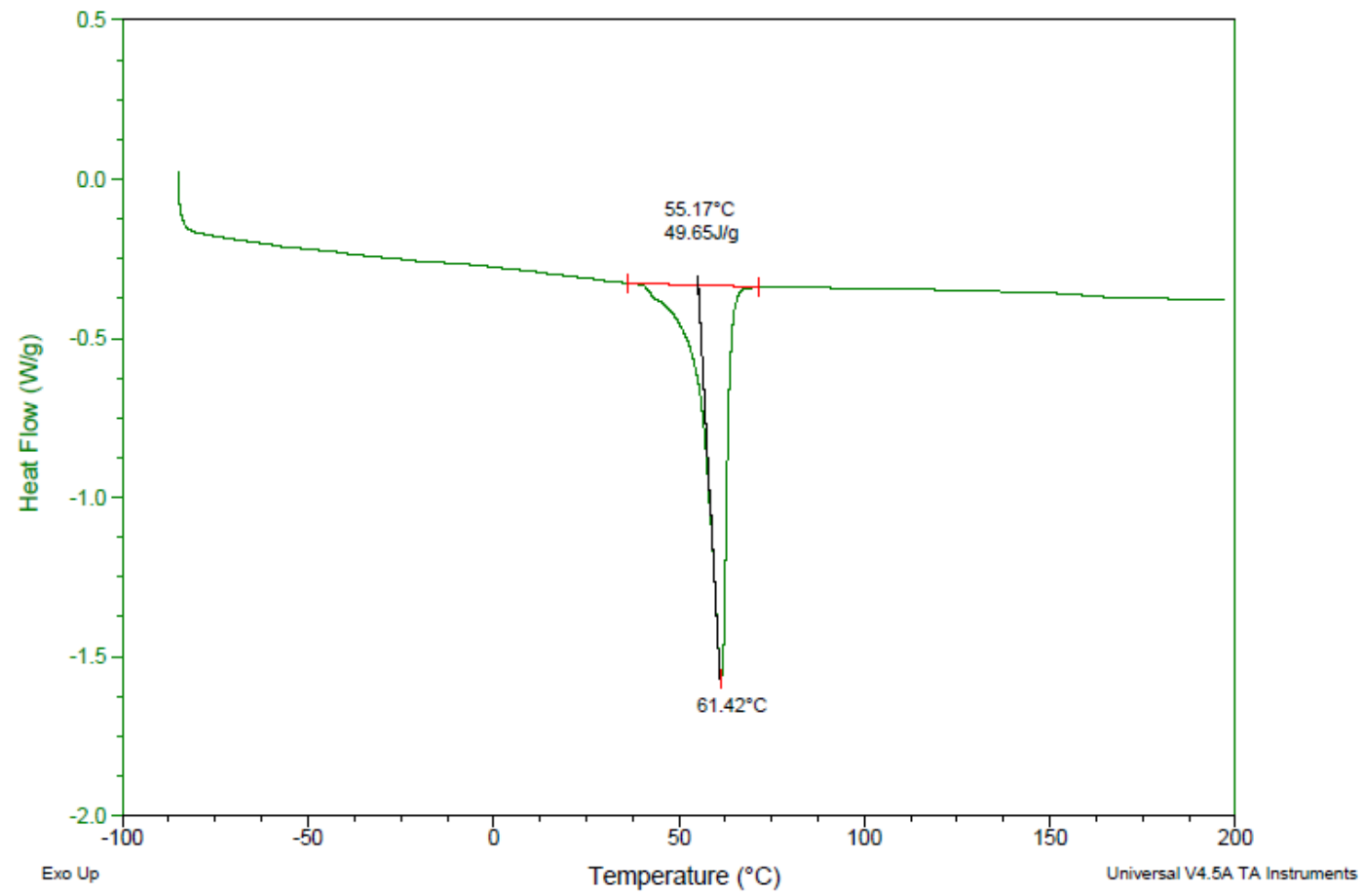

Fonte: elaborada pela autora 
Figura 55 - Sobreposição das Curvas DSC para os 4 materiais

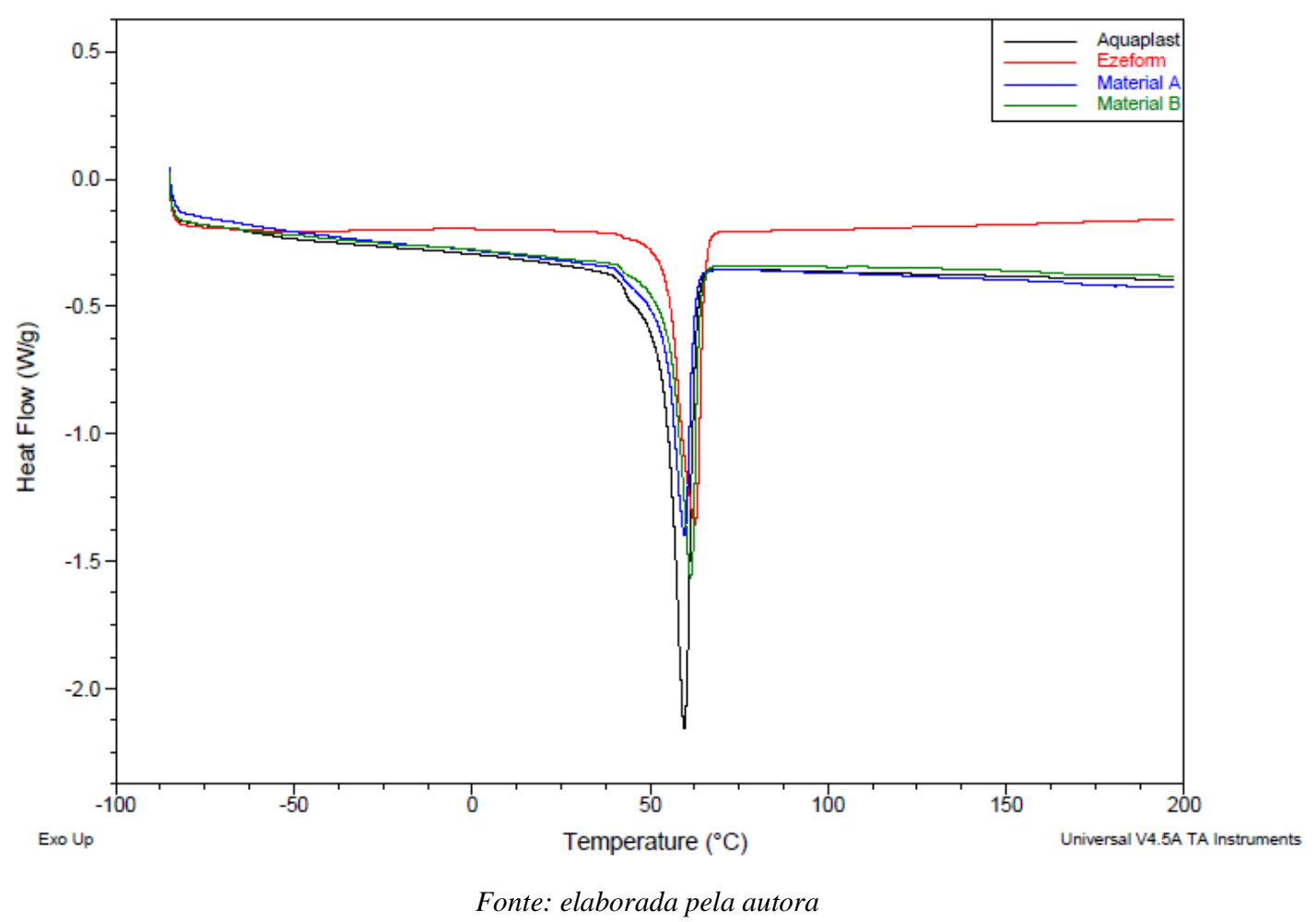

De acordo com as observações da Figura 51 à Figura 55 constatou-se que, na região da fusão cristalina do PCL, há grande semelhança entre os materiais.Para que esta afirmação possa ser entendida adequadamente devem obrigatoriamente ser considerados os seguintes aspectos, além da intrínseca variação experimental da técnica de DSC: os materiais podem ser baseados em diferentes tipos de PCL, com características estruturais diferentes; a história térmica de cada material pode influenciar na cristalinidade do PCL; o teor de PCL é diferente em cada um dos materiais. Assim, a fusão do PCL, avaliada pela sua entalpia de fusão, é influenciada por estes aspectos. Por exemplo, na Figura 52, o material Aquaplast-T ${ }^{\mathrm{TM}}$, que é constituído praticamente apenas de PCL, apresentou uma área de fusão não normalizada superior aos outros 3 materiais, que contêm teores de inorgânicos entre 19\% e 22\% (composições apresentadas na análise complementar de Termogravimetria, no Apêndice VI).

Quanto ao outro ensaio do critério Temperatura de Trabalho, a Tabela 7 mostra os valores da Temperatura de Amolecimento Vicat. 
Tabela 7 - Temperatura de Amolecmento Vicat para os quatro materiais

\begin{tabular}{|c|c|c|c|c|}
\hline \multirow{2}{*}{ Materiais } & \multicolumn{3}{|c|}{$\begin{array}{c}\text { Temperatura de } \\
\text { Amolecimento Vicat }\left({ }^{\circ} \mathbf{C}\right)\end{array}$} & $\begin{array}{c}\text { Média e Desvio-padrão } \\
\left({ }^{\circ} \mathbf{C}\right)\end{array}$ \\
\hline Ezeform $^{\text {TM }}$ & 58,2 & 56,1 & 58,3 & $57,5 \pm 1,2$ \\
\hline Aquaplast-T & & 57 \\
\hline Material A & 57,6 & 55,2 & 57,7 & $56,8 \pm 1,4$ \\
\hline Material B & 60,0 & 60,0 & 59,6 & $59,9 \pm 0,2$ \\
\hline \multicolumn{4}{|c|}{ Fonte: elaborada pela autora } \\
\hline
\end{tabular}

Observa-se que os valores obtidos para a Temperatura de Amolecimento Vicat para os 4 materiais foram próximos. Também é possível constatar que as medidas para os materiais A e B apresentaram baixo desvio-padrão, indicando que estes materiais têm uma satisfatória homogeneidade.

A Tabela 8 apresenta os valores obtidos nos ensaios, relacionados às especificações técnicas dos materiais comerciais, segundo o fabricante, e a faixa de temperatura de trabalho calculada se acordo com os critérios estabelecidos no MPMTO.

Tabela 8 - Características térmicas e Faixa de Temperatura de Trabalho MPMTO

\begin{tabular}{|c|c|c|c|c|}
\hline Material & $\begin{array}{c}\text { Temperatura de } \\
\text { Amolecimento } \\
\text { Vicat }\left({ }^{\circ} \mathrm{C}\right)\end{array}$ & $\begin{array}{l}\text { Temperatura de } \\
\text { Fusão Cristalina } \\
\left({ }^{\circ} \mathrm{C}\right)\end{array}$ & $\begin{array}{c}\text { Recomendação do } \\
\text { Fabricante* } \\
\left({ }^{\mathrm{O}} \mathrm{C}\right)\end{array}$ & $\begin{array}{c}\text { Faixa de Temperatura } \\
\text { de Trabalho MPMTO } \\
\left({ }^{\circ} \mathrm{C}\right)\end{array}$ \\
\hline Ezeform $^{\mathrm{TM}}$ & 57,5 & 62,6 & $\begin{array}{l}\text { Temperatura da } \\
\text { água: } 70-75 \\
\text { Por } 1 \text { minuto }\end{array}$ & $63^{\circ} \mathrm{C}$ a $73^{\circ} \mathrm{C}$ \\
\hline Aquaplast-T ${ }^{\mathrm{TM}}$ & 56,8 & 59,6 & $\begin{array}{c}\text { Temperatura da } \\
\text { água: } 70-75 \\
\text { Por } 1 \text { a } 2 \text { minutos }\end{array}$ & $62^{\circ} \mathrm{C}$ a $72^{\circ} \mathrm{C}$ \\
\hline Material A & 59,9 & 59,6 & ----- & $65^{\circ} \mathrm{C}$ a $75^{\circ} \mathrm{C}$ \\
\hline Material B & 59,9 & 61,4 & ----- & $65^{\circ} \mathrm{C}$ a $75^{\circ} \mathrm{C}$ \\
\hline
\end{tabular}

*informações de Performance Health / Patterson Medical (2018), considerando a espessura de 3,2mm

Fonte: elaborada pela autora.

O DSC fornece uma caracterização térmica e estrutural do material, enquanto a Temperatura de Amolecimento Vicat é um ensaio mais simples, assim como o equipamento utilizado. Através de ambos os métodos utilizados foi possível identificar valores equivalentes entre os materiais comerciais e os materiais desenvolvidos, com pequena variação entre os dois 
procedimentos. Essa similaridade e a faixa de temperatura em que se tornam maleáveis é o que os caracteriza como termoplásticos de baixa temperatura e os torna viáveis para uma aplicação direta no corpo humano, como a confecção de órteses sob medida e dispositivos de tecnologia assistiva.

A faixa de Temperatura de Trabalho de cada material foi calculada de acordo com o parâmetro estabelecido pelo instrumento MPMTO, descrito na metodologia, correspondendo ao intervalo entre $5^{\circ} \mathrm{C}$ e $15^{\circ} \mathrm{C}$ acima da Temperatura de Amolecimento Vicat e/ou a Temperatura de Fusão Cristalina $\left(\mathrm{T}_{\mathrm{m}}\right)$. Como foram realizados os dois ensaios sugeridos, consideramos como temperatura inicial de trabalho $5^{\circ} \mathrm{C}$ acima da Temperatura de Amolecimento Vicat.

Embora o material esteja pronto para ser manuseado quando atingir a Temperatura de Fusão Cristalina e/ou a Temperatura de Amolecimento Vicat, após a retirada da água o tempo para a moldagem de uma órtese pode ser curto até que o material comece a resfriar e endurecer. Nas marcas comerciais analisadas observa-se que a temperatura recomendada para o amolecimento em água é de aproximadamente $10^{\circ} \mathrm{C}$ acima da Temperatura de Fusão Cristalina ( $\mathrm{T}_{\mathrm{m}}$ ) ou da Temperatura de Amolecimento Vicat. Dessa forma, aquecendo-se o material a uma temperatura acima destas, haverá mais tempo para se trabalhar manualmente com o material.

Em relação ao tempo de trabalho, é importante ressaltar que o resfriamento de um material não é uniforme, o que pode prejudicar a confecção. Como existem diversas aplicações em órteses, o tempo desejado para se manusear o material pode variar de acordo com as condições clínicas do usuário, o modelo da órtese, a experiência do terapeuta, entre outros fatores. Quanto ao Aquaplast-T ${ }^{\mathrm{TM}}$, por exemplo, há uma queixa que diz respeito ao tempo de enrijecimento, registrado por Lindemayer (2004) como longo (em torno de 4 a 5 minutos), quando comparado aos demais. Segundo o fabricante, considerando materiais com espessura 3,2mm, se a temperatura for respeitada, o tempo de trabalho do Ezeform ${ }^{\mathrm{TM}}$ será de 4 a 6 minutos e do Aquaplast- $\mathrm{T}^{\mathrm{TM}}$ será de aproximadamente 4 minutos, sendo que os mesmos apresentam tempo de trabalho menor quando a espessura é menor. Um tempo maior de trabalho permite ajustes e detalhes a serem feitos na órtese, porém para pessoas com alterações neurológicas, por exemplo, esse tempo de espera pode se tornar inviável para a confecção do dispositivo.

Algumas estratégias podem ser adotadas para adequar o tempo de trabalho, como por exemplo, reduzir a temperatura na qual o material é aquecido o que leva a uma diminuição da faixa de Temperatura de Trabalho e, consequentemente, do tempo de trabalho. Além disso, as placas perfuradas propiciam maior superfície de troca de calor e, portanto, o tempo de trabalho pode ser menor. 
Ressalta-se que, conhecer a temperatura de trabalho de cada material e respeitar a faixa estabelecida para isso, é importante para manter a integridade das propriedades dos materiais. Em temperaturas mais baixas do que o necessário, o material termoplástico pode não se tornar suficientemente moldável para uma confecção de órtese apropriada. Em temperaturas muito elevadas, como ressalta Lindemayer (2004), os materiais podem sofrer deformação plástica perante o alongamento e não retornar a sua forma original. Nesse sentido a autora apresenta, como sugestão para trabalhos futuros, a realização de teste para verificação da Temperatura de Fusão, em conjunto com outros testes, a fim de alcançar maior conhecimento sobre os materiais utilizados na confecção de órteses. Os resultados da presente pesquisa satisfazem essas expectativas, sendo que o DSC foi realizado para os dois materiais mais utilizados na confecção de órteses para membros superiores.

Temperaturas acima das que são determinadas também podem provocar dor e/ou lesões no usuário (MALICK, 1978). Alguns cuidados devem ser tomados, como: não deixar o material aquecido em contato com a pele por muito tempo e prestar atenção a sinais durante o contato, como vermelhidão, coceira e outras reações, sendo que a dor e o desconforto referidos pelo paciente servem como alerta (ASSUMPÇÃO, 2005; FESS; PHILIPS, 1987). Tratando-se de termoplásticos de baixa temperatura, algumas recomendações devem ser feitas ao paciente, pois a órtese precisa ser mantida afastada de fontes de calor como fornos, água quente, chamas abertas e janelas de carros ensolarados, sendo que perderá seu formato em temperaturas que atinjam a faixa de trabalho dos materiais.

A Temperatura de Trabalho é o parâmetro de maior controle por parte dos profissionais na prática clínica, uma vez que essa informação geralmente está disponível, dependendo da marca do material, ou então pode ser deduzida de acordo com outras informações técnicas fornecidas (EFECTIVE MEDICAL DEVICES, 2018; MN, 2018; POLITEC SAÚDE, 2018). A faixa de trabalho resultante desta pesquisa apresenta-se em consonância com as temperaturas apresentadas pelos fabricantes.

Além do controle da temperatura, que é uma grandeza física objetiva, é importante levar em consideração o conforto térmico e a tolerância do indivíduo durante o contato do material aquecido com a pele. Mesmo tratando-se de termoplásticos de baixa temperatura, pode haver casos em que é necessário oferecer uma barreira para proteção da pele, como por exemplo o uso de algum outro material de proteção (FESS; PHILIPS, 1987). Na prática clínica são adotadas diversas estratégias para proteger a pele do paciente ou ainda para reduzir o atrito com o material, tais como o uso de forrações (principalmente malha tubular) e o uso de talco durante a moldagem. Diante de situações especiais, como bebês, pessoas com diminuição de 
sensibilidade ou idosos, cuja pele é frágil e suscetível a ferimentos, uma conduta importante por parte do terapeuta é experimentar a temperatura do material antes de colocar sobre a pele do paciente (FERRIGNO, 2007).

\section{2) MOLDABILIDADE}

Os ensaios desenvolvidos para o segundo item do instrumento MPMTO foram importantes pois permitem mensurar a Moldabilidade, uma das propriedades mais decisivas para o uso deste grupo de materiais na confecção de órteses. Foram avaliados dois parâmetros diferentes: um com aplicação de força, a fim de simular a pressão depositada pelo terapeuta sobre o material durante a confecção da órtese e verificar a conformação do material ao objeto (Figura 56), e o outro refere-se ao caimento do material, com a ação da gravidade (Figura 57).

Figura 56 - Realização do ensaio de Moldabilidade com aplicação de força, no parâmetro Conformação (a) e e realização da medida de deformação utilizando paquímetro (b)

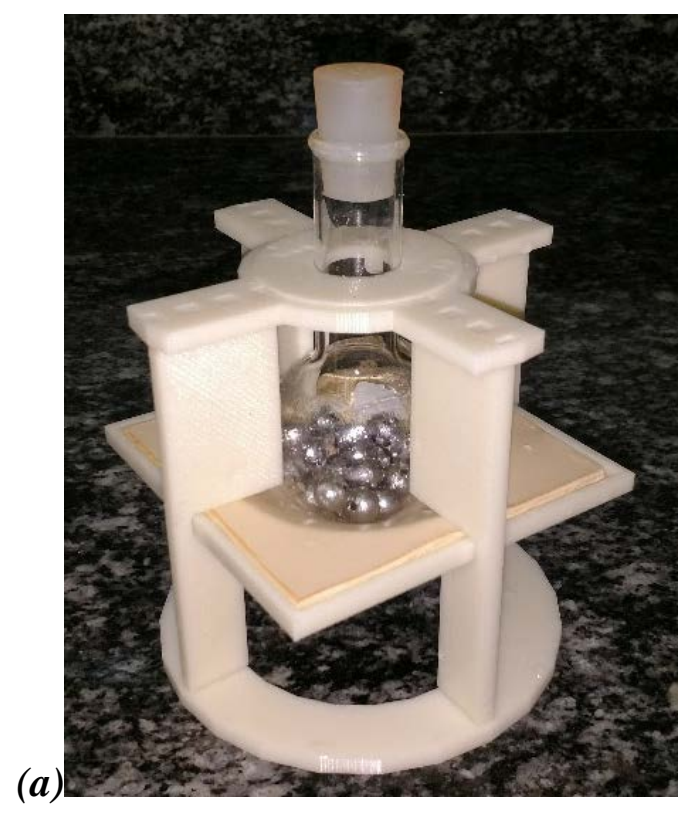

(b)

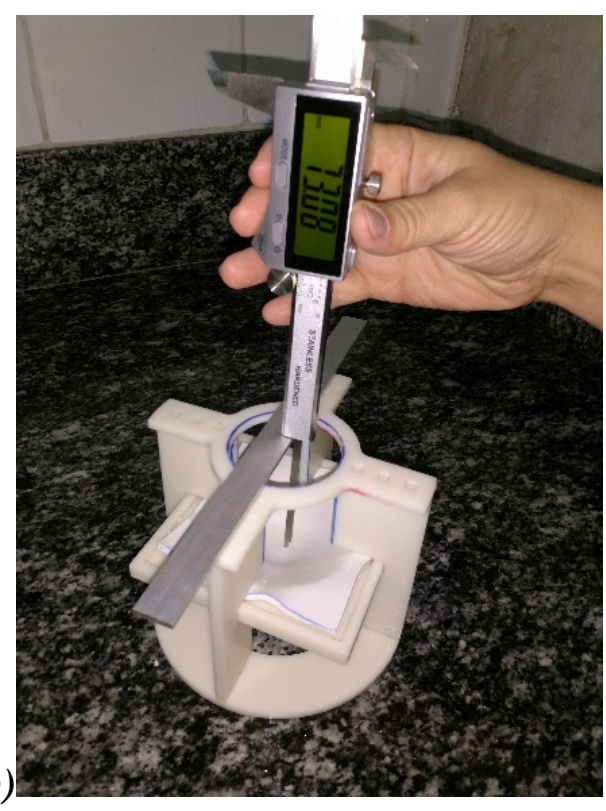

Fonte: elaborada pela autora 
Figura 57 - Realização do ensaio de Moldabilidade, no parâmetro Caimento: no banho aquecido (a) e durante o resfriamento $(b)$
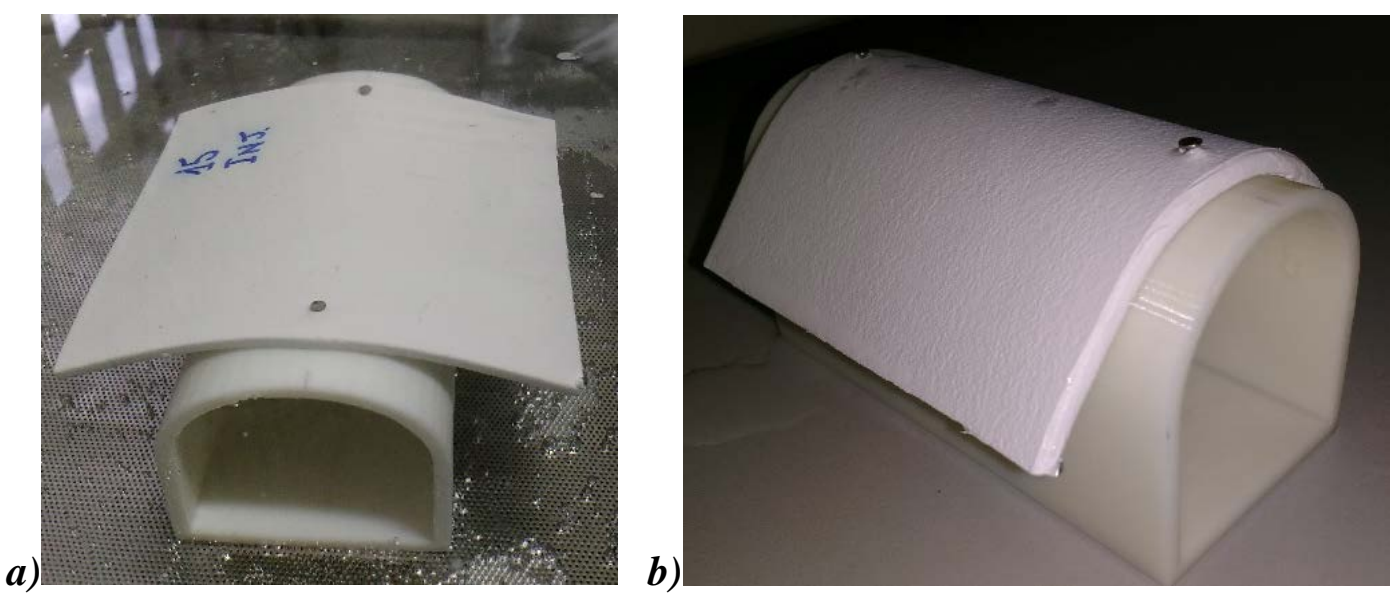

Fonte: elaborada pela autora

De acordo com os ensaios realizados (Figura 58) e das medidas obtidas conforme a padronização adotada para isso, foram calculadas, para cada material analisado, as porcentagens de Moldabilidade, tanto no quesito Conformação (com aplicação de massa - 300g) como no quesito Caimento (sem aplicação de força).

Figura 58 - Realização do ensaio de Moldabilidade, simultaneamente nos dois quesitos (Conformação e Caimento)

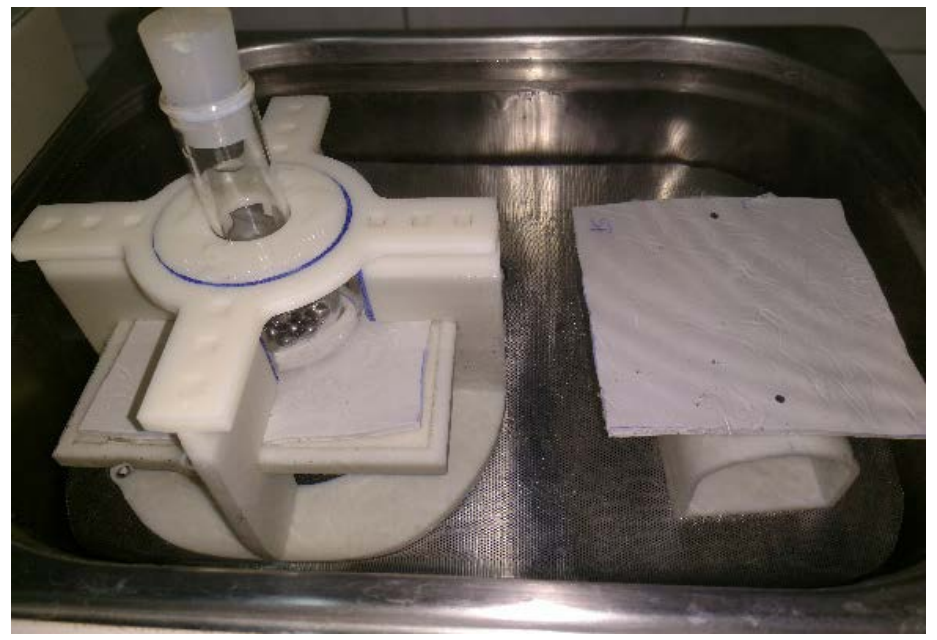

Fonte: elaborada pela autora

A Tabela 9 apresenta as porcentagens calculadas para os quatro materiais, referentes aos dois parâmetros de Moldabilidade. Destacam-se os valores do material comercial Aquaplast$\mathrm{T}^{\mathrm{TM}}$, que mostrou boa Conformação do objeto (55\%) e ótimo Caimento, com 100\% (Figura 59). Verifica-se que o Material A apresentou um ótimo resultado no primeiro parâmetro de Moldabilidade (53\%), mostrando uma porcentagem muito próxima à do Aquaplast-TM (55\%) 
e superior à do Ezeform ${ }^{\mathrm{TM}}$ (46\%), material comercial mais utilizado na prática clínica. No quesito Caimento apresentou um valor menor em relação aos materiais comerciais. O Material B apresentou 26\% de Conformação e 51\% de Caimento, ambos menores do que os materiais comerciais, mas menos distante do Ezeform ${ }^{\mathrm{TM}}$.

Tabela 9 - Resultados dos dois Ensaios de Moldabilidade do MPMTO

\begin{tabular}{|c|c|c|}
\hline Material & $\begin{array}{c}\text { Conformação } \\
\text { (300g de carga) }\end{array}$ & Caimento \\
\hline Ezeform $^{\mathrm{TM}}$ & $46 \%$ & $77 \%$ \\
\hline Aquaplast-TTM $^{\mathrm{TM}}$ & $55 \%$ & $100 \%$ \\
\hline Material A & $53 \%$ & $56 \%$ \\
\hline Material B & $26 \%$ & $51 \%$ \\
\hline \multicolumn{2}{|c|}{ Fonte: elaborada pela autora } \\
\end{tabular}

Figura 59 - Resultado do ensaio de Moldabilidade no quesito Caimento, para o material Aquaplast-T

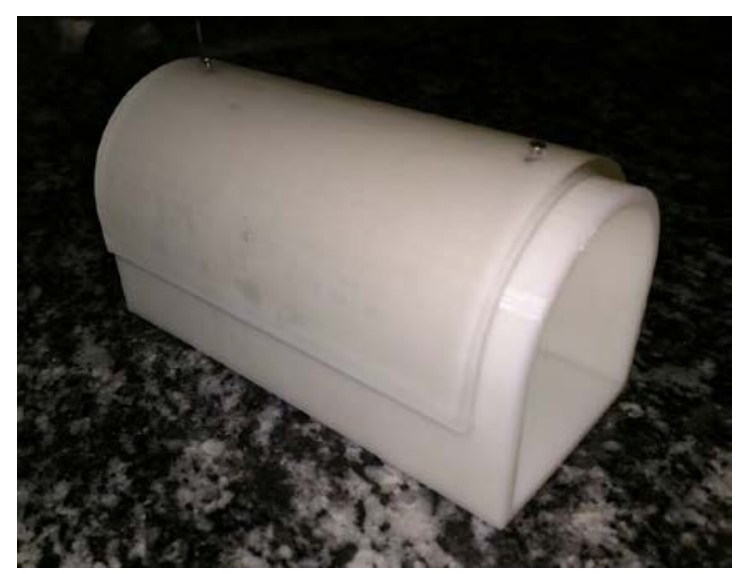

Fonte: elaborada pela autora

Os resultados obtidos foram relacionados às informações gerais fornecidas pelo fabricante quanto às características de manuseio (Tabela 10). A Figura 60 apresenta uma escala de Conformabilidade e de Resistência de todos os produtos da marca Rolyan ${ }^{\circledR}$, da empresa Fabricante Performance Health / Patterson Medical, incluindo o Ezeform ${ }^{\mathrm{TM}}$ e o Aquaplast-T ${ }^{\mathrm{TM}}$. Nota-se que os resultados dos testes desenvolvidos corroboram com as informações descritas no catálogo dos produtos, demonstrando o potencial dos ensaios elaborados para quantificar os quesitos relacionados a Moldabilidade. 
Tabela 10 - Relação entre a descrição do fabricante e os resultados do MPMTO quanto a Moldabilidade

\begin{tabular}{|c|c|c|c|}
\hline Material & Informações do Fabricante & $\begin{array}{c}\text { MPMTO } \\
\text { Conformação } \\
\text { (300g de carga) }\end{array}$ & $\begin{array}{l}\text { MPMTO } \\
\text { Caimento }\end{array}$ \\
\hline Ezeform $^{\mathrm{TM}}$ & $\begin{array}{l}\text { Boa conformabilidade. } \\
\text { A superfície é ligeiramente pegajosa quando o material } \\
\text { é aquecido, para ajudar a manter a posição da órtese. } \\
\text { Tolera bem o manuseio e proporciona excelente } \\
\text { acabamento de borda. }\end{array}$ & $46 \%$ & $77 \%$ \\
\hline $\begin{array}{c}\text { Aquaplast- } \\
\text { TTM }^{\mathrm{TM}}\end{array}$ & $\begin{array}{l}\text { Combinação ideal de conformabilidade e resistência ao } \\
\text { alongamento. } \\
\text { No branco é transparente quando aquecido e nas cores } \\
\text { mais claras é semitransparente. }\end{array}$ & $55 \%$ & $100 \%$ \\
\hline
\end{tabular}

Fonte: elaborada pela autora

Figura 60 - Escala de Conformabilidade e de Resistência dos termoplásticos de baixa temperatura da Rolyan ${ }^{\circledR}$

\section{Rolyan Low Temperature Thermoplastics}

- Heat activated between $150-170^{\circ} \mathrm{F}\left(65-75^{\circ} \mathrm{C}\right)$ in 30 seconds to 2 minutes,

- Working time of 1-6 minutes

- Thicknesses including 1/16" (1.6 mm), 1/12" (2.0 mm), 3/32" (2.4 mm), $1 / 8^{\prime \prime}(3.2 \mathrm{~mm}), 3 / 16^{\prime \prime}(4.8 \mathrm{~mm})$

- Solid or perforated material options

\section{Select a material that suits your splinting needs}

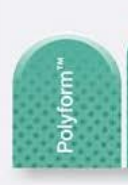

High

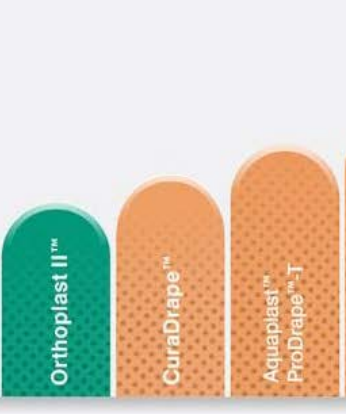

Conformability

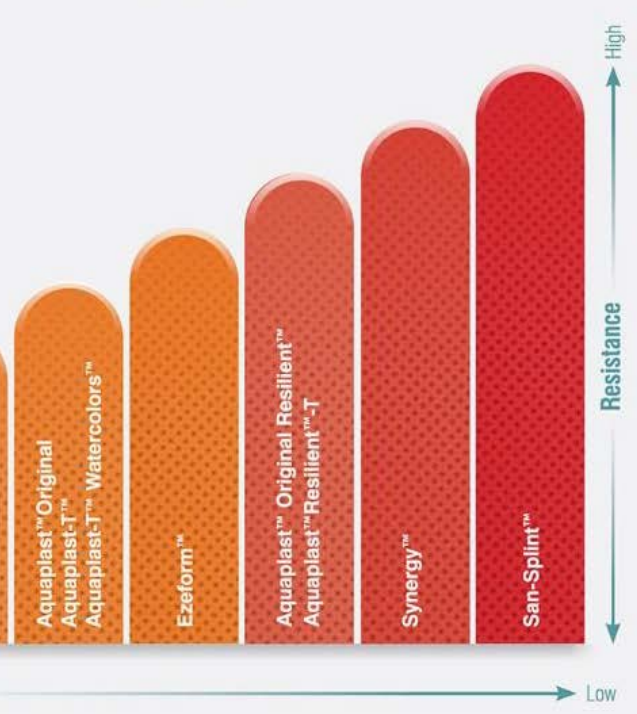

Fonte: Performance Health (2018b)

Após a avaliação dos dois materiais desenvolvidos, já na fase final do trabalho, optouse por realizar ajustes na formulação, a fim de produzir um material que pudesse ter um desempenho ainda mais satisfatório. Dessa forma, apesar de não estar previsto nos materiais e métodos, foi injetado um novo material, correspondente à $18^{\mathrm{a}}$ formulação da pesquisa, denominado, para esta análise, como material C. O mesmo foi testado e apresentou 53\% de 
Moldabilidade e 89\% de Caimento, valores discretamente superiores ao Ezeform ${ }^{\mathrm{TM}}$, nos dois parâmetros avaliados, e inferiores ao Aquaplast-T ${ }^{\mathrm{TM}}$, mas não muito distantes.

Alguns materiais disponíveis no mercado tornam-se transparentes quando aquecidos, como é o caso do Aquaplast-T ${ }^{\mathrm{TM}}$ e de alguns materiais da linha Orfit ${ }^{\circledR}$, podendo facilitar a avaliação da moldabilidade, especialmente durante os primeiros minutos de moldagem, na medida em que permitem a visualização da superfície na qual o material está sendo moldado, das proeminências ósseas e de possíveis pontos de pressão (EFECTIV MEDICAL DEVICES, 2018; SOUZA, 2014).

A facilidade com que o material se molda aos relevos anatômicos e sua capacidade para acomodar proeminências ósseas é crucial para o conforto da órtese, especialmente no caso do punho e da mão. Materiais de difícil aplicação e que não apresentam um bom caimento favorecem a formação de pregas e rugas indesejáveis no produto final, podendo ser considerados de má qualidade (CANELÓN, 1995). Ao investigar as propriedades físicas dos materiais utilizados na fabricação de órteses e palmilhas, Paton et al. (2007) mencionam que um material de fácil moldagem cede e reduz consideravelmente em um curto período de compressão aplicada. Entre as recomendações para uma boa moldagem, sugere-se que o seu manuseio seja no plano horizontal, em posição assistida pela ação da gravidade (NORTH COAST MEDICAL, 2018).

Materiais melhores quanto à moldabilidade apresentam excelente reprodução de detalhes, com alta precisão, e permanecem no formato desejado sem necessidade de pressionar enquanto estão sendo resfriados, sendo frequentemente associados à facilidade no processo de confecção de órteses (EFECTIV MEDICAL DEVICES, 2018; FESS, 2002; NORTH COAST MEDICAL, 2018). Por outro lado, materiais muito moldáveis podem ser difíceis de trabalhar, como por exemplo para a confecção de órteses de maior porte, para grandes segmentos do corpo. Nestes casos, materiais mais firmes, com alongamento mínimo, podem acomodar melhor.

Apesar da literatura e das empresas que atuam no ramo apresentarem estratégias para se avaliar a moldabilidade, isso é feito de forma descritiva, em relação às características observadas nos materiais. Na prática clínica a avaliação da moldabilidade, assim como de outras características, é feita, na maioria das vezes, pela observação e pela percepção do terapeuta que manipula e molda manualmente o material, e pela inspeção visual da qualidade do produto moldado (AGNELLI MARTINEZ et al., 2017). Isso também foi feito na fase exploratória desta pesquisa, através dos testes práticos empíricos, o que traz importantes contribuições, porém sem quantificar esta propriedade. 
O instrumento MPMTO possibilitou o cálculo numérico da Moldabilidade e contemplou dois parâmetros relatados na literatura: materiais que se moldam quando cedem à aplicação de toques por parte de quem o manipula e materiais que apresentam bom caimento, sem a necessidade de segurar constantemente. Ambos os parâmetros apresentam a expectativa de uma boa acomodação das superfícies anatômicas.

\section{3) MEMÓRIA}

Um dos sistemas de ensaio criados para avaliação da Moldabilidade, com peças projetadas e produzidas especificamente para isso, foi planejado também para avaliar e mensurar a Memória, propriedade que também é bastante considerada por profissionais e pesquisadores. Devido à memória, definida por Sauron (2003) como a tendência do material em retornar ao seu estado original, alguns materiais termoplásticos são interessantes para órteses seriadas, com boa vida útil, além de permitirem ajustes imediatos durante o processo de confecção (CANELÓN, 1995; POLITEC SAÚDE, 2018).

A Tabela 11 apresenta os cálculos para a Memória dos materiais avaliados, sendo que os materiais nacionais apresentaram valores superiores ao do Ezeform ${ }^{\mathrm{TM}}$.

Tabela 11 - Resultados do Ensaio de Memória

\begin{tabular}{|c|c|}
\hline Material & \%Memória \\
\hline Ezeform $^{\mathrm{TM}}$ & $12 \%$ \\
\hline Aquaplast-T $^{\mathrm{TM}}$ & $60 \%$ \\
\hline Material A & $44 \%$ \\
\hline Material B & $42 \%$ \\
\hline
\end{tabular}

Fonte: elaborada pela autora

O gráfico radar da Figura 61 apresenta os resultados do ensaio de memória, associados aos quesitos de Moldabilidade. O desempenho do material C, processado após as sugestões dos terapeutas participantes, também está representado no gráfico. 
Figura 61 - Gráfico Radar dos Ensaios de Moldabilidade e Memória

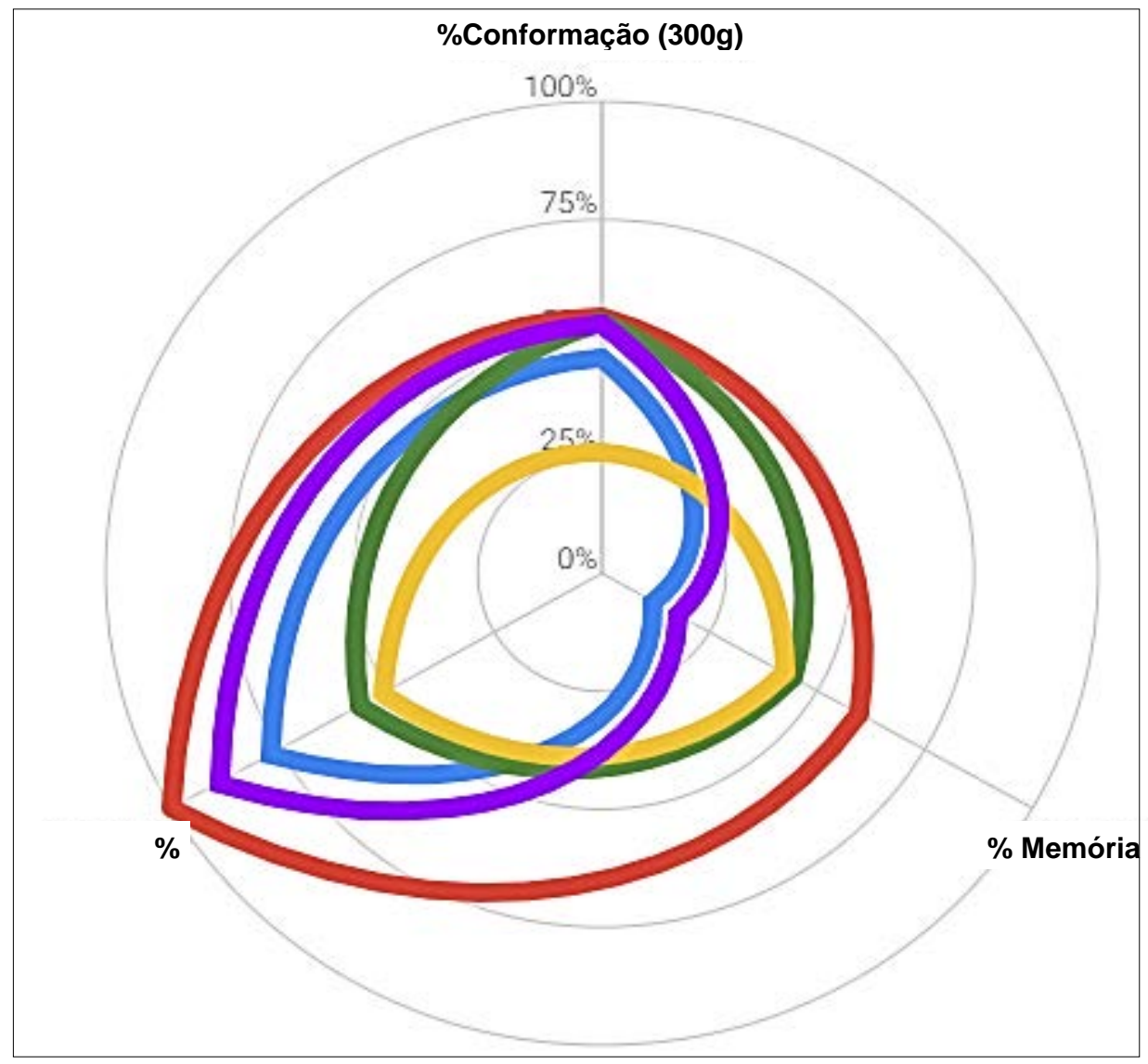

- Ezeform

- Aquaplast

- Material A

- Material B

- Material C

Fonte: elaborada pela autora

O Material C, produzido posteriormente, apresentou 18\% de Memória e, assim como nos quesitos de Moldabilidade, apresentou valor discretamente superior ao do Ezeform ${ }^{\mathrm{TM}} \mathrm{e}$ inferior ao do Aquaplast-T ${ }^{\mathrm{TM}}$. Em relação aos produtos comerciais, dados semelhantes são encontrados na literatura, em que o Aquaplast- ${ }^{\mathrm{TM}}$ apresenta melhor desempenho do que o Ezeform $^{\mathrm{TM}}$, no que diz respeito à memória e moldabilidade, especialmente no quesito caimento (LINDEMAYER, 2004).

No presente trabalho, o sistema construído para avaliar a memória, assim como demais ensaios do MPMTO, busca maneiras de traduzir a propriedade em valores numéricos passíveis de comparação e replicação, padronizando todos os procedimentos a fim de eliminar ou minimizar a interferência de variáveis externas. Os testes de moldabilidade e de memória aqui apresentados, diferentemente dos testes encontrados na literatura (LINDEMAYER, 2004; SOUZA, 2014), não envolvem o manuseio direto do material por parte do pesquisador ou sua percepção em relação ao material, já que houve padronização de todas as etapas, desde a moldagem até a verificação do retorno do material ao seu formato original. Além disso os testes 
práticos de memória descritos na literatura são unidirecionais, enquanto o teste do MPMTO envolve retorno do material após a acomodação tridimensional do objeto (cilíndrico).

Materiais com alta memória exigem um manuseio firme por parte do terapeuta e podem oferecer maior resistência, podendo ser indicados para grandes articulações; para algumas órteses pós-cirúrgicas; casos envolvendo espasticidade; queimaduras e em geral órteses para ganho de amplitude de movimento articular (AGNELLI; TOYODA, 2003; NORTH COAST MEDICAL, 2018).

A esse respeito, nos materiais desenvolvidos notou-se que, ao melhorar o caimento, perde-se em memória, o que parece ter sido, de alguma maneira, resolvido para o material comercial Aquaplast-T ${ }^{\mathrm{TM}}$. Este mostrou-se um material diferenciado, cujos resultados apontam um alto grau de moldabilidade somado a $60 \%$ de memória. Apesar disto, pode haver queixas quanto ao Aquaplast-T ${ }^{\mathrm{TM}}$ no que diz respeito ao tempo de enrijecimento, como já relatado nos resultados do primeiro item do MPMTO (Temperatura de Trabalho).

Os resultados dos produtos comerciais referentes à Memória foram relacionados às informações gerais fornecidas pelo fabricante e estão dispostos na Tabela 12.

Tabela 12 - Relação entre a descrição do fabricante e os resultados do MPMTO no quesito Memória

\begin{tabular}{|c|c|c|}
\hline Material & Informações do Fabricante & $\begin{array}{c}\text { MPMTO } \\
\text { Memória }\end{array}$ \\
\hline Ezeform $^{\text {TM }}$ & $\begin{array}{c}\text { Ele permanece no lugar enquanto os } \\
\text { contornos críticos são moldados. }\end{array}$ & $12 \%$ \\
\hline Aquaplast-T & $\begin{array}{c}\text { Apresenta } 100 \% \text { de memória, } \\
\text { permitindo revisões e remodelagens }\end{array}$ & $60 \%$ \\
\hline \multicolumn{2}{|c}{} \\
\hline
\end{tabular}

Além de quantificar as características descritas no catálogo, o ensaio se mostrou eficiente pois os dados obtidos estão em concordância com as informações do fabricante, que afirma que o Aquaplast-T ${ }^{\mathrm{TM}}$ apresenta mais memória do que o Ezeform ${ }^{\mathrm{TM}}$.

\section{4) AUTOADERÊNCIA}

Optou-se por padronizar os procedimentos para a obtenção da aderência entre as extremidades de um mesmo material, a fim de controlar a força a ser aplicada e possibilitar a comparação. Dessa forma, a massa a ser depositada foi calculada simulando-se a força que o terapeuta utiliza para o acabamento e aderência de termoplásticos na prática clínica.

O sistema construído (Figura 62) mostrou-se eficiente na padronização da aderência, eliminando-se o risco de realizar o procedimento com imprecisão da força a ser aplicada. Dessa 
forma, foram preparadas as amostras (Figura 63) para o Ensaio de Aderência com solicitação de tração.

Figura 62 - Sistema construído para realização da aderência de forma padronizada (a) e durante o uso (b)
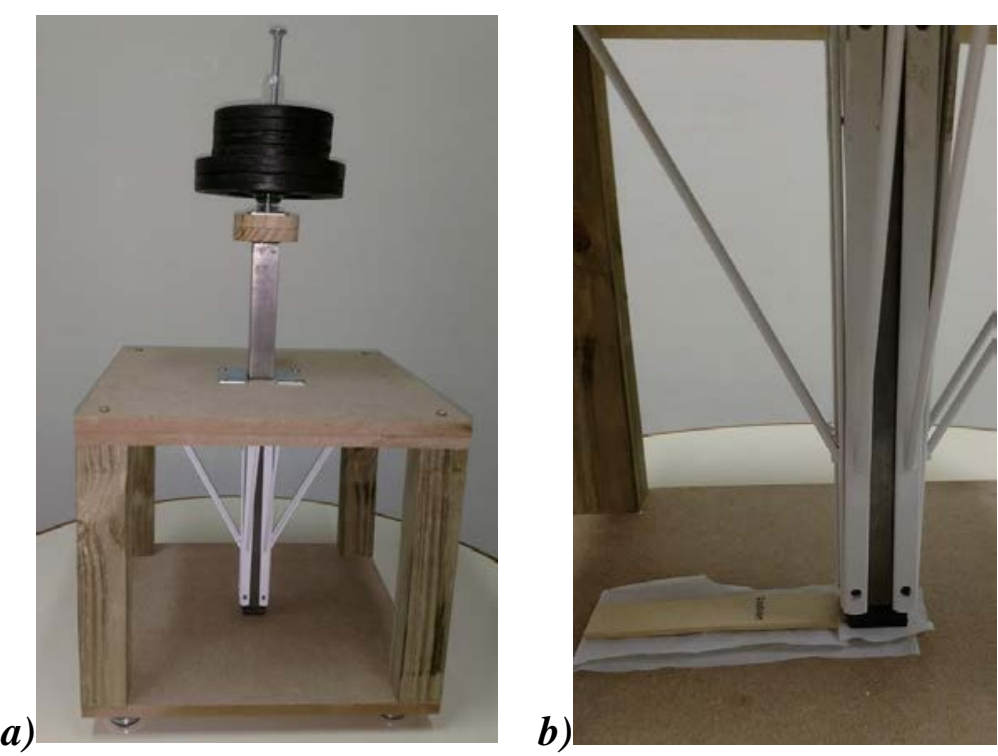

Fonte: elaborada pela autora

Figura 63 - Amostra preparada para o Ensaio de Aderência com solicitação de tração

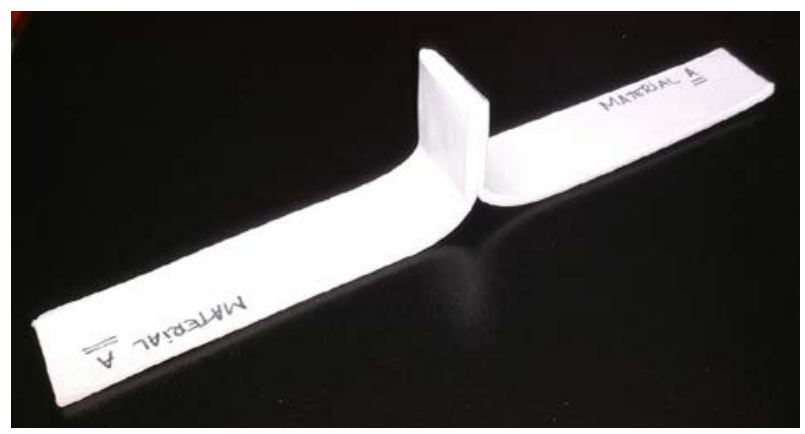

Fonte: elaborada pela autora

Para compor os critérios de avaliação foi selecionado o Ensaio de Aderência com solicitação de tração (ASTM, 2014a), ilustrado na Figura 64, pois mede a força necessária para o destacamento entre as partes aderidas, de forma que a execução deste foi realizada somente após a realização das outras etapas pré-determinadas. 
Figura 64 - Realização do Ensaio de Tração

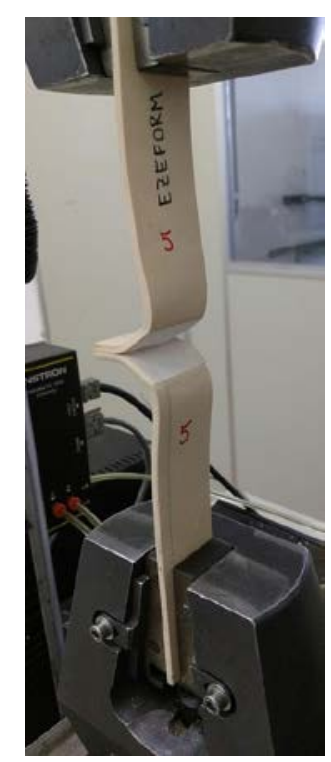

Fonte: elaborada pela autora

O ensaio normatizado selecionado para compor o protocolo aqui elaborado também foi utilizado por alguns autores, porém com uma aplicabilidade diferente. Lindemayer (2004) utilizou o ensaio para verificar as propriedades mecânicas, mais especificamente a resistência à ruptura e a rigidez dos materiais avaliados, correlacionando com a resistência da órtese na prática clínica. No trabalho de Souza (2014), o ensaio foi usado para verificar a resistência do material após alterações em sua composição (como o acréscimo de carga). No instrumento MPMTO o referido ensaio foi escolhido para auxiliar na padronização da avaliação do item quatro, Autoaderência, em que a tração foi utilizada na separação das partes aderidas do material e para quantificar a força necessária para isso.

A Figura 65 e a Tabela 13 apresentam os resultados fornecidos pelos ensaios de aderência com solicitação de tração, para os quatro materiais. Considerou-se que a Resistência da Adesão (ao destacamento) é a força média na região de escoamento dividida pela largura do corpo de prova $(3 \mathrm{~cm})$. 
Figura 65 - Curvas da Resistência da Adesão (ao destacamento)

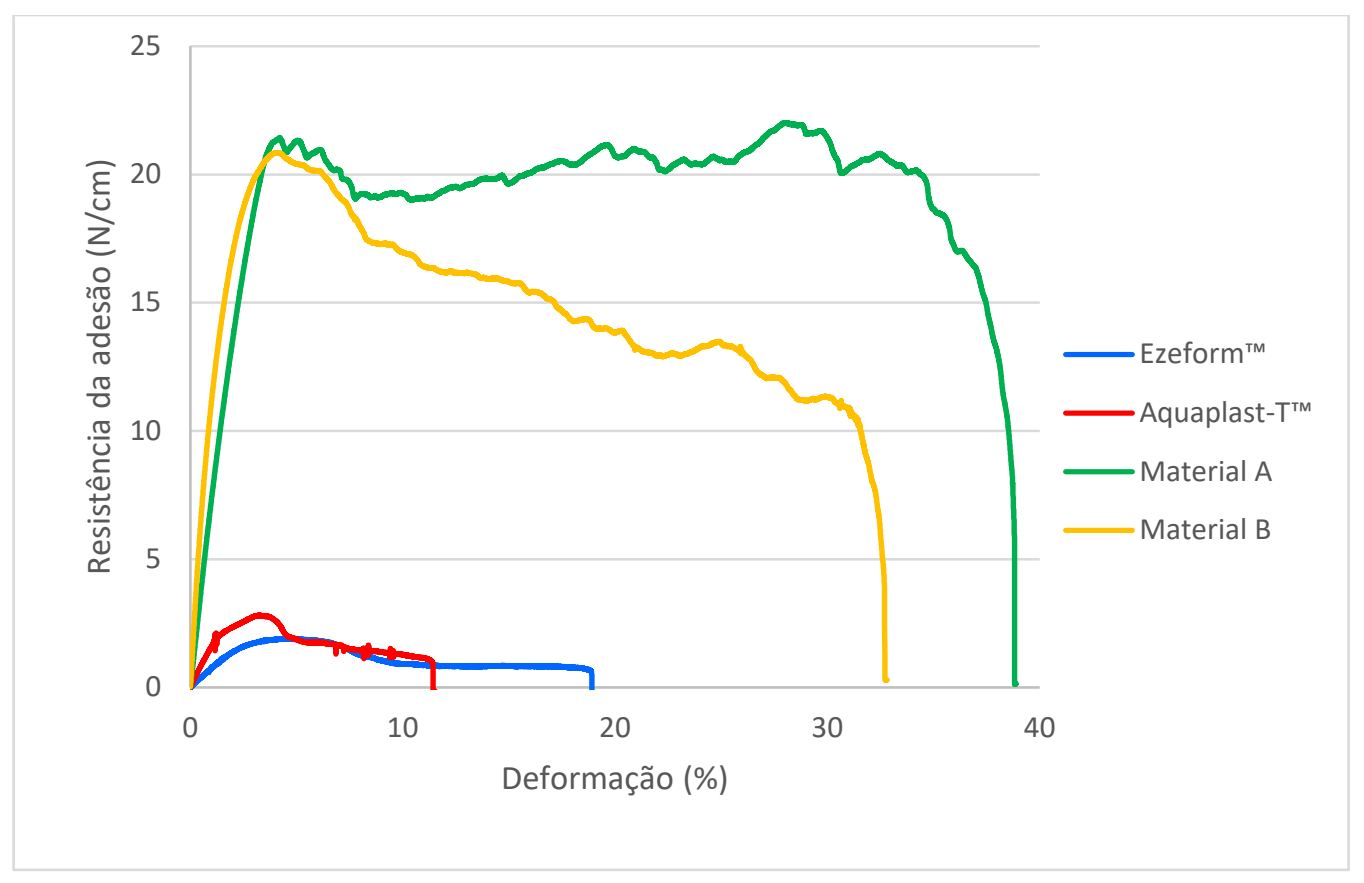

Fonte: elaborada pela autora

Tabela 13 - Valores obtidos no Ensaio de Aderência com solicitação de tração, relacionados à descrição do fabricante.

\begin{tabular}{|c|c|c|}
\hline Material & Informações descritivas do Fabricante & $\begin{array}{c}\text { Resistência da adesão } \\
\text { (N/cm) }\end{array}$ \\
\hline Aquaplast-T $^{\mathbf{T M}}$ & $\begin{array}{c}\text { Pode ser usado para uma ligação temporária, } \\
\text { comprimindo as superfícies aquecidas. }\end{array}$ & $1,5 \pm 0,2$ \\
\hline Ezeform $^{\mathrm{TM}}$ & $\begin{array}{c}\text { Liga-se permanentemente quando superfícies } \\
\text { aquecidas são comprimidas }\end{array}$ & $0,83 \pm 0,04$ \\
\hline Material A & ----- & $20,5 \pm 0,7$ \\
\hline Material B & ---- & $14,3 \pm 1,6$ \\
\hline
\end{tabular}

Fonte: elaborada pela autora

O catálogo de uma das empresas que fabrica materiais termoplásticos para órteses explica que a quantidade de revestimento varia entre os materiais e afeta diretamente o nível de aderência e o tipo de ligação entre suas partes (NORTH COAST, 2014). Os materiais que não apresentam revestimento tendem a ser pegajosos quando aquecidos e podem criar um vínculo permanente quando duas partes são pressionadas uma contra a outra.

Devido a esse vínculo permanente, como é descrito no caso do Ezeform ${ }^{\mathrm{TM}}$ (PERFORMANCE HEALTH, 2018a), as partes se unem e praticamente se fundem diante da pressão aplicada, gerando um tipo de aderência diferente da que acontece no Aquaplast-TM, 
em que as partes se unem, mas não se misturam. Isso ficou claro durante a aplicação do ensaio de aderência com solicitação de tração, em que o primeiro material se descola gradativamente durante o ensaio (Figura 66), apresentando inclusive mudança de textura e de coloração nas partes aderidas. Quanto ao Aquaplast-T ${ }^{\text {TM }}$ (Figura 67), as duas extremidades foram separadas repentinamente, demonstrando ligação temporária e indicando a existência de revestimento.

Figura 66 - Ensaio de Aderência com solicitação de tração, com o Material Ezeform ${ }^{\mathrm{TM}}$

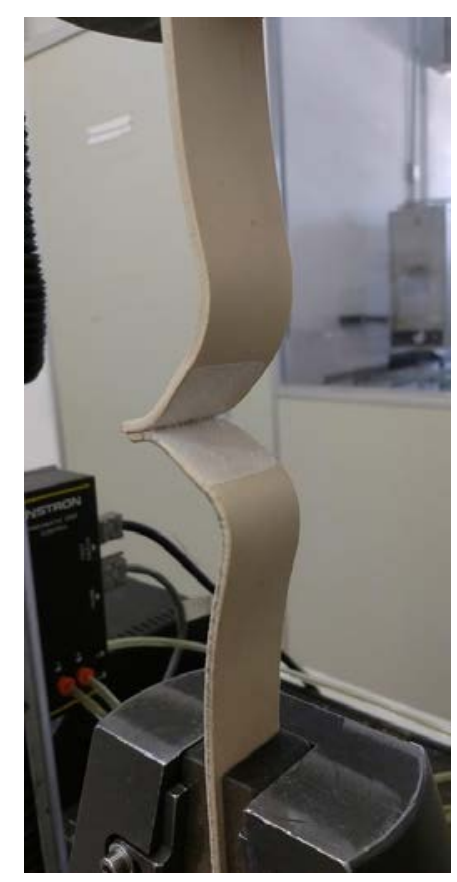

Fonte: elaborada pela autora

Figura 67 - Ensaio de Aderência com solicitação de tração, com o Material Aquaplast-TM, início do teste (a), destacamento repentino $(b)$

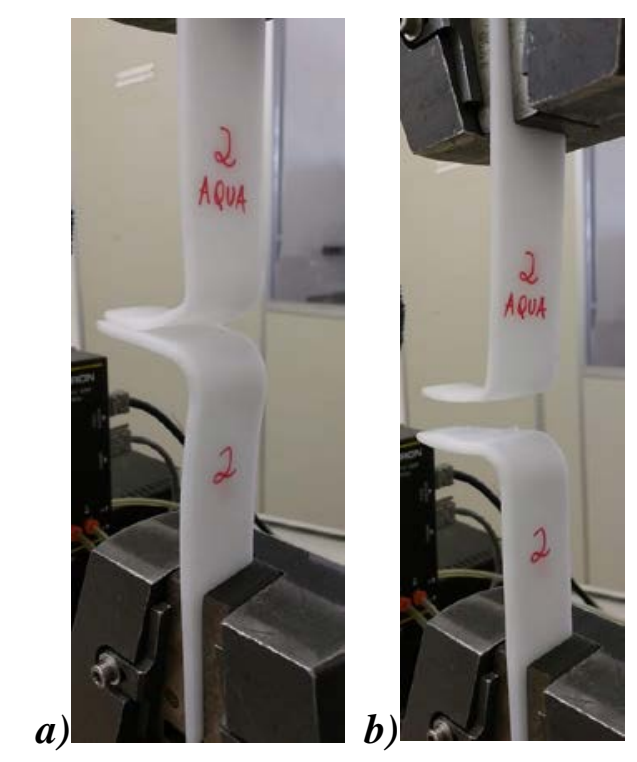

Fonte: elaborada pela autora 
Apesar de apresentarem um tipo de ligação ou aderência diferente, não houve diferença significativa entre os materiais comerciais, quanto à força necessária para o destacamento. Verifica-se que a aderência do Aquaplast-T ${ }^{\mathrm{TM}}$ é considerada temporária por causa do tipo de ligação e não devido à força necessária para desfazê-la. Dessa forma, mesmo não sendo considerada permanente, a aderência do Aquaplast-T $\mathrm{T}^{\mathrm{TM}}$ se mostra eficaz, cujas partes se mantêm unidas tão fortemente quanto ao Ezeform ${ }^{\mathrm{TM}}$.

Quanto aos materiais desenvolvidos, observa-se a necessidade de uma força cerca de 20 vezes maior para o material $\mathrm{B}$ e 14 vezes maior para o material $\mathrm{A}$, em relação à média dos materiais comerciais. Isso pode ser considerada uma vantagem para determinadas situações, pois ressalta uma ótima capacidade de adesão quando comparados aos materiais do mercado. Como não apresentam revestimento de superfície, o tipo de ligação dos produtos desenvolvidos foi permanente e o descolamento foi gradativo, assim como no Ezeform ${ }^{\mathrm{TM}}$, havendo mudança na textura e na coloração das partes aderidas (Figura 68 e Figura 69).

Figura 68 - Ensaio de Aderência com solicitação de tração, com o Material A em dois momentos: início (a) e final (b)
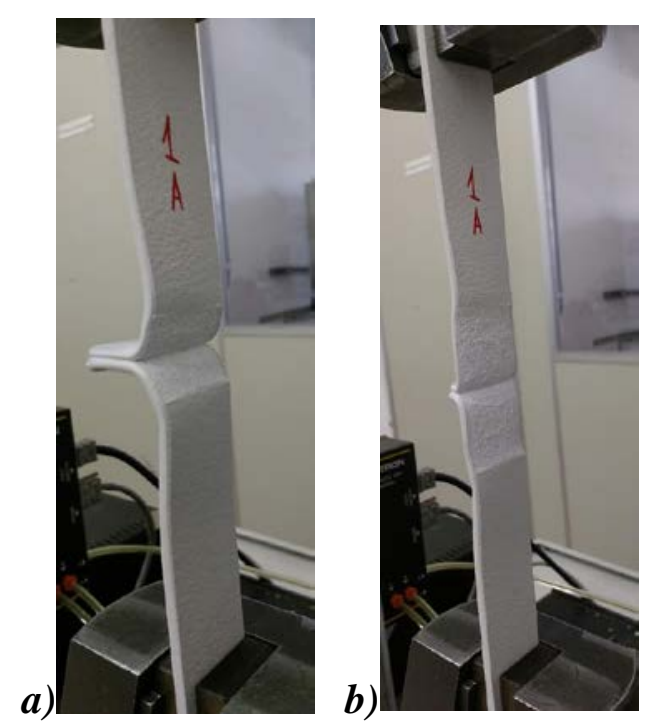

Fonte: elaborada pela autora 
Figura 69 - Ensaio de Aderência com solicitação de tração, com o Material B

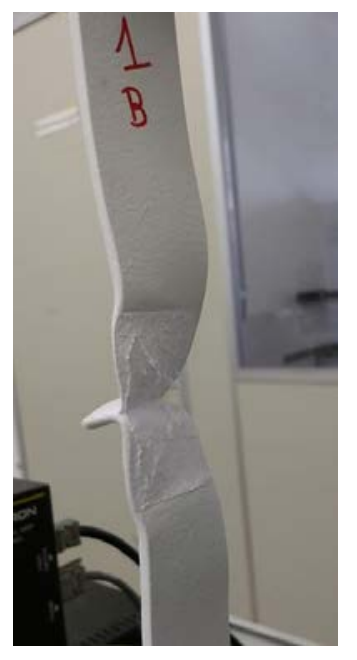

Fonte: elaborada pela autora

O instrumento foi capaz de quantificar a diferença existente entre a força necessária para separar os quatro materiais analisados e o desempenho dos materiais durante os ensaios apontou para o tipo de ligação proporcionada pelos materiais.

Além de facilitar o processo de confecção, um material com boa capacidade de adesão favorece o acabamento, permitindo arredondamentos e dobras em algumas extremidades, influenciando inclusive na integridade e na durabilidade das órteses (CANELÓN, 1995; LINDEMAYER, 2004). Essa propriedade muitas vezes favorece a fixação de outros componentes nas órteses, como velcros, ganchos ou correias.

De uma forma geral a aderência é vista como um aspecto positivo na prática clínica, porém é importante ressaltar que materiais excessivamente aderentes, como alguns dos que tinham sido formulados no início desta pesquisa, podem ser prejudiciais para o processo de confecção e para a qualidade do produto moldado. Materiais que se aderem demais ao se tocarem naturalmente, sem a aplicação de força, dificultam o manuseio e acabam aderindo em regiões não desejadas pelo terapeuta, além do fato de possivelmente se apresentarem grudentos à mão do terapeuta e à pele do usuário. Por outro lado, materiais que necessitam de bastante pressão por parte do terapeuta para se aderirem, podem levar à deformação e até mesmo a uma diminuição da espessura no local aderido, podendo ficar mais frágil/fraco. Ressalta-se que essas observações são relativas, uma vez que as vantagens ou desvantagens dependem da aplicação.

Verifica-se que há materiais com revestimento no mercado de termoplásticos para órteses, possibilitando ligações/aderências quando suas partes são pressionadas, porém de forma temporária. Dessa forma, diante da diversidade de aplicações, atualmente estão 
disponíveis comercialmente produtos com três diferentes características quanto ao revestimento, proporcionando ligações/aderências diferentes:

- Materiais sem revestimento: criam uma ligação eficaz e permanente somente com pressão enquanto estiverem aquecidos, sem a necessidade de solventes. Tendem a ser pegajosos quando aquecidos. Alguns exemplos de materiais sem revestimento: Orfit ${ }^{\circledR}$ Classic (ORFIT INDUSTRIES, 2018), Solaris ${ }^{\mathrm{TM}}$ (NORTH COAST MEDICAL, 2018), Rolyan ${ }^{\circledR}$ Ezeform $^{\mathrm{TM}}$, Rolyan ${ }^{\circledR}$ Polyflex II ${ }^{\mathrm{TM}}$ e Rolyan ${ }^{\circledR}$ San-Splint ${ }^{\mathrm{TM}}$ (PERFORMANCE HEALTH, 2018a).

- Materiais com revestimento tradicional: pode-se obter aderência temporária entre as partes apenas com o aquecimento e a pressão das extremidades, porém a força necessária para isso e para separá-las posteriormente irá depender da quantidade e do tipo de revestimento. Para que a adesão seja permanente, é necessária a aplicação de solvente. Esse tipo de revestimento é interessante para evitar ligações permanentes quando indesejadas. Alguns exemplos são: Clinic ${ }^{\circledR}$, Prism $^{\mathrm{TM}}$, Vanilla ${ }^{\mathrm{TM}}$, Spectrum ${ }^{\mathrm{TM}}$, Encore ${ }^{\mathrm{TM}}$ (NORTH COAST MEDICAL, 2018), Orfit ${ }^{\circledR}$ Natural NS; Orfit ${ }^{\circledR}$ Colors NS, Orfit ${ }^{\circledR}$ NS, Orfibrace ${ }^{\mathrm{TM}}$, Orfit ${ }^{\circledR}$ Soft-Fit NS (ORFIT INDUSTRIES, 2018) e Rolyan ${ }^{\circledR}$ Aquaplast-T ${ }^{\mathrm{TM}}$, (PERFORMANCE HEALTH, 2018a).

- Materiais com revestimento em pó: incorporam uma quantidade de talco natural, para melhorar a facilidade de uso. Este revestimento tem um nível moderado de aderência quando duas partes do material forem aquecidas e pressionadas, e pode exigir um mínimo de solvente para remover o pó para uma colagem permanente, se for necessário. Alguns exemplos desse grupo são: Preferred ${ }^{\circledR}$, Omega $^{\text {TM }}$ Max, Omega ${ }^{\text {TM }}$ Plus (NORTH COAST MEDICAL, 2018).

Para que seja possível a obtenção de adesões permanentes, alguns materiais com revestimento tradicional são comercializados com a orientação para uso de solventes nas regiões do material que precisarem de aderência, além de aquecer e pressionar firmemente. Uma recomendação disponível é raspar o revestimento externo da placa de material termoplástico para uma junção mais efetiva, com aplicação de calor localizado e pressão firme (NORTH COAST MEDICAL, 2018). Nas informações técnicas do Aquaplast-T ${ }^{\mathrm{TM}}$ existe a recomendação para remover o revestimento, com solvente ou com uma lixa, caso seja necessária uma colagem permanente (PERFORMANCE HEALTH, 2018a).

Um dos fabricantes apresenta opções do mesmo material, com e sem revestimento. Quanto aos materiais mais aderentes, não revestidos, o mesmo fabricante recomenda a utilização de talco para evitar adesão excessiva durante a moldagem (ORFIT INDUSTRIES, 2018). 


\section{5) RIGIDEZ}

Para mensurar a rigidez, quinto e último item do instrumento MPMTO, selecionou-se o Ensaio de Flexão em três pontos, pois esta é considerada como uma das solicitações mais representativas das condições práticas do uso de órteses. De forma prática, para esta aplicação, a rigidez pode ser entendida como a capacidade do material em permanecer no formato moldado/resfriado.

A Figura 70 apresenta as curvas médias para os ensaios de flexão e a Tabela 14 apresenta os valores numéricos da Tensão de Flexão a 5\% de deformação e do Módulo de Rigidez.

Figura 70 - Curvas médias para os ensaios de flexão dos quatro materiais

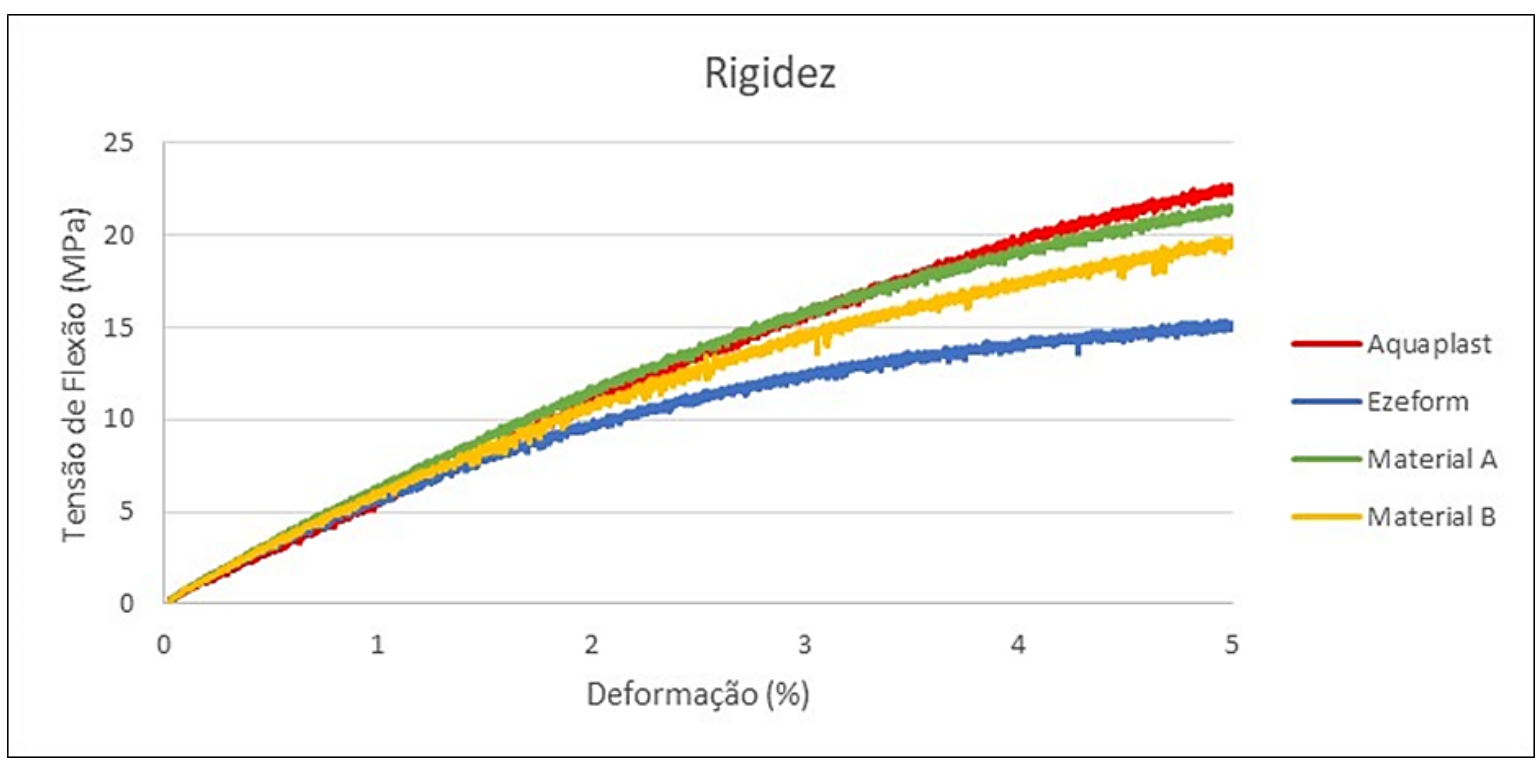

Fonte: elaborada pela autora

Tabela 14 - Valores obtidos no Ensaio de Flexão em três pontos

\begin{tabular}{|c|c|c|}
\hline Material & Módulo de Rigidez (GPa) & $\begin{array}{c}\text { Tensão de Flexão a 5\% de } \\
\text { deformação (MPa) }\end{array}$ \\
\hline Aquaplast-T $^{\mathrm{TM}}$ & $0,56 \pm 0,02$ & 22,7 \\
\hline Ezeform $^{\text {TM }}$ & $0,59 \pm 0,04$ & 15,3 \\
\hline Material A & $0,61 \pm 0,06$ & 21,6 \\
\hline Material B & $0,59 \pm 0,03$ & 19,8 \\
\hline
\end{tabular}

O módulo de rigidez é obtido através do comportamento do material no início do ensaio, ou seja, representa a rigidez intrínseca do material considerando a tensão necessária para a deformação inicial do material. Quanto ao Módulo de rigidez verifica-se que os materiais 
apresentaram valores muito próximos, variando de 0,56GPa (Aquaplast-T ${ }^{\mathrm{TM}}$ ) a 0,61GPa (Material A). Considerando o erro padrão, não há diferenças significativas entre eles.

Na Tensão de Flexão a 5\% de deformação, que corresponde à tensão necessária para a flexão do material após a fase inicial de deformação, foi possível verificar que os materiais não se mantêm semelhantes como no início do ensaio. Considerando este critério, observa-se que o Aquaplast- $\mathrm{T}^{\mathrm{TM}}$ foi o material que demonstrou um valor maior, enquanto o Ezeform ${ }^{\mathrm{TM}}$ apresentou o menor valor. Os materiais desenvolvidos apresentaram valores próximos ao Aquaplast-T TM , sendo que o Material A mostrou maior tensão do que o Material B.

Algumas aplicações em órteses necessitam que o material seja resistente a deformações diante de uma força aplicada constantemente, principalmente quando o objetivo do dispositivo é alinhar, proteger e/ou imobilizar uma articulação, evitando deformidades, ou ainda nos casos de órteses seriadas com a finalidade de alongamento de tecidos e melhora da amplitude de movimento. Materiais mais rígidos devem manter a forma moldada mesmo diante da ação de músculos fortes, de componentes dinâmicos ou ainda de hipertonia (EFECTIV MEDICAL DEVICES, 2018; LINDEMAYER, 2004; NORTH COAST MEDICAL, 2018). No entanto nem sempre há disponibilidade de materiais mais rígidos, capazes de suportar o excesso de força e pressão decorrente da espasticidade, sendo necessário, nestes casos, aplicar reforços na estrutura das órteses, especialmente nas regiões em que houver maior pressão. Uma estratégia que pode ser adotada na prática clínica para tornar a órtese menos flexível baseia-se no princípio de que um corpo plano é mais flexível do que um corpo côncavo ou abaulado. Portanto, modelando-se o dispositivo com curvaturas ou acrescentando-se tubos circunferenciais a algumas regiões da órtese, é possível torná-la mais rígida (FERRIGNO, 2007).

Quanto ao método selecionado para avaliar a rigidez, o Ensaio de Flexão em três pontos foi eficaz para a avaliação deste quesito e, de fato, se mostrou uma das solicitações mais representativas das condições práticas dessa aplicação, corroborando com os estudos de Leite (2007), Ramos (2017) e Rodrigues (2007), que também utilizaram esse ensaio na avaliação de materiais para órteses, com resultados satisfatórios.

Ressalta-se que a maioria das órteses usadas na clínica são confeccionadas a partir do princípio de forças de três pontos, que se organiza em um consistente padrão linear de forças paralelas e opostas, em que uma força central é direcionada em oposição a uma força distal e a uma outra proximal (FESS, 1995; RODRIGUES; CAVALCANTI; GALVÃO, 2007). Esse tipo de órtese baseia-se no sistema de alavanca de primeira classe e os terapeutas experientes comumente utilizam princípios de vantagem mecânica, a fim de influenciar na durabilidade e no conforto do produto. Seguindo esse raciocínio, uma estratégia a ser adotada é equilibrar a 
aplicação de forças e aumentar o braço de alavanca. Além disso, melhorar a distribuição de pressão também pode deixar uma órtese mecanicamente mais forte. (FERRIGNO, 2007; FESS, 2011; RODRIGUES; CAVALCANTI; GALVÃO, 2007).

Os resultados da Tensão de Flexão a 5\% de deformação puderam descrever numericamente o que os fabricantes afirmaram qualitativamente em seus catálogos, de acordo com a Tabela 15.

Tabela 15 - Relação entre a descrição do fabricante e os resultados do MPMTO no quesito Rigidez

\begin{tabular}{|c|c|c|}
\hline Material & Informações do Fabricante & $\begin{array}{c}\text { MPMTO - Rigidez } \\
\text { Critério: Tensão de flexão a } \\
5 \% \text { de deformação (MPa) }\end{array}$ \\
\hline $\begin{array}{c}\text { Ezeform } \\
(3,2 \mathrm{~mm})\end{array}$ & $\begin{array}{c}\text { Material forte e durável; } \\
\text { Resistência máxima ao estiramento; } \\
\text { Placas com espessura de 4,8mm apresentam } \\
\text { rigidez máxima }\end{array}$ & 15,3 \\
\hline $\begin{array}{c}\text { Aquaplast-T } \\
(3,2 \mathrm{~mm})\end{array}$ & $\begin{array}{c}\text { Resistente moderada ao estiramento; } \\
\text { Placas com espessura de 4,8mm apresentam } \\
\text { rigidez máxima }\end{array}$ & 22,7 \\
\hline
\end{tabular}

As informações técnicas disponíveis sobre os produtos comerciais a respeito da Rigidez não são específicas a esta propriedade, exclusivamente. São fornecidas informações descritivas, principalmente sobre a resistência ao estiramento, que não deve ser interpretada como rigidez, embora essas duas características possam estar relacionadas. Nesse sentido, Rodrigues et al. (2007) alertam para possíveis dúvidas que acontecem na prática clínica, como por exemplo confundir a resistência ao alongamento (durante o processo de moldagem) com a rigidez (da órtese após moldada).

Um dado importante do catálogo é que os materiais da marca Rolyan® apresentam máxima rigidez nas placas com espessura de 4,8mm. No entanto, os dados são genéricos e não escalonados, não sendo possível comparar os valores obtidos no MPMTO às informações do fabricante quanto a este quesito. Independentemente disso, o ensaio selecionado para compor o instrumento é normalizado e, portanto, confiável para quantificar a Rigidez dos materiais.

\section{Resultados gerais do MPMTO}

Após a aplicação sistematizada dos cinco itens do MPMTO, com quatro materiais diferentes, os resultados foram satisfatórios e o instrumento apresentou potencial para a 
comparação entre materiais, podendo ser utilizado na prática clínica, assim como em outros estudos com a finalidade de testar materiais para órteses.

A realização de todos os ensaios para verificar as propriedades dos termoplásticos para órteses, seja no estudo inicial dos materiais do mercado, seja na fase experimental, esclarece aspectos dos materiais que empiricamente se percebe na prática clínica. Nesse sentido, testes padronizados são importantes na medida em que proporcionam uma análise precisa dos materiais a serem utilizados em alguns contextos de reabilitação (CALLISTER; RETHWISCH, 2016; LINDEMAYER, 2004). Os ensaios do instrumento MPMTO foram elaborados justamente para estabelecer parâmetros e procedimentos a serem adotados, passíveis de replicação e comparação entre os materiais, possibilitando correta interpretação de dados obtidos.

A quantificação das propriedades dos materiais destinados à confecção de órteses é um passo importante e necessário para se categorizar os materiais disponíveis e compreender as diferenças entre eles, mesmo que sejam sutis, uma vez que, segundo Breger-Lee e Buford Junior (1992), as informações nem sempre estão disponíveis detalhadamente nos catálogos. Atualmente os catálogos online oferecem informações detalhadas e abrangentes, inclusive com sugestões e possibilidades de aplicação. Apesar disto, não há uma quantificação numérica que possibilite, por exemplo, a comparação entre produtos de diferentes fabricantes, o que facilitaria a seleção de materiais por parte dos terapeutas.

O instrumento MPMTO possibilitou quantificar as informações do fabricante, mostrando concordância com os dados do catálogo, no que diz respeito às propriedades selecionadas para compor o protocolo, exceto no quesito Rigidez. O instrumento passou por pré-testes e a versão final foi aplicada na íntegra, mostrando-se eficaz para essa finalidade. No entanto como foram testados somente dois produtos, não se pode afirmar que o instrumento está validado. Para que isto seja possível, sugere-se sua aplicação com outros materiais do mercado, inclusive de outros fabricantes, para, de fato, mensurar e comprovar as diferenças descritas entre diversos materiais. Foi possível gerar valores de referência para uma análise mais aprofundada e verificação de sua aplicabilidade, na medida em que isto for feito com outros termoplásticos de baixa temperatura e em um número maior de amostras.

Os aspectos relevantes quanto aos materiais para a confecção de órteses estão incorporados no MPMTO, conforme se verifica na literatura, que aponta as principais características e propriedades que favorecem o uso dos termoplásticos de baixa temperatura na confecção de órteses para os membros superiores: moldabilidade; adesão ou autoaderência; rigidez, diante de forças aplicadas; a durabilidade, definida por alguns autores como a 
capacidade de um material em resistir a estresse repetitivo; memória, que é a tendência do material a retornar ao seu estado original; e acabamento, definido como a suscetibilidade de absorver marcas na superfície enquanto quentes (AGNELLI; TOYODA, 2003; ASSUMPÇÃO, 2005; CANELÓN, 1995; LINDEMAYER, 2004; MN, 2018; O’BRIEN; BAILEY, 2011; POLITEC SAÚDE, 2018; SAURON, 2003; SILVA, 2014).

Quanto à Temperatura de Trabalho, parece ser a característica de maior controle por parte dos profissionais na prática clínica, uma vez que essa informação geralmente está disponível, dependendo da marca do material, ou pode ser deduzida de acordo com outras informações técnicas fornecidas (EFECTIVE MEDICAL DEVICES, 2018; MN, 2018; POLITEC SAÚDE, 2018).

\subsubsection{Avaliação de dois materiais desenvolvidos, de acordo com critérios da prática clínica, por profissionais com experiência na área}

Dos 34 profissionais convidados a participarem da pesquisa, 5 não aceitaram. No total 29 terapeutas responderam a Pesquisa inicial sobre confecção de órteses e 24 deles, de fato, realizaram a avaliação dos materiais desenvolvidos.

\section{Caracterização da Amostra}

Dos profissionais que responderam à Pesquisa Inicial, 10 participantes eram fisioterapeutas e 19 eram terapeutas ocupacionais, todos com experiência na confecção de órteses para membros superiores e no uso de termoplásticos de baixa temperatura há mais de quatro anos. A maioria dos profissionais utiliza este material desde que começou a atuar nessa área e, nesses casos, o tempo de experiência com órteses corresponde exatamente ao tempo de experiência com os materiais termomoldáveis.

Houve um número considerável de profissionais com bastante experiência na área, sendo que 38\% possuía mais de 20 anos de prática na confecção de órteses para membros superiores e 31\% mais de 10 anos (entre 10 e 20 anos de experiência). Demais profissionais (31\%) confeccionam órteses há menos de 10 anos (entre 4 e 10 anos). Essa experiência é interessante diante do objetivo do estudo.

Quanto ao local em que atuam, identificou-se que 52\% trabalha em ambulatórios ou grandes hospitais vinculados a universidades públicas; 41\% trabalha em consultórios/clínicas particulares e/ou como autônomo; 14\% em Centros de Reabilitação ou Hospitais Públicos; 3\% 
em um centro municipal de saúde. Alguns participantes mencionaram dois locais de trabalho, os quais foram contabilizados na porcentagem informada.

Dentre as áreas de atuação receberam destaque a Traumato-ortopedia (79\%) e a Reumatologia (65,5\%), o que reflete a maioria dos profissionais brasileiros. Demais áreas também apresentaram porcentagem considerável de profissionais atuantes, conforme a Figura 71.

Figura 71 - Gráfico contendo as áreas de atuação dos profissionais participantes

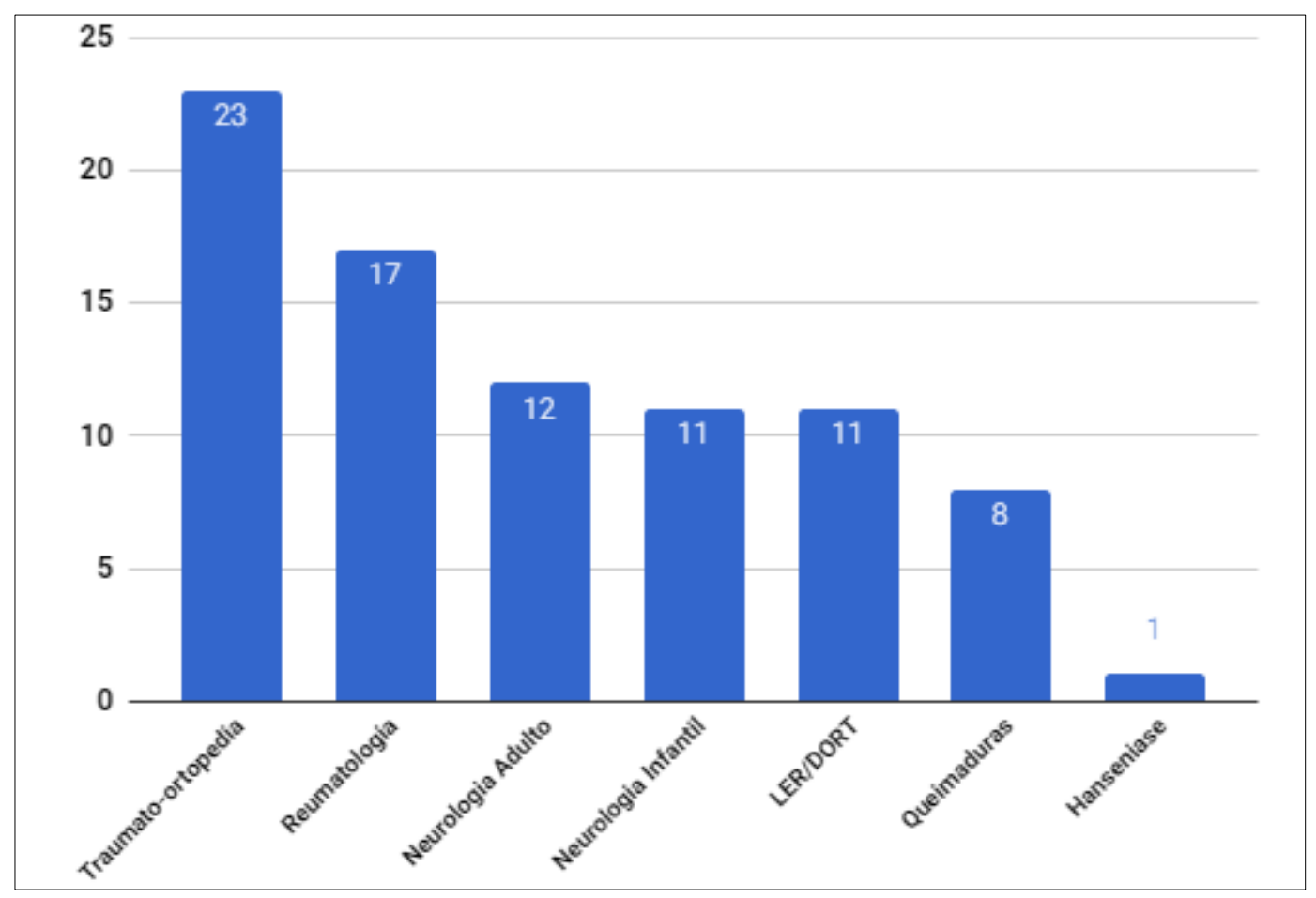

Fonte: elaborada pela autora 


\section{Pesquisa Inicial sobre Confecção de Órteses}

O material mais utilizado pelos terapeutas foi o termoplástico de baixa temperatura, no entanto esse não foi o único, sendo citados, na sequência, os tecidos (Neoprene, couro e tecido automotivo) e os materiais à base de gesso (atadura gessada e gesso sintético), de acordo com a Figura 72.

Figura 72 - Materiais utilizados na confecção de órteses pelos profissionais participantes

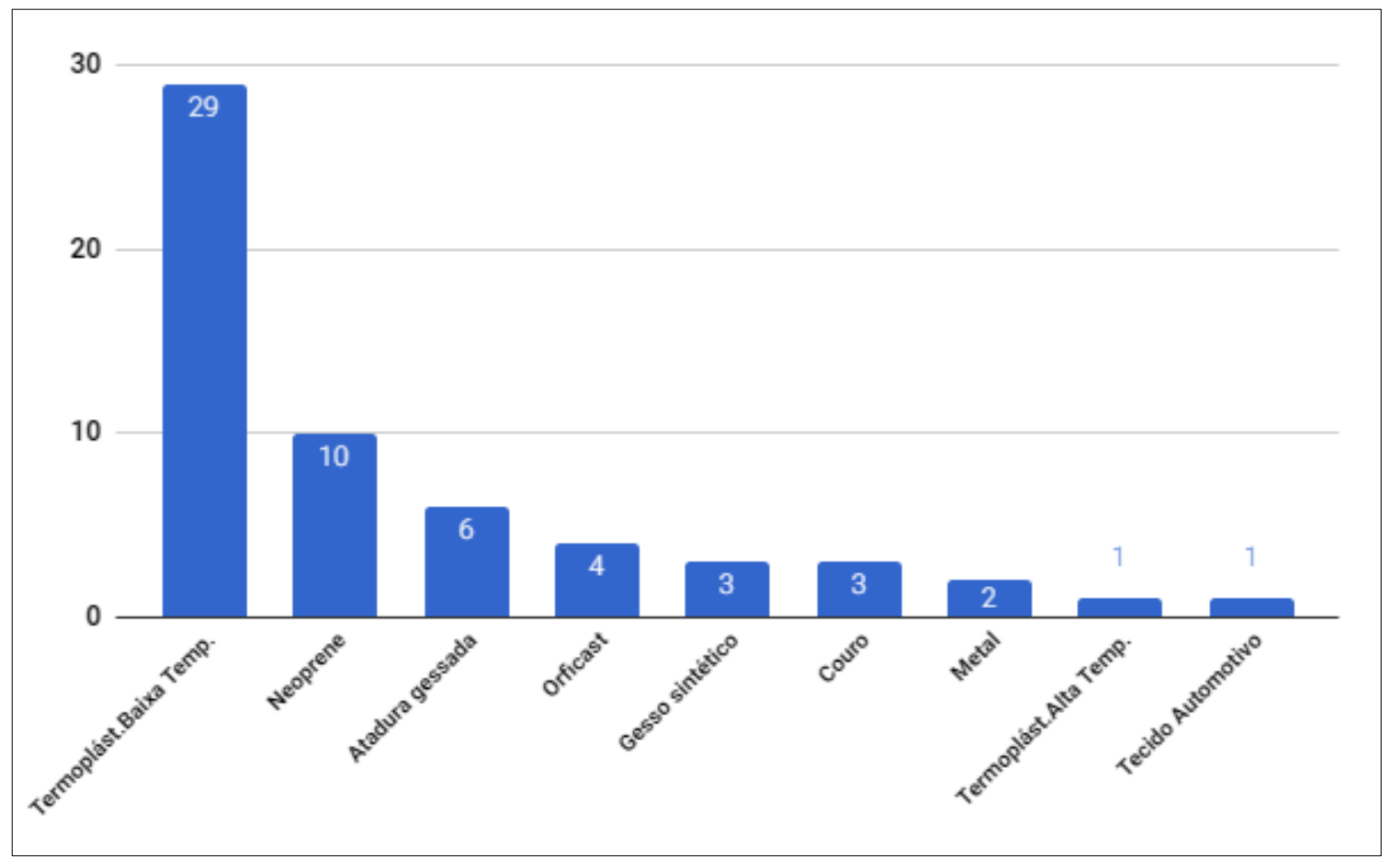

Fonte: elaborada pela autora

Os resultados mostraram que o neoprene ${ }^{\circledR}$ foi o segundo material mais utilizado, mencionado por 34\% dos participantes, corroborando com a pesquisa de Almeida et al. (2016), em que 23\% dos participantes utiliza este material, tendo sido registrado como o segundo mais utilizado, depois dos termoplásticos de baixa temperatura. A literatura aponta que o neoprene ${ }^{\circledR}$ também tem sido utilizado em conjunto com materiais termoplásticos, compondo órteses híbridas, a fim de associar a flexibilidade do primeiro à rigidez do polímero, promovendo benefícios como melhorias funcionais, redução da dor, entre outros (FORD; MCKEE; SZILAGYI, 2003; MCKEE; RIVARD, 2011; WEISS et al., 2004).

Os materiais a base de gesso (atadura ou gesso sintético) foram citados por 24\% dos profissionais, proporção parecida aos dados coletados por Agnelli e Toyoda (2003), em que 22,7\% dos terapeutas brasileiros mencionou utilizar estes materiais especialmente para os casos com hipotonia ou relacionados a LER/ DORT. A vantagem mencionada foi o custo e as 
desvantagens referem-se à baixa resistência (quebradiço), dificuldade de higienização, além de ressecar facilmente a pele do cliente e do terapeuta.

Em relação ao uso dos termoplásticos de alta temperatura, um dos participantes mencionou o uso e, embora seja menos utilizado nos dispositivos para os membros superiores, há relatos na literatura para esta aplicação, tendo sido registrado como o terceiro mais utilizado em um estudo envolvendo profissionais que confeccionam órteses para pacientes com osteoartrite (ALMEIDA et al, 2016), em que 15\% dos participantes mencionou o seu uso. No estudo conduzido por Silva (2014), dos 47 terapeutas participantes, cinco relataram utilizar o PVC (Policloreto de Vinila), sendo que, neste caso, a maioria está vinculada à Universidade do Estado do Pará, local em que a técnica de confecção com este material foi mais difundida.

O metal também foi citado por uma minoria, provavelmente para o uso de dobradiças, reforços e outros componentes acoplados a órteses de outros materiais (MCKEE; MORGAN, 1998).

As marcas comerciais de termoplásticos de baixa temperatura mais utilizados estão descritas na Figura 73.

Figura 73 - Marcas comerciais de termoplásticos de baixa temperatura para órteses utilizadas pelos participantes

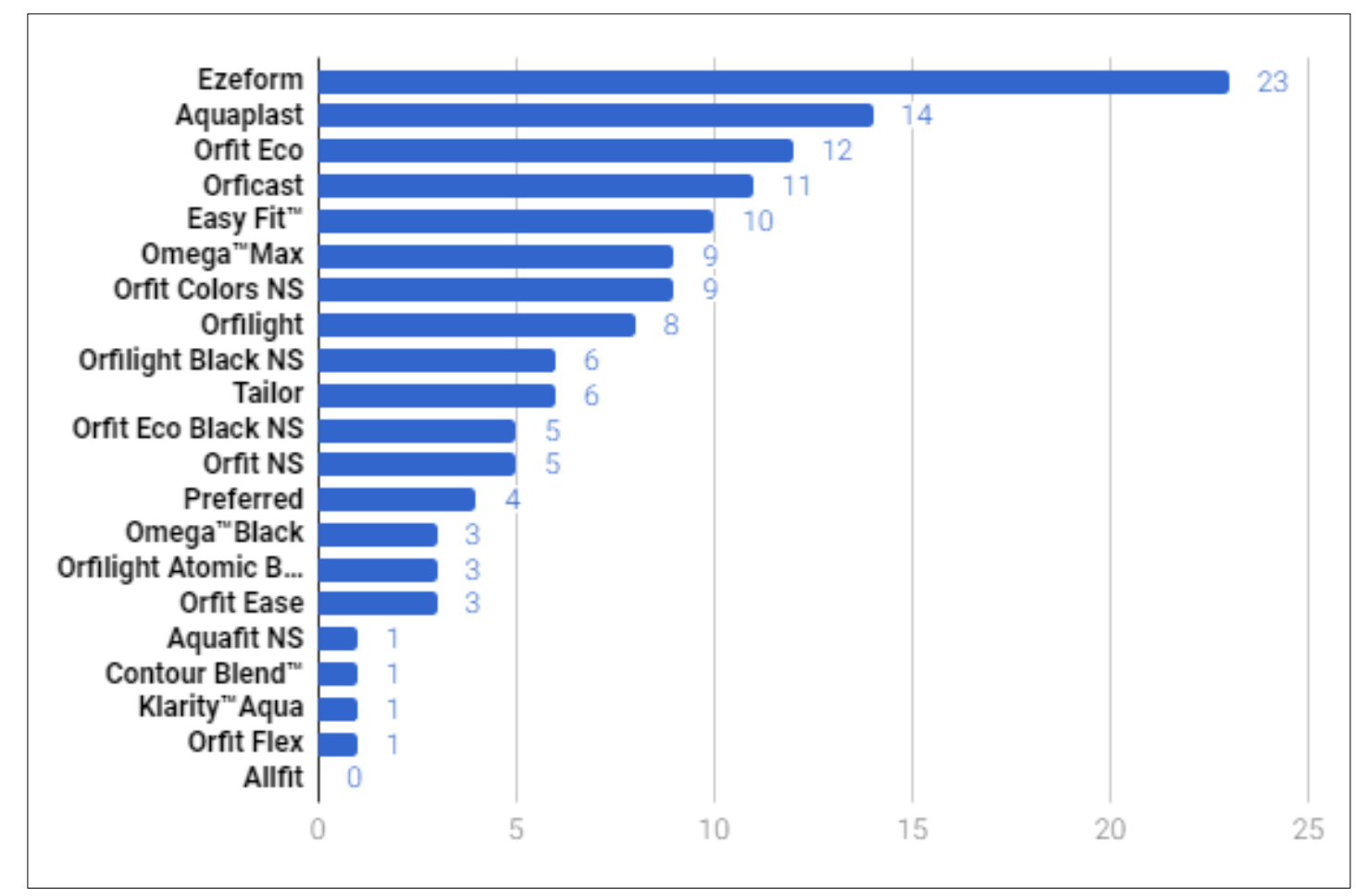

Fonte: elaborada pela autora

O Ezeform ${ }^{\mathrm{TM}}$ é o material comercial mais utilizado (79\%), seguido pelo Aquaplast-T ${ }^{\mathrm{TM}}$ (48\%) e pelo Orfit® Eco (38\%) corroborando com os estudos de Silva (2014), no que diz 
respeito ao Ezeform ${ }^{\mathrm{TM}}$, que também foi a marca comercial prevalente. Outros autores também mencionam que este produto é o mais utilizado, não apenas no Brasil, mas em outros países (AGNELLI; TOYODA, 2003; ALMEIDA et al, 2016; LINDEMAYER, 2004; VAN PETTEN; ÁVILA, 2010).

Além disso ele tem sido selecionado para pesquisas nacionais na área, como referência para a comparação com materiais alternativos (FERRIGNO et al, 2009; LINDEMAYER, 2004; RODRIGUES, 2007; SILVA, 2014; VAN PETTEN; ÁVILA, 2010; VAN PETTEN; ÁVILA; LIMA, 2014), por ser o mais utilizado na prática e/ou por ser considerado um material satisfatório. Isso também acontece com o Ômega ${ }^{\mathrm{TM}}$ (LEITE, 2007; LINDEMAYER, 2004; SOUZA, 2014), embora se tenha menos relatos. Agnelli e Toyoda (2003) relatam que as marcas comerciais Ômega ${ }^{\mathrm{TM}}$ e Ezeform ${ }^{\mathrm{TM}}{ }^{\circledR}$ foram as que mais receberam destaque por parte dos profissionais na época do estudo.

O Orfit ${ }^{\circledR}$ Eco, terceiro material mais utilizado segundo terapeutas participantes deste estudo, e demais materiais da linha Orfit ${ }^{\circledR}$, que também foram todos mencionados, têm sido cada vez mais utilizados no Brasil. Esses materiais também têm sido mencionados em pesquisas na literatura internacional (BANI et al., 2013; MENG; HU; ZHU, 2008; O’BRIEN; BAILEY, 2011).

A espessura adotada por esta pesquisa $(3,2 \mathrm{~mm})$ foi relatada como a mais utilizada na prática clínica, mas demais espessuras também são bastante utilizadas (Figura 74).

Figura 74 - Espessuras (a) e tipos de placas (b) utilizadas pelos participantes deste estudo
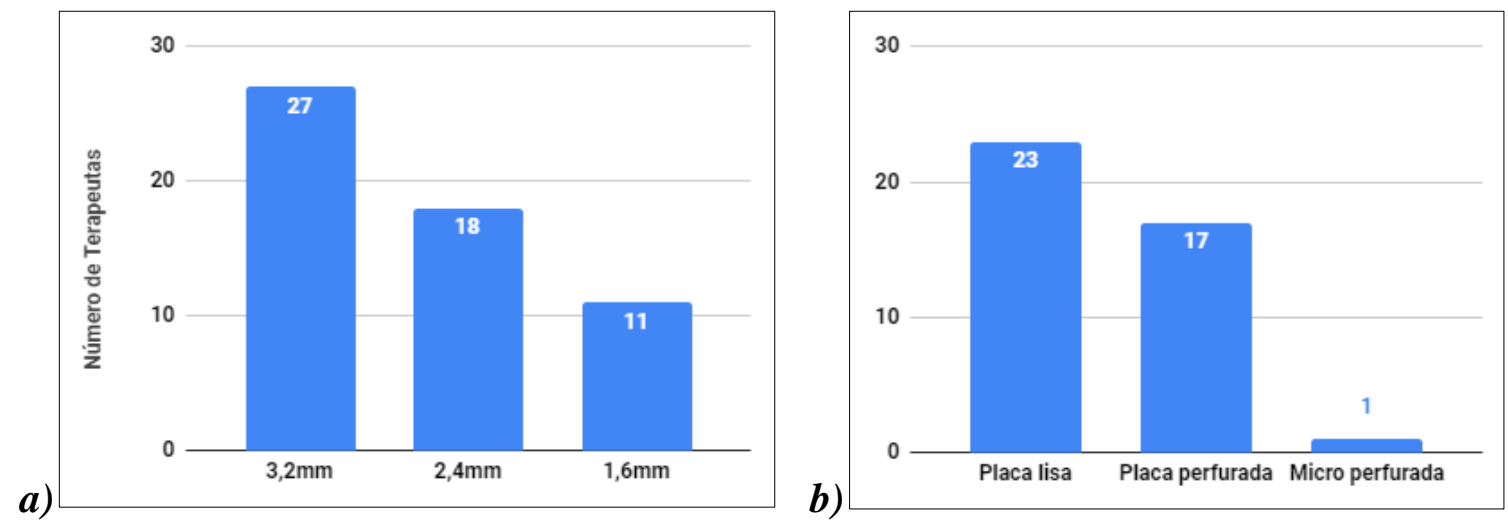

Fonte: elaborada pela autora

Agnelli e Toyoda (2003) relatam que as menores espessuras são usadas no caso de bebês e crianças, assim como em alguns casos de traumato-ortopedia (como rizartrose) e reumatologia (desvio ulnar). Bani et al. (2013) mencionam ter utilizado termoplástico com 1,6mm de espessura, associado a 1,6mm de forração em espuma (Plastazote $\left.{ }^{\circledR}\right)$, em órteses para pacientes 
com osteoartrite do polegar, com as quais se verificou melhora nos níveis de dor e de função. O’Brien e Bailey (2011) também utilizaram essa espessura na confecção de órteses para lesões agudas nos dedos, encontrando bons resultados.

Quanto ao tipo de placa, a lisa foi referida como a mais utilizada, mas as perfuradas também são utilizadas com frequência. A micro perfurada foi citada por um participante (Figura 74). Além de serem mais leves e arejadas, há uma hipótese de que as placas perfuradas apresentem maior estiramento do que as lisas, durante a moldagem. Testes realizados com três produtos comerciais, NCM Preferred ${ }^{\circledR}$ NCM Clinic ${ }^{\circledR}$ e Orfit ${ }^{\circledR}$ Soft, demonstraram maior deformação das perfuradas, em relação às amostras lisas dos mesmos materiais, mas não foram conclusivos quanto a isso (BREGER-LEE; BUFORD JUNIOR, 1992). Os dados da pesquisa citada concordam com as informações atualmente fornecidas pelos fabricantes.

Quanto ao processo de confecção, 10,3\% dos participantes não regula a temperatura da água durante a confecção de órteses, sendo que o termostato é o equipamento mais utilizado pelos profissionais que a controlam (82,1\%). Uma minoria (10,7\%) utiliza o termômetro. Conforme discutido anteriormente, o controle da temperatura é importante e deve ser feito de acordo com as recomendações do material utilizado (FESS, 2011).

\section{Avaliação dos materiais desenvolvidos}

Os participantes elegerem um material que mais utilizam, para adotarem como referência durante a comparação com os materiais desenvolvidos, sendo que os três materiais mais utilizados permaneceram os mesmos: Ezeform ${ }^{\mathrm{TM}}$, Aquaplast-T ${ }^{\mathrm{TM}}$ e Orfit ${ }^{\circledR}$ Eco (Figura 75). Ressalta-se que cada participante comparou os materiais desenvolvidos A e B com o material comercial que mais utiliza. 
Figura 75 - Materiais escolhidos pelos participantes como o mais utilizado

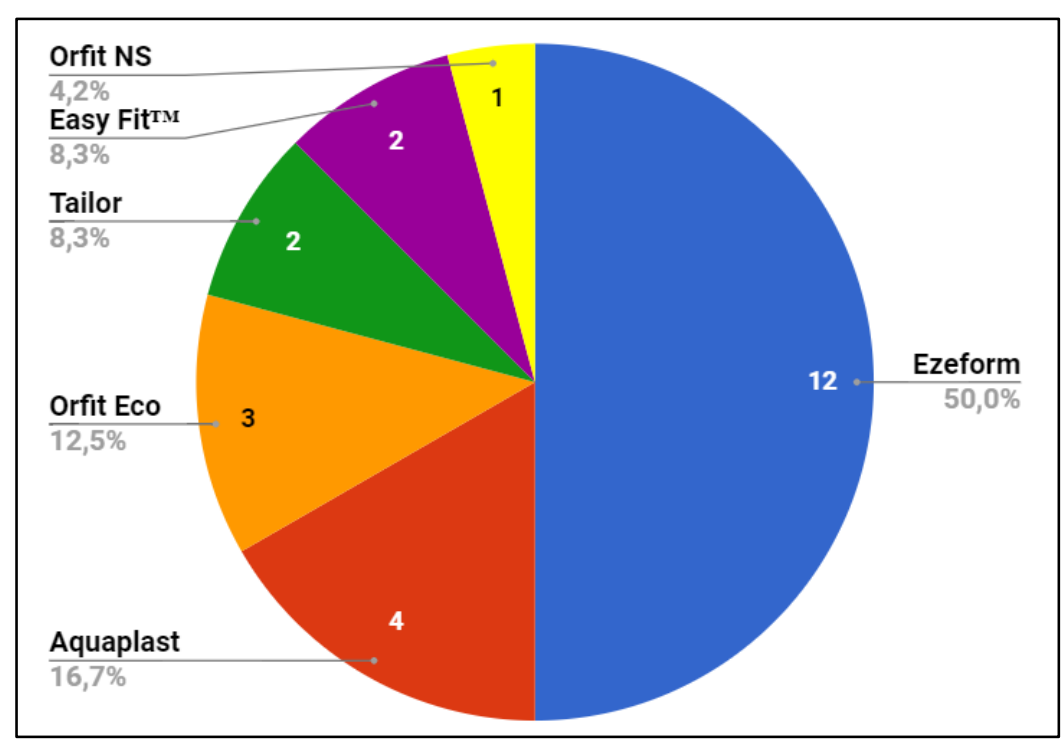

Fonte: elaborada pela autora

A partir do "Formulário para Avaliação dos Materiais Termoplásticos” (Apêndice V), foi possível conhecer a opinião dos terapeutas sobre os materiais desenvolvidos. Isso foi feito através de testes práticos relacionados a 14 características, as mesmas que compuseram o "Roteiro de Procedimentos de Testes Práticos Empíricos” que conduziu a formulação dos materiais.

O gráfico da Figura 76 apresenta a média das pontuações de cada característica, com o desvio-padrão, para os três materiais avaliados: Material A, Material B e material comercial que cada participante mais utiliza. Em uma escala de 1 a 5, de "Muito Insatisfeito" a "Muito Satisfeito”, as pontuações mais altas correspondem a melhores níveis de satisfação. 
Figura 76 - Pontuações médias e desvio padrão (x) em relação a cada característica dos materiais

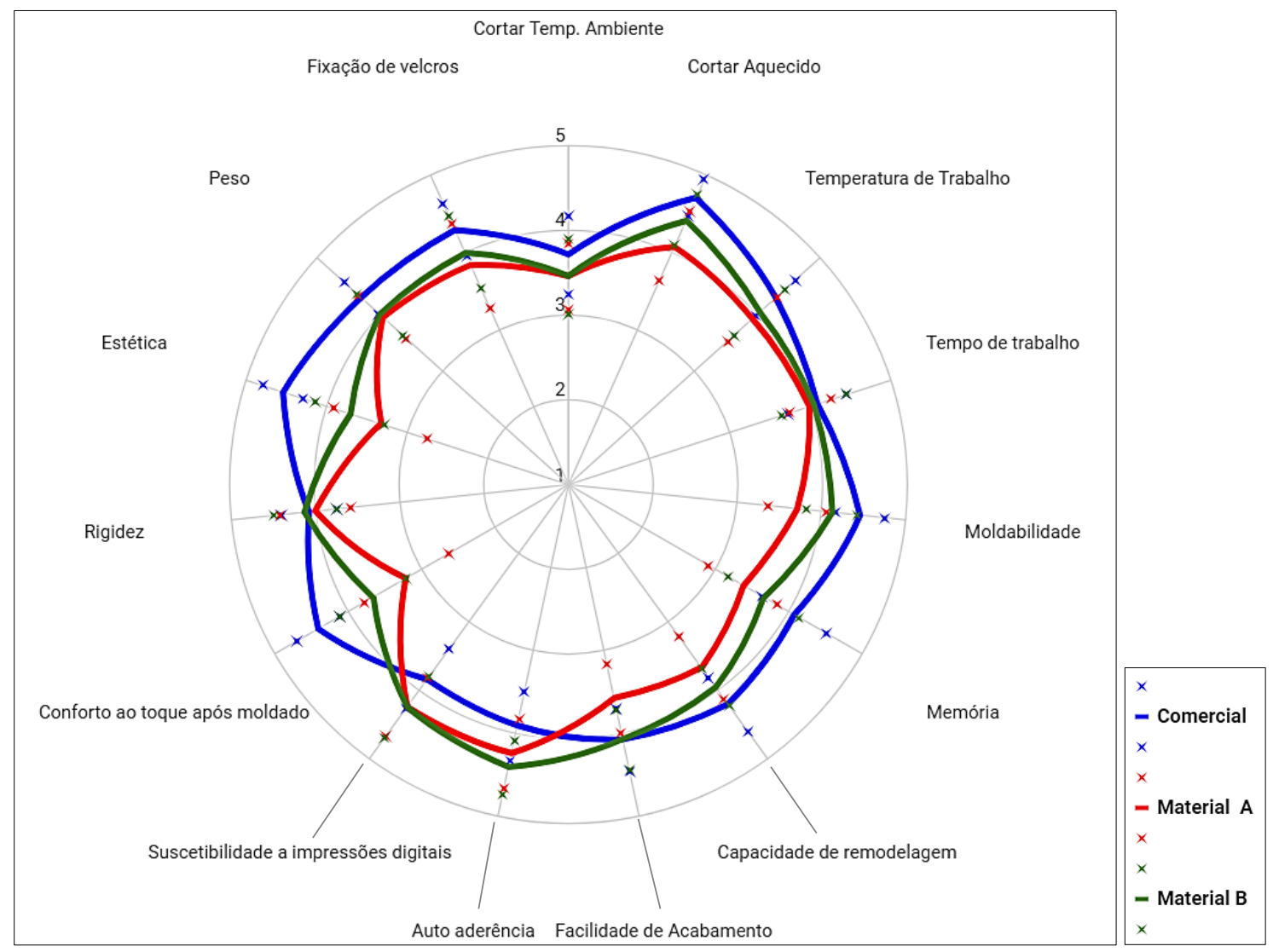

Fonte: elaborada pela autora

\section{Material A}

Grande parte dos participantes refere que apresenta boa moldabilidade, capacidade de remodelagem e temperatura de trabalho, características que somadas foram referidas pelos próprios participantes como algo importante para que possa ser usado. Nem todos os participantes concordam com as vantagens do material no que diz respeito à memória e à autoaderência, sendo que alguns referiram que o material aderido se soltou depois de um tempo.

A principal desvantagem do Material A, relatada por quase todos os participantes, refere-se à modificação de textura após aquecido, ou seja, o material fica rugoso e áspero durante e após a moldagem, apresentando-se, consequentemente, desagradável ao toque. Essa percepção refletiu na avaliação dos itens “Conforto ao toque” e "Estética”. Além disso vários profissionais destacaram desvantagens ligadas ao tempo de trabalho, referindo que o material resfria rápido demais, e dificuldade para cortar o material resfriado.

Outras características também foram mencionadas, por alguns participantes, como desvantagens do material A: apresenta bom acabamento após o corte, com bordas seladas, mas 
que se abrem após um tempo; não adere bem aos velcros; contrai quando aquecido e de forma heterogênea.

\section{Material B}

O material B recebeu pontuações mais altas do que o A e próximas ao produto de referência para a comparação. As vantagens foram apontadas em vários itens testados, apresentando pontuação média de 4 pontos ou mais nos seguintes itens: temperatura de trabalho, tempo de trabalho, moldabilidade, capacidade de remodelagem, facilidade no acabamento, autoaderência, suscetibilidade a impressões digitais, rigidez, peso, fixação de velcros e facilidade de cortar o material aquecido. Em quatro desses itens a pontuação média superou não apenas o material A, mas o material comercial: suscetibilidade a impressões digitais, autoaderência, acabamento e rigidez. Esta última apresentou opiniões divergentes entre os participantes e, apesar da pontuação média apontar para o Material B como sendo o mais rígido, esta diferença não foi significativa se considerarmos o desvio padrão (representado por " $x$ ”, para cada material na Figura 76). Apesar do MPMTO ter quantificado uma diferença entre os materiais A e B, quanto à Tensão de Flexão a 5\% de deformação, de 19,8MPa (A) para 21,6MPa (B), isso não é facilmente perceptível ao manuseio.

Foi mencionado que o material $B$ se assemelha mais aos materiais utilizados rotineiramente, com desempenho quase tão bom quanto aos comerciais, com a vantagem de ser nacional. Dois profissionais acreditam que ele poderia ser indicado para pacientes neurológicos.

Algumas características foram melhor explicadas pelos participantes, como por exemplo a memória, considerada satisfatória e melhor do que no material A, porém um participante avaliou que ele demora um pouco para retomar ao formato original, mas que isso não chegou a ser um problema.

Quanto à moldabilidade, alguns relataram que é preciso pressionar, mas que, apesar disso, o material se molda bem. Um dos participantes referiu que a moldabilidade observada nos materiais $\mathrm{A}$ e B se assemelha à do material Ezeform, mas que nem sempre este grau de Conformação é o mais desejado na prática clínica. Isto reforça a necessidade de materiais diferentes, em vista da variabilidade de casos e situações em que as órteses estão indicadas.

No que diz respeito ao tempo de trabalho, foi considerado adequado para alguns, curto demais para outros (material resfriando muito rápido, dificultando a moldagem) ou ainda longo demais para outros participantes, que mencionaram a necessidade de manter a órtese na posição desejada por um certo tempo. Um dos participantes concluiu que o tempo de trabalho é suficiente para órteses menores e simples, e curto para a confecção de órteses mais complexas. 
Do mesmo modo, não houve consenso em relação à memória, à rigidez, à temperatura de trabalho e retenção de calor, com comentários opostos sobre essas características. Apesar de ser minoria, dois participantes demonstraram preferência pelo material A, especialmente quanto à moldabilidade, remodelagem e acabamento com o soprador térmico.

Nesse sentido, autores apontam para a dificuldade em avaliar a qualidade de um material em si, sem considerar o propósito que se deseja. Algumas características podem ser positivas para determinadas situações e negativas para outras. Um profissional experiente certamente utilizará qualquer material com habilidade, desde que as características de trabalho de cada um sejam compreendidas (BREGER-LEE; BUFORD JUNIOR, 1992; LINDEMAYER, 2004).

As principais desvantagens do material B foram a dificuldade para cortar o material em temperatura ambiente (resfriado), o conforto ao toque e a estética, estas últimas devido à rugosidade da superfície após o aquecimento. No entanto vários terapeutas referiram que essas características foram menos intensas do que no material A, e alguns participantes não consideraram um impedimento para o uso do material, referindo melhora da sensação ao toque após o resfriamento.

Ressalta-se que foi calculado o desvio-padrão para todas as características avaliadas, para cada material, representado por um " $\mathrm{x}$ ” na cor de cada material (segundo a legenda), conforme apresentado na Figura 76. Em quase todas as características houve intersecção entre as faixas do desvio-padrão do material comercial e dos materiais desenvolvidos, de forma que os resultados estão próximos se considerarmos essa margem. Isso não aconteceu em duas características: o conforto e a estética, em que a faixa do desvio-padrão do material comercial não se sobrepõe aos demais, atingindo, de fato, uma satisfação superior em relação aos demais. 


\section{Satisfação com os materiais desenvolvidos}

A Figura 77 apresenta o grau de satisfação geral em relação aos materiais avaliados, na mesma escala de 1 a 5 , com pontuações mais altas indicando maior satisfação. O principal parâmetro de comparação foi a resposta dos terapeutas em relação ao material comercial, que atingiu exatamente a pontuação 4 (“Satisfeito”). É possível identificar uma satisfação acima de 3 (“Indiferente”) para o material A e muito próxima a 4 (“Satisfeito”) para o material A.

Figura 77 - Gráfico referente à satisfação dos profissionais participantes com os materiais desenvolvidos (A e B)

MUITO SATISFEITO $\mathbf{5 , 0}$

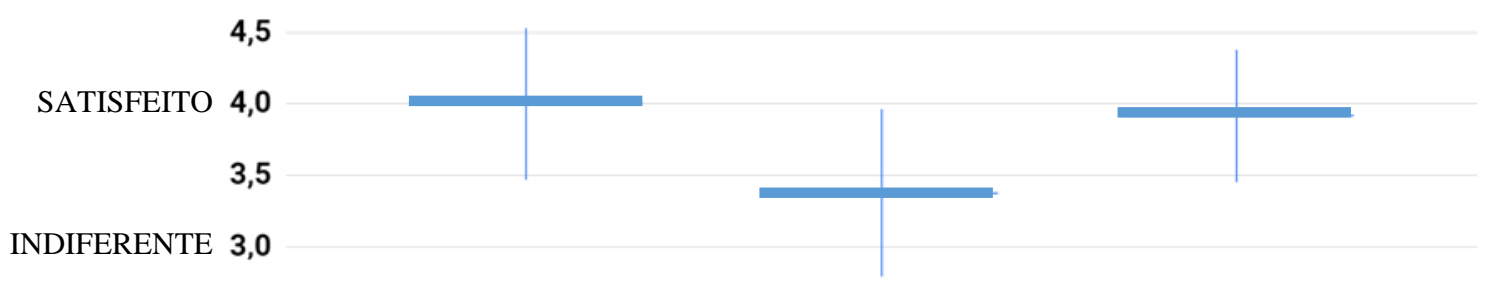

2,5

INSATISFEITO 2,0

1,5

MUITO INSATISFEITO $\mathbf{1 , 0}$

Comercial

Material A

Material B

Fonte: elaborada pela autora

Este resultado é bastante significativo, pois aponta para uma avaliação positiva do material B, quase equiparada com a satisfação dos participantes em relação ao produto comercial que mais utilizam. Houve relatos de que o material B atende, de maneira geral, as necessidades para a confecção de órteses e que apresenta potencial para o mercado, com a sugestão de melhoria na rugosidade. Segundo os participantes, este fator não impede que o material seja comercializado para a confecção de órteses, mas precisa ser alertado se não for aprimorado, uma vez que a placa original é lisa e brilhante e causa uma impressão diferente do material após o aquecimento.

As principais desvantagens verificadas pelos participantes, relativas ao conforto e à estética, também foram avaliadas pela equipe que conduziu a pesquisa. Acredita-se que a rugosidade do material esteja relacionada à utilização de injetora e moldes de placas não projetados para essa utilização, além do fato de que não foi possível um detalhamento nos parâmetros de injeção. Pretende-se, portanto, solucionar a principal desvantagem avaliada, antes de iniciar os testes em usuários. Para isso será necessária uma quantidade maior de 
matéria-prima e a utilização de uma injetora adequada, bem como de moldes projetados para a finalidade desejada.

Dessa forma, os resultados são ainda mais promissores, uma vez que as principais desvantagens relatadas são passíveis de modificação, e apontam para uma possível viabilidade de utilização do Material B na prática clínica envolvendo a confecção de órteses sob medida para os membros superiores. Além disso um novo material (C) foi formulado e processado, a partir de melhorias identificadas na etapa final do trabalho, com alta probabilidade de demonstrar um comportamento adequado, uma vez que foi elaborado a partir dos materiais desenvolvidos anteriormente.

As insatisfações específicas quanto ao conforto e estética são fatores muito importantes e se apresentam como os prioritários no processo de melhorias do material. A literatura também aponta para a importância destas duas características na confecção de órteses, sendo fundamentais inclusive para evitar o abandono (ASSUMPÇÃO, 2005; DESHAIS, 2005; MAC DONALD, 1998). Francisco (2004) relata que o conforto e a estética passam pela subjetividade e são extremamente importantes, pois influenciam diretamente na utilização do dispositivo. A autora sugere estudos qualitativos para investigar essas características dos materiais para órteses.

Como houve diferença entre os materiais que os participantes mais utilizam, eles compararam os materiais desenvolvidos (A e B) com materiais comerciais diferentes, o que levou a uma análise detalhada, a partir das marcas utilizadas. Optou-se, portanto, por analisar a satisfação com os materiais desenvolvidos a partir desse detalhamento (Figura 78), na escala de 1 a 5, de “Muito Insatisfeito” a “Muito Satisfeito”. 
Figura 78 - Satisfação geral em relação aos materiais desenvolvidos, de acordo com o material que cada participante mais utiliza

MUITO SATISFEITO 5

Material "A"

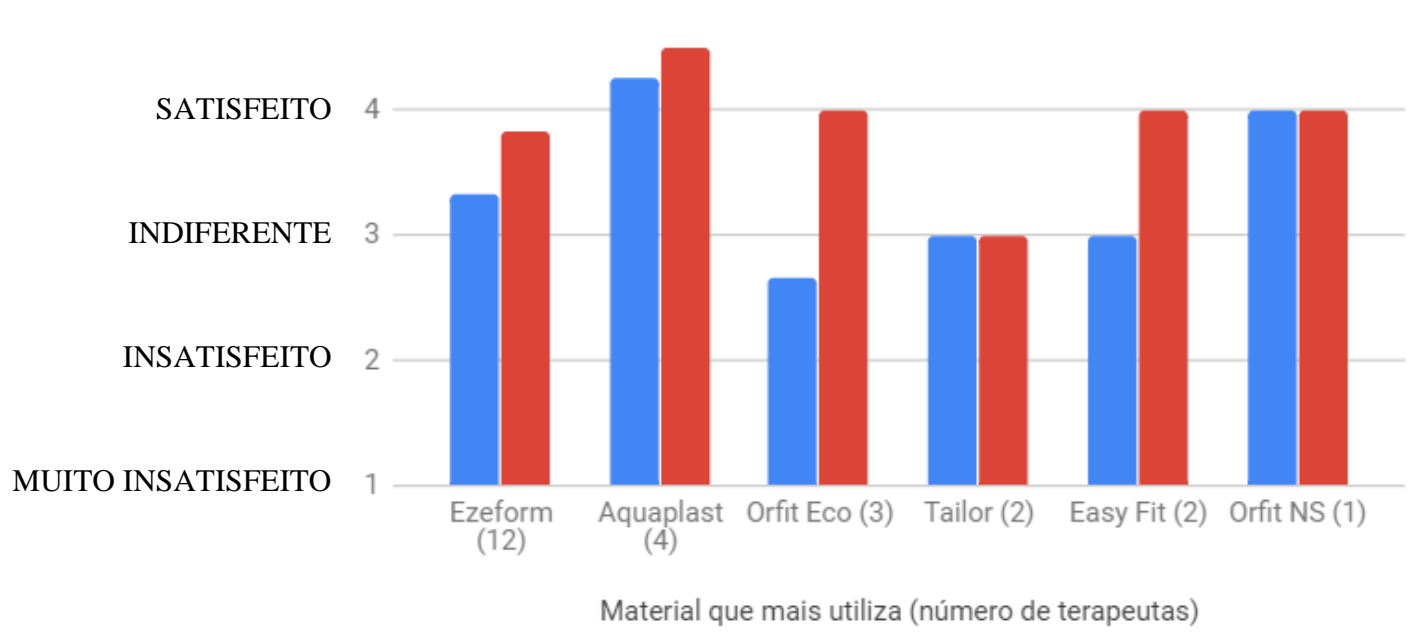

Fonte: elaborada pela autora

Verifica-se que a diferença entre os materiais que cada participante mais utiliza não interferiu no nível médio de satisfação com os Materiais A e B. No entanto observa-se que houve uma tendência a menores níveis de satisfação por parte de quem utiliza frequentemente o Orfit ${ }^{\circledR}$ Eco, principalmente em relação ao Material A, que chegou a obter pontuação menor do que 3 (“Indiferente”). A satisfação também foi menor no caso de quem utiliza o Tailor, resultando em pontuação 3 para ambos os materiais desenvolvidos, e de quem utiliza Easy Fit, com pontuação 3 para o Material B.

Através da aplicação do MPMTO, verificou-se que os materiais desenvolvidos apresentam características próximas às do Ezeform ${ }^{\mathrm{TM}}$ e do Aquaplast-T ${ }^{\mathrm{TM}}$, também avaliados pelo instrumento. Essa semelhança pode ter influenciado na satisfação dos participantes que utilizam principalmente estes materiais comerciais em sua prática profissional. Além disso, cinco participantes relataram que os materiais desenvolvidos, especialmente o $\mathrm{B}$, apresentam moldabilidade semelhante à de alguns materiais comerciais, e citaram o Ezeform ${ }^{\mathrm{TM}}$ como exemplo, corroborando com os resultados do MPMTO. Um dos participantes relatou que os materiais são diferentes dos materiais da linha Orfit ${ }^{\circledR}$, dificultando a comparação nestes casos.

Esse resultado aponta para as possíveis semelhanças e diferenças existentes entre eles e os diversos materiais comerciais, assim como também ocorre nas comparações entre os produtos disponíveis no mercado. 


\subsection{Considerações sobre a potencial aplicabilidade clínica}

Os resultados obtidos representam um avanço científico e tecnológico, especialmente para a área da saúde. A prática clínica evidencia a necessidade de novas soluções no que diz respeito a materiais eficazes para a confecção de órteses, sendo que o terapeuta ocupacional deve buscar alternativas acessíveis e realizar pesquisas de novos materiais (FESS, 2002).

Os avanços da tecnologia, as pesquisas clínicas e o auxílio da bioengenharia são importantes para a criação e aperfeiçoamento dos termoplásticos, possibilitando a confecção de aparelhos ortopédicos mais adequados e funcionais (SAURON, 2003). Apesar da diversidade de materiais e de todos os avanços que já se tornaram realidade na confecção de órteses para os membros superiores, tem sido contínua a busca por melhorias na qualidade e nas opções de materiais para essa finalidade (RODRIGUES, 2007).

Ao investigar o índice de satisfação de profissionais brasileiros em relação aos materiais disponíveis no mercado para a confecção de órteses, Agnelli e Toyoda (2003) relatam que menos da metade (36\%) considerou os materiais satisfatórios, sendo que os principais argumentos de insatisfação foram a falta de opções nacionais e o preço elevado dos materiais melhores. Na presente pesquisa, ao responderem sobre a satisfação com o produto que mais utilizam, alguns participantes reforçaram que os materiais importados têm muitas vantagens e uma desvantagem importante, que diz respeito ao custo da placa, quando comparado a outros tipos de materiais, corroborando com relatos de outras pesquisas (AGNELLI; TOYODA, 2003; FRANCISCO, 2004; LEITE, 2007; SILVA, 2001). O custo final é absorvido pelo governo ou ainda repassado para a população, quando adquire as órteses em serviços privados.

É importante ressaltar que o custo final de uma órtese não corresponde apenas ao preço da matéria-prima utilizada, mas se refere também ao processo de confecção. Portanto devem ser considerados: a facilidade de aquisição a materiais/equipamentos, de acordo com as particularidades dos diferentes processos de confecção; o valor da matéria prima somado ao valor dos equipamentos e da infraestrutura necessária; impostos, no caso de materiais importados; número de profissionais envolvidos e qualificação dos mesmos (mão de obra especializada); tempo total despendido na confecção; número de visitas do usuário até o serviço, dentre outros fatores que podem interferir no custo final (FRANCISCO, 2004; SILVA, 2014).

Existem relatos na literatura internacional que apontam para a redução de custos com a utilização dos termoplásticos de baixa temperatura, seja direta ou indiretamente. Alguns autores afirmam que, após o acesso a esses materiais, o processo de fabricação de órteses para membros superiores se tornou menos complexo e passou a exigir menos tempo dos profissionais 
(BREGER-LEE; BUFORD JUNIOR, 1992; MCKEE; RIVARD, 2011). No entanto, embora os materiais desse grupo, melhores e mais acessíveis a cada dia, tenham facilitado os processos e revolucionado a prática nessa área, os profissionais no Brasil ainda os consideram de alto custo. Como ainda não existe um material fabricado no país, que esteja disponível comercialmente, o acesso a esse recurso importante pode ser considerado restrito para os profissionais e para a população, principalmente de baixa renda (SILVA, 2001; SOUZA, 2014).

Apesar de existir uma variedade de produtos, com os três principais fabricantes sendo representados no Brasil e alguns modelos de menor valor, o mercado nacional não disponibiliza todos os tipos de materiais fornecidos pelas empresas. A variabilidade de marcas, espessuras e perfurações apresentadas nos sites e catálogos dos fabricantes não está disponível integralmente no mercado brasileiro, havendo uma redução considerável das opções disponíveis para a escolha e aquisição no Brasil. Além disso, em uma análise qualitativa verificou-se que alguns participantes desta pesquisa, especialmente os que estão vinculados a serviços públicos de saúde, queixaram-se não apenas do custo, mas do acesso a materiais melhores. Para os profissionais desse grupo (quase 70\% da amostra), o material mais utilizado na prática clínica não foi necessariamente o material de sua escolha, a depender dos procedimentos e meios pelos quais os termoplásticos de baixa temperatura são adquiridos, a depender do local de trabalho. Isso reflete a realidade brasileira do Serviço Único de Saúde (SUS), em que o profissional precisa se adequar ao material termoplástico que está disponível ou utilizar materiais alternativos na falta de termomoldáveis. Os dados da presente pesquisa corroboram com Rodrigues, Cavalcanti e Galvão (2007), que explicam que alguns profissionais e serviços precisam optar pela aquisição do material termomoldável mais barato, sem levar em consideração as diferenças existentes entre os tipos e as características específicas em função da aplicação.

Em uma situação ideal, a escolha do material para cada caso deve ser feita a partir de suas características e propriedades de trabalho, que são diferentes inclusive para materiais que tenham uma mesma matriz polimérica, a depender da composição (BREGER LEE; BUFORD JUNIOR, 1992; FESS, 2002). O terapeuta deve ter clareza sobre as características e propriedades dos materiais para que seja possível a seleção adequada do material indicado para cada caso.

É importante que se compreenda a que se refere cada propriedade e como utilizá-la no processo de confecção da órtese ou na construção de outros dispositivos de tecnologia assistiva, para os quais também podem ser indicados os materiais termoplásticos de baixa temperatura, visando a obtenção de recursos anatômicos, por exemplo com a possibilidade de remodelagens 
e ajustes ao longo do tempo. Nem sempre há clareza sobre a definição e aplicação das propriedades desse grupo de materiais, ou ainda sobre a terminologia mais adequada para cada característica verificada na prática.

Ao estudar o comportamento dos termoplásticos de baixa temperatura, nota-se que existe uma forte associação entre suas propriedades e características, tais como: a Moldabilidade, por exemplo, é fortemente influenciada pela Memória e pela Resistência ao Estiramento; a Temperatura pode interferir na Autoaderência; perfurações na placa podem modificar a Moldabilidade e o Tempo de Trabalho de determinados materiais; a espessura pode interferir na Rigidez; dentre outras informações que podem interferir no processo de moldagem e/ou no resultado final e devem ser consideradas na comparação entre materiais.

Existem muitos trabalhos cujo objeto de estudo são as órteses, porém a maioria deles avalia a funcionalidade e a aplicação, discutindo a eficácia dos dispositivos na força, na amplitude de movimento, destreza, entre outros. Poucos trabalhos são conduzidos especificamente para avaliar, definir e testar as propriedades dos materiais para essa aplicação.

A caracterização dos materiais realizada nesta pesquisa e os instrumentos elaborados, seja para testes empíricos ou para uma avaliação padronizada, poderão auxiliar profissionais e pesquisadores da área. Um profissional bem preparado otimiza as propriedades do material para a confecção de órteses, desde a sua seleção, buscando uma produção customizada com o desafio de aliar a funcionalidade terapêutica às expectativas e necessidades dos usuários, com boa resolutividade dos produtos (BRASIL, 2013).

De acordo com Marcolino et al. (2015), dispositivos feitos sob medida, por mais simples que sejam, requerem conhecimentos básicos em princípios da engenharia dos materiais e da engenharia mecânica para serem confeccionados corretamente. Assumpção (2005) considera o conhecimento e a compreensão destes princípios como um pré-requisito para a elaboração e construção de qualquer tipo de órtese. Nesse contexto, é de extrema importância a parceria entre profissionais de diferentes áreas, com um trabalho conjunto entre os diversos profissionais da equipe de reabilitação e a troca de experiências destes com profissionais das engenharias.

Uma estrutura interdisciplinar onde atuam diversos profissionais possibilita a articulação e implementação de ações voltadas para um objetivo maior, uma meta principal, especialmente na área de tecnologia assistiva. Da mesma forma, esse caráter interdisciplinar deve ser considerado no desenvolvimento de pesquisas, especialmente quando se propõe inovação e desenvolvimento de novos recursos. Ressalta-se que os materiais termoplásticos resultantes deste trabalho foram desenvolvidos especificamente para a aplicação em órteses, 
uma vez que a equipe da engenharia esteve aliada aos requisitos determinados pela equipe de Terapia Ocupacional, sendo que a formulação dos materiais foi conduzida a partir dessa interação. O instrumento MPMTO também foi criado a partir da expertise de profissionais/pesquisadores de diferentes áreas. Outros trabalhos envolvendo materiais para órteses também foram conduzidos a partir desse tipo de parceria (DANCKWARDT, 2016; SILVA, 2001)

Considera-se que os objetivos da pesquisa foram alcançados, desde a criação da metodologia e instrumentos que conduziram as Fases Exploratória e Experimental, passando pelo desenvolvimento de materiais baseados em termoplásticos de baixa temperatura e finalizando-se com a avaliação de que um deles se mostra viável, segundo profissionais com experiência prática considerável, cuja maioria utiliza esse grupo de materiais há mais de 10 anos. Isso pode representar um marco para os profissionais brasileiros que atuam nessa área e para a população de uma forma geral. 


\section{CONCLUSÕES}

A metodologia criada, com etapas desenvolvidas especificamente para o desenvolvimento e teste de novos materiais para órteses, mostrou-se eficaz para a concretização dos objetivos propostos.

Foram desenvolvidos dois materiais termoplásticos de baixa temperatura no Brasil, considerados viáveis pelos experimentos realizados e pela análise de terapeutas ocupacionais e fisioterapeutas com experiência na área, o que representa uma importante conquista para os profissionais brasileiros e para a população de uma forma geral.

Houve avaliação positiva dos materiais desenvolvidos por parte dos profissionais participantes, especialmente do Material $\mathrm{B}$, cuja satisfação mostrou-se muito próxima à satisfação do produto comercial que mais utilizam. Existem melhorias a serem realizadas nos materiais desenvolvidos, as quais estão em andamento, especialmente quanto ao conforto após a moldagem e a estética, porém, segundo os participantes, isso não inviabiliza sua utilização para a confecção de órteses e outros recursos de tecnologia assistiva.

Foram criados dois instrumentos destinados à avaliação de materiais para órteses: um prático empírico e outro padronizado. O "Roteiro de Procedimentos de Testes Práticos Empíricos” permite avaliar os materiais qualitativamente, de acordo com a percepção do profissional e sua opinião, considerando a experiência prática na confecção de órteses. $\mathrm{O}$ “Manuseio Padronizado de Materiais Termoplásticos para Órteses (MPMTO)” possibilita uma avaliação padronizada e com métricas precisas quanto a propriedades importantes para os materiais utilizados na confecção de órteses: Temperatura de Trabalho, Moldabilidade, Memória, Autoaderência e Rigidez. O MPMTO mostrou potencial para quantificar as informações fornecidas pelos fabricantes de termoplásticos de baixa temperatura para órteses, no que diz respeito às cinco propriedades selecionadas, e precisa ser validado para sua aplicação sistemática. Ambos os instrumentos desenvolvidos poderão ser utilizados por profissionais que atuam na área, como ferramenta para direcionar condutas e para evidenciar a prática clínica, ou ainda por pesquisadores de diferentes áreas, que necessitam testar e comparar materiais para órteses.

Os ensaios realizados com os materiais comerciais confirmaram que eles foram desenvolvidos com fundamentos avançados da ciência dos materiais, o que não impede que outros materiais sejam pesquisados e formulados. Embora os produtos estejam cada vez mais acessíveis, com variados tipos e marcas comerciais, os profissionais no Brasil, especialmente 
os que estão inseridos em serviços públicos de saúde, ainda consideram os termoplásticos de baixa temperatura como materiais de custo elevado.

As propriedades dos materiais foram avaliadas através de empirismo e de experimentos padronizados, de maneira complementar, e os resultados apresentados poderão direcionar algumas intervenções por parte dos profissionais, na medida em que possibilitam ampliar a compreensão de aspectos importantes a serem considerados, por exemplo, na escolha do material apropriado para cada situação.

O trabalho conjunto entre profissionais de áreas distintas, como a parceria aqui apresentada, é essencial para a produção de conhecimento tanto na área da saúde como na engenharia. Especificamente na área de confecção de órteses, a interdisciplinaridade e o diálogo entre os profissionais, cada qual com sua especialidade, certamente proporciona, direta ou indiretamente, benefícios do ponto de vista clínico, econômico e social para o usuário final.

Os resultados obtidos envolvem inovação, tanto no que diz respeito ao desenvolvimento e teste de termoplásticos de baixa temperatura, quanto à criação de procedimentos e instrumentos de avaliação voltados para esse grupo de materiais, podendo impactar nas intervenções relativas à confecção de órteses para os membros superiores, Além de apresentar relevância social, ampliando as opções de tratamento e gerando melhorias à população, os resultados fornecidos representam um importante avanço científico e tecnológico. 


\section{LIMITAÇÕES DO ESTUDO E SUGESTÕES PARA TRABALHOS FUTUROS}

A pesquisa desenvolveu dois materiais termoplásticos de baixa temperatura, os quais se mostraram viáveis para a aplicação em órteses. No entanto as amostras testadas pelos profissionais apresentaram uma rugosidade após o aquecimento, comprometendo a avaliação do conforto ao toque. Esta característica foi atribuída, pela equipe da pesquisa, à utilização de injetora e moldes de placas não projetados para essa utilização, além do fato de que não foi possível um detalhamento nos parâmetros de injeção. Sugere-se, portanto, melhorar este processamento e realizar ajustes finais nos Materiais B e C, para que, após a realização das melhorias identificadas, os materiais possam ser testados em usuários, visando sua inserção no mercado. Em relação à formulação, uma sugestão é a produção de compostos de termoplásticos de baixa temperatura utilizando fibras naturais. Após a otimização no desenvolvimento dos materiais será necessária uma análise de custo.

Embora o polímero matriz dos materiais desenvolvidos (policaprolactona) seja biocompatível e os demais componentes selecionados sejam amplamente utilizados para aplicações na área da saúde, pretende-se verificar a biocompatibilidade dos produtos considerados viáveis para a aplicação em órteses.

Uma limitação do processo de avaliação dos materiais foi o número de profissionais participantes, que foi o máximo possível, de acordo com o número de placas produzidas, uma vez que a pesquisa não obteve financiamento. Pretende-se realizar nova pesquisa para a continuidade das formulações, se possível com o apoio de alguma agência de fomento, para que seja possível ampliar a amostra de profissionais.

Outro aspecto importante é o teste dos materiais desenvolvidos por usuários. Essa era uma etapa que fazia parte da proposta inicial, mas que não foi possível, devido a outras prioridades do desenvolvimento dos termoplásticos e da metodologia. Pretende-se elaborar um estudo específico para a aplicação em usuários, a fim de se avaliar o conforto da órtese com os novos materiais, a facilidade de higiene, a eficácia nas atividades funcionais, o peso, a estética, entre outros. Para esta proposta pretende-se utilizar os materiais após as melhorias previstas.

Algumas sugestões referem-se ao instrumento elaborado especificamente para o teste de materiais termoplásticos de baixa temperatura (MPMTO). Este mostrou potencial para quantificar as cinco propriedades selecionadas, porém foi aplicado na íntegra somente com quatro materiais, sendo que dois foram desenvolvidos na pesquisa. Dessa forma, sugere-se sua aplicação em um número maior de amostras e com um número maior de produtos comerciais, de diferentes fabricantes, a fim de relacionar as medidas obtidas às informações técnicas de 
vários produtos, correlacionando-os e comprovando as diferenças descritas. Sugere-se, portanto, um estudo para o processo de validação do instrumento.

Quanto a alguns itens do protocolo, foram identificadas melhorias e acréscimos a serem realizados, a começar pelo item 2, referente à Moldabilidade. Foram avaliados dois parâmetros, denominados, para este instrumento, como Conformação e Caimento. O primeiro parâmetro diz respeito à conformabilidade dos materiais e tem o objetivo de quantificar quanto os materiais cedem com a aplicação de uma força, através de um objeto esférico. O segundo parâmetro foi o caimento natural, com a ação da gravidade, porém isso foi mensurado em apenas uma direção, em objeto cilíndrico. Embora ambos tenham proporcionado medidas importantes, não foi mensurada precisamente a superfície de contato entre o material e o objeto, assim como a capacidade de se acomodar a várias curvas e relevos. Propõe-se elaborar um terceiro parâmetro (quesito) e construir um sistema de ensaio especificamente para isso, a fim de compor a avaliação do segundo item do MPMTO (Moldabilidade). Este novo parâmetro deverá verificar o caimento do material em uma base com vários contornos e proeminências (com ou sem estiramento) e quantificar o ajuste do material à superfície. Este parâmetro contemplaria melhor o que a literatura internacional aponta como drape ou drapability.

Considerando o sistema de Ensaio A, utilizado para avaliar a Moldabilidade (Conformação) e a Memória, foi utilizado como referência para a medida inicial o material resfriado (plano). Seria interessante mensurar também a deformação do material após o seu caimento natural, antes da aplicação do peso (objeto esférico), sendo que esta poderia ser uma referência mais precisa para a medida inicial e posterior cálculo de conformação e de memória.

No item referente a Autoaderência, item 4 do instrumento, foi identificada a diferença entre materiais com e sem revestimento. Seria interessante realizar o mesmo ensaio após a retirada do revestimento, por exemplo, com o Aquaplast-T ${ }^{\mathrm{TM}}$, ou ainda podem ser realizados ensaios com os três grupos de materiais quanto ao revestimento (sem revestimento, com revestimento em pó e com revestimento tradicional). Pode-se também realizar um estudo para verificar a aplicabilidade da norma ASTM D1876 - Norma de ensaio para resistência à remoção de adesivos.

Ao realizar os ensaios de flexão em três pontos, para avaliação do item 5 do protocolo (Rigidez), verificou-se a importância de acrescentar um item 6 ao instrumento, a Resistência ao Estiramento, que é considerada uma característica importante para a seleção de termoplásticos e mencionada pelos principais fabricantes. Diz respeito à força necessária para esticar um material quando está aquecido, buscando identificar os manuseios que ele pode suportar. A sugestão é realizar o ensaio de tração, sendo que os resultados podem auxiliar na identificação 
de quais materiais de fato podem ser aplicados a situações específicas, por exemplo, que exigem maior solicitação desse tipo de resistência.

Uma outra proposta diz respeito ao ensaio de flexão em três pontos, para identificação do Módulo de Rigidez. Este experimento geralmente é realizado a uma temperatura ambiente padrão $\left(23^{\circ} \mathrm{C}\right)$, porém além desta, considera-se a possibilidade de realiza-lo em temperaturas mais próximas do real, considerando a aplicação em órteses. Sugere-se realizar o ensaio a $10^{\circ} \mathrm{C}$, por exemplo, simulando as estações do ano com temperaturas menos elevadas, e a $35^{\circ} \mathrm{C}$, simulando os dias de verão e também o clima de algumas regiões do país. Isto não precisa compor o instrumento MPMTO e pode ser feito não apenas com produtos comerciais, mas com amostras dos produtos desenvolvidos. Outra sugestão para trabalhos futuros é a realização de ensaios mecânicos e/ou ensaios de envelhecimento dos materiais, com órteses moldadas (colocando-se, por exemplo, estabilizantes para aumentar o tempo de vida útil dos materiais).

Além disso, pretende-se organizar um kit do instrumento MPMTO, que contenha um guia de instruções, com as definições técnicas e descrição dos ensaios, além de um formulário preparado para a aplicação, com ilustrações para o preenchimento das medidas e campos específicos para as pontuações.

Além disso um desafio que se propõe é a formulação de termoplásticos de baixa temperatura com alta rigidez e alta resistência ao estiramento, que possa ser aplicado e testado para órteses de membros inferiores, como uma alternativa ao processo de confecção atualmente mais utilizado. 


\section{REFERÊNCIAS}

AGNELLI, L.B., TOYODA, C. Y. Estudo dos materiais para a confecção de órteses e sua utilização prática por terapeutas ocupacionais no Brasil. Cadernos de Terapia Ocupacional da UFSCar, v.11, n.2, p.83-94, 2003.

AGNELLI, L.B.; TOYODA, C.Y.; FERRIGNO, I.S.V. Características térmicas e mecânicas de termoplásticos de baixa temperatura utilizados na confecção de órteses. 2010. 90f. Monografia (Trabalho de Conclusão do Curso) - Pós-graduação lato-sensu em Terapia da Mão e Reabilitação do Membro Superior, Universidade Federal de São Carlos, São Carlos, 2010.

AGNELLI MARTINEZ, L.B. et al. Elaboração de instrumento padronizado para o teste de materiais termoplásticos para órteses. Revista Interinstitucional Brasileira de Terapia Ocupacional, v.1, n.4, p.518-525, 2017. Suplemento.

AKAO, Y. Introdução ao desdobramento da qualidade. Belo Horizonte: Fundação Christiano Ottoni, 1996.

ALMEIDA, P.H.T.Q. et al. Terapia ocupacional na artrite reumatoide: o que o reumatologista precisa saber?. Revista Brasileira de Reumatologia, v.55, n.3, p.272-280, 2015.

Órteses para o paciente com osteoartrite do polegar. Revista de Terapia

Ocupacional da Universidade de São Paulo, v.27, n.3, p. 289-296, 2016.

AMERICAN SOCIETY FOR TESTING AND MATERIALS. ASTM D4065-12: Standard practice for plastics: dynamic mechanical properties: determination and report of procedures. West Conshohocken, 2012. Disponível em:<www.astm.org>. Acesso em: 3 nov. 2018.

ASTM E1252-13: Standard practice for general techniques for obtaining infrared spectra for qualitative analysis. West Conshohocken, 2013. Disponível em:<www.astm.org $>$. Acesso em: 3 nov. 2018.

ASTM D638-14: Standard test method for tensile properties of plastics. West Conshohocken, 2014a. Disponível em:<www.astm.org>. Acesso em: 3 nov. 2018.

ASTM E1131-14: Standard test method for compositional analysis by thermogravimetry. West Conshohocken, 2014b. Disponível em: $<$ www.astm.org $>$. Acesso em: 3 nov. 2018.

ASTM D3418-15: Standard test method for transition temperatures and enthalpies of fusion and crystallization of polymers by differential scanning calorimetry. West Conshohocken, 2015. Disponível em:<www.astm.org>. Acesso em: 3 nov. 2018.

ASTM D790-17: Standard test methods for flexural properties of unreinforced and reinforced plastics and electrical insulating materials. West Conshohocken, 2017a. Disponível em:<www.astm.org>. Acesso em: 3 nov. 2018.

ASTM D1525-17: Standard test method for vicat softening temperature of plastics. West Conshohocken, 2017b. Disponível em:<www.astm.org>. Acesso em: 3 nov. 2018. 
ANDRADE, C.T. et al. Dicionário de polímeros. Rio de Janeiro: Interciência, 2001.

ASSOCIAÇÃO BRASILEIRA DE NORMAS E TÉCNICAS. Disponível em:<http://abnt.org.br/abnt/conheca-a-abnt>. Acesso em: 3 nov. 2018.

ASSOCIAÇÃO DE ASSISTÊNCIA À CRIANÇA DEFICIENTE. Oficina ortopédica da AACD em Porto Alegre (RS). Disponível em: $<$ http://aacd-rs.org.br/noticias/nova-oficinaortopedica-da-aacdrs/>. Acesso em: 20 ago. 2018.

ASSUMPÇÃO, T.S. Órteses: princípios básicos. In: FREITAS, P.P. Reabilitação da mão. São Paulo: Atheneu, 2005. Cap.34, p.539-553.

BANI, M.A. et al. Comparison of custom-made and prefabricated neoprene splinting in patients with the first carpometacarpal joint osteoarthritis. Disability and Rehabilitation: assistive technology, v.8, n.3, p.232-237, 2013.

BARROSO, P.N. Nova órtese de extensão de punho e abdutora de polegar para crianças com paralisia cerebral: avaliação de suas contribuições para o incremento da funcionalidade manual. 2010. 141f. Tese (Doutorado) - Escola de Engenharia, Universidade Federal de Minas Gerais, Belo Horizonte, 2010.

Órteses para o polegar. In: FONSECA, M.C.R. et al. Órteses e próteses: indicação e tratamento. Rio de Janeiro: Águia Dourada, 2015. Cap.9, p.173-188.

BEASLEY, J. Therapist's examination and conservative management of arthritis of the upper extremity. In: SKIRVEN, T.M. et al. Rehabilitation of the hand and upper extremity. $6^{\text {th }}$ ed. Philadelphia: Elsevier Mosby, 2011. Cap.103.

BERSCH, R. Introdução à tecnologia assistiva. Porto Alegre, 2017. Disponível em: $<$ http://www.assistiva.com.br/Introducao_Tecnologia_Assistiva.pdf $>$. Acesso em: 3 nov. 2018.

BRASIL. Ministério da Saúde. Confecção e manutenção de órteses, próteses e meios auxiliares de locomoção: confecção e manutenção de próteses de membros inferiores, órteses suropodálicas e adequação postural em cadeira de rodas. Brasília: Secretaria de Gestão do Trabalho e da Educação na Saúde, 2013. Disponível

em: $<$ http://bvsms.saude.gov.br/bvs/publicacoes/confecao_manutencao_orteses_proteses.pdf $>$. Acesso em: 20 ago. 2018.

BREGER-LEE, D.E.; BUFORD JUNIOR, W.L. Properties of thermoplastic splinting materials. Journal of Hand Therapy, v.5, n.4, p.202-211, 1992.

BRETAS, R.E.S.; D’ÁVILA, M.A. Reologia de polímeros fundidos. 2.ed. São Carlos: EdUFSCar, 2005.

CALLINAN, N. Confecção de órteses para a mão. In: TROMBLY, C.A.; RADOMSKI, M. V. Terapia ocupacional para disfunções físicas. São Paulo: Santos, 2005. Cap.15, p.351370 . 
CALLISTER, W.D.; RETHWISCH, D.G. Ciência e engenharia de materiais: uma introdução. 9.ed. Rio de Janeiro: LTC, 2016.

CANELÓN, M.F. Material properties: a factor in the selection and application of splinting materials for athletic wrist and hand injuries. Journal of Orthopaedic and Sports Physical Therapy, v.22, n.4, p.164-172, 1995.

CANEVAROLO, S.V. Técnicas de caracterização de polímeros. São Paulo: Artliber, 2004.

Ciência dos polímeros: um texto básico para tecnólogos e engenheiros. 3.ed. São Paulo: Artliber, 2010.

CAPELLO, V.A.; TOYODA, C.Y. Indicação e confeç̧ão de órteses: papel do terapeuta ocupacional no tratamento da mão. 2000. Monografia (Trabalho de Conclusão de Curso) Faculdades Salesianas de Lins, Lins, 2000.

CARVALHO, J.A. Órteses: um recurso terapêutico complementar. 2.ed. Baruerí: Manole, 2013.

CASEY, C.A.; KRATZ, E.J. Soft splinting with neoprene: the thumb abductoion supinator splint. American Journal of Occupational Therapy, v.42, n.6, p.395-398, 1988.

CHENG, L.C. QFD planejamento da qualidade. Belo Horizonte: Fundação Christiano Ottoni, 1995.

CHENG, L.C.; MELO FILHO, L.D.R. QFD: desdobramento da função qualidade na gestão de desenvolvimento de produtos. São Paulo: Blucher, 2007.

COLDITZ, J.C. Splinting the hand with a peripheral-nerve injury. In: SKIRVEN, T.M.et al. Rehabilitation of the hand and upper extremity. $6^{\text {th }} \mathrm{ed}$. Philadelphia: Elsevier Mosby, 2011. Cap.34.

COOMBES, A.G.A.; GREENWOOD, C.D.; SHORTER, J.J. Materiais plásticos para próteses e ortesis externas. In: WISE, D.L. et al. Human biomaterials applications. Totowa: Humana Press, 1996.

COOMBES, A.G.A. et al. Precipitation casting of polycaprolactone for applications in tissue engineering and drug delivery. Biomaterials, v.25, n.2, p.315-325, 2004.

CORDE - Comitê de ajudas técnicas. Tecnologia assistiva nas escolas - manual sobre recursos básicos de acessibilidade sócio-digital para pessoas com deficiência. Brasília: ITS Brasil; Ministério da Ciência e Tecnologia, 2008.

CRISTIANO, J.J.; LIKER, J.K.; WHITE, C.C. Customer-driven product development through quality function deployment in the U.S. and Japan. Journal of Product Innovation Management, v.17, n.4, p.286-308, 2000.

CURY, V.C.R. et al. Efeitos do uso de órtese na mobilidade funcional de crianças com paralisia cerebral. Revista Brasileira de Fisioterapia, v.10, n.1, p.67-74, 2006. 
DANCKWARDT, F. Elaboração de fichas técnicas de materiais visando o design de órteses de membros superiores e inferiores. 2016. 104f. Dissertação (Mestrado) - Escola de Engenharia, Universidade Federal do Rio Grande do Sul, Porto Alegre, 2016.

DESHAIS, L.D. Órteses de membro superior. In: TROMBLY, C.A.; RADOMSKI, M.V. Terapia ocupacional para disfunções físicas. São Paulo: Santos, 2005. Cap.14, p.313-349.

EFECTIV MEDICAL DEVICES. Disponível em:<https://www.efectiv.com.br/>. Acesso em: 20 ago. 2018.

ELUI, V.M.C. Comparação da função de duas órteses na reabilitação da mão em garra móvel de hansenianos. 2001. 115f. Tese (Doutorado) - Escola de Enfermagem de Ribeirão Preto, Universidade de São Paulo, Ribeirão Preto, 2001.

FAPESP - Fundação de Amparo à Pesquisa do Estado de São Paulo. Disponível em:<http://www.agencia.fapesp.br/inicial/>. Acesso em: 10 ago. 2016.

FARIA, A.F. et al. Desenvolvimento de produto orientado para o cliente: aplicação do método QFD em um projeto de pesquisa tecnológica. In: ENCONTRO NACIONAL DE ENGENHARIA DE PRODUCAO, 31., 2011, Belo Horizonte. Anais... Rio de Janeiro: ABEPRO, 2011.

FERRIGNO, I.S.V. O Uso de órteses em terapia da mão. In: Terapia da mão: fundamentos para a prática clínica. São Paulo: Santos, 2007. Cap.10, p.123-127.

FERRIGNO, I.S.V.F. et al. Electromyography of the upper limbs during computer work: a comparison of 2 wrist orthoses in healthy adults. Archives of Physical Medicine Rehabilitation, v.90, n.7, p.1152-1158, 2009.

FESS, E.E. Splints: mechanics versus convention. Journal of Hand Therapy, v.8, n.2, p.124-130, 1995.

A History of splinting: a understand the present, view the past. Journal of Hand Therapy, v.15, n.2, p.97-132, 2002.

Orthoses for mobilization of joints: principles and methods. In: SKIRVEN, T.M.et al. Rehabilitation of the hand and upper extremity. $6^{\text {th }} \mathrm{ed}$. Philadelphia: Elsevier Mosby, 2011. Cap.124.

FESS, E.E.; PHILIPS, C. Hand splinting: principles and methods. $2^{\text {nd }}$ ed. St.Louis: Mosby, 1987.

FORD, M.; MCKEE, P.; SZILAGYI, M. Protecting the ulnar collateral ligament and metacarpophalangeal joint of the thumb. Journal of Hand Therapy, p.64-68, 2003.

FOSS-CAMPBELL, B. Principles of splinting the hand. Plastic Surgical Nursing, v.18, n.3, p.199-203, 1998. 
FRANCISCO, N.P.F. Avaliação das características de três materiais de baixo custo utilizados na confecção de órtese para estabilização de punho. 2004. 81p. Dissertação (Mestrado) - Instituto de Pesquisa e Desenvolvimento, Universidade do Vale do Paraíba, São José dos Campos, 2004.

FUNDAÇÃO DE AMPARO À PESQUISA DO ESTADO DE SÃO PAULO. Disponível em:<http://www.fapesp.br/>. Acesso em: 20 ago. 2018.

GARCIA, A.; SPIM, J.A.; SANTOS, C.A. Ensaios dos materiais. Rio de Janeiro: LTC, 2000.

GMI TRUSTED LABORATORY SOLUTIONS. Thermo nicolet nexus 4700 FT-IR spectrometer. 2018. Disponível em:<https://gmi-inc.com/thermo-nicolet-nexus-4700-ft-irspectrometer.html>. Acesso em: $10 \mathrm{dez} .2018$.

GOIA, D.N. Estudo e projeto conceitual de órtese auto-articulada para correção de deformidade em desvio ulnar dos dedos para portadores de artrite reumatoide. 2012.

85f. Dissertação (Mestrado) - Programa de Pós-Graduação Interunidades em Bioengenharia da Escola de Engenharia de São Carlos; Faculdade de Medicina de Ribeirão Preto e Instituto de Química de São Carlos, Universidade de São Paulo, São Carlos, 2012.

GRADIM, L.C.C.; PAIVA, G. Modelos de órteses para membros superiores: uma revisão da literatura. Cadernos Brasileiros de Terapia Ocupacional, v.26, n.2, p.479-488, 2018.

HARDY, M.A.; FREELAND, A.E. Hand fracture fixation and healing: skeletal stability and digital mobility. In: SKIRVEN, T.M.et al. Rehabilitation of the hand and upper extremity. $6^{\text {th }}$ ed. Philadelphia: Elsevier Mosby, 2011.

IMAMURA, A.Y. et al. Órtese para correção de microstomia: estudo de caso. Revista Brasileira de Queimaduras, v.11, n.4, p.263-265, 2012.

INTERNATIONAL ORGANIZATION FOR STANDARTIZATION. ISO 9999 - 2016: Assistive products for persons with disability - classification and terminology. Geneva, 2016. Disponível em:<https://www.sis.se/api/document/preview/920988/>. Acesso em: 20 ago. 2018.

LEITE, F.A. Desempenho térmico, mecânico e clínico de material à base de polímero derivado do óleo de mamona para confecção de órteses e comparação com outro material existente no mercado. 2007. 103f. Dissertação (Mestrado) - Programa de PósGraduação Interunidades em Bioengenharia da Escola de Engenharia de São Carlos /Faculdade de Medicina de Ribeirão Preto/Instituto de Química de São Carlos, Universidade de São Paulo, São Carlos, 2007.

LIKERT, R. A Technique for the measurement of attitudes. Archives of Psychology, v. 22, n.140, p.5-55, 1932.

LINDEMAYER, C.K. Estudo e avaliação de termoplásticos utilizados na confeç̧ão de órtese. 2004. 69p. Dissertação (Mestrado) - Universidade do Vale do Paraíba, São José dos Campos, 2004. 
LORENZETTI, J. et al. Tecnologia, inovação tecnológica e saúde: uma reflexão necessária. Texto e Contexto Enfermagem, v.21, n.2, p. 432-439, 2012.

LUZO, M.C.M. et al. Recursos tecnológicos em Terapia Ocupacional - órteses e tecnologia assistiva. In: DE CARLO, M.M.R.P.; LUZO, M.C.M. (Org.). Terapia ocupacional reabilitação física e contextos hospitalares. São Paulo: Roca, 2004. p.99-126.

MAC DONALD, E.M. Terapia ocupacional em reabilitação. 4.ed. São Paulo: Santos, 1998.

MACKEE, P.; MORGAN, L. Orthotics in rehabilitation: splinting the hand and body. Philadelphia: F.A.Davis, 1998.

MACKEE, P.; RIVARD, A. Foundations of orthotic intervention. In: SKIRVEN, T.M.et al. Rehabilitation of the hand and upper extremity. $6^{\text {th }}$ ed. Philadelphia: Elsevier Mosby, 2011.

MAITZ, M.F. Applications of synthetic polymers in clinical medicine. Biosurface and Biotribology, v.1, p.161-176, 2015.

MALICK, M.H. Manual on dynamic hand splinting with thermoplastic materials. $2^{\text {nd }} e d$. Pittsburgh: Harmarville Rehabilitation Center, 1978.

MANO, E.B. Polímeros como materiais de engenharia. São Paulo: Edgard Blücher, 1991. MANO, E.B.; MENDES, L.C. Introdução a polímeros. 2.ed. São Paulo: Edgard Blücher, 1999.

MARCOLINO, A.M. et al. Órteses da mão e membro superior. In: FONSECA, M.C.R. et al. Órteses e próteses: indicação e tratamento. Rio de Janeiro: Águia Dourada, 2015. Cap.8, p.147-171.

MELVIN, J.L. Tratamento ortótico da mão - quais são as novidades?. A Folha Médica, v.111, n.2, p. 217-220, 1995.

MENG, Q.; HU, J. A Review of shape memory polymer composites and blends.

Composites: part A, v.40, p.1661-1672, 2009.

MENG, Q.; HU, J.; ZHU, Y. Properties of shape memory polyurethane used as a lowtemperature thermoplastic biomedical orthotic material: influence of hard segment content. Journal of Biomaterials Science. Polymer edition, v.19, n.11, p.1437-1454, 2008.

MN - Importação, Exportação e Comércio de Suprimentos Terapêuticos e de Reabilitação Ltda. São Paulo, 2018. Disponível em:<http://www.mnsuprimentos.com.br/menu/termoplasticos/>. Acesso em: 20 ago. 2018.

NORTH COAST - Medical and Rehabilitation Products. Disponível em:<https://www.ncmedical.com/>. Acesso em: 20 ago. 2018. 
MOORE, M.L.; DEWEY, W.S.; RICHARD, R.L. Rehabilitation of the burned hand. Hand Clinics, v.25, n.4, p.529-541, 2009.

MORAN, S.; TOMHAVE, W. Management of congenital hand anomalies. In: SKIRVEN, T.M.et al. Rehabilitation of the hand and upper extremity. $6^{\text {th }}$ ed. Philadelphia: Elsevier Mosby, 2011. Cap.128.

NAIR, C.K. et al. Dynamic commissural splint. Indian Journal of Dental Research, v.19, n.2, p.165-168, 2008.

NAVARRO, R.F. Materiais e ambiente. João Pessoa: Ed.Universitária, 2001.

NORTH COAST MEDICAL. Disponível em:<https://www.ncmedical.com/>. Acesso em: 20 ago. 2018.

NUNES, E.C.D.; LOPES, F.R.S. Polímeros: conceitos, estrutura molecular, classificação e propriedades. São Paulo: Érica, 2014.

O'BRIEN, V.H. Orthosis a orthotic: which is it when. Journal of Hand Therapy, v.26, n.4, p.369-370, 2013.

O’BRIEN, L.J.; BAILEY, M.J. Single blind prospective, randomized controlled trial comparing dorsal aluminum and custom thermoplastic splints to stack splint for acute mallet finger. Archives of Physical Medicine Rehabilitation, v.92, n.2, p.191-198, 2011.

ORFIT INDUSTRIES - Leader in Thermoplastic Inovations. Disponível em: $<$ https://www.orfit.com/. Acesso em: 20 ago. 2018.

PADILHA, A.F. Materiais de engenharia. São Paulo: Hemus, 1997.

PATON, J. et al. The Physical characteristics of materials used in the manufacture of orthoses for patients with diabetes. Foot \& Ankle International, v.28, n.10, p.1057-1063, 2007.

PEREIRA, M.M. Conceitos básicos de ciência dos materiais. In: ORÉFICE, R.L.; PEREIRA, M.M.; MANSUR, H.S. Biomateriais: fundamentos e aplicações. Rio de Janeiro: Cultura Médica, 2006. Cap.1.

PERFORMANCE HEALTH. Disponível em:<https://www.performancehealth.com/>. Acesso em: 20 ago. 2018a.

Splinting sheets. 2018b. Disponível

em:<https://www.performancehealth.com/products/hand-therapy-splinting/splinting-sheets>. Acesso em: 20 ago. 2018.

POLITEC SAÚDE - Importação e Comércio Ltda. São Paulo. Disponível em:<http://www.politecsaude.com.br/>. Acesso em: 20 ago. 2018.

PORTAL NACIONAL DE TECNOLOGIA ASSISTIVA. Disponível em:< https://assistivaitsbrasil.wordpress.com/catalogo/>. Acesso em: 20 ago. 2018. 
RAMAKRISHNA, S. et al. Biomedical applications of polymer-composite materials: a review. Composites Science and Technology, v.61, n.9, p.1189-1224, 2001. RAMOS, S.L.F. Membranas de policaptrolactana obtidas por eletrofiação para utilização em engenharia tecidual. 2011. 77p. Dissertação (Mestrado) - Faculdade de Engenharia Mecânica, Universidade Estadual de Campinas, Campinas, 2011.

RAMOS, L.D. Estudo da viabilidade de utilização das blendas de copolímero pp e pebd reciclado na confecção de placas termo moldáveis para produção de órteses estáticas estabilizadoras de punho. 2017. 88p. Dissertação (Mestrado Profissional) - Centro Universitário de Volta Redonda, Fundação Oswaldo Aranha, Volta Redonda, 2017.

REDFORD, J.B.; BASMAJIAN, M.D.; TRAUTMAN, P. Orthotics: clinical practice and rehabilitiation technology New York: Churchill Livingstone, 1995.

RODOLFO, J.R.; NUNES, L.R.; ORMANJI, W. Tecnologia do PVC. 2.ed. São Paulo: Braskem, 2006.

RODRIGUES, A.M.V.N. Desenvolvimento de compósito sanduíche para confecção de órteses e o efeito da órtese de compósito na função manual e na ativação dos músculos do antebraço. 2007. 156f. Tese (Doutorado) - Escola de Engenharia, Universidade Federal de Minas Gerais, Belo Horizonte, 2007.

RODRIGUES, A.V.N. et al. Terapia ocupacional: fundamentação e prática. Rio de Janeiro: Guanabara Koogan, 2007. Cap.46.

RODRIGUES JUNIOR, J.L. Órteses de baixo custo. In: CRUZ, D.M.C. Terapia ocupacional na reabilitação pós-acidentes vascular encefálico: atividades de vida diária e interdisciplinaridade. São Paulo: Santos, 2012.

ROSSI, J.D.M.B.A. et al. Estudo comparativo entre aparelhos gessados clássicos e de material sintético. Revista Brasileira de Ortopedia, v.22, n.10, p.297-300, 1987.

SASMAZEL, H.T.; GÜMÜŞDERELIOĞLU, M.; GÜRPINAR, A. Comparation of cellular proliferation on dense and porous PCL scaffolds. Bio-Medical Materials and Engineering, v.18, p.119-128, 2008.

SAURON, F.N. Órteses para membros superiores. In: TEIXEIRA, E. et al. Terapia ocupacional na reabilitação física. São Paulo: Roca, 2003. Cap.16.

SCHAF, S. Órtese de jeans para desvio ulnar dos dedos. Revista Brasileira de Reumatologia, v.44, n.2, p.150-151, 2004.

SILVA, F.P. Órtese abdutora do polegar: estudo do material alternativo aos termoplásticos de baixa temperatura atualmente utilizados. 2001. Dissertação (Mestrado) - Universidade do Vale do Paraíba, São José dos Campos, 2001.

SILVA, L.G. Órteses em PVC para membro superior: utilização por terapeutas ocupacionais brasileiros, propriedades físico-mecânicas e de toxicidade e desempenhos funcional e mioelétrico. 2014. 164f. Dissertação (Mestrado) - Universidade Federal de São Carlos, São Carlos, 2014. 
SILVEIRA, A. O Polipropileno na confecção de órteses e próteses. Revista Brasileira de Ortopedia, v.16, n.2, p.47-50, 1981.

SINHA, V.R. et al. Poly-€-caprolactone microspheres and nanospheres: an overview. International Journal of Pharmaceutics, v. 278, n.1, p.1-23, 2004.

SOUZA, M.S.A. Caracterização e modificação de poliuretano derivado de óleo vegetal para confecção de órteses. 2014. Dissertação (Mestrado) - Programa de Pós-Graduação Interunidades em Bioengenharia. Escola de Engenharia de São Carlos/Faculdade de Medicina de Ribeirão Preto/Instituto de Química de São Carlos, Universidade de São Paulo, São Carlos, 2014.

SOUZA, W.B.; ALMEIDA, G.S.G. Engenharia dos polímeros: tipos de aditivos, propriedades e aplicações. São Paulo: Érica, 2015.

STANLEY, B.G.; TRIBUZI, S.M. Concepts in hand rehabilitation. Philadelphia: F.A.Davis, 1992.

TRAJANO, V.C.C. Avaliação da atividade osteogênica da doxiciclina em uma matriz de compósito biodegradável de poli(e-caprolactona), poli(ácido lático-co-glicólico) e biocerâmica in vitro. 2012. Dissertação (Mestre) - Faculdade de Odontologia, Universidade Federal de Minas Gerais, Belo Horizonte, 2012.

VAN PETTEN, A.M.V.N.; ÁVILA, A.F.; LIMA , C.G.S. Efeito do uso de órtese de punho na função manual. Cadernos Brasileiro de Terapia Ocupacional - UFSCar, v.22, n.1, p.79-87, 2014.

VAN PETTEN, A.M.V.N.; AVILA, A.F. Efeito do uso de órtese de punho na ativação da musculatura flexora e extensora do punho. Revista Brasileira de Ortopedia, v.45, n.1, p.7278, 2010.

VANALLE, R.M. Caracterização e elementos de projeto de órteses para membros inferiores. 1987. 171p. Dissertação (Mestrado) - Universidade Federal do Rio de Janeiro, Rio de Janeiro, 1987.

VIEIRA, G.C. et al. Avaliação das propriedades mecânicas de atadura gessada de três diferentes fabricantes, utilizada para confecção de órteses. Acta Ortopedica Brasileira, v.14, n.3, p.122-125, 2006.

WACH, A. Mechanical characterization of carbon fiber and thermoplastic ankle foot orthoses. 2015. Tese (Doutorado) - Faculty of the Graduate School, Marquette University, Milwaukee, 2015.

WEISS, S. et al. Splinting the degenerative basal joint: custom-made or prefabricated neoprene. Journal of Hand Therapy, v.17, n.4, p.401-406, 2004.

WESSLER, K. Sistemas de $\mathbf{p}(3 \mathrm{HB})$ e $\mathbf{p}(3 \mathrm{HB}-\mathrm{co}-3 \mathrm{HV})$ com policaprolactona-triol: comportamento de fases, reologia, propriedades mecânicas e processabilidade. 2007. 
Dissertação (Mestrado) - Centro de Ciências Tecnológicas, Universidade do Estado de Santa Catarina, Joinville, 2007.

WIKIPEDIA: a enciclopédia livre. Ciências dos materiais. 2018. Disponível em:<https://pt.wikipedia.org/wiki/Engenharia_de_materiais>. Acesso em: 20 ago. 2018.

YODA, R. Elastomers for biomedical applications. Journal of Biomaterials Science. Polymer edition, v.9, n.6, p.561-626, 1998. 


\section{APÊNDICE I \\ Roteiro de Procedimentos de \\ Testes Práticos Empíricos}




\section{Roteiro de Procedimentos para os Testes Empíricos}

\section{Critérios Gerais}

Esse roteiro é focado na análise do material (não envolvendo clientes) e apresenta 14 itens com características a serem verificadas nos termoplásticos de baixa temperatura para órteses. Para cada item existe uma recomendação de procedimento(s) para testes práticos, com alternativas de resposta a serem assinaladas para cada material testado, seguindo uma graduação em relação às facilidades e dificuldades verificadas durante os manuseios. Para realizar os testes é necessário aquecer os materiais utilizando água a uma temperatura de $80^{\circ} \mathrm{C}$.

Para facilitar a avaliação do material, pode ser confeccionada uma órtese, de um modelo a escolher, que seja possível de acordo com o tamanho das amostras disponíveis, como por exemplo: canaleta para os dedos, órtese em “8”, órtese para abdução de polegar, órtese para dedo em gatilho, entre outras.

\section{PROCEDIMENTOS PARA OS TESTES EMPÍRICOS}

\section{1) Facilidade para cortar o material resfriado}

Utilizar uma tesoura multi-uso, do tipo alicate, para materiais rígidos. Preferencialmente, deve-se utilizar a tesoura que já é usada habitualmente para cortar a placa do material para órteses, antes de aquecer.

Extremamente fácil

Comentários e Impressões pessoais:

Fácil

Moderado

Difícil

Extremamente difícil

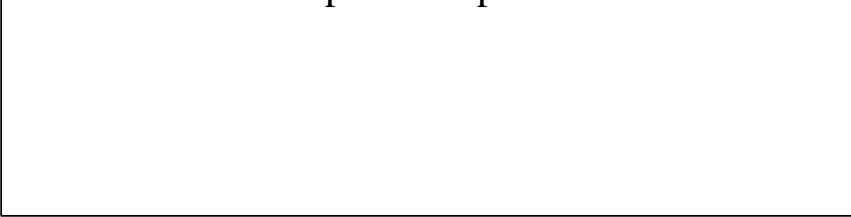

Não é possível cortar o material resfriado

\section{2) Facilidade para cortar o material aquecido}

Utilizar uma tesoura com bom corte, preferencialmente uma tesoura que seja utilizada apenas para materiais termoplásticos de baixa temperatura aquecidos.

$\square \quad$ Extremamente fácil

$\square$ Fácil

$\square$ Moderado

$\square$ Difícil

$\square \quad$ Extremamente difícil

$\square \quad$ Não é possível cortar o material aquecido

\section{3) Percepção Térmica}

Testar o material aquecido sobre a pele e verificar a temperatura em que é possível moldar o material, desde a saída da água até o contato com a pele.

$\square$ Sensação agradável

$\square$ Quente

$\square \quad$ Muito quente

$\square \quad$ Intolerável
Comentários e Impressões pessoais:

Comentários e Impressões pessoais: 


\section{4) Tempo de Trabalho}

Verificar e avaliar o tempo disponível para se moldar uma órtese até que o material seja resfriado.

Demasiadamente longo

Longo

Moderado

Curto

Insuficiente

Comentários e Impressões pessoais:

Comentários e Impressões pessoais:

\section{5) Moldabilidade}

Avaliar a pressão necessária para moldar a órtese e o quanto ela se ajusta ao corpo, acomodando curvas e relevos anatômicos.

Material escorre e deforma, não sendo possível moldar

- Material se ajusta ao corpo sem precisar pressionar

Material se ajusta ao corpo com leve pressão

Material se ajusta ao corpo, sendo necessária bastante pressão

Material não se ajusta ao corpo

\section{6) Memória}

Avaliar se o material apresenta a tendência de retornar ao formato anterior, ou seja, se retorna ao seu tamanho e curvatura original quando aquecido. Pode-se esticar levemente o material e observar o seu retorno. Após ser moldado e resfriado, o material moldado pode ser novamente depositado na água quente para verificar se ele volta ao seu formato original (parcial ou totalmente).

Material não se molda à superfície desejada pois apresenta muita Comentários e Impressões pessoais: resistência ao manuseio, retornando constantemente ao formato original Permite manuseio e, quando necessário, retorna totalmente ao formato original

Quando necessário, retorna parcialmente ao formato original Retorna pouco ao formato original Material se deforma e não retorna ao formato original

7) Facilidade de acabamento 
Verificar a capacidade do material para pequenos ajustes e acabamento das bordas. Após a moldagem, aquecer alguns locais específicos do material, como, por exemplo, as bordas, realizando pressão com a ponta dos dedos para arredondá-las e/ou alisá-las.

As bordas ficam arredondadas $e$ com bom acabamento após o corte

Comentários e Impressões pessoais: do material

As bordas são facilmente ajustadas

As bordas são ajustadas

moderadamente

Material de difícil acabamento

\section{8) Auto-aderência}

Verificar a capacidade de adesão do material, fazendo a sobreposição de uma superfície sobre a outra. Após a aderência e o resfriamento do material, separar as partes para verificar sua eficácia.

Material não adere, mesmo sendo Comentários e Impressões pessoais: pressionado

$\square$ Material apresenta fraca aderência, mesmo sendo pressionado

$\square$ Material adere somente com bastante pressão

$\square$ Material adere com pressão moderada

$\square \quad$ Material adere quando duas partes se tocam

\section{9) Suscetibilidade a impressões digitais}

Durante a moldagem, verificar se o material deixa marca da digital.

$\square \quad$ Material não apresenta marcas após o manuseio

$\square \quad$ Material apresenta marcas após pressão moderada

- Material marca demais

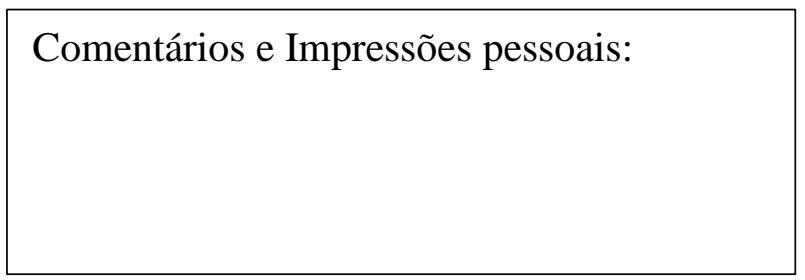

\section{0) Conforto ao toque após moldado}

Após a moldagem e resfriamento do material, verificar se ele é agradável para a pele e para o contato humano. "Vestir” a órtese moldada (se for o caso) e verificar a sensação causada pelo material.

Material muito agradável

Material agradável

Comentários e Impressões pessoais:

Moderado

Material desagradável

Material muito desagradável 


\section{1) Rigidez}

Verificar se o material mantém, após resfriado, o formato moldado e se resiste a deformações, mesmo diante da aplicação de força constante.

$\square$ Material muito rígido

$\square$ Material rígido

$\square$ Moderado

$\square \quad$ Material flexível

$\square \quad$ Material muito flexível

Comentários e Impressões pessoais:

\section{2) Estética do material}

Inspecionar visualmente a qualidade do produto moldado.

$\square \quad$ Ótimo
$\square \quad$ Bom
$\square \quad$ Moderado
$\square \quad$ Ruim
$\square \quad$ Péssimo

Comentários e Impressões pessoais:

\section{3) Peso do material}

Avaliar o peso do material quando for depositado em algum segmento do corpo.
Leve
Moderado
Pesado

Comentários e Impressões pessoais:

\section{4) Fixação de velcros}

Fixar um pedaço do velcro que o profissional estiver acostumado a utilizar (seja autoadesivo ou com cola de contato).
Boa fixação
Fixação moderada
Fixação ruim
Não fixa

Comentários e Impressões pessoais: 


\section{APÊNDICE II \\ Termo de Consentimento \\ Livre e Esclarecido}




\section{Termo de Consentimento Livre e Esclarecido (TCLE)}

Você está sendo convidado a participar da pesquisa DESENVOLVIMENTO NO BRASIL DE TERMOPLÁSTICO DE BAIXA TEMPERATURA PARA UTILIZAÇÃO EM ÓRTESES. O objetivo principal deste estudo é criar uma metodologia para o desenvolvimento de um novo material termomoldável para a confecção de órteses para os membros superiores e verificar sua aplicação na prática clínica.

Com esta pesquisa, pretende-se contribuir com o desenvolvimento de um material nacional para a confecção de órteses para membros superiores, que possa ser moldado diretamente no corpo do usuário, respeitando aspectos anatômicos, com propriedades semelhantes aos materiais termoplásticos de baixa temperatura importados atualmente utilizados. Além de apresentar grande relevância social, ampliando as opções de tratamento com qualidade e gerando melhorias à população, resultaria em um avanço tecnológico para o país, bem como em produção de conhecimento e novas pesquisas na área.

Além disso, como o trabalho estabelece uma metodologia para o desenvolvimento de materiais para órteses, envolvendo inclusive a criação de um protocolo para Manuseio Padronizado de Materiais Termoplásticos para Órteses (MPMTO), produzirá importantes contribuições para pesquisadores e profissionais que necessitam de instrumentos para a mesma finalidade. Tanto a metodologia estabelecida, com todas as suas etapas, como o instrumento padronizado elaborado poderão ser utilizados para o desenvolvimento e teste de outros materiais.

São necessárias algumas características para o grupo que irá compor parte deste trabalho: deve ser um profissional terapeuta ocupacional ou fisioterapeuta que atua com a reabilitação da mão e do membro superior, mais especificamente com a prescrição e confecção de órteses para membros superiores. Como critérios de inclusão, foi estabelecido que todos os participantes tenham experiência na área de confecção de órteses de no mínimo 3 anos e que necessariamente utilizem os materiais termoplásticos de baixa temperatura para essa finalidade.

Após todo o processo de desenvolvimento do material nacional, sua participação consistirá em testar e avaliar dois materiais termoplásticos de baixa temperatura desenvolvidos no Brasil. Dessa forma, na medida em que você aceitar participar da pesquisa e responder a essa pesquisa inicial sobre a confecção de órteses, estando dentro dos critérios de aceitação, 
serão fornecidas duas placas pequenas, uma de cada material, juntamente com um guia de orientações e recomendações para a realização do teste prático. A sua avaliação deverá estar centrada na análise do material e de suas propriedades, das facilidades e dificuldades no manuseio e de outras características do processo de confecção das órteses.

Após utilizar os materiais desenvolvidos você deverá responder a um questionário online que foi elaborado especialmente para isso (cujo link será disponibilizado juntamente com o material), organizado à partir de uma abordagem de escala de classificação, com opções de resposta que variam de um extremo a outro. Além disso o questionário contém também perguntas abertas e mais abrangentes, a respeito, por exemplo, das vantagens, desvantagens e semelhanças do material desenvolvido em comparação ao material comercial termomoldável que você adota em sua prática clínica. A participação não demandará muito de seu tempo, pois envolverá basicamente o teste prático do material e o preenchimento do questionário, tarefas que provavelmente não excederão uma hora.

Através da etapa de testes práticos do material por profissionais com experiência na área, da qual você irá participar, a equipe de pesquisa espera obter opinião e parecer em relação ao novo material, com a expectativa de que este seja eficaz para o posicionamento de membros superiores e possa se apresentar como uma alternativa viável para a confecção de órteses no Brasil. Após a análise dos dados e a conclusão do trabalho, você receberá um comunicado com os principais resultados obtidos e terá acesso a outros dados que forem de seu interesse, bem como será comunicado quanto a publicações que resultarem desta pesquisa.

Ressaltamos que, para a formulação e processamento dos materiais desenvolvidos, a serem testados, foram incluídos somente componentes amplamente utilizados na área médica e que apresentam biocompatibilidade comprovada. Apesar disto, existe um risco de o material causar algum tipo de alergia de contato após o manuseio do mesmo. Dessa forma, se você notar qualquer tipo de irritação ou reação adversa na pele, mediante o contato e manuseio do material, os testes práticos deverão ser interrompidos imediatamente.

Cabe ressaltar que esta possibilidade de risco não envolve gravidade e não compromete sua vida, sendo que você terá direito a indenização conforme as leis vigentes no país, caso ocorra algum dano decorrente de sua participação na pesquisa.

\section{Outras informações importantes:}

a) Poderão ser realizados esclarecimentos antes e durante o decorrer da pesquisa, a respeito dos procedimentos a serem realizados;

b) Os pesquisadores que coordenam a pesquisa possuem formação em Terapia Ocupacional e apresentam qualificação para o desempenho deste trabalho; 
c) Os dados coletados e resultados obtidos, serão divulgadas apenas com a finalidade de estudo e pesquisa, mantendo sigilo em relação ao endereço e dados pessoais do participante em qualquer tipo de aula, apresentação ou artigo referente à pesquisa. Dessa forma, está garantido o sigilo que assegura sua privacidade quanto aos dados que forem confidenciais;

d) Sua participação não é obrigatória, estando livre para recusar entrar na pesquisa ou para retirar o seu consentimento em qualquer momento do trabalho, sem qualquer penalização ou prejuízo;

e) Você não terá despesas com a participação na pesquisa. Não há, portanto, formas de ressarcimento de despesas;

f) Neste termo constam telefone e endereço do pesquisador principal, sendo que você pode tirar suas dúvidas sobre o projeto e sua participação, agora ou em qualquer momento.

Em caso de dúvidas, você poderá tirá-la com os pesquisadores a qualquer momento, enquanto durar a pesquisa. Basta entrar em contato nos emails: to@luagnelli.com.br ou velui@fmrp.usp.br, ou pelos telefones 3315-4417 e (16) 99712-0189.

Para esclarecimentos de dúvidas éticas entrar em contato com o Comitê de Ética em Pesquisa do HCFMRP-USP cujos contatos são: email cep@hcrp.fmrp.usp.br e telefone (16) 3602-2228, das 8:00 às 17:00.

Declaro:

\section{Luciana Bolzan Agnelli Martinez} Pesquisadora Responsável

Concordo com o termo de consentimento e aceito participar da pesquisa

Não concordo com o termo e com as condições de participação na pesquisa

Não desejo participar da pesquisa

Não participarei da pesquisa pois não trabalho com a confecção de órteses há 3 anos ou mais e/ou não tenho experiência com materiais termoplásticos de baixa temperatura

Local e data 


\section{APÊNDICE III}

Guia de Instruções para o

Teste Prático de Materiais 


\section{GUIA DE INSTRUÇÕES PARA O TESTE PRÁTICO DE MATERIAIS}

Você está recebendo duas amostras de materiais termoplásticos de baixa temperatura que foram desenvolvidos no Brasil, através do trabalho intitulado "Desenvolvimento no Brasil de Termoplástico de Baixa Temperatura para utilização em órteses”. Trata-se da pesquisa de doutorado da Terapeuta Ocupacional Luciana Bolzan Agnelli Martinez, sob a orientação da Profa. Dra. Valéria Meirelles Carril Elui, vinculada ao Programa de Pós-Graduação Interunidades em Bioengenharia (EESC / FMRP / IQSC - USP) / Linha de Pesquisa: “Tecnologias Clínicas e de Reabilitação” / Área: Inovação, Tecnologia Assistiva e Recursos Terapêuticos. O trabalho está sendo desenvolvido em parceria com o Departamento de Engenharia de Materiais da Universidade Federal de São Carlos (UFSCar), através do Laboratório de Polímeros Biodegradáveis.

Os materiais que você está recebendo já foram testados através de um instrumento de avaliação que foi elaborado especificamente para isso, o protocolo denominado "Manuseio Padronizado de Materiais Termoplásticos para Órteses - MPMTO” e atualmente estão sendo testados por terapeutas ocupacionais e fisioterapeutas que atuam com a confecção de órteses para membros superiores no Brasil.

\section{INSTRUÇÕES GERAIS}

- Este guia de instruções contém informações sobre as condições para o teste prático, que deverá ser focado na análise do material (neste momento não envolvendo clientes);

- É recomendado que os testes sejam realizados seguindo as indicações que se seguem, realizando o manuseio dos dois materiais enviados;

- Durante ou após o teste dos materiais você deverá responder a um questionário sobre os novos materiais e sobre o material que você normalmente mais utiliza, sendo que o instrumento de coleta de dados está organizado a partir de uma escala de classificação (escala do tipo Likert);

- O link para acessar o questionário será enviado no endereço de email registrado na pesquisa inicial. Esta encontra-se disponível em www.luagnelli.com.br

- O questionário sobre os materiais deve ser respondido durante o teste prático ou então logo após este, para que as percepções em relação aos materiais desenvolvidos sejam registradas, sem que as informações principais sejam perdidas; 
- De acordo com a preferência de cada profissional, os mesmos testes sugeridos poderão ser realizados com a marca comercial mais utilizada (para facilitar a comparação entre os materiais e o preenchimento do questionário);

- Para realizar os testes é necessário aquecer os materiais utilizando água a uma temperatura na faixa de 70 a $90^{\circ} \mathrm{C}$;

- Pode ser confeccionada uma órtese pequena, de um modelo a escolher, que seja possível de acordo com o tamanho de cada amostra (16,3cm X 12,2cm, com 3,2mm de espessura), como por exemplo: canaleta para os dedos, órtese em “8”, órtese para abdução de polegar, órtese para dedo em gatilho, entre outras. Uma sugestão é que seja feita o mesmo teste com os dois materiais.

\section{DEFINIÇÕES E INSTRUÇÕES ESPECÍFICAS}

Este trabalho considera algumas definições em relação às propriedades e características dos materiais termoplásticos de baixa temperatura para órteses e oferece sugestões para o teste desses requisitos, conforme se segue.

- Facilidade para cortar o material resfriado: A sugestão é que seja utilizada uma tesoura multi-uso, do tipo alicate, para materiais rígidos. Preferencialmente, deve-se utilizar a tesoura que já é usada habitualmente para cortar a placa do material comercial (antes de aquecer).

- Facilidade para cortar o material aquecido: A sugestão é que seja utilizada uma tesoura com bom corte, preferencialmente uma tesoura que seja utilizada apenas para materiais termoplásticos.

- Temperatura de Trabalho: Avalie a temperatura em que é possível moldar o material, desde a saída da água até o contato com a pele.

- Tempo de Trabalho: Verificar e avaliar o tempo disponível para se moldar uma órtese até que o material seja resfriado.

- Moldabilidade: Avalie a pressão necessária para moldar a órtese. Considerando a aplicação para a confecção de órteses, um material com moldabilidade excelente é aquele que apresenta fácil manuseio e fornece um acabamento satisfatório do produto moldado (órtese), ajustandose à região do corpo que se pretende imobilizar e possibilitando acomodação de curvas e relevos anatômicos. 
- Memória: Um material que apresenta boa memória é aquele que retorna ao seu tamanho e curvatura original quando aquecido. Uma sugestão para se testar a memória é verificar, durante a moldagem, se o material apresenta a tendência de retornar ao formato anterior (com o material aquecido, durante o tempo de trabalho). Pode-se, por exemplo, esticar levemente o material e observar o seu retorno. Além disso, após ser moldado e resfriado, o material pode ser novamente depositado na água quente para verificar se ele volta ao seu formato original (parcial ou totalmente).

- Capacidade de remodelagem: Depois de moldado e resfriado, verificar se o material possibilita uma segunda moldagem, aquecendo-o novamente para remodelar.

- Facilidade de acabamento: Verificar a capacidade do material para pequenos ajustes e o acabamento das bordas, na medida em que o estiver cortando com a tesoura (enquanto está quente). Sugestão: após a moldagem, aquecer alguns locais específicos do material, como, por exemplo, as bordas, realizando pressão com a ponta dos dedos para arredondá-las e/ou alisálas.

- Auto-aderência: Verificar a capacidade de adesão do material, fazendo a sobreposição de uma superfície sobre a outra.

- Suscetibilidade a impressões digitais: Durante a moldagem, verificar se o material deixa marca da digital.

- Conforto ao toque após moldado: após a moldagem e resfriamento do material, verificar se ele é agradável para a pele e para o contato humano. "Vestir” a órtese moldada (se for o caso) e verificar a sensação causada pelo material.

- Rigidez: Para o teste da rigidez é necessário verificar se o material mantém, após resfriado, o formato moldado e se resiste a deformações, mesmo diante da aplicação de força constante.

- Estética do material: avaliada pela inspeção visual da qualidade do produto moldado.

- Peso do material: avaliada pela percepção do profissional quando o material for depositado em algum segmento do corpo. 
- Fixação de velcros: sugere-se que seja fixado um pedaço do velcro que o profissional estiver acostumado a utilizar (seja auto-adesivo ou com cola de contato).

\section{O link para responder o questionário será enviado por email}

Para dúvidas e informações, entrar em contato com Luciana Bolzan Agnelli Martinez: (16)997120189 / to@luagnelli.com.br 


\section{APÊNDICE IV \\ Formulário para Pesquisa Inicial sobre Confecção de Órteses}




\section{Pesquisa Inicial - Desenvolvimento de Termoplástico de Baixa Temperatura}

*Obrigatório

1. Endereço de e-mail *

2. Nome Completo *

3. Data do Preenchimento *

Exemplo: 15 de dezembro de 2012

4. Declaro:

Marcar apenas uma oval.

Concordo com o termo de consentimento e aceito participar da pesquisa

Não concordo com o termo e com as condições de participação na pesquisa

Pare de preencher este formulário.

\section{Não desejo participar da pesquisa \\ Pare de preencher este formulário.}

Não participarei da pesquisa pois não trabalho com a confeç̧ão de órteses há 3 anos ou mais e/ou não tenho experiência com materiais termoplásticos de baixa temperatura Pare de preencher este formulário. 


\section{Endereço *}

Rua, Número, Complemento, Bairro, Cidade, Estado e CEP (este será o endereço para envio das amostras a serem testadas)

6. Qual a sua formação profissional? *

Caso possua, acrescente em outros formações complementares que tenham vínculos com a confecção de órteses

Marque todas que se aplicam.

Terapia Ocupacional

Fisioterapia

Outro:

\section{Titulação *}

Marque todas que se aplicam.

- Graduação

- Mestrado

Doutorado

Pós-Doutorado

\section{Cursos de Especialização}

9. Cidade e Estado em que você atua *

10. Local/Instutuição em que você trabalha * 
11. Qual é sua área de atuação? *

Marque todas que se aplicam.

Traumato-ortopedia

Reumatologia

$\square$ Neurologia Infantil

— Neurologia Adulto

— LER/DORT

$\square$ Queimaduras

Outro:

12. Tem experiência em confecção de órteses para membros superiores (MMSS)? *

Marcar apenas uma oval

$\int \operatorname{Sim}$

Não Após a última pergunta desta seção, interromper o preenchimento deste

formulário.

13. Quantos anos de experiência na área de confecção de órteses para MMSS? *

14. Nos últimos seis meses, quantas órteses em média, por semana, você confeccionou? * Marcar apenas uma oval

menos de 1 por semana

1 por semana

2 a 5 por semana

mais de 5 por semana

15. Quando atuava mais ativamente em confecção de órteses, quantas órteses em média, por semana, você confeccionava.

Marcar apenas uma oval.

menos de 1 por semana

1 por semana

2 a 5 por semana

mais de 5 por semana 
16. Que materiais você utiliza atualmente na confecção de órteses para MMSS: * Marque todas que se aplicam.
Termoplástico de baixa temperatura
Termoplástico de alta temperatura
- Atadura gessada
Gesso sintético
Metal
$\square$ Neoprene
Couro
$\square$ Lona
$\square$ Outro:

17. Quantos anos de experiência utilizando materiais termoplásticos de baixa temperatura na confecção de órteses? *

18. Quais são as marcas comerciais de material termoplástico de baixa temperatura que você utiliza na confecção de órteses para membros superiores? *

Marque todas que se aplicam.

Allfit

Aquafit NS

$\square$ Aquaplast

$\square$ Contour Blend ${ }^{\mathrm{TM}}$

Easy Fit ${ }^{\mathrm{TM}}$

$\square$ Ezeform

Klarity ${ }^{\mathrm{TM}}$ Aqua

$\square$ Omega ${ }^{\text {TM Max }}$

$\square$ Omega ${ }^{\text {TMBlack }}$

Orficast

Orfilight

Orfilight Atomic Blue NS

$\square$ Orfilight Black NS

$\square$ Orfit Colors NS

$\square$ Orfit Ease

Orfit Eco

$\square$ Orfit Eco Black NS

$\square$ Orfit Flex

$\square$ Orfit NS

$\square$ Tailor

Outro: 
19. Quais são as espessuras e os tipos de placa que você utiliza? *

Marque todas que se aplicam.

$\square 1,6 \mathrm{~mm}$

$2,4 \mathrm{~mm}$

$3,2 \mathrm{~mm}$

Placa lisa

Placa perfurada

Outro:

20. Quais são os equipamentos e ferramentas que você utiliza para confeccionar órteses para membros superiores? *

Marque todas que se aplicam.

Aquecedor elétrico para banho termostático (panela elétrica)

Aquecedor elétrico manual (soprador)

Panela/recipiente comum (sem regulagem de temperatura)

Aquecedor elétrico e portátil, de imersão ("rabo quente")

\Marcador de termoplásticos (lápis para termoplásticos)

$\square$ Tesoura comum

Tesoura curva

$\square$ Tesoura multi-uso (alicate)

- Componentes para órteses dinâmicas

$\square$ Elásticos ou bandas de borracha

$\square$ Furadeira manual

$\square$ Barras de aluminio

$\square$ Velcro

$\square$ Espuma

$\square$ Forrações

$\square$ Outro:

21. Você regula a temperatura da água? *

Marcar apenas uma oval.

$\operatorname{Sim}$

Não

22. Como você regula a temperatura da água? *

Uma cópia das suas respostas será enviada para o endereço de e-mail fornecido 


\section{APÊNDICE V \\ Formulário para Avaliação dos Materiais Termoplásticos}




\section{Avaliação de Materiais Termoplásticos}

Este questionário deverá ser respondido durante ou após o Teste Prático com os materiais fornecidos (identificados como "A" e "B"), de acordo com as sugestões do Guia de Instruções enviado juntamente com as amostras.

*Obrigatório

1. Endereço de e-mail *

\section{Material termoplástico que você mais utiliza na prática clínica}

2. Qual é a marca comercial do material termoplástico de baixa temperatura (com espessura de $3,2 \mathrm{~mm}$ ) que você mais utiliza? *

Marcar apenas uma oval.

Allfit

Aquafit NS

Aquaplast

Contour Blend ${ }^{\mathrm{TM}}$

Easy Fit ${ }^{\mathrm{TM}}$

Ezeform

Klarity ${ }^{\mathrm{TM}}$ Aqua

Omega ${ }^{\text {TM Max }}$

Omega ${ }^{\text {TMPlus }}$

Omega ${ }^{\text {TM} B l a c k}$

Orficast

Orfilight

Orfilight Atomic Blue NS

Orfilight Black NS

Orfit Colors NS

Orfit Ease

Orfit Eco

Orfit Eco Black NS

Orfit Flex

Orfit NS

Tailor

Nenhum dos Anteriores 
3. Você realizou o teste prático do Guia de Instruções com o material da marca comercial que você mais utiliza? *

Marcar apenas uma oval

$\int \operatorname{Sim}$

Não

4. Considerando a resposta da questão anterior, como você avalia as seguintes características do material que você mais utiliza? *

Marcar apenas uma oval por linha.

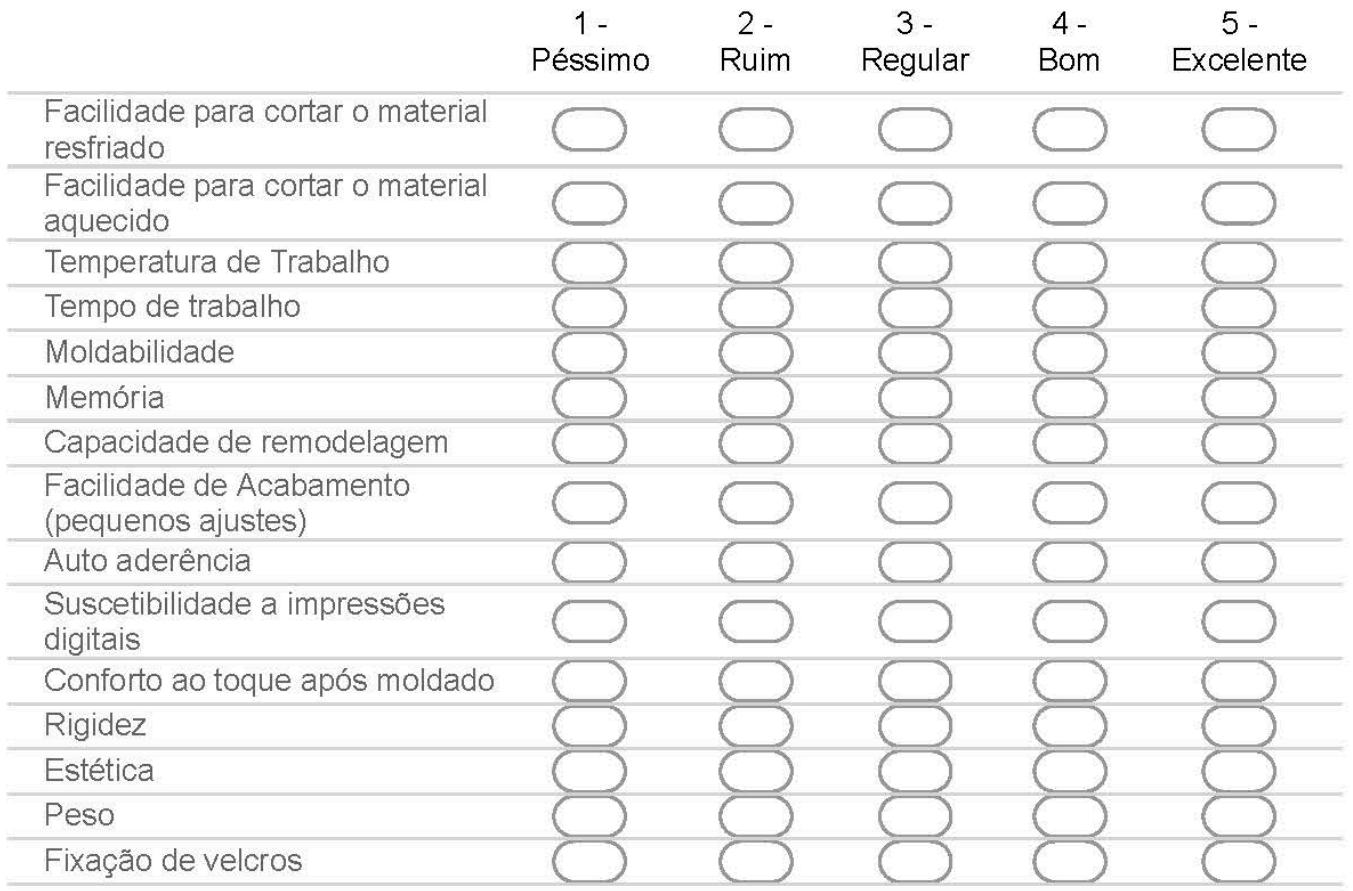

5. Dê sua opinião sobre as vantagens e desvantagens do material que você mais utiliza.

Para os itens "Tempo de Trabalho", "Moldabilidade" e "Memória" seria interessante esclarecer o porquê da resposta.

6. De uma forma geral, em comparação aos materiais existentes no mercado, como você considera a sua satisfação em relação ao material que você mais utiliza? *

Marcar apenas uma oval.
1 - Muito insatisfeito
2 - Insatisfeito
3 - Indiferente
4 - Satisfeito
5 - Muito Satisfeito

Material Desenvolvido Identificado como "A" 
7. Como você avalia as seguintes características no material desenvolvido identificado como "A"? *

Marcar apenas uma oval por linha

\begin{tabular}{|c|c|c|c|c|c|}
\hline & $\begin{array}{c}1- \\
\text { Péssimo }\end{array}$ & $\begin{array}{l}2 \text { - } \\
\text { Ruim }\end{array}$ & $\begin{array}{c}3- \\
\text { Regular }\end{array}$ & $\begin{array}{c}4- \\
\text { Bom }\end{array}$ & $\begin{array}{c}5- \\
\text { Excelente }\end{array}$ \\
\hline \multicolumn{6}{|c|}{$\begin{array}{l}\text { Facilidade para cortar o material } \\
\text { resfriado }\end{array}$} \\
\hline \multicolumn{6}{|c|}{$\begin{array}{l}\text { Facilidade para cortar o material } \\
\text { aquecido }\end{array}$} \\
\hline \multicolumn{6}{|c|}{ Temperatura de Trabalho } \\
\hline \multicolumn{6}{|l|}{ Tempo de trabalho } \\
\hline \multicolumn{6}{|l|}{ Moldabilidade } \\
\hline \multicolumn{6}{|l|}{ Memória } \\
\hline \multicolumn{6}{|c|}{ Capacidade de remodelagem } \\
\hline \multicolumn{6}{|c|}{$\begin{array}{l}\text { Facilidade de Acabamento } \\
\text { (pequenos ajustes) }\end{array}$} \\
\hline \multicolumn{6}{|l|}{ Auto aderência } \\
\hline \multicolumn{6}{|c|}{$\begin{array}{l}\text { Suscetibilidade a impressões } \\
\text { digitais }\end{array}$} \\
\hline \multicolumn{6}{|c|}{ Conforto ao toque após moldado } \\
\hline \multicolumn{6}{|l|}{ Rigidez } \\
\hline \multicolumn{6}{|l|}{ Estética } \\
\hline \multicolumn{6}{|l|}{ Peso } \\
\hline Fixação de velcros & & & & & \\
\hline
\end{tabular}

8. Dê sua opinião sobre as vantagens e desvantagens do material identificado como "A".

Para os itens "Tempo de Trabalho", "Moldabilidade" e "Memória" seria interessante esclarecer o porquê da resposta.

9. Você confeccionou alguma órtese para testar o material desenvolvido identificado como "A"? *

Marcar apenas uma oval.

Sim

Não

10. Qual o modelo e quais são suas considerações em relação ao processo de confecção da órtese com o material "A"? 
11. De uma forma geral, em comparação aos materiais existentes no mercado, como você considera a sua satisfação em relação ao material desenvolvido identificado como " $A$ "? * Marcar apenas uma oval.
1 - Muito insatisfeito
2 - Insatisfeito
3 - Indiferente
4 - Satisfeito
5 - Muito Satisfeito

\section{Material Desenvolvido Identificado como "B"}

12. Como você avalia as seguintes características no material desenvolvido identificado como "B"? *

Marcar apenas uma oval por linha

\begin{tabular}{|c|c|c|c|c|c|}
\hline & $\begin{array}{c}1- \\
\text { Péssimo }\end{array}$ & $\begin{array}{l}2 \text { - } \\
\text { Ruim }\end{array}$ & $\begin{array}{l}3- \\
\text { Regular }\end{array}$ & $\begin{array}{c}4- \\
\text { Bom }\end{array}$ & $\begin{array}{c}5- \\
\text { Excelente }\end{array}$ \\
\hline \multicolumn{6}{|c|}{$\begin{array}{l}\text { Facilidade para cortar o material } \\
\text { resfriado }\end{array}$} \\
\hline \multicolumn{6}{|c|}{$\begin{array}{l}\text { Facilidade para cortar o material } \\
\text { aquecido }\end{array}$} \\
\hline \multicolumn{6}{|c|}{ Temperatura de Trabalho } \\
\hline \multicolumn{6}{|l|}{ Tempo de trabalho } \\
\hline \multicolumn{6}{|l|}{ Moldabilidade } \\
\hline \multicolumn{6}{|l|}{ Memória } \\
\hline \multicolumn{6}{|c|}{ Capacidade de remodelagem } \\
\hline \multicolumn{6}{|c|}{$\begin{array}{l}\text { Facilidade de Acabamento } \\
\text { (pequenos ajustes) }\end{array}$} \\
\hline \multicolumn{6}{|l|}{ Auto aderência } \\
\hline \multicolumn{6}{|c|}{$\begin{array}{l}\text { Suscetibilidade a impressões } \\
\text { digitais }\end{array}$} \\
\hline \multicolumn{6}{|c|}{ Conforto ao toque após moldado } \\
\hline \multicolumn{6}{|l|}{ Rigidez } \\
\hline \multicolumn{6}{|l|}{ Estética } \\
\hline \multicolumn{6}{|l|}{ Peso } \\
\hline Fixação de velcros & & & & & \\
\hline
\end{tabular}

13. Dê sua opinião sobre as vantagens e desvantagens do material identificado como " $B$ "

Para os itens "Tempo de Trabalho", "Moldabilidade" e "Memória" seria interessante esclarecer o porquê da resposta.

14. Você confeccionou alguma órtese para testar o material desenvolvido identificado como "B"? *

Marcar apenas uma oval.

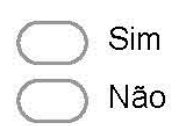


15. Qual o modelo e quais são suas considerações em relação ao processo de confecção da órtese com o material "B"?

16. De uma forma geral, em comparação aos materiais existentes no mercado, como você considera a sua satisfação em relação ao material desenvolvido identificado como "B"? * Marcar apenas uma oval.

1 - Muito insatisfeito

2 - Insatisfeito

3 - Indiferente

4 - Satisfeito

5 - Muito Satisfeito

17. Sugestões e comentários sobre os materiais desenvolvidos.

Uma cópia das suas respostas será enviada para o endereço de e-mail fornecido 


\section{APÊNDICE VI \\ Análise Complementar \\ Termogravimetria}




\section{RESULTADOS COMPLEMENTARES DE TERMOGRAVIMETRIA PARA OS 4} MATERIAIS DA FASE EXPERIMENTAL

A Análise por Termogravimetria - TG para os 4 materiais da Fase Experimental foi realizada com o mesmo procedimento descrito nos Materiais e Métodos.

As Curvas TG e DTG referentes aos 4 materiais estão apresentadas nas Figuras $1 \mathrm{a}$ 4. Para uma melhor visualização, a Figura 5 apresenta a sobreposição das Curvas TG referentes a estes materiais.

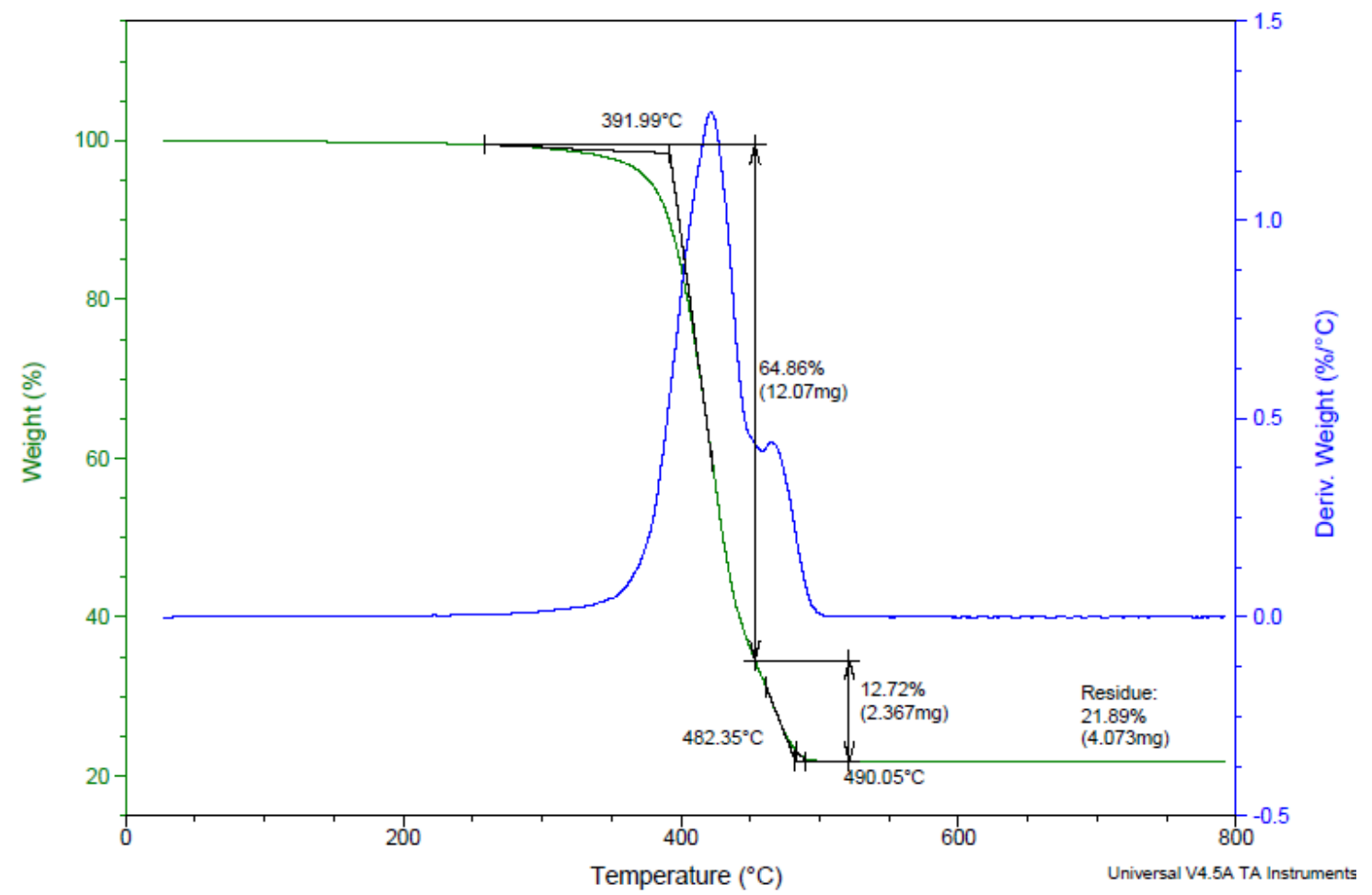

Figura 1 - Curva TG para o Ezeform ${ }^{\mathrm{TM}}$ 


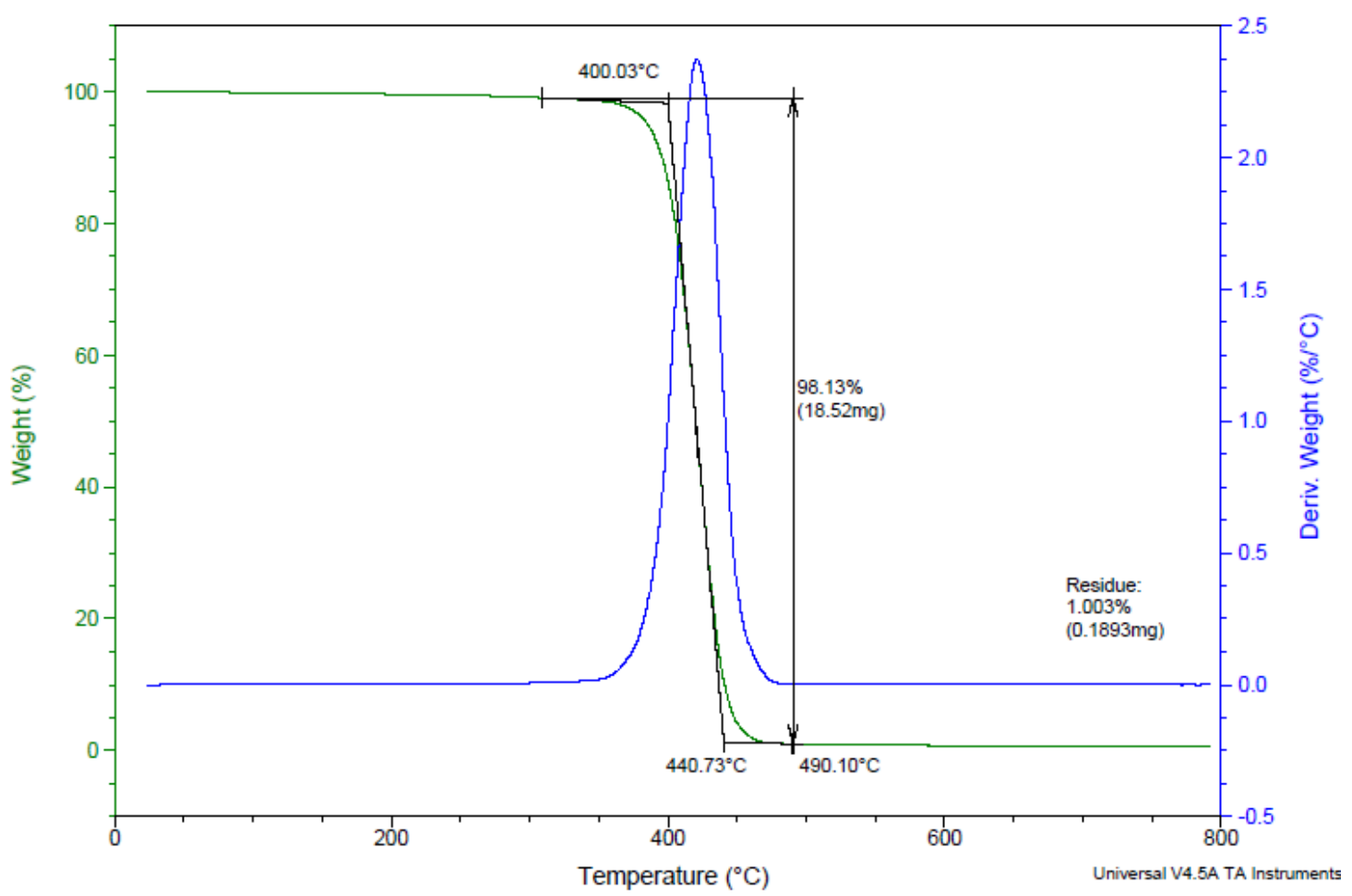

Figura 2 - Curva TG para o Aquaplast-T ${ }^{\mathrm{TM}}$

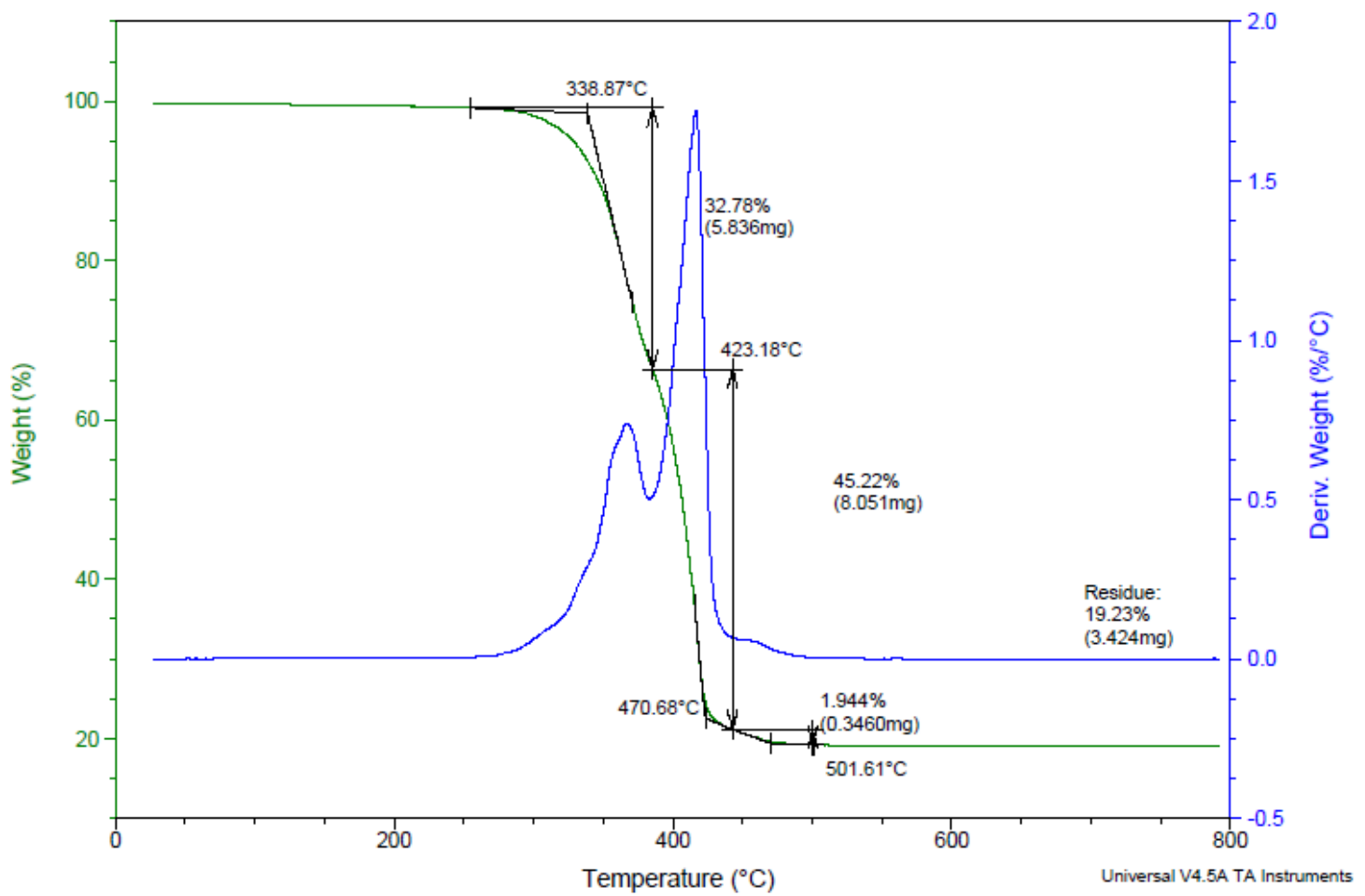

Figura 3 - Curva TG para o Material A 


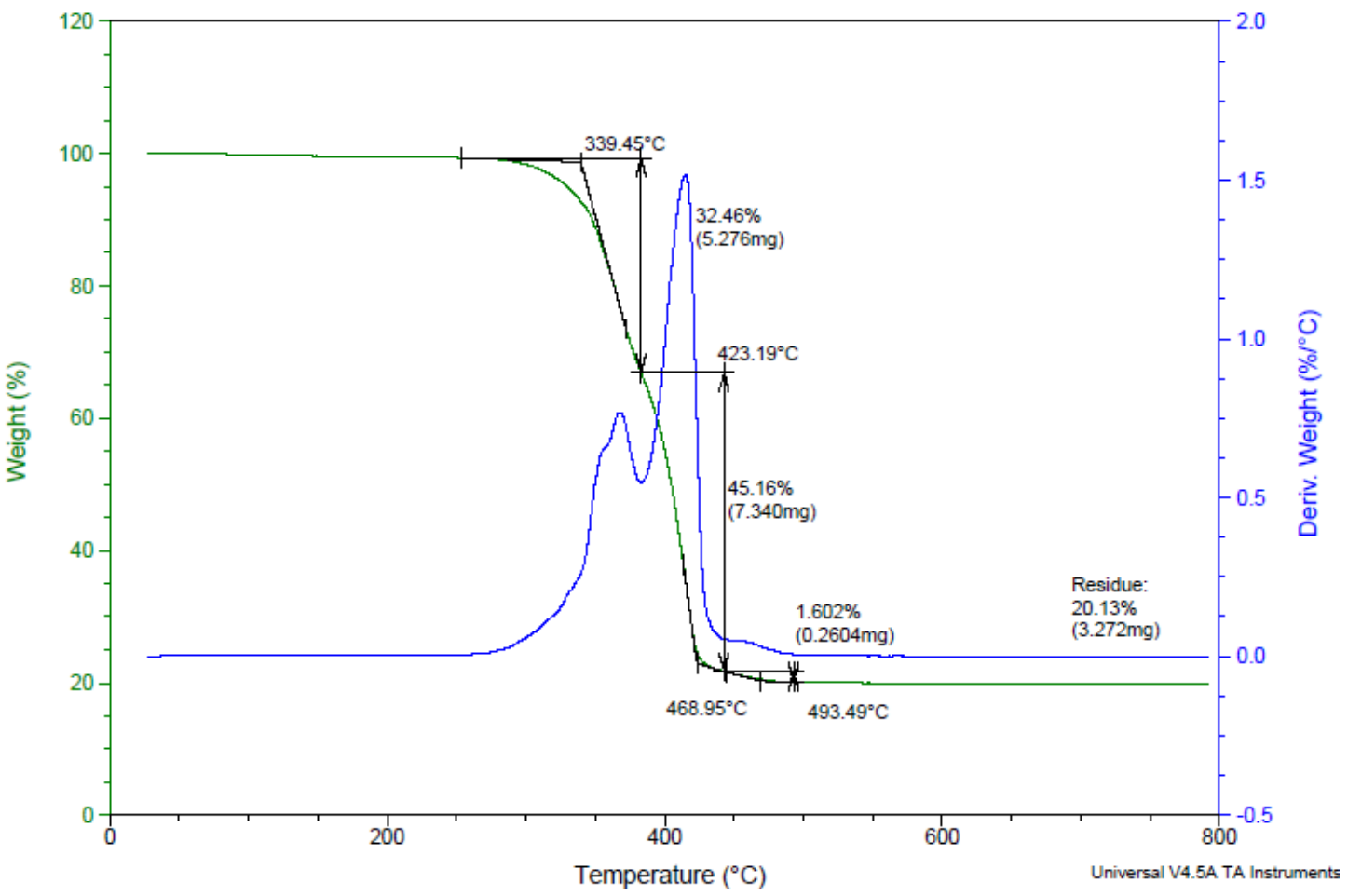

Figura 4 - Curva TG para o Material B

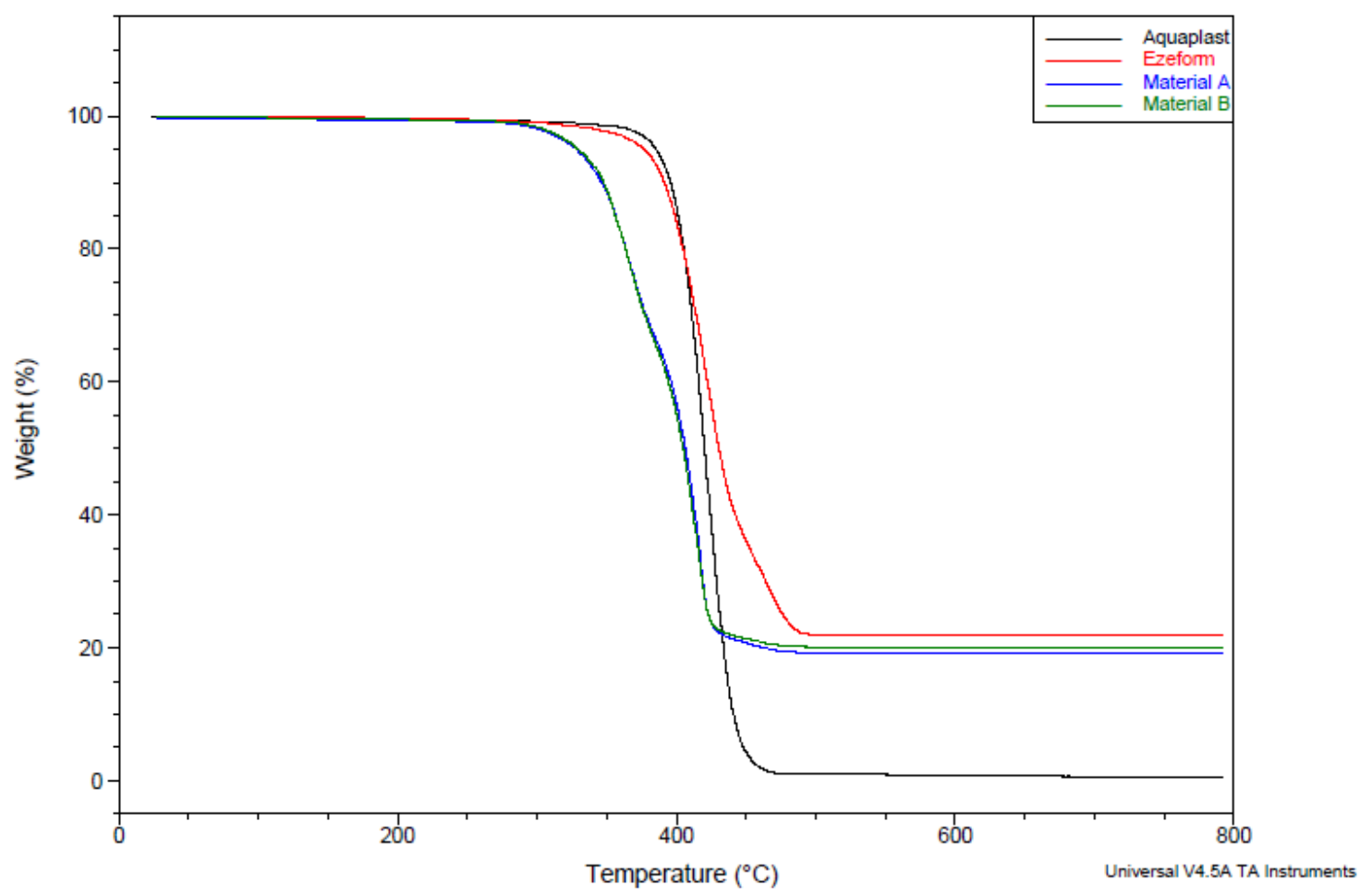

Figura 5 - Sobreposição das Curvas TG para os 4 Materiais 
As Curvas TG indicam o perfil de perda de massa característico do polímero (ou dos polímeros no caso de blendas poliméricas) e indicam o "resíduo inorgânico total”, constituído pelos Teores de cargas minerais, de fibras de vidro, de pigmentos inorgânicos e de cinzas dos outros aditivos. Após a eliminação dos componentes orgânicos (polímero(s) e aditivos orgânicos), a massa residual corresponde ao teor de material inorgânico contido nos 4 Materiais, como mostrado na Tabela 1.

Tabela 1 - Teor de Inorgânicos obtidos por Termogravimetria (TG)

\begin{tabular}{|c|c|}
\hline Material & Teor de Inorgânicos (\%) \\
\hline Ezeform $^{\mathrm{TM}}$ & 21,9 \\
\hline Aquaplast-T $^{\mathrm{TM}}$ & 1,0 \\
\hline Material A & 19,2 \\
\hline Material B & 20,1 \\
\hline
\end{tabular}

É possível observar que as composições poliméricas do Material Ezeform ${ }^{\mathrm{TM}}$, do Material A e do Material B apresentam teores de inorgânicos bem próximos. O Material Aquaplast-T TM não contém cargas e reforços inorgânicos, sendo constituído muito majoritariamente pelo polímero PCL, podendo conter um pequeno teor de modificadores elastoméricos e de aditivos de proteção ou com outras funções.

Os teores de inorgânicos do Material A e do Material B indicaram uma pequena diferença entre os teores nominais e os teores reais obtidos na análise por TG. 
ANEXO I

Parecer do Comitê de Ética em Pesquisas envolvendo seres humanos 


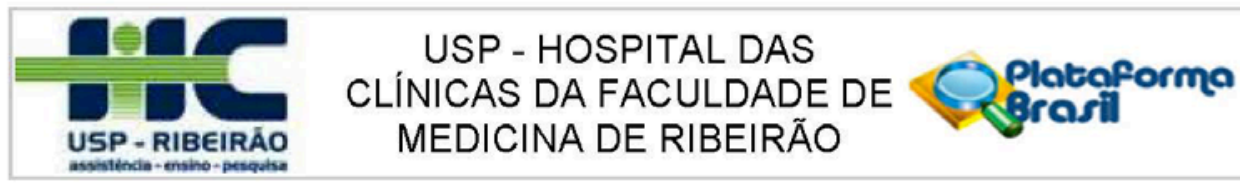

\section{PARECER CONSUBSTANCIADO DO CEP}

\section{DADOS DO PROJETO DE PESQUISA}

Título da Pesquisa: ESTUDO DE UM MATERIAL TERMOPLÁSTICO DE BAIXA TEMPERATURA DESENVOLVIDO NO BRASIL: ANÁLISE FÍSICO-MECÂNICA E SUA APLICAÇĀO NA CONFECÇÄO DE ÓRTESES PARA MEMBROS SUPERIORES

Pesquisador: Luciana Bolzan Agnelli Martinez

Área Temática:

Versão: 2

CAAE: 61275016.7 .0000 .5440

Instituição Proponente: Faculdade de Medicina de Ribeirão Preto da Universidade de São Paulo

Patrocinador Principal: Universidade Federal de São Carlos/UFSCar

\section{DADOS DO PARECER}

Número do Parecer: 1.827 .471

\section{Apresentação do Projeto:}

As órteses fazem parte de um arsenal de recursos terapêuticos e seu objetivo principal é promover equilibrio biomecånico por meio da aplicaçăo de forças ao segmento do corpo que se pretende imobilizar. Elas săo utilizadas em conjunto com outras estratégias de tratamento para melhorar o desempenho ocupacional, sendo constatado que a maioria dos profissionais do Brasil utiliza, para esta finalidade, materiais termoplásticos de baixa

temperatura, cujas marcas comerciais disponiveis no mercado são importadas. O presente estudo tem por objetivo criar uma metodologia para o desenvolvimento de um material nacional e verificar sua aplicaçăo na prática clínica. A primeira etapa será exploratória, visando um levantamento das características e dos componentes que o material a ser desenvolvido deve ter, criando-se uma matriz de requisitos que conduza a formulação do material. Serão processadas amostras de diferentes materiais, dentre as quais será selecionado aquele que obtiver êxito durante o processo de avaliação. A segunda etapa do estudo terá, portanto, caráter experimental, em que serăo realizados experimentos para caracterização estrutural e térmica do material selecionado. Seråo realizados os ensaios: Calorimetria Exploratória Diferencial (DSC), Termogravimetria (TG), Temperatura de Amolecimento Vicat, ensaio de flexão em três pontos e, de maneira

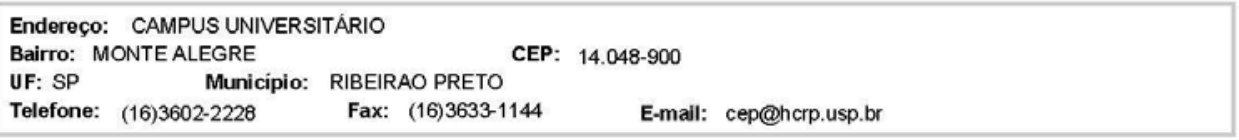




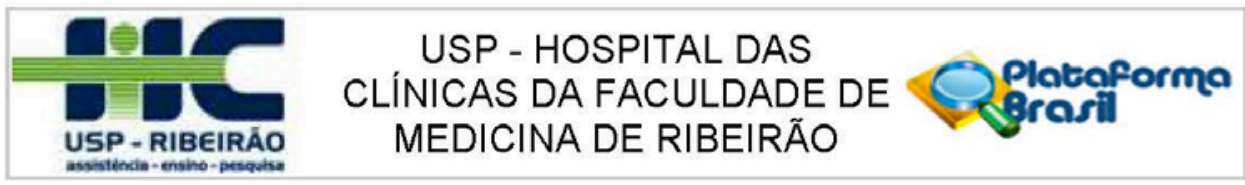

Continuaçẩo do Parecer. 1.827.471

complementar, Microscopia Eletrônica de Varredura (MEV). Posteriormente o material será analisado na prática clínica, em quatro etapas: teste de resistência e simulação do produto final; investigaçăo dos aspectos de biocompatibilidade; teste clínico por profissionais da área e aplicaçăo em usuários, em uma população a ser definida e selecionada à partir de dois serviços de reabilitação distintos. Os instrumentos de coleta de dados para o teste do material (por profissionais e por usuários) serăo do tipo questionário, organizados no formato de escala do tipo Likert. Como resultados, pretende-se contribuir para o desenvolvimento de um material nacional, com propriedades semelhantes aos materiais termoplásticos de baixa temperatura importados atualmente utilizados, que possa ser moldado diretamente no corpo do usuário e que seja apropriado e viável para a confecção de órteses para membros superiores.

\section{Objetivo da Pesquisa:}

Elaborar uma metodologia para o desenvolvimento e teste de novos materiais para a confecção de órteses e desenvolver e testar um material nacional especificamente para esta finalidade.

\section{Avaliação dos Riscos e Benefícios:}

Riscos:

Somente a segunda etapa da pesquisa envolverá seres humanos, mais especificamente a etapa em que o material desenvolvido deverá ser testado segundo critérios da prática clínica, tanto por profissionais que atuam na área como por usuários de órteses.Para a formulação e processamento das amostras e, consequentemente, do material selecionado, serăo utilizados somente componentes amplamente utilizados na área médica e que apresentam biocompatibilidade comprovada. Dessa forma, apesar do material desenvolvido a ser testado apresentar risco mínimo para o usuário, este será alertado quanto aos riscos de desenvolver algum tipo de alergia de contato após utilização das órteses e serão instruídos a interromper o uso caso apresente qualquer sinal de irritação. Cabe ressaltar que os usuários poderão apresentar irritação ou alergia năo somente em relaçăo ao

material desenvolvido, como também após o uso das órteses confeccionadas com material disponivel no mercado para esta finalidade. Na prática clínica, é usual que o terapeuta avalie e oriente adequadamente o indivíduo a respeito desses riscos, antes, durante e após qualquer procedimento envolvendo a confecção de dispositivos que sejam acoplados ao corpo, mesmo que sejam externos, como é o caso das órteses para membros superiores. Desse modo, independente do material com que as órteses sejam confeccionadas (seja o material comercial ou o material em teste) os mesmos cuidados e procedimentos terapéuticos serăo

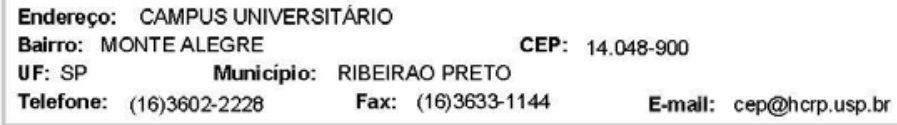




\begin{tabular}{|c|c|}
\hline IBEIRÃo & $\begin{array}{l}\text { USP - HOSPITAL DAS } \\
\text { CLIINICAS DA FACULDADE DE S Pratoforma } \\
\text { MEDICINA DE RIBEIRÃO }\end{array}$ \\
\hline
\end{tabular}

Continuaçąo do Parecer. 1.827 .471

realizados durante as intervençбes previstas para este estudo. Apesar das órteses serem confeccionadas em um modelo indicado para os participantes (órtese ventral para imobilização do punho com dedos livres), a órtese confeccionada com o material que foi desenvolvido na pesquisa pode năo apresentar as qualidades esperadas, podendo não ser efetiva no tratamento. Para que não haja riscos permanentes ou prejuízos ao usuário, foi estipulado o período de uso de apenas uma semana. Além disso é possivel que o usuário

não se adapte à órtese confeccionada com o material desenvolvido, ou até mesmo à órtese confeccionada com material já existente no mercado, podendo sentir algum desconforto durante sua utilização, o que deverá ser relatado no questionário após uma semana de uso com cada aparelho. Cabe ressaltar que nenhuma das possibilidades de risco apresentadas acima apresenta gravidade envolvendo sua vida e saúde física, uma vez que a órtese que o indivíduo irá utilizar definitivamente, após as duas semanas de teste, será a órtese confeccionada com o material comercial. Esta deverá ser reavaliada e ajustada (remodelada) após uma semana de uso, caso haja necessidade para isso. Todos os riscos envolvidos serão descritos no termo de consentimento livre e esclarecido, juntamente com outras informações sobre o estudo. Beneficios:

Um dos maiores beneficios dos materiais termoplásticos de baixa temperatura é o fato de possibilitarem acomodação anatômica da parte do corpo que se pretende imobilizar, uma vez que podem ser moldados diretamente na pele do usuário. Apesar de ser possivel a confecção com outros materiais, o presente estudo determina que as órteses dos usuários sejam feitas com materiais termo-moldáveis, como também podem ser denominados, que atualmente são os materiais mais recomendados para a confecção de órteses para membros superiores.

Contudo todas as marcas comerciais deste tipo de material disponiveis no mercado são importadas, não havendo um material nacional com propriedades e caracteristicas semelhantes. Embora se tenha dois distribuidores no Brasil (MN, 2013; POLITEC, 2013), com várias marcas comerciais, o custo é acrescido de impostos, frete e condicionado à cotação do dólar. 0 custo final é absorvido pelo governo, no caso de serviços e hospitais públicos que utilizam o material, ou ainda repassado para a população, quando adquire as órteses em serviços privados. O custo desses materiais ainda é considerado alto quando comparado a outros, como por exemplo os materiais à base de gesso, que também podem satisfazer, mesmo que parcialmente, as necessidades do cliente e dos profissionais, e os termoplásticos de alta temperatura, como o PVC e o polipropileno. Dessa forma, o presente estudo propõe o desenvolvimento de um material nacional que apresente características semelhantes aos

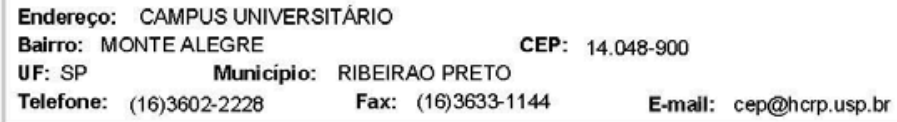




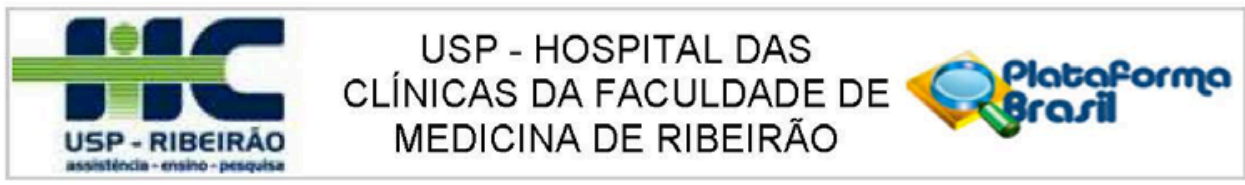

Continuaçąo do Parecer. 1.827 .471

materiais importados, aliadas à reduçăo de custos finais. Além de apresentar grande relevância social, ampliando as opções de tratamento com qualidade e

gerando melhorias à populaçăo, resultaria em um avanço tecnológico para o país, bem como em produçăo de conhecimento e novas pesquisas na área.

\section{Comentários e Consideraçōes sobre a Pesquisa:}

A primeira etapa (exploratória) consistirá no desenvolvimento do material, através da criaçăo de uma metodologia que conduza a formulação do material de acordo com a finalidade que se deseja para este. Será elaborada uma matriz de requisitos, em que estes serăo classificados por prioridade e estarăo relacionados às características que o material precisa ter para ser eficiente na confecção de órteses para membros superiores,

tais como: conformabilidade, temperatura de amolecimento, capacidade de remodelação, rigidez, durabilidade, acabamento, entre outras. Após um estudo de mercado a cerca de materiais, formulaçōes e processos que supram os requisitos, serăo processadas várias amostras de materiais que deverăo ser analisadas e comparadas. Para cada amostra será elaborado um protocolo de avaliação, a fim de testar e pontuar os requisitos, de

forma padronizada, para classificar os materiais e selecionar um deles. O material selecionado passará por uma análise estrutural e físico-mecânica, cujos testes serăo realizados por profissionais qualificados, no Laboratório de Polímeros Biodegradáveis, do Departamento de Engenharia de Materiais-UFSCar. Para a caracterização térmica serão empregadas as técnicas: Calorimetria Exploratória Diferencial, Termogravimetria e Temperatura de Amolecimento Vicat. A caracterização físico-mecânica será feita através do ensaio de flexão em três pontos, por ser esta uma das solicitações mais representativas das condições práticas do uso de órteses. Posteriormente o material será testado segundo critérios da prática clínica, tanto por profissionais que atuam na área como por usuários de órteses.Serão convidados aproximadamente 30 terapeutas ocupacionais ou fisioterapeutas que atuam com a confecçăo de órteses para membros superiores no Brasil. Será fornecida uma placa do material desenvolvido para que eles confeccionem uma órtese do modelo estipulado em um adulto voluntário, que necessariamente não ofereça resistência ao manuseio e que não apresente alterações de tônus, rigidez articular e outras características que dificultem o processo de confecção, a fim de focar a análise no

material e facilitar a comparaçăo entre as opiniões dos terapeutas. Os participantes receberăo um guia de instruçőes com os critérios para o teste prático e, após utilizarem o material, deverão responder a um questionário a cerca das facilidades e dificuldades no manuseio e de outras características do processo de confecção das órteses a serem discriminadas.Pretende-se

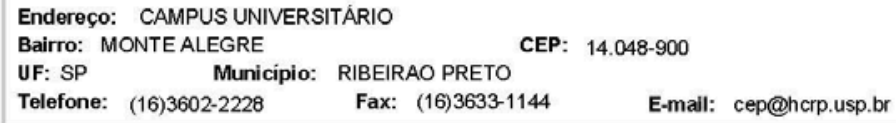




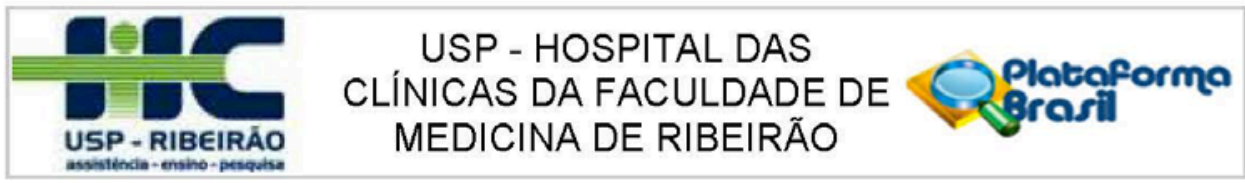

Continuaçąo do Parecer. 1.827 .471

selecionar aproximadamente 30 adultos usuários de órteses, com diagnósticos em neurologia, reumatologia e/ou alterações ósteo-musculares, que tenham indicação para uso de uma órtese ventral para imobilização do punho, com todos os dedos livres (conhecida como cock up ventral). Será realizado um estudo comparativo entre órteses confeccionadas com o material desenvolvido e órteses confeccionadas com uma marca comercial utilizada em larga escala para essa finalidade. Dessa forma, serăo moldadas duas órteses para cada indivíduo, uma com cada material, de forma que utilizarão cada órtese em sua rotina diária durante uma semana. O tempo para uso diário do aparelho durante as duas semanas de teste será estipulado de acordo com a demanda de cada

usuário. Haverá um sorteio (às cegas) para definir qual material será utilizado para a confecção da órtese na primeira semana. Após o uso de cada órtese, todos os participantes responderăo a um questionário sobre: conforto durante o uso; facilidades e dificuldades na colocação e retirada; peso do aparelho; desempenho nas atividades; temperatura; estética; higienizaçåo da órtese; entre outras. Pretende-se realizar a seleçåo dos

participantes e os procedimentos desta etapa em dois serviços de reabilitação: o Centro de Reabilitação (CER) do Hospital das Clínicas da Faculdade de Medicina de Ribeirão Preto (FMRP-USP) e a Unidade Saúde Escola (USE) da Universidade Federal de Såo Carlos (UFSCar).

\section{Consideraçőes sobre os Termos de apresentação obrigatória:}

Os termos foram modificados conforme recomendações emitidas no parecer.

\section{Recomendaçőes:}

Não há.

Conclusões ou Pendências e Lista de Inadequaçöes:

Diante do exposto e à luz da Resolução CNS 466/2012, o Projeto de pesquisa Versão 2: 15/11/2016 e os Termos de Consentimento Livre e Esclarecido Versão 2: 15/11/2016 podem ser enquadrados na categoria APROVADO.

\section{Consideraçōes Finais a critério do CEP:}

Projeto Aprovado: Tendo em vista a legislaçăo vigente, devem ser encaminhados ao CEP, relatórios parciais anuais referentes ao andamento da pesquisa e relatório final ao término do trabalho. Qualquer modificação do projeto original deve ser apresentada a este CEP em nova versăo, de forma objetiva e com justificativas, para nova apreciação.

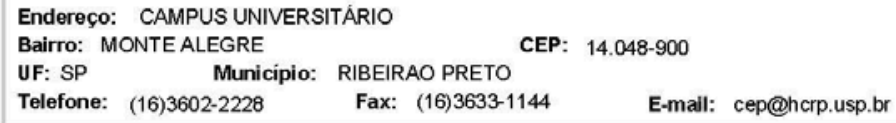




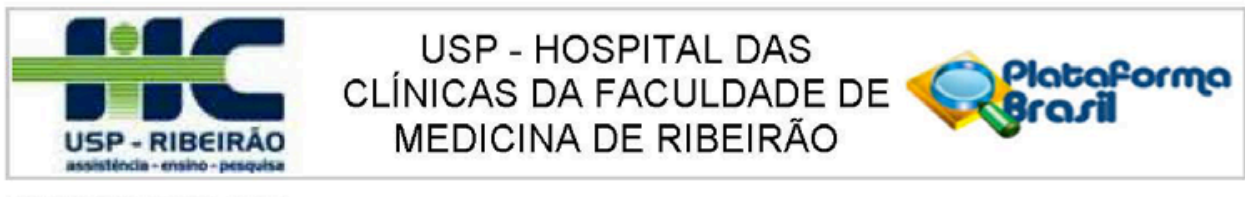

Continuaçảo do Parecer. 1.827.471

Este parecer foi elaborado baseado nos documentos abaixo relacionados:

\begin{tabular}{|c|c|c|c|c|}
\hline Tipo Documento & Arquivo & Postagem & Autor & Situação \\
\hline $\begin{array}{l}\text { Informações Básicas } \\
\text { do Projeto }\end{array}$ & $\begin{array}{l}\text { PB_INFORMAÇŌES_BÁSICAS_DO_P } \\
\text { ROJETO 700277.pdf }\end{array}$ & $\begin{array}{c}15 / 11 / 2016 \\
16: 57: 48 \\
\end{array}$ & & Aceito \\
\hline Outros & $\begin{array}{l}\text { Carta_resposta_PARECER_CONSUBS } \\
\text { TANCIADO CEP 1809844.pdf } \\
\end{array}$ & $\begin{array}{c}15 / 11 / 2016 \\
16: 57: 05 \\
\end{array}$ & $\begin{array}{l}\text { Luciana Bolzan } \\
\text { Agnelli Martinez } \\
\end{array}$ & Aceito \\
\hline $\begin{array}{l}\text { Projeto Detalhado / } \\
\text { Brochura } \\
\text { Investigador }\end{array}$ & $\begin{array}{l}\text { Projeto_doutorado_detalhado_CEP_201 } \\
\text { 6_VERSAO_2.pdf }\end{array}$ & $\begin{array}{c}15 / 11 / 2016 \\
16: 54: 14\end{array}$ & $\begin{array}{l}\text { Luciana Bolzan } \\
\text { Agnelli Martinez }\end{array}$ & Aceito \\
\hline $\begin{array}{l}\text { TCLE / Termos de } \\
\text { Assentimento / } \\
\text { Justificativa de } \\
\text { Ausência }\end{array}$ & $\begin{array}{l}\text { Termo_de_Consentimento_Livre_e_Escl } \\
\text { arecido_terapeutas_participantes_VERS } \\
\text { AO_2.pdf }\end{array}$ & $\begin{array}{c}15 / 11 / 2016 \\
16: 52: 53\end{array}$ & $\begin{array}{l}\text { Luciana Bolzan } \\
\text { Agnelli Martinez }\end{array}$ & Aceito \\
\hline $\begin{array}{l}\text { TCLE / Termos de } \\
\text { Assentimento / } \\
\text { Justificativa de } \\
\text { Ausência }\end{array}$ & $\begin{array}{l}\text { Termo_de_Consentimento_Livre_e_Esci } \\
\text { arecido_participantes_usuarios_orteses } \\
\text { _VERSAO_2.pdf }\end{array}$ & $\begin{array}{c}15 / 11 / 2016 \\
16: 52: 40\end{array}$ & $\begin{array}{l}\text { Luciana Bolzan } \\
\text { Agnelli Martinez }\end{array}$ & Aceito \\
\hline Cronograma & Cronograma_VERSAO_2.xIsx & $\begin{array}{c}15 / 11 / 2016 \\
16: 52: 17 \\
\end{array}$ & $\begin{array}{l}\text { Luciana Bolzan } \\
\text { Agnelli Martinez }\end{array}$ & Aceito \\
\hline $\begin{array}{l}\text { Projeto Detalhado / } \\
\text { Brochura } \\
\text { Investigador }\end{array}$ & $\begin{array}{l}\text { Projeto_doutorado_detalhado_CEP_201 } \\
\text { 6.doc }\end{array}$ & $\begin{array}{c}24 / 10 / 2016 \\
09: 11: 27\end{array}$ & $\begin{array}{l}\text { Luciana Bolzan } \\
\text { Agnelli Martinez }\end{array}$ & Aceito \\
\hline $\begin{array}{l}\text { TCLE / Termos de } \\
\text { Assentimento / } \\
\text { Justificativa de } \\
\text { Ausência }\end{array}$ & $\begin{array}{l}\text { Termo_de_Consentimento_Livre_e_Escl } \\
\text { arecido_participantes_usuarios_de_orte } \\
\text { ses.docx }\end{array}$ & $\begin{array}{c}17 / 10 / 2016 \\
17: 54: 37\end{array}$ & $\begin{array}{l}\text { Luciana Bolzan } \\
\text { Agnelli Martinez }\end{array}$ & Aceito \\
\hline $\begin{array}{l}\text { TCLE / Termos de } \\
\text { Assentimento / } \\
\text { Justificativa de } \\
\text { Ausência }\end{array}$ & $\begin{array}{l}\text { Termo_de_Consentimento_Livre_e_Escl| } \\
\text { arecido_terapeutas_participantes.docx }\end{array}$ & $\begin{array}{c}17 / 10 / 2016 \\
17: 54: 19\end{array}$ & $\begin{array}{l}\text { Luciana Bolzan } \\
\text { Agnelli Martinez }\end{array}$ & Aceito \\
\hline $\begin{array}{l}\text { Declaração de } \\
\text { Instituiçăo e } \\
\text { Infraestrutura }\end{array}$ & $\begin{array}{l}\text { UPC_assinado_departamento_orientado } \\
\text { ra.pdf }\end{array}$ & $\begin{array}{c}14 / 10 / 2016 \\
15: 57: 28\end{array}$ & $\begin{array}{l}\text { Luciana Bolzan } \\
\text { Agnelli Martinez }\end{array}$ & Aceito \\
\hline Cronograma & Cronograma_2015_a_2018.xlsx & $\begin{array}{c}15 / 09 / 2016 \\
09: 21: 35\end{array}$ & $\begin{array}{l}\text { Luciana Bolzan } \\
\text { Agnelli Martinez }\end{array}$ & Aceito \\
\hline Orçamento & Orcamento_2016.pdf & $\begin{array}{c}15 / 09 / 2016 \\
09: 20: 40\end{array}$ & $\begin{array}{l}\text { Luciana Bolzan } \\
\text { Agnelli Martinez }\end{array}$ & Aceito \\
\hline Cronograma & cronograma.docx & $\begin{array}{c}15 / 09 / 2016 \\
09: 10: 35 \\
\end{array}$ & $\begin{array}{l}\text { Luciana Bolzan } \\
\text { Agnelli Martinez }\end{array}$ & Aceito \\
\hline $\begin{array}{l}\text { Declaração de } \\
\text { Instituição e } \\
\text { Infraestrutura } \\
\end{array}$ & $\begin{array}{l}\text { Aprovacao_comite_Unidade_saude_esc } \\
\text { ola_USE_carimbo.pdf }\end{array}$ & $\begin{array}{c}15 / 09 / 2016 \\
09: 07: 11\end{array}$ & $\begin{array}{l}\text { Luciana Bolzan } \\
\text { Agnelli Martinez }\end{array}$ & Aceito \\
\hline Folha de Rosto & pagina_rosto_Plataforma_Brasil.pdf & $\begin{array}{c}05 / 05 / 2016 \\
13: 14: 01 \\
\end{array}$ & $\begin{array}{l}\text { Luciana Bolzan } \\
\text { Agnelli Martinez }\end{array}$ & Aceito \\
\hline $\begin{array}{l}\text { Declaraçăo de } \\
\text { Instituição e } \\
\text { Infraestrutura }\end{array}$ & $\begin{array}{l}\text { Aprovacao_comite_centro_de_reabilitac } \\
\text { ao_CER.pdf }\end{array}$ & $\begin{array}{c}22 / 04 / 2016 \\
19: 31: 53\end{array}$ & $\begin{array}{l}\text { Luciana Bolzan } \\
\text { Agnelli Martinez }\end{array}$ & Aceito \\
\hline
\end{tabular}

Endereço: CAMPUS UNIVERSITÁRIO

\begin{tabular}{llll} 
Bairro: & MONTE ALEGRE & \multicolumn{4}{c}{ CEP: } & $14.048-900$ \\
UF: SP & \multicolumn{1}{l}{ Municipio: } & RIBEIRAO PRETO & \\
Telefone: & (16)3602-2228 & Fax: $(16) 3633-1144$ & E-mail: cep@hcrp.usp.br
\end{tabular} 


USP - HOSPITAL DAS
CLÍNICAS DA FACULDADE DE
MEDICINA DE RIBEIRÃO $\quad \begin{aligned} & \text { Plotoforma } \\ & \text { Grasil }\end{aligned}$

Continuaçảo do Parecer. 1.827.471

Situação do Parecer:

Aprovado

Necessita Apreciação da CONEP:

Não

RIBEIRAO PRETO, 18 de Novembro de 2016

Assinado por:

MARCIA GUIMARĀES VILLANOVA

(Coordenador)

Endereço: CAMPUS UNIVERSITÁRIO 